\author{
Universidade de São Paulo \\ Instituto de Astronomia, Geofísica e Ciências Atmosféricas \\ Departamento de Geofísica
}

Wilbor Poletti

\title{
Archaeomagnetic field intensity evolution during the last two millennia
}

São Paulo 

Candidate: Wilbor Poletti

Supervisor: Prof. Dr. Ricardo Ivan Ferreira da Trindade

\section{Archaeomagnetic field Intensity evolution during the last two millennia}

Thesis presented to the Instituto de Astronomia, Geofísica e Ciências Atmosféricas of the Universidade de São Paulo as a partial requirement to obtain a Doctor of Sciences degree Area: Geophysics

São Paulo 

Dedico às mulheres da minha vida:

Angélica, Ivane, Grasiane e Alice. 



\section{Acknowledgements}

For the sake of convenience, both English and Portuguese were used here.

I thank my supervisor, Prof. Ricardo Trindade, for having been an exceptional mentor since before my $\mathrm{PhD}$. I like the analogy concerning his orientation as a chess game, in which he always articulated with strategy, never hesitating to give me as many checks as possible, thus demonstrating that the only way I could stay in the game would be through intelligent inversions. This certainly has changed my perception in science and in life. Things that good supervisors do!

I thank Prof. Andy Biggin for the excellent reception and mentoring during my two internships at the University of Liverpool, UK. It was always enjoyable the egalitarian way he received me in his group, as well as the way he supervised me. Also, he helped me to tackle intellectual challenges that I had never imagined to do. Today I have the courage to face scientific questions that I would never have before, because of him.

I thank Prof. Gelvam Hartmann for all his support during the development of this thesis, emphasizing all the detailed teaching of the experimental methodology used.

I thank Prof. Igor Pacca for following me during my $\mathrm{PhD}$ through my semiannual reports. In addition, I appreciate the suggestion to study the ruins of the Guarani Jesuit Missions that resulted in a publication.

I thank all the archaeologists involved with my work, for the partnership and for making the necessary materials available for carrying out the measurements. In special for Nadir Damiani and Raquel Rech.

I thank the São Paulo Research Foundation (FAPESP) (grants 2013/16382-0 and 2016/22960-4).

I thank all my colleagues during my internship at the University of Liverpool. To postgraduate students, postdocs, technicians and professors, in special: Yael Engbers, Louise Hawkins, Daniele Thallner, Elliot Hurst, Greig Paterson, Mimi Hill, Richard Holme and Andy Biggin. Also to my friends from Liverpool: Suellen Melo e Nickolas Tripodis. 
Agradeço ao Departamento de Geofísica da Universidade de São Paulo pelo espaço a mim concedido, e também a todos os seus funcionários. Em especial, agradeço às técnicas Daniele Brandt e Sônia Alonso e ao técnico Giovanni Moreira por todo o suporte.

Agradeço a todos aqueles que de alguma forma fizeram, ou ainda fazem, parte do USPMag: alunos de iniciação científica, mestrandos, doutorandos, pós-doutorandos, técnicos e professores. Em especial, aos colegas: Daniele Brandt, Plínio Jaqueto, Janine Araújo, Grasiane Mathias, Karine Carvas, Filipe Terra-Nova, Rafael Monteiro, Elder Yokoyama, Jairo Savian, Gelvam Hartmann, Ricardo Trindade, Thiago Moncinhatto, Raphael Prieto, Filipe Temporim, Jhon Afonso, Kamilla Borges, Marta Jácomo, Caio Amaral, Aruã Leite, Giovanni Moreira e Bruno Giacomini.

Agradeço aos meus colega de pós-graduação do Departamento de Geofísica (USP) pelo convívio e ambiente agradável. Agradeço também imensamente aos membros e aos agregados da Sala-E208 do Departamento de Geofísica (USP) por me aguentarem e, principalmente, por toda conversa! Ressalto meus agradecimentos à Karine Carvas, minha grande amiga e por muitas vezes "psicóloga"!

Agradeço ao meu irmão e parceiro, Clodoaldo Poletti, por todo o incentivo e força durante meu doutorado. Foram inúmeras as vezes em que ele me impulsionou quando eu titubeei. Sem dúvidas, um dos pilares mais fortes desse caminho.

Agradeço à minha mãe, Ivane Poletti, por nunca deixar de me apoiar nos momentos em que me faltaram forças. Por me transmitir segurança e me tranquilizar, mesmo no momento em que vivia sua maior adversidade. E também, pela sua garra e, principalmente, por todo seu amor.

Agradeço à minha parceira no crime, Grasiane Mathias. A intensidade na qual eu desenvolvi o meu doutorado foi apenas um reflexo da intensidade de minha vida pessoal, proporcionada justamente pela Grá. No período de um doutorado, nós namoramos, casamos, tivemos uma filha (que, por sua vez, me mostrou o que realmente é a vida!), moramos em outro país, nos permitimos e evoluímos. Hoje somos um time de três (Grá, Alice e eu) e somos mais fortes, como consequência direta do que vivemos juntos. A ciência não seria para mim tão bela e reveladora se Grá e Alice não fossem o filtro delicado de parte de minha miopia! 


\section{Abstract}

Temporal variations of Earth's magnetic field provide a great range of geophysical information about the dynamics at different layers of the Earth. Since it is a planetary field, regional and global aspects can be explored, depending on the timescale of variations. In this thesis, the geomagnetic field variations for the last two millennia were investigated. For that, some improvement on the methods to recover the ancient magnetic field intensity from archeological material were done, new data was acquired and a critical assessment of the global archaeomagnetic database was performed. Two methodological advances are reported, comprising: i) the correction for microwave method of the cooling rate effect, which is associated to the difference between the cooling times during the manufactory of the material and that of the heating steps during the archaeointensity experiment; (ii) a test for thermoremanent anisotropy correction from the arithmetic mean of six orthogonal samples. The temporal variation of the magnetic intensity for South America was investigated from nine new data, three from ruins of the Guaraní Jesuit Missions and six from archaeological sites associated with jerky beef farms, both located in Rio Grande do Sul, Brazil, with ages covering the last 400 years. These data combined with the regional archaeointensity database, demonstrates that the influence of significant non-dipole components in South America started at 1800 CE. Finally, from a reassessment of the global archaeointensity database, a new interpretation was proposed about the geomagnetic axial dipole evolution, where this component falls constantly since $700 \mathrm{CE}$ associated to the breaking of the symmetry of the advective sources operating in the outer core. 



\section{Resumo}

Variações temporais do campo magnético da Terra fornecem uma grande diversidade de informações geofísicas sobre a dinâmica das diferentes camadas da Terra. Por ser um campo planetário, aspectos regionais e globais podem ser explorados, dependendo da escala de tempo das variações. Nesta tese, foram investigadas as variações do campo geomagnético para os dois últimos milênios. Para isso, aprimoramentos nos métodos de aquisição da intensidade geomagnética registrada em materiais arqueológicos foram realizados, bem como a aquisição de novos dados e uma avaliação crítica da base de dados arqueomagnética global. Dois novos avanços metodológicos são aqui propostos, sendo eles: i) correção para o método de micro-ondas do efeito da taxa de resfriamento, que está associada à diferença entre os tempos de resfriamento durante a manufatura do material e o das etapas de aquecimento durante o experimento de arqueointensidade; (ii) teste para correção da anisotropia termorremanente a partir da média aritmética de seis amostras posicionadas ortogonalmente umas às outras durante o experimento de arqueointensidade. A variação temporal da intensidade magnética para a América do Sul foi investigada a partir de nove dados inéditos, sendo três provenientes das ruínas das Missões Jesuíticas Guaraníticas e seis de sítios arqueológicos associados a fazendas de charque, ambos localizados no Rio Grande do Sul, Brasil, com idades que cobrem os últimos 400 anos. Esses dados, combinados com o banco de dados regionais de arqueointensidade, demonstram que a influência significativa de componentes não-dipolares do campo magnético na América do Sul começou em 1800 CE. Finalmente, a partir de uma reavaliação do banco de dados globais de arqueointensidade uma nova interpretação foi proposta a respeito da evolução do dipolo axial geomagnético, sugerindo que essa componente está decrescendo constantemente desde $700 \mathrm{CE}$ devido à quebra da simetria das fontes advectivas que operam no núcleo externo. 



\section{Summary}

\section{Chapter 1}

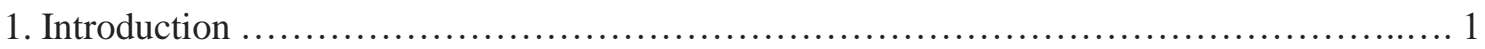

1.1. Overview about the Earth's magnetic field ......................................... 1

1.2. Secular variation in the southern hemisphere .................................... 3

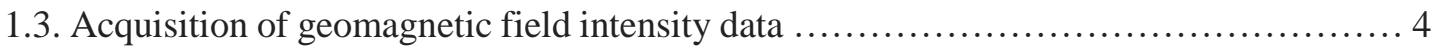

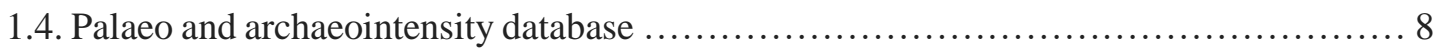

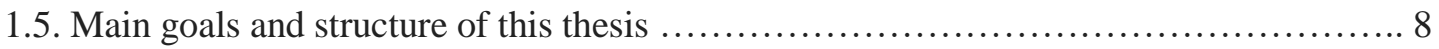

\section{Chapter 2}

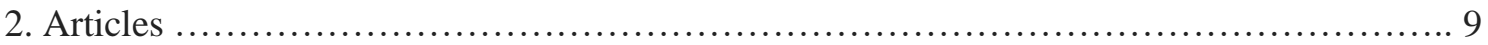

2.1. The cooling-rate effect on microwave archeointensity estimates .................... 11

2.2. Archeomagnetism of Jesuit Missions in South Brazil (1657-1706 AD) and assessment of the South American database ................................... 21

2.3. New archeointensity data from South Brazil and the influence of the South Atlantic Anomaly in South America

2.4. Continuous millennial decrease of the Earth's magnetic axial dipole 59

\section{Chapter 3}

3. Synthesis and perspectives 87

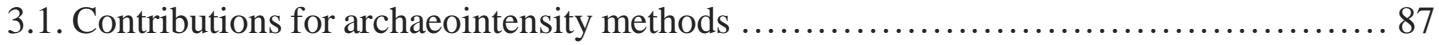

3.2. Archaeomagnetic field intensity evolution in South America ........................ 90

3.3. The Earth's magnetic axial dipole evolution for the last millennia .................... 94

\section{Appendix I}

A1. The cooling-rate effect on microwave archeointensity estimates

A2. Archeomagnetism of Jesuit Missions in South Brazil (1657-1706 AD) and assessment of the South American database

A3. New archeointensity data from South Brazil and the influence of the South Atlantic Anomaly in South America

A4. Continuous millennial decrease of the Earth's magnetic axial dipole 



\section{Chapter 1}

\section{Introduction}

\subsection{Overview about the Earth's magnetic field}

The Earth's magnetic field is one of the most important geophysical phenomena, and allows us to understand the deep interior of our planet. It provides insights to uncover the Earth's evolution, since its geometry and intensity reveals the structure and physical processes operating in different layers: upper crust, lower mantle, outer core and inner core (e.g., Trindade et al., 2006; Biggin et al., 2012; 2015; Finlay et al., 2016). The magnetic field produced into this telluric planet is a keystone about his own evolutionary history and plays a major role in its habitability. The geomagnetic field lines form a barrier that prevents the fall of energetically charged particles, mainly coming from solar winds. This protection prevented the full degassing of volatiles and enabled the formation of a stable atmosphere, implying in less variations of physical parameters on the Earth's surface, such as temperature, humidity and radiation, therefore promoting the conditions for life appearance and development (Kono, 2010). In the social sphere, the geomagnetic field was widely used for geographical orientation through the compass. Using a magnetized needle capable to aligning with the geomagnetic field lines it was possible to cross the oceans and a large expansion of territories was made feasible, which implied, for example, in the miscegenation observed today (Kono, 2010).

The geomagnetic field from internal sources is generated by the movement of the conductive fluid at the outer core, located around 2890 and $5100 \mathrm{~km}$ deep in the Earth. Given its planetary scale, the geodynamo produces a dominantly dipolar field. However, since the field results from the fluid motion into an inhomogeneous physical environment, several regional factors related to the internal structure of the Earth, such as thermal and topological inhomogeneity at core-mantle and inner-outer core boundaries, play an important role on the generation of non-dipolar field components (e.g., Holme, 2007). Nevertheless, the prevalence of the dipole regarding the other components can be quantified, for example, from power spectrums (e.g., Olsen et al., 2007). With the advent of geodynamo theory, the understanding of the Earth's core fluid motion has increased 
significantly, thus improving the knowledge about the physical mechanisms responsible to the field generation and evolution (Holme, 2007).

The geomagnetic field has been recorded during billions of years in geological materials (rocks, speleothems, and sedimentary depositions), thousands of years in archaeological artifacts (e.g., ceramics, bricks, tiles) and at the scale of centuries and decades by geomagnetic observatories and satellites. Geomagnetic records at the scale of billions to millions of years were fundamental to demonstrate the tectonic movements of lithospheric plates, providing a means for quantitatively assess the dynamic configuration of the upper layers of the planet (e.g., Pesonen et al., 2003; Kono, 2010). On the other hand, the geomagnetic record at the scale of thousands of years to years (and less) is the way to probe the geodynamic processes acting at the deepest layers of the Earth, at the core and its neighborhood, including heat-flow changes at the core-mantle boundary, movements of the conductive fluid in the outer core, and interactions between the inner and outer cores, and the lower mantle (e.g., Kono, 2010; Aubert et al., 2013; Finlay et al., 2016; Poletti et al., 2018).

The temporal variability of the Earth's magnetic field generated in the core ranges from years (or less) to thousands of years (e.g., Korte et al., 2018). Rapid variations (i.e., years or less) are called geomagnetic jerks, and are observed from the second derivative of the geomagnetic signal calculated from observatories and satellites data. Although there is some speculation about the origin of the geomagnetic jerks (e.g., Bloxham et al., 2002; Mandea et al., 2010; Demetrescu and Dobrica, 2014; Feng et al., 2018) its physical mechanism is still not fully understood. Centennial to millennial variations are investigated through records of geological and archaeological materials, and are essential to understand most of the operant physical mechanisms in the outer core at these timescales (e.g., Brown et al., 2015; Constable et al., 2006; Poletti et al., 2018), as well as physical interactions between the mantle and the core (e.g., Tarduno et al., 2015, TerraNova et al., 2017). These variations will be better explored throughout this $\mathrm{PhD}$ thesis through regional and global approaches. Finally, long period variations, essentially recorded in geological materials, are used to explore the process responsible for geomagnetic excursions and reversals (e.g., Gubbins, 1999, Laj and Channel, 2007; Valet and Fournier, 2016). 


\subsection{Secular variation in the southern hemisphere}

Secular variation can be defined as the first temporal derivative of the geomagnetic field signal or, in other words, as the temporal variation of the Earth's magnetic field. Geomagnetic field models for the last millennia based on the most recent estimates from archaeological materials, volcanic rocks and lake/marine sediments (Brown et al., 2015), show a persistent high secular variation in the southern hemisphere (Constable et al., 2016). Specifically, in South America and South Atlantic this secular variation has manifested itself in the last millennia through the growth and westward drift of large magnetic anomalies (Panovska et al., 2015, Constable et al., 2016).

Currently, the most enigmatic feature of the geomagnetic field is the South Atlantic Anomaly (SAA), where the field intensity presents its lowest values (e.g., Jackson et al., 2000; Hartmann and Pacca, 2009). It has emerged on the African continent and continually drifted westward over the last few centuries, traveling through the South Atlantic and over the South American continent, while expanding in area. Although there are some speculations about its origin, we still do not know conclusively how it is generated (Tarduno et al., 2015, Finlay et al., 2016, Constable et al., 2016; Terra-Nova et al., 2017).

Recent geodynamo models (e.g., Aubert et al., 2013) suggest that the secular variations observed in the surface geomagnetic field might be associated with compositional and thermal heterogeneities revealed by seismic tomography in the inner core and at the core-mantle boundary (e.g., Burke et al., 2008). For the southern hemisphere, a direct link between long-lived mantle heterogeneities and the SAA have been postulated, where a large low shear velocity province (LLSVP) at the core-mantle boundary beneath Africa would be a preferential site for the expulsion of reversed magnetic flux from the core (Tarduno et al., 2015; Hare et al., 2018). Since the LLSVP is a geographically fixed region with an age greater than >100 Ma (Burke et al., 2008), if the SAA generation is linked to it, then the SAA is expected to be a recurring (or persistent) feature. Rapid geomagnetic variations recorded on thousands of years old Tristan da Cunha volcanic rocks, situated along the track of the SAA (Shaah et al., 2016), suggest that the South Atlantic is indeed a preferential site for anomalous fields at this time-scale. But a more detailed account of the direct relationship between the SAA and reversed flux patches beneath Africa and South America via kernel functions shows that a link between both features is not straightforward (Terra-Nova et al., 2017). 
Another interesting research topic derived from the study of secular variations in the southern hemisphere, and specifically about the SAA, is the possible imminent process of geomagnetic reversal (e.g., Pavón-Carrasco et al., 2016; Finlay et al., 2016). The main component of the Earth's magnetic field can be approximated by a geocentric and axial dipole. Its stability is balanced by the equilibrium of normal and reverse magnetic flux patches (Olson and Amit, 2006). When normal flux patches move to the poles and reverse patches move to the equator the geomagnetic dipole intensity increase and vice-versa (e.g., Olson and Amit, 2006). In this light, the analysis of geomagnetic field models (Gillet et al., 2013) and geodynamo models (e.g., Aubert et al., 2013) suggests an asymmetry in the advective sources of the field implying in the decrease of the Earth's magnetic dipole intensity in the last 185 years (Finlay et al., 2016). The growth of the SAA is a likely candidate to explain the asymmetry.

In the past decades, the quality of geodynamo models has enormously advanced thanks to the dramatic increase in computing power (e.g., Aubert et al., 2013). At the same time, innovations on inversion strategies to generate geomagnetic field models will soon be capable of coupling the geomagnetic field models to these sophisticated geodynamo models (Sanchez et al., 2016; Davies and Constable, 2017). However, it is well known that the database that feeds the geomagnetic models is not improving at the same pace, particularly in the southern hemisphere, where most of the field variation occurred in the past millennia (Constable et al., 2016). Hence, new and high-quality archaoemagnetic data, mainly archaeointensity data, remain essential to reconstruct the field through time and better understand the workings of the geodynamo.

\subsection{Acquisition of geomagnetic field intensity data}

The Earth's magnetic field is represented by its inclination, declination and intensity at each geographic location and age (Tauxe, 2008; Kono, 2010). To understand its evolution, it is crucial to know the distribution of at least one of these parameters as a function of time. Thanks to methodological advances and modern laboratory equipment, directional data (i.e., inclination and declination) are simple to obtain, and require relatively rapid measurements. However, the methodology to recover the magnetic intensity is more complex and time consuming. In this $\mathrm{PhD}$ thesis, the explored parameter is the geomagnetic field intensity.

Several laboratory methods were proposed in order to recover the geomagnetic field intensity recorded in geological and archaeological materials: modified Thellier- 
Thellier (Coe, 1967; Aitken et al., 1988; Yu et al., 2004); Shaw (1974); Games (1977); Microwave (Shaw et al., 1996); Triaxe (Le Goff and Gallet, 2004); Multiple-specimen (Fabian and Leonhardt, 2010); Preisach (Muxworthy and Heslop, 2011); and adapted pseudo-Thellier (e.g., De Groot et al., 2013). The methods used in this thesis to acquire new results are the modified Thellier-Thellier and the Microwave (see below). The other methods were only taken into account during the reassessment of published results (details in Poletti et al., 2013, 2016 and 2018).

\subsubsection{Theory of ancient intensity estimation}

Estimates of the absolute geomagnetic field intensity are performed by palaeo or archaeointensity techniques that make use of the fine-grained magnetic particles present in volcanic rocks and archaeological artifacts that preserve the thermoremanent magnetization (TRM) from their last substantial heating (Dunlop, 1981). The intensity of the Earth's magnetic field recorded in these materials can be determined because TRM and low intensity magnetic fields $(<100 \mu \mathrm{T})$ show a linear relation (Neel, 1955; Tauxe and Yamazaki, 2007; Dunlop, 2011). In this way, we have:

$\mathrm{M}_{\mathrm{NRM}} \approx \alpha_{\mathrm{anc}} \mathrm{H}_{\mathrm{anc}} \quad$ and $\quad \mathrm{M}_{\mathrm{lab}} \approx \alpha_{\mathrm{lab}} \mathrm{H}_{\mathrm{lab}}$

where $\mathrm{M}_{\mathrm{NRM}}$ and $\mathrm{M}_{\text {lab }}$ represents natural remanent magnetization (NRM) and laboratory thermoremanent magnetization, respectively; $\mathrm{H}_{\mathrm{anc}}$ and $\mathrm{H}_{\mathrm{lab}}$ are intensities of the ancient and laboratory magnetic field (inductor field), respectively; and, finally, $\alpha_{\text {anc }}$ e $\alpha_{\text {lab }}$ are dimensionless constants of proportionality, associated with the magnetic properties of the materials. Since magnetization and inducing field (laboratory field) have a linear correspondence, we can assume, for a same material, that $\alpha_{\text {ant }}=\alpha_{\text {lab }}$. Consequently, we have:

$\mathrm{H}_{\mathrm{anc}}=\frac{\mathrm{M}_{\mathrm{NRM}}}{\mathrm{M}_{\mathrm{lab}}} \mathrm{H}_{\mathrm{lab}}$

In other words, knowing the NRM for a given material, and from a controlled laboratory magnetization acquisition, it is possible to recover the ancient geomagnetic field intensity. The archaeointensity recorded can be retrieved using laboratory techniques developed more than one hundred years ago (Folgheraiter, 1899), that were subsequently 
significantly improved (Thellier and Thellier, 1959; Coe, 1967; Coe et al., 1978; Aitken et al., 1988; Shaw et al., 1996; Riisager and Riisager, 2001; Yu et al., 2004).

Although the archaeointensity theory above mentioned seems to be conceptually simple, several processes may cause a non-linear relation between remanent magnetization and magnetic intensity. The most common problems are: i) thermochemical magnetic mineralogy alteration during the experiment, and ii) the presence of multidomain magnetic grains (MD). There are two ways to minimize the first problem. The first one is to estimate the magnetic susceptibility as a function of temperature from room temperature up to $\sim 580^{\circ} \mathrm{C}$ before the archaeointensity procedure, in order to retain only samples with susceptibility changes less than or equal to $10 \%$ (e.g., Poletti et al., 2016); and the second one is to apply additional steps during the archaeointensity experiment in order to monitor step by step possible alterations (i.e., pTRM checks - Coe et al., 1978). The influence of MD grains is mainly monitored in a similar way of thermochemical alterations during the archaeointensity acquisition (e.g., pTRM tail checks - Riisager and Riisager, 2001).

\subsubsection{Basic differences between Thellier-Thellier and Microwave methods}

The classical archaeointensity double-heating method (TT) (Thellier and Thellier, 1959; Coe, 1967; Coe et al., 1978; Aitken et al 1988; Yu et al., 2004) is used by almost all palaeomagnetic laboratories around the globe. In contrast, the microwave method (MW) is exclusive to the Geomagnetism Laboratory at the University of Liverpool. The essential difference between both methods is that while in the TT protocol the whole sample is heated, the MW method excites only the magnetic minerals by high-frequency microwaves. On the one hand, the TT method has the advantage to be the greatest established archaeointensity method around the world, both in theoretical and experimental aspects. On the other hand, the advantages of the MW method is the minimization of thermochemical alterations, since this method does not, in theory, directly heat the sample (Walton et al., 1992; 1993; Poletti et al., 2013). Also, it requires small amount of material for measurements, as well as it is less laboratory time consuming.

\subsubsection{Analysis of results}

The new results of each specimen are validated through the parameters that provide the best fit of the relation between remained NRM and gained thermoremanent 
magnetization (i.e., Arai diagram - Nagata et al., 1963; Paterson et al., 2012; 2014) (Table 1.3.1). Valid results were grouped according to the following criteria (Genevey and Gallet, 2002; Hartmann et al., 2010; 2011; Poletti et al., 2013; 2016): i) Standard deviation at fragment level $\leq 5 \%$, with a minimum of 2 specimens per fragment; and ii) standard deviation at site level $\leq 10 \%$. Remember that one site represents only one value of geomagnetic field intensity as a function of the age of the material (details about site/fragment/sample definition in "2.2. Selection criteria" - Poletti et al., 2018) (details about the selection criteria of new archaeointensity results in "3.3. Selection criteria" Poletti et al., 2016).

Table 1.3.1: Selection criteria parameters (modified from Paterson et al., 2012).

\begin{tabular}{|c|c|c|}
\hline Factor & Acceptable values & Definition \\
\hline $\mathrm{N}$ & $\geq 3$ & Number of specimens \\
\hline FRAC & $\geq 0.35$ & $\begin{array}{l}\text { NRM fraction used for the best-fit on an Arai diagram } \\
\text { (Coe et al., 1978) }\end{array}$ \\
\hline$\beta$ & $\leq 0.1$ & $\begin{array}{l}\text { Ratio of the standard error of the slope to the absolute } \\
\text { value of the slope (Coe et al., 1978) }\end{array}$ \\
\hline delCK & $\leq 10$ & $\begin{array}{l}\text { Maximum difference produced by a pTRM check, } \\
\text { normalized by the TRM (obtained from the intersection } \\
\text { of the best-fit line and the x-axis on an Arai plot) } \\
\text { (Leonhardt et al., 2004) }\end{array}$ \\
\hline DRAT & $\leq 10$ & $\begin{array}{l}\text { Maximum difference produced by a pTRM check, } \\
\text { normalized by the length of the best-fit line (Selkin and } \\
\text { Tauxe, 2000) }\end{array}$ \\
\hline CDRAT & $\leq 10$ & Cumulative DRAT (Kissel and Laj, 2004) \\
\hline$\alpha$ & $\leq 15$ & $\begin{array}{l}\text { Angular diference between the anchored and free- } \\
\text { floating best-fit directions on a vector component } \\
\text { diagram (Tauxe, 2010) }\end{array}$ \\
\hline MAD & $\leq 15$ & $\begin{array}{l}\text { Maximum angular deviation of the anchored directional } \\
\text { fit to the paleomagnetic vector on a vector component } \\
\text { diagram (Kirschvink, 1980) }\end{array}$ \\
\hline DRAT tail & $\leq 10$ & $\begin{array}{l}\text { Maximum difference produced by a pTRM tail check, } \\
\text { normalized by the length of the best-fit line (Biggin et } \\
\text { al., 2007) }\end{array}$ \\
\hline
\end{tabular}




\subsection{Palaeo and archaeointensity database}

Several palaeointensity data have been generated around the globe in the past decades, significantly improving the spatial and temporal distribution of the data (e.g., Brown et al., 2015). Notwithstanding, the spatial data coverage is still concentrated on the northern continents ( $~ 96 \%$ of the data) (Genevey et al., 2008, Donadini et al., 2009, Poletti et al., 2016). For the southern hemisphere, the data are concentrated in South America, but show several gaps (Poletti et al., 2016). This is particularly critical since north and south hemispheres seem to behave distinctly through the past millennia, with a much higher variability in the south (Constable et al., 2016).

The database used during the development of this $\mathrm{PhD}$ thesis was GEOMAGIA50.v3.2 (Brown et al., 2015). This database includes one of the largest compilations of indirect palaeomagnetic data; including rock, archaeological and sedimentary data. In addition, it has different geomagnetic field models, calculated from the insertion of the data into spherical harmonic functions, on a friendly and simple platform. For more details, see http://geomagia.gfz-potsdam.de/.

\subsection{Main goals and structure of this thesis}

This work was conducted in order to: i) obtain methodological advances in the archaeointensity data acquisition; ii) expand the database, with new archaeological material from South Brazil; iii) understand the regional geomagnetic field morphology and improve the time-evolution map of SAA, based on the assessment of the South American archaeointensity database for the last millennia; and iv) reconstruct the recent evolution of the Earth's magnetic dipole, its generating processes, and provide some insights about its future behavior; all from the reassessment of the global archaeointensity database.

This thesis is organized in three chapters. Chapter 2 reports the obtained results in the form of four articles (Poletti et al., 2013, 2016, 2018 and Hartmann et al., submitted). Chapter 3 presents a summary with the key findings and perspectives. Lastly, the Appendix contains the highlights, supplementary materials and the peer-reviews for each publication. 


\section{Chapter 2}

\section{Articles}

In this chapter, three fully published scientific articles and one submitted manuscript are presented. I emphasize that I am the senior author of the three published papers $(2.1,2.2,2.4)$, and the second author of the submitted paper (2.3). All these works reflect the main results obtained during the development of my $\mathrm{PhD}$ project. The articles are arranged in a logical sequence, in order to facilitate the reader's understanding. Supplementary materials and peer-reviews (from the published articles) are presented in the Appendix I.

The references to the four articles are:

i) Poletti, W., Hartmann, G.A., Hill, M.J., Biggin, A.J. and Trindade, R.I.F., 2013. The cooling-rate effect on microwave archeointensity estimates. Geophysical Research Letters, 40(15), 3847-3852.

ii) Poletti, W., Trindade, R.I.F., Hartmann, G.A., Damiani, N. and Rech, R.M., 2016. Archeomagnetism of Jesuit Missions in South Brazil (1657-1706 AD) and assessment of the South American database. Earth and Planetary Science Letters, 445, 36-47.

iii) Hartmann, G. A., Poletti, W., Trindade, R. I. F., Ferreira, L. M. and Sanches, P. New archeointensity data from South Brazil and the influence of the South Atlantic Anomaly in South America. Submitted.

iv) Poletti, W., Biggin, A.J., Trindade, R.I.F., Hartmann, G.A. and Terra-Nova, F., 2018. Continuous millennial decrease of the Earth's magnetic axial dipole. Physics of the Earth and Planetary Interiors, 274, 72-86. 


\title{
2.1. The cooling-rate effect on microwave archeointensity estimates
}

\section{$\underline{\text { Wilbor Poletti }}^{1,2}$,}

Gelvam A. Hartmann ${ }^{1}$, Mimi J. Hill ${ }^{2}$, Andrew J. Biggin ${ }^{2}$ and Ricardo I.F. Trindade ${ }^{1}$

\footnotetext{
${ }^{1}$ Departamento de Geofísica, Instituto de Astronomia, Geofísica e Ciências Atmosféricas, Universidade de São Paulo, Rua do Matão, 1226, 05508-090, São Paulo, Brazil; ${ }^{2}$ Geomagnetism Laboratory, Department of Earth, Ocean and Ecological Sciences, University of Liverpool, Liverpool, UK.
}

\begin{abstract}
New microwave (MW) paleointensity data on historical bricks from Northeast Brazil presented a bias towards higher fields when compared to previous cooling-rate corrected double-heating paleointensity estimates; the same relates to the previously reported values for pottery from Southwestern Pacific islands. A simple theoretical approach suggests that the MW bias in both collections is due to a cooling-rate effect on MW estimates. We then experimentally corrected the MW cooling-rate effect on Brazilian fragments, increasing the degree of consistency between the previous and new results (reducing discrepancies from $25 \%$ to $8 \%$ ). Results indicate similar experimental behavior between microwave and thermal procedures despite the different ways in which the energy is transferred into the spin system. Finally, they allow cooling-times of less than 90 seconds to be empirically estimated in most of these MW experiments highlighting the need for systematic cooling-rate corrections to be applied in similar MW paleointensity studies in the future.
\end{abstract}

Keywords: paleointensity methods, microwave, cooling-rate correction, Archeomagnetism. 


\section{Introduction}

The strength of the past Earth's magnetic field can be inferred from the fossil magnetism of igneous rocks and archeological baked clay materials. Several variants of the classical double-heating paleointensity method have been developed since the pioneering work of Thellier and Thellier (1959). Some of the most popular today are: (a) the modifications of the classical Thellier-Thellier (TT) protocol, proposed by Coe (1967), Aitken et al. (1988), and Yu et al. (2004), (b) the Triaxe method (TR) (Le Goff and Gallet, 2004; Gallet and Le Goff, 2006) and (c) the Microwave method (MW) (Walton et al., 1992; 1993; Shaw et al., 1996). In all of these methods, the natural remanent magnetization (NRM) is stepwise replaced by partial thermoremanent magnetizations (pTRM).

Modern TT protocols apply additional heating steps for monitoring thermomagnetic alteration (Coe et al., 1978), magnetic anisotropy (e.g. Rogers et al., 1979; Veitch et al., 1984) and multidomain (MD) effects (e.g. McClelland et al., 1996; Riisager and Riisager, 2001). This method and their corrections can be easily implemented in any paleomagnetic laboratory but it is very time consuming ( 1.5 hour per temperature step). The TR method is conducted in a three-axis (Triaxe) vibrating sample magnetometer, coupled to a small furnace (Le Goff and Gallet, 2004). Measurements are made continuously while the sample is heated and the system allows the application of a laboratory magnetic field (up to $200 \mu \mathrm{T}$ ) along the direction of the original remanence, thus minimizing anisotropy effects. Several studies have demonstrated the equivalence between TR and TT paleointensity methods (Le Goff and Gallet, 2004; Gallet and Le Goff, 2006; Genevey et al., 2009; Hartmann et al., 2010; 2011). The Triaxe provides fast paleointensity estimates ( 2.5 hours per sample) and seems to be unaffected by cooling-rate effects on archeological baked clay materials (Le Goff and Gallet, 2004), but the sensitivity of the vibrating sample system limits its application to strongly magnetized samples $\left(>10^{-2} \mathrm{~A} / \mathrm{m}\right)$.

In the MW method, magnetic minerals are directly excited by high-frequency microwaves (Walton et al., 1992; 1993). In general, the progressive increase in microwave power successively affects magnetic carriers with increasing unblocking temperatures. The MW method also produces rapid paleointensity estimates ( 1.5 hour per sample) and, most importantly, it can significantly reduce magnetic alteration as the bulk sample is heated to lower temperatures and for less time than in conventional thermal 
experiments (e.g. Shaw et al., 1996; 1999; Hill and Shaw 1999; 2000; Hill et al., 2002a, 2002b; Casas et al., 2005; Ertepinar et al., 2012).

It is well known that the differences between cooling times in nature and in the laboratory can influence paleointensity estimations, potentially leading to overestimates of more than $10 \%$ for single domain (SD) grains (e.g. Fox and Aitken, 1980; Dodson and McClelland-Brown, 1980; Halgedhal et al., 1980; Yu, 2011; Biggin et al., 2013). This influence can be described by a cooling-rate factor used to correct paleointensity estimates, which is expressed by:

$\mathrm{f}_{\mathrm{CR}}=(1+\Delta \mathrm{TRM})^{-1}=\left[1+\mathrm{k} \cdot \log _{10}\left(\frac{\mathrm{CT}_{\text {natural }}}{\mathrm{CT}_{\text {laboratory }}}\right)\right]^{-1}$

where $\triangle \mathrm{TRM}$ represents the fraction of the TRM fraction under- or over-estimated in paleointensity experiments, $\mathrm{k}$ is a constant which depends on the material properties, and $\mathrm{CT}_{\text {natural }}$ and $\mathrm{CT}_{\text {laboratory }}$ are the cooling times in nature and laboratory, respectively (Dodson and McClelland-Brown, 1980; Halgedhal et al., 1980). Experimentally, the TT cooling-rate correction is routinely applied to archeological materials where the original (or natural) cooling times can be reproduced (or approximated) in the laboratory. It can be carried out by comparing the pTRM acquired in typical laboratory cooling times and the pTRM acquired in slow cooling times, which are as close as possible to that of the original cooling time (e.g. Chauvin et al., 2000; Genevey and Gallet, 2002; Genevey et al, 2009; Hartman et al, 2010; 2011; Ertepinar et al., 2012). In the TR method, paleointensity experiments using different cooling times $\left(25^{\circ} \mathrm{C} / \mathrm{min}, 6^{\circ} \mathrm{C} / \mathrm{min}, 2^{\circ} \mathrm{C} / \mathrm{min}\right)$ gave similar intensity results suggesting that a cooling-rate correction is unnecessary on archeological baked clay materials (Le Goff and Gallet, 2004; Gallet and Le Goff, 2006). These findings are corroborated by the good agreement within $5 \%$ between TR paleointensity estimations and cooling-rate (and anisotropy) corrected TT estimations on the same archeological materials (Le Goff and Gallet, 2004; Gallet and Le Goff, 2006; Genevey et al., 2009; Hartmann et al., 2010; 2011). For the MW method, the majority of studies have been carried out on subaerial lavas where the vortex-state or interacting nature of the ferrimagnetic grains implies that the cooling-rate correction is probably not critical (see Biggin et al., 2013). However, for archeological baked clay materials and chilled geological materials (e.g. volcanic glasses), the application of a cooling-rate correction may be important because these materials tend to have finer magnetic grain 
sizes. In addition, as the MW method has rapid cooling times this effect could be especially important. Although some authors have applied different kinds of MW cooling-rate corrections (Shaw et al., 1999; Ertepinar et al., 2012) their effectiveness has not yet been fully investigated.

In this paper we test MW cooling-rate corrections in two sets of archeological fragments. One corresponds to new experimental results using the MW method from archeological brick fragments from Northeast Brazil previously studied using the TT and TR methods (Hartmann et al., 2010). The second one comprises archeological pottery from Southwest Pacific islands for which both MW and TT paleointensity estimates were obtained (Stark et al., 2010). We strengthen these two important paleointensity results by reconciling microwave paleointensity data with classical double-heating methods to add a sizable new dataset. A comparison of the different paleointensity methods is made and based on these results we propose an experimental correction for the cooling-rate effect on MW estimations taking into account the laboratory and original cooling times.

\section{Materials and methods}

We have analyzed archeological brick fragments from Northeast Brazil with ages ranging from $1574 \mathrm{AD}$ to $1910 \mathrm{AD}$ (Hartmann et al., 2010, Supplementary table A1.2.1). Previous analyses indicate that the main magnetic carrier is (titano)magnetite with different Ti contents and domain states, as revealed by hysteresis loops, heating and cooling cycles of low-field susceptibility showing a strong decrease at $580^{\circ} \mathrm{C}$ (Hartmann et al., 2010). Unblocking temperatures varied between $200^{\circ} \mathrm{C}$ and $475^{\circ} \mathrm{C}$ for most samples except for fragment MAE2-01 for which the maximum unblocking temperature reaches $550^{\circ} \mathrm{C}$. For some fragments, hematite and also a high-coercivity, low-unblocking temperature magnetic phase are present (McIntosh et al., 2007; 2011), which is probably associated to a substituted hematite phase (Hartmann et al., 2010; 2011).

A total of 155 specimens (112 for paleointensity measurements and 43 for cooling-rate correction) from 26 brick fragments corresponding to 10 sites were analyzed using the MW method. An automated microwave system working at a frequency of 14 $\mathrm{GHz}$ and coupled to a SQUID magnetometer (Tristan's model DRM 300 rock magnetometer) was used for the experiments (Shaw and Share, 2007). For each fragment, one cylindrical specimen ( $5 \mathrm{~mm}$ diameter $\mathrm{x} 3 \mathrm{~mm}$ long) was first demagnetized with the microwave system, providing an appropriate demagnetization range to perform the paleointensity measurements. Subsequently, a minimum of two sister specimens were 
selected for MW paleointensity measurements using the Coe (1967) protocol, i.e., the first step in zero-field and the second step in an applied laboratory field. Stepwise magnetization measurements were carried out between $5 \mathrm{~W}$ and $40 \mathrm{~W}$ with microwave application time intervals varying between 2.5 and $5 \mathrm{~s}$. Each microwave application at a given power for a given time produces a "power-integral" corresponding to a remanence fraction (equivalent to peak temperature in a thermal experiment). Laboratory fields were applied following previous paleointensity results (25-40 $\mu \mathrm{T})$ (Hartmann et al., 2010). Magnetic mineralogical alteration was monitored through additional steps of microwave partial remanence ( $\mathrm{pT}_{\mathrm{M} R M}$ ) checks (Coe, 1978) after every two steps. Multidomain bias was determined by applying the $\mathrm{pT}_{\mathrm{M}} \mathrm{RM}$ tail checks (Riisager and Riisager, 2001), also after every two steps. In addition, domain state bias was evaluated by applying parallel and antiparallel laboratory fields for at least one specimen per fragment. Following insights from modeling and experiments, if parallel and antiparallel estimates yield the same intensity within error, MD bias is likely to be small (Biggin, 2006; 2010). Anisotropy of remanence effects were minimized by applying the magnetic field either parallel or antiparallel to the NRM (Rogers et al., 1979; Le Goff and Gallet, 2004). Strict selection criteria for paleointensity estimates at specimen and at fragment level follow Hartmann et al. (2010; 2011; see Supplementary table A1.2.2).

The MW cooling-rate experimental correction used here on the Brazilian brick fragments was based on that developed by Shaw et al. (1999), involving two different steps for at least two specimens per fragment. Firstly, a laboratory TRM was imparted in the specimens using a slow cooling time of $25 \mathrm{~h}$ from $480^{\circ} \mathrm{C}$ to room temperature in an applied laboratory field of $35 \mu \mathrm{T}$. Then, we attempted to recover the imparted laboratory field in these specimens using the MW method following exactly the same routine described before for virgin specimens. As a result, up to two cooling-rate correction factors (fMW) per fragment were determined by computing the ratios between the laboratory field $(35 \mu \mathrm{T})$ and the respective paleointensities recovered by the MW method:

$\mathrm{fMW}=\frac{35}{\text { PI_CR }}$

where PI_CR represents the MW paleointensity estimation. The corrected paleointensity (PIC) was given by: 
which is the product between the MW paleointensity measured in virgin specimens (PI) and the cooling-rate correction factor (fMW). Finally, an intensity value at fragment level $\left(\mathrm{PI}_{\mathrm{F}}\right)$ was computed from the paleointensity average,

$\mathrm{PI}_{\mathrm{F}}=\frac{\sum_{\mathrm{a}=1}^{\mathrm{m}}\left[(\mathrm{PIC})_{\mathrm{a}}\right]}{\mathrm{m}}$

where $\mathrm{m}$ represents the number of MW paleointensity results. It is worth noting that we have systematically corrected the parallel or antiparallel induced paleointensity estimates by its respective parallel or antiparallel cooling-rate correction factor.

\section{Results and discussion}

From the 155 analyzed specimens (26 fragments), a total of 74 (47 for MW paleointensity and 27 for cooling-rate correction factors) yielded reliable results (see Supplementary table A1.2.1). The main reasons to reject results were: (a) their low magnetization $(<15 \mu \mathrm{A} / \mathrm{m})$ due to the small sizes of the specimens, (b) their low percentage of demagnetization $(f<0.4)$ and $(c)$ magnetic alteration during the experiments evidenced by loss of Arai plot linearity and/or pTRM check failure. Magnetic mineralogical alteration was mainly detected after very unstable microwave absorption, which can be attested by the growth of melt spots in the specimens after stepwise measurements. The $\mathrm{pT}_{\mathrm{M}} \mathrm{RM}$ tail checks were employed to detect non-ideal MD-like effects and these produced maximum discrepancies of $\sim 5 \%$ in those experiments where the laboratory field was aligned antiparallel to the NRM. In parallel experiments, where their usefulness is known to be more limited (Biggin and Thomas, 2003; Biggin, 2006), the maximum discrepancies were $\sim 1.5 \%$. At fragment level, intensity averages coolingrate corrected are within $2 \%$ when compared with the global average (product between cooling-rate factors average and PI results average, both determined with parallel and antiparallel laboratory fields). All told, these results suggest negligible potential for bias of our paleointensity results from MD-like effects.

Figure 2.1.1 shows four typical examples of accepted Arai and orthogonal diagrams from two different fragments. Fragment SE2-19 presents very stable thermal demagnetization behavior (Fig. 2.1.1a). The MW experiment shows a similar result (Fig. 
2.1.1b), but the NRM fraction used to compute the MW intensity ( $f=0.52$ ) is smaller than that of the TT value ( $\mathrm{f}=0.71$ ) with a $\Delta \mathrm{f}$ of 0.19 . This behavior results from the less efficient demagnetization/remagnetization in microwave experiments, and is observed in all specimens, with $\Delta \mathrm{f}$ values varying from 0.05 to 0.20 . For fragment MAS-03, we compared MW results for two specimens, a virgin one (Fig. 2.1.1c) and a sister specimen into which an artificial TRM was imparted in the laboratory (Fig. 2.1.1d). Both specimens presented similar fitting parameters ( $\mathrm{f}, \mathrm{g}$ and $\mathrm{q}$ ) in Arai diagrams. The specimen MAS03-c01 provided a paleointensity of $44.9 \pm 0.4 \mu \mathrm{T}$ (Fig. 2.1.1d), which is significantly different from the field imparted in the laboratory $(35 \mu \mathrm{T})$ using the conventional oven, demonstrating a potential influence of the MW experimental cooling time on the paleointensity estimate and, consequently, the need for a cooling-rate correction.
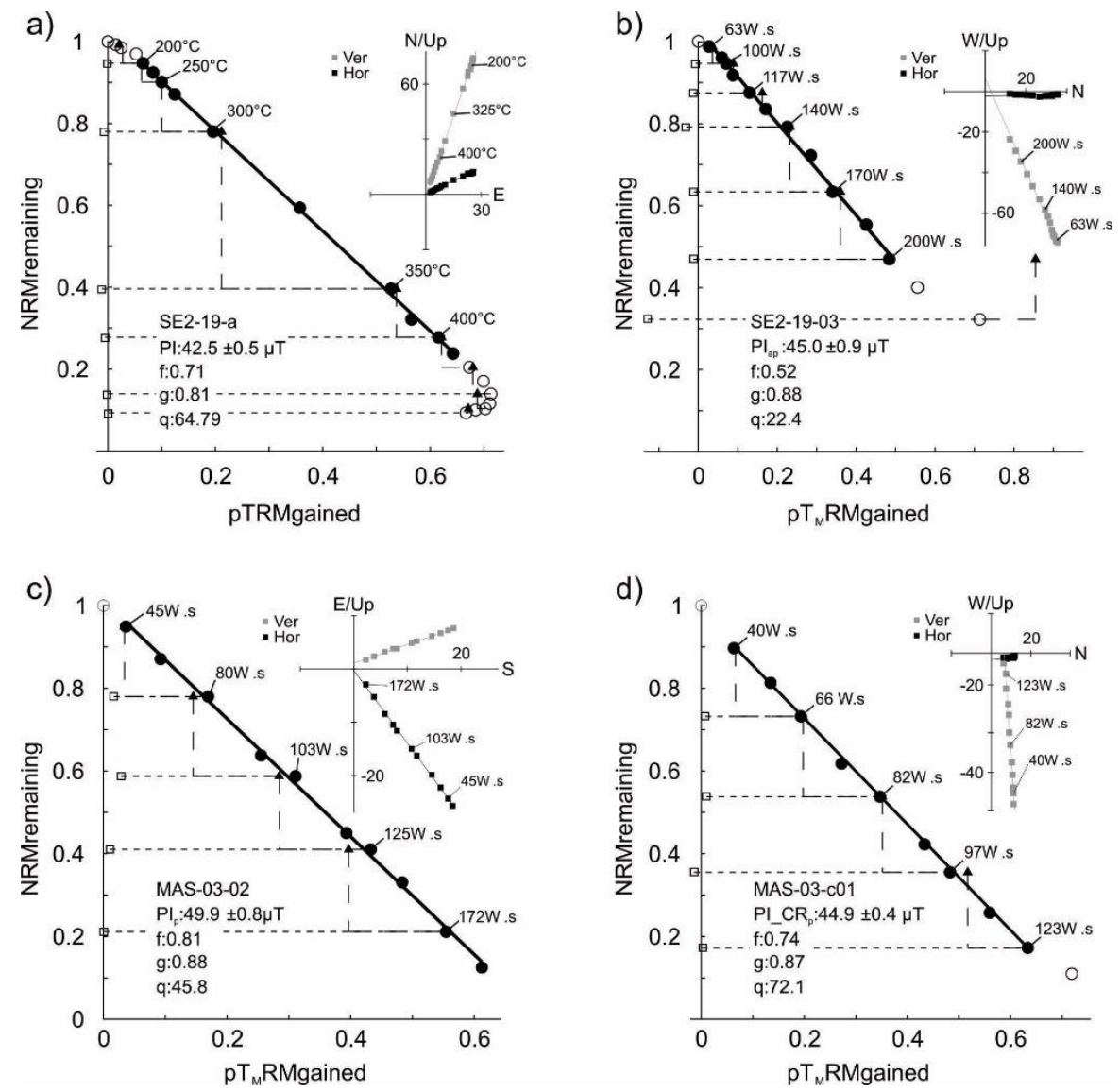

Figure 2.1.1: Examples of Arai and orthogonal (insets) diagrams for fragments SE2-19 (a-b) and MAS-03 (c-d). TT (a) and MW (b) results are shown for the same fragment. In Arai diagrams, circles represent NRM remaining versus $\mathrm{pTRM}$ or $\mathrm{pT}_{\mathrm{M}} \mathrm{RM}$ gained, triangles represent $\mathrm{pTRM}$ or $\mathrm{pT}_{\mathrm{M}} \mathrm{RM}$ checks, and squares represent normalized pTRM or $\mathrm{pT}_{\mathrm{M}} \mathrm{RM}$ tail checks. Subscripts " $\mathrm{p}$ " and "ap" indicate the direction parallel and antiparallel for the laboratory applied field, respectively (see text for further details). In orthogonal diagrams, gray and black squares represent vertical and horizontal projections, respectively. Note that TT results in (a) are from Hartmann et al. (2010) (extracted from Poletti et al., 2013). 
a)

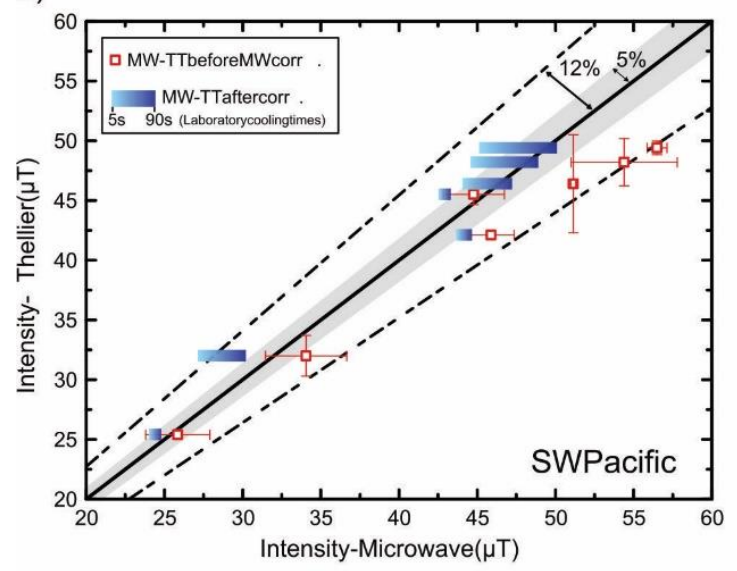

b)

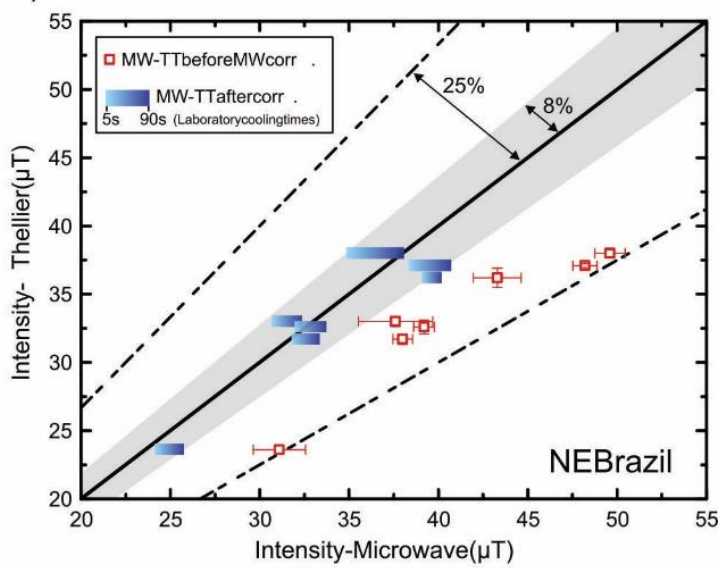

c)

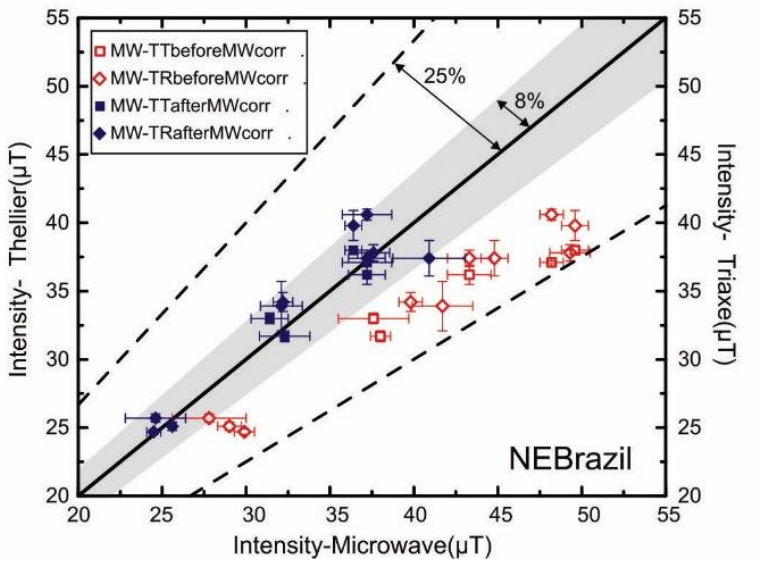

Figure 2.1.2: Comparison of intensity results between microwave (MW) and double-heating methods (TT and TR) based on theoretical (a-b) and experimental (c) approaches. Results are shown before (red open symbols) and after (blue scale bars and solid blue symbols) MW cooling-rate correction for: (a) SW Pacific islands pottery (MW and TT data from Stark et al., 2010), (b and c) NE Brazilian bricks (TT and TR data from Hartmann et al., 2010). Standard deviations were determined for each fragment (red and blue bars). MW data in (b) and (c) were obtained in this study. Dashed lines indicate the area within $\pm 12 \%$ (a) and $\pm 25 \%$ (b and c) and light gray area indicates the area within $\pm 5 \%$ (a) and $\pm 8 \%$ (b and c) deviations (extracted from Poletti et al., 2013).

We have corrected the cooling-rate effect in two ways: theoretically and experimentally (Fig. 2.1.2). Figures 2.1.2a and 2.1.2b show TT-MW data for Southwest Pacific islands and Northeast Brazil, after extrapolating Equation 2.1.1 for cooling times between 5 and $90 \mathrm{~s}$ that represent the range of cooling times after microwave applications. For both collections, this simple theoretical MW cooling-rate correction produces a better agreement between TT and MW data (Supplementary table A1.2.3). Results of the MW cooling-rate experimental correction for Brazilian fragments are shown in Figure 2.1.2c against TT and TR data. Before cooling-rate correction, MW results produced values systematically higher (up to 25\%) than those obtained with TT and TR methods (Fig. 
2.1.2c). But after cooling-rate correction, the difference between TT and TR with MW methods was reduced from $25 \%$ to a maximum of $8 \%$, and in some fragments these differences were eliminated entirely (Fig. 2.1.2c). At fragment level, intensity estimates were highly consistent with standard deviations less than $8 \%$ of the mean (Supplementary table A1.2.1).

Finally, we compared the MW cooling-rate experimental correction proposed here with that obtained for TT estimations on Brazilian fragments by Hartmann et al. (2010). Firstly, six TT cooling-rate correction factors $\left(\mathrm{CT}_{\text {natural }}=25 \mathrm{~h} ; \mathrm{CT}_{\text {laboratory }}=30 \mathrm{~min}\right)$ were extrapolated to the shorter cooling time of MW treatment using Equation 2.1.1. These functions are represented as straight solid lines in Figure 2.1.3 which are plotted alongside the corresponding MW cooling-rate experimental correction factors for each fragment (dashed lines in Fig. 2.1.3). The intersection between straight and dashed lines for each fragment provides an estimate of the laboratory cooling time for MW experiments. For most fragments the MW cooling times are between $5 \mathrm{~s}$ and $90 \mathrm{~s}$ though two fragments (MAS-03 and IMS-04) have shown cooling times of less than one second $\left(\sim 10^{-1} \mathrm{~s}\right.$ and $\sim 10^{-2} \mathrm{~s}$, respectively). These differences are likely to be indicative of differing amounts of absorption from the magnetic and electric components of the microwave field (Walton and Boehnel, 2008; Suttie et al., 2010). Nevertheless, the comparisons suggest that for this fragment set (a) TT and MW cooling-rate corrections have similar experimental behavior, despite the different ways of transferring energy into the spin system (lattice vibrations and electromagnetic), and (b) the different cooling times between natural and laboratory conditions is a significant source of bias in the MW estimates.

\section{Conclusions}

The TT-TR-MW experiments and corrections reported here indicate that all three methods can reliably be employed to obtain the past Earth's magnetic field intensity in baked clay materials. Together they confirm the previous archeointensity results for Northeast Brazil presented by Hartmann et al. (2010) and improve the estimates presented by Stark et al. (2010). Several studies have demonstrated that a cooling-rate correction is needed for the TT method but is not necessary for the TR method. By comparing TT and TR with MW methods we show that the cooling-rate effect could significantly affect MW paleointensity estimates in baked clay materials by up to $25 \%$. However, this effect can be accounted for by applying a simple experimental correction, which relies on paleointensity measurements for sister specimens with an imparted TRM. After applying 
the cooling-rate correction, multi-method paleointensity estimates agreed to within $\pm 8 \%$. This study has thus demonstrated, for these fragments, the need to perform cooling-rate corrections during MW paleointensity acquisitions and suggests that this influence, underrated in previous studies, should be investigated for other materials too.

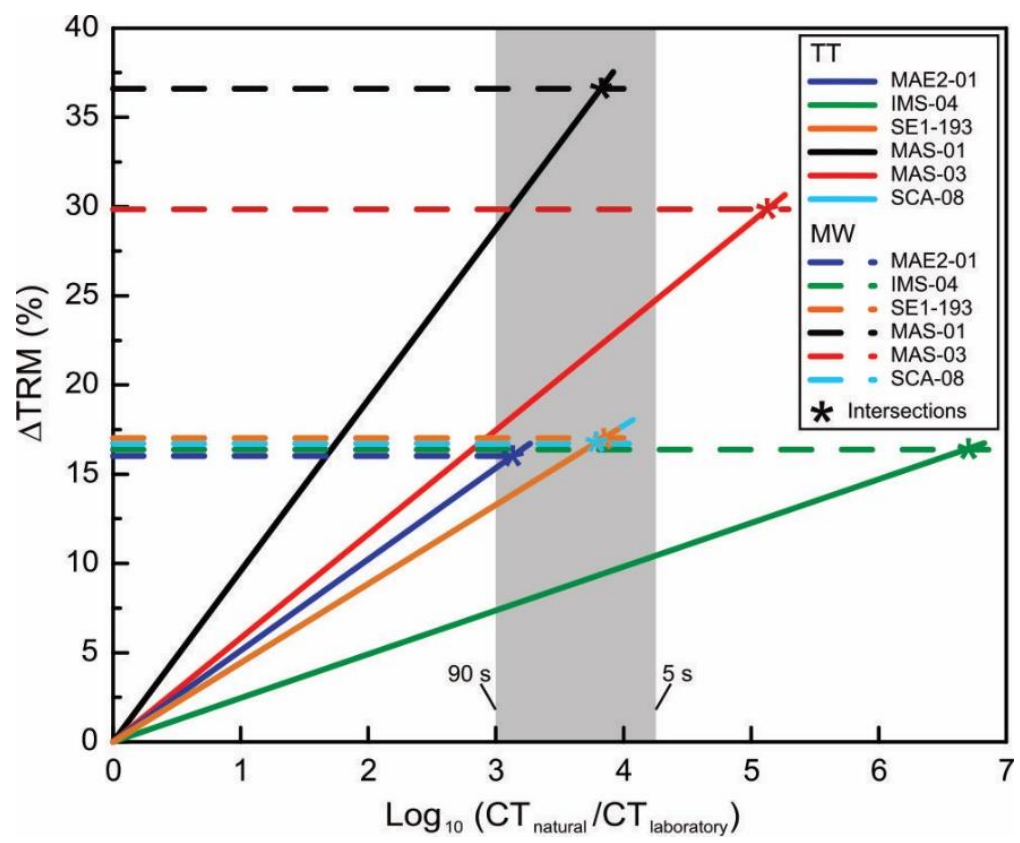

Figure 2.1.3: Comparison between the TT and MW cooling-rate factors for six fragments. Straight lines represent TT cooling-rate factors obtained by Hartmann et al. (2010), extrapolated using Equation 3.1.1 $\left(\mathrm{CT}_{\text {natural }}=25 \mathrm{~h} ; \mathrm{CT}_{\text {laboratory }}=30 \mathrm{~min}\right.$ ), and plotted as $\Delta \mathrm{TRM}$ (in \%) versus $\log _{10}\left(\mathrm{CT}_{\text {natural }} / \mathrm{CT}_{\text {laboratory }}\right.$ ). Dashed lines represent the average of $f M W$ per fragment converted to $\triangle T R M$ (in \%). Stars represent the intersection between extrapolated TT cooling-rate factors and MW cooling-rate factors for the same fragments. The gray area represents the cooling time expected for MW heating steps (5 to $90 \mathrm{~s}$ ) (extracted from Poletti et al., 2013).

\section{Acknowledgments}

This work was supported by a USP International Mobility scholarship to W. Poletti. G.A. Hartmann acknowledges grant \#2010/10754-4, São Paulo Research Foundation (FAPESP). M. Hill acknowledges NERC (grant NE/I013873/1). A. Biggin performed this research while funded by a NERC Advanced Fellowship (grant NE/F015208/1). R. Trindade is funded by a CNPq PQ grant. We thank Mark J. Dekkers and anonymous reviewer for their comments that improved this paper. 


\title{
2.2. Archeomagnetism of Jesuit Missions in South Brazil (1657-1706 AD) and assessment of the South American database
}

\author{
Wilbor Poletti ${ }^{1}$, \\ Ricardo I.F. Trindade ${ }^{1}$, Gelvam A. Hartmann ${ }^{2}$, Nadir Damiani ${ }^{3}$ and Raquel M. Rech
}

${ }^{1}$ Departamento de Geofísica, Instituto de Astronomia, Geofísica e Ciências Atmosféricas, Universidade de São Paulo, Rua do Matão, 1226, 05508-090, São Paulo, Brazil; ${ }^{2}$ Observatório Nacional, Rio de Janeiro, Brazil; ${ }^{3}$ Departamento de História, URI, Santo Ângelo, Rio Grande do Sul, Brazil; ${ }^{4}$ Museu Municipal Dr. José Olavo Machado, Santo Ângelo, Rio Grande do Sul, Brazil.

\begin{abstract}
South America contributes only a small fraction of the global archeomagnetic data. Recent work in the region has expanded significantly the previous database with new data being generated from Chile, Argentina, Northeast and Southeast Brazil. We report here new results from Jesuit Missions in South Brazil, at the triple border with Argentina and Paraguay. Our archeological collection comprises a total of 24 fragments of baked clay construction materials from three Jesuit missions, São Luiz Gonzaga 1657-1687 AD (3 fragments), São João Batista 1667-1697 AD (4 fragments) and Santo Ângelo 1676-1706 AD (17 fragments). Archeointensity determinations were performed with the double-heating technique in its modified form, with pTRM checks and pTRM tail checks. Measurements were complemented by anisotropy and cooling-rate corrections.
\end{abstract} A total of 24 specimens (11 fragments) passed strict quality selection, corresponding to a success rate of $45 \%$. We also performed an experimental test for the 6-specimen average anisotropy correction technique and show that it does not correct for the effects of TRM anisotropy. Results were similar within error for the three missions: São Luiz Gonzaga $(40.2 \pm 2.4 \mu \mathrm{T})$, São João Batista $(39.1 \pm 1.6 \mu \mathrm{T})$ and Santo Ângelo $(41.1 \pm 2.0 \mu \mathrm{T})$. These data were then compared with the most reliable data from South America, after a critical assessment of the current database. According to our analysis, only 39 intensity data for the continent can be considered as highquality, most within the last 700 years; only three data were retained for older periods (800-1100 $A D)$. The filtered data match reasonably well the available models for the past five centuries. A combined curve for South and Southeast Brazil plus Argentina plot systematically below relocated data from NE Brazil and Chile. These differences are likely due to complexities in the geometry of the field in South America not appropriately accounted for by a simple axial dipole. Our analysis highlights the need for high-quality data for the continent.

Keywords: Archeomagnetism, Archeointensity, South America, Brazil, Jesuit Missions. 


\subsubsection{Introduction}

Earth's magnetic dipole moment has decreased by $\sim 10 \%$ since direct measurements started with C. F. Gauss in 1839. Most of its decrease originates in the southern hemisphere, associated with the growth of reversed polarity patches observed in downward-continued models at the core-mantle boundary (Olson and Amit, 2006; TerraNova et al., 2015). The intensification of these reversed flux regions is temporally and spatially associated with the expansion of the South Atlantic Geomagnetic Anomaly (SAGA; also referred in the literature as South Atlantic Anomaly or South Atlantic Magnetic Anomaly) that now covers a large sector of southern South America (Hartmann and Pacca, 2009). The ability to track this and other important geomagnetic features in the past hinges on a high-quality database of archeointensity data (Pavon-Carrasco et al., 2014). Unfortunately, South America contributes with only $3.8 \%$ of the current archeomagnetic database (Brown et al., 2015) and most studies were performed before modern quality standards were introduced (e.g. Paterson et al., 2012, 2014).

The first archeointensity studies in South America date from the early 1960s with the works of Nagata et al. (1965) and Kitazawa and Kobayashi (1968) on archeological artifacts from Ecuador, Peru and Bolivia. Since then, few archeomagnetic studies have been performed in the region for the past two millennia with a 14-years gap between 1996 and 2010. Recently, this kind of work has been revived and in the last five years the number of studies has doubled (Hartmann et al., 2010, 2011; Goguitchaichvili et al., 2011, 2012, 2015; Roperch et al., 2014, 2015) focusing dominantly on archeological material from Brazil, Argentina and Chile and also on volcanic lavas from Chile. Previous studies in Brazil were performed first in Northeast Brazil (Hartmann et al., 2010), and then in Southeast Brazil (Hartmann et al., 2011), deliberately occupying different latitudes in order to assess the influence of non-dipolar components related to the arrival of the SAGA. Here we went further south, to the ruins of Jesuit Missions in South Brazil, at the triple border with Argentina and Paraguay. In this paper we present three new highquality entries to the South American database and discuss the available data for the continent after filtering out less reliable results.

\subsubsection{Archeological background and sampling}

\subsubsection{Guarani Jesuit Missions}

The Guarani Jesuit Missions at their apogee comprised thirty indigenous villages organized and led by Jesuit priests, spread throughout South Brazil, North Argentina and 
Paraguay (Fig. 2.2.1). These communities were also known as 'reductions'. Their creation took place during Native Americans catechization campaigns promoted by the Company of Jesus and sponsored by the Spanish and Portuguese crowns in order to establish a Christian society in the heart of the new world. Priests who came to form new reductions were trained in previously established reductions where they developed administrative skills and learned how to deal with the Guarani people. This initial training was extremely important since each reduction consisted of about five thousand Natives that were overseen by only two priests, one in charge of the reduction administration and the other was dedicated to spiritual duties. The Jesuit missions in South America started in the seventeenth century and declined in the eighteenth century, when the 1750 AD Treaty of Madrid redefined the borders of Spanish and Portuguese colonies in the region that presently comprises Uruguay, Paraguay, North Argentina and South Brazil (Baptista, 2010).

\subsubsection{Sampling and dating}

Our archeological collection comprises a total of 24 fragments of baked clay construction materials from three Jesuit reductions, São Luiz Gonzaga (3 fragments), São João Batista (4 fragments) and Santo Ângelo (17 fragments), respectively founded in $1687 \mathrm{AD}, 1697 \mathrm{AD}$ and $1706 \mathrm{AD}$ (Table 2.2.1). The settling time and the construction of the main buildings (main church and houses) of each reduction usually took around 30 years (Baptista, 2010). This is the uncertainty in the age attributed to each sampling site. When sampling we favored pavement tiles ('ladrillos') from the main churches that are well preserved in several reductions (Figs. 2.2.1e and 2.2.1f), as well as bricks from the walls of surrounding priest houses. For Santo Ângelo reduction, roof tiles from the official archeological collection were also sampled (Rech, 2008). From each fragment, we

prepared at least three cubic specimens of $\sim 1 \mathrm{~cm}^{3}$ for which we attributed arbitrary coordinates XYZ; one of these specimens was set aside for the cooling-rate experiment (see below). Additional sub-sampling was performed for thermomagnetic curves, isothermal remanent magnetization (IRM), hysteresis and first order reversals curves (FORCs). 

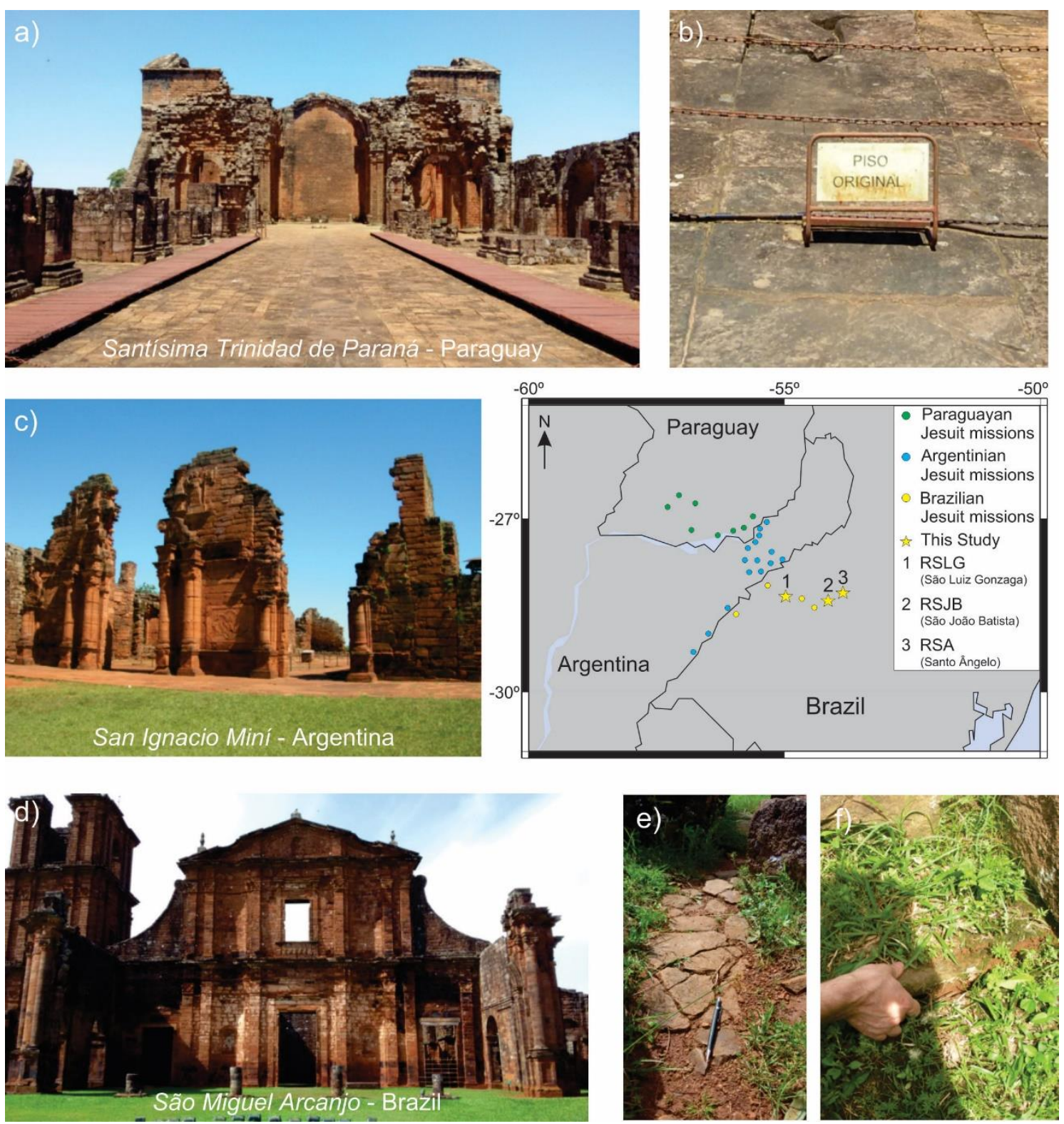

Figure 2.2.1: Jesuit Missions. The map indicates all reductions in Brazil (yellow), Argentina (blue) and

Paraguay (green). Stars represent sampled reductions. Pictures (a-d) show examples of best-preserved buildings for each country. (a) Reduction of Santisima Trinidad, Paraguay; (b) shows indication of original floor in that site. (c) Reduction of San Ignacio Mini, Argentina. (d) Reduction of São Miguel Arcanjo, Brazil. Pictures (e) and (f) show pavement tiles sampled in São João Batista reduction (pen for scale) and São João Batista reduction (hand for scale), respectively (extracted from Poletti et al., 2016).

\subsubsection{Methods}

\subsubsection{Magnetic mineralogy}

Magnetic mineralogy was characterized through continuous curves of magnetic susceptibility against temperature, IRM, hysteresis loops and FORC analyses. Thermomagnetic curves were used to pre-selected suitable fragments for archeomagnetic analyses by choosing samples that ideally show reversibility between heating and cooling 
curves, indicating stability of their magnetic mineralogy during thermal treatment (Fig. 2.2.2). These curves were performed from room temperature up to $600{ }^{\circ} \mathrm{C}$ in a Kappabridge KLY4S coupled with a CS4 furnace (Agico Ltd.). This maximum temperature was chosen in order to cover the blocking temperature spectrum of almost all fragments (> 90\%), and also matches the peak temperature used in the archeointensity protocol. We used a heating rate of $35^{\circ} \mathrm{C} / \mathrm{min}$ for $\sim 100 \mathrm{mg}$ of powdered sample. IRM acquisition curves and hysteresis loops were performed at room temperature with a peak field of $1000 \mathrm{mT}$ in a VSM MicroMag 3900 (Princeton Measurements Corp.). FORC diagrams were obtained after 200 reversal curves with an averaging time of $200 \mathrm{~ms}$, a smoothing factor of 5-6, and using the input parameters of Egli et al. (2010) (Hc1 = $0 \mathrm{mT}$, $\mathrm{Hc} 2=110 \mathrm{mT}$; Hu1 $=-40 \mathrm{mT}$, Hu2 $=+40 \mathrm{mT} ; \delta \mathrm{H}=0.99 \mathrm{mT}$ ). FORC diagrams were drawn using FORCinel software (Harrison and Feinberg, 2008). These analyses were conducted in order to further explore the magnetic mineralogy (i.e., magnetic coercivity spectrum, domain structure, magnetic interactions) of fragments selected from their thermomagnetic behavior.

\subsubsection{Archeointensity protocol}

Archeointensity determinations were performed using the classical ThellierThellier double-heating technique in its modified form (Coe, 1967) - the "ZI-protocol". Applying increasing temperature steps, the protocol combines Zero-field steps of demagnetization of the natural remanent magnetization (NRM) and In-field steps of acquisition of partial thermoremanence (pTRM) in a known laboratory field. For In-field steps, an $\mathrm{H}_{\mathrm{lab}}$ of $35 \mu \mathrm{T}$ was applied parallel to sample's Z-axis during the whole heatingcooling cycle. Heating and cooling had duration of 30 minutes each for both Zero-field and In-field steps. They were performed in air inside a programmable ASC Scientific single-chamber oven mounted with an inducing field coil. After testing the homogeneity in temperature and field intensity inside the oven, a $20 \mathrm{~cm}$ long section was selected in the middle of the heating/cooling chamber where temperature and induced field vary by less than $2{ }^{\circ} \mathrm{C}$ and $0.3 \mu \mathrm{T}$, respectively. We paid close attention to maintain the same position and orientation of specimens inside the oven throughout the whole measurement campaign to ensure reproducibility between heating and cooling steps. Specimens from a given fragment were positioned orthogonal to each other in order to provide a consistency test for TRM anisotropy corrections. Twenty double heating-cooling steps were performed between $100{ }^{\circ} \mathrm{C}$ and $600{ }^{\circ} \mathrm{C}$ (temperature intervals of $50{ }^{\circ} \mathrm{C}$ from $100{ }^{\circ} \mathrm{C}$ to 
$150{ }^{\circ} \mathrm{C}$ and $25^{\circ} \mathrm{C}$ above). Additional In-field steps (pTRM-checks) were included every two regular steps in order to monitor thermochemical alteration during thermal treatment (Coe et al., 1978). Additional Zero-field (pTRM-tail checks) were added every four steps to detect multidomain (MD) grains in our specimens (Riisager and Riisager, 2001). TRM anisotropy and cooling-rate effects on intensity determinations were also taken into account through specific corrections. Magnetization after each heating step was measured on a horizontal 755-1.65 UC SQUID magnetometer (2G Enterprises) housed into a magnetically shielded room with ambient field $<500 \mathrm{nT}$. All measurements were made at the Laboratório de Paleomagnetismo, Universidade de São Paulo (USP).

Anisotropy of TRM (ATRM) can adversely affect intensity estimates. The magnitude of these effects depends on the anisotropy degree and the angular distance between ancient and laboratory fields. They were corrected following Veitch et al. (1984). ATRM tensors were calculated at two different heating steps (ATRM@350 ${ }^{\circ} \mathrm{C}$ and ATRM@500 $\left.{ }^{\circ} \mathrm{C}\right)$ through pTRM acquisition along six successive positions $(\mathrm{X},-\mathrm{X}, \mathrm{Y}$, $-\mathrm{Y}, \mathrm{Z}$ and $-\mathrm{Z}$ ). ATRM@350 ${ }^{\circ} \mathrm{C}$ was applied only when the NRM fraction removed at 350 ${ }^{\circ} \mathrm{C}$ was higher than $40 \%$. The remaining samples were corrected using the tensor ATRM@500 $\mathrm{C}$. After each ATRM tensor determination a pTRM-check and a pTRMtail check were performed to monitor thermochemical alteration.

The cooling-rate correction factor was estimated for each fragment using an additional pristine specimen following the protocol described in Hartmann et al. (2010, 2011). This protocol involves three pTRM acquisition steps (in the same oven) - a rapid cooling, a slow cooling and a final rapid cooling. Each rapid cooling has the duration of a typical measurement step (30 min) whereas the slow cooling takes $18 \mathrm{~h}$. The slow cooling step was performed introducing thermal insulators into the oven and turning off the cooling fan. Comparison between rapidly acquired TRMs allows one to evaluate alteration during the experiment. When the difference between the two rapidly acquired TRMs is within 5\% we consider that alteration is negligible and a cooling-rate correction factor can be computed. The cooling-rate correction factor corresponds to the ratio between the average of the two rapidly acquired TRMs to the slowly acquired TRM. The temperature at which the cooling-rate experiments were performed was carefully chosen for each fragment to ensure that at least $50 \%$ of the NRM was used and no alteration was detected during intensity determinations.

Since these are the first archeointensity results obtained exclusively in the USP laboratory, we tested the protocol on 25 well characterized specimens ( 8 fragments) from 
NE and SE Brazil for which paleointensity estimates have been previously obtained with Thellier-Thellier, Triaxe and microwave techniques in the Institut de Physique du Globe de Paris (IPGP) and University of Liverpool (UL) (Hartmann et al., 2010, 2011; Poletti et al., 2013). Results obtained at USP agree within $4 \%$ with previous results (Supplementary table A2.2.1).

\subsubsection{Selection criteria}

Our intensity determinations were evaluated and selected using strict criteria following the TTB limits of Paterson et al. $(2012,2014)$ with stricter q, MAD and relaxed $\alpha$, implemented in the ThellierTool 4.0 software (Leonhardt et al., 2004). These criteria are similar to those used previously by Hartmann et al. $(2010,2011)$ in other archeomagnetic studies in Brazil.

At the specimen level, an intensity estimate is considered valid if:

- it uses a minimum of four temperature steps $(\mathrm{N} \geq 4)$ including at least $35 \%$ of the total NRM (f $\geq 0.35$ ) (Coe et al., 1978);

- standard errors of the slope are below 15\% $(\beta \leq 0.15)$ (Selkin and Tauxe, 2000);

- the overall quality index of the paleointensity estimate is above $5(q \geq 5)$ (Coe et al., 1978);

- the intensity value is obtained along the same temperature interval in which the characteristic magnetic component was isolated with an unanchored $\mathrm{MAD} \leq 10^{\circ}$;

- the angular difference between anchored and free-floating best-fit directions on a vector component diagram is below $15^{\circ}(\alpha \leq 15)$;

- maximum difference produced by a pTRM check normalized by the TRM is smaller than $9 \%(\delta C K \leq 9)($ Leonhardt et al., 2004);

- the measure of cumulative alteration determined by the ratio of the alteration-corrected intensity estimate (Valet et al., 1996) to the uncorrected estimate, normalized by the uncorrected estimate is below $18 \%$ ( $\delta$ pal $\leq 18)$ (Leonhardt et al., 2004);

- maximum difference produced by a pTRM tail check normalized by the NRM is below $20 \%(\delta \mathrm{TR} \leq 20)$ (Leonhardt et al., 2004).

At the fragment level, a mean intensity was retained only when:

- the difference between individual intensity values per fragment was less than $5 \%$ after anisotropy correction; 
- alteration measured by the difference between the two rapidly acquired TRMs during cooling rate experiments was less than 5\% (Hartmann et al., 2010; 2011);

- at least two independent intensities were obtained for each fragment.

At site level, a total mean was calculated by averaging results from at least three fragments and the standard deviation of the mean is less than $10 \%$.

\subsubsection{Archeointensity Results}

\subsubsection{Magnetic mineralogy}

Figure 2.2.2 illustrates two examples of thermomagnetic curves for each reduction. Five of them show reversibility between heating and cooling curves (Fig. 2.2.2a-e); consequently, they passed the first pre-selection screening. Figure 2.2.2f represents a sample that did not pass pre-selection. For fragments RSLG1-01, RSA5-01 and RSLG1-03 (Fig. 2.2.2a, 2.2.2c and 2.2.2d) the susceptibility decreases by around 90\% from $420{ }^{\circ} \mathrm{C}$ up to $580{ }^{\circ} \mathrm{C}$, suggesting the presence of titanomagnetite (with similar $\mathrm{Ti}$ content) as the main carrier likely within a very narrow range of grain sizes. For fragments RSJB-10 and RSJB-11 (Fig. 2.2.2b and 2.2.2d) the susceptibility decreases gradually from room temperature up to $560^{\circ} \mathrm{C}$, suggesting a more varied composition of magnetic carriers and/or a broader distribution of grain sizes.
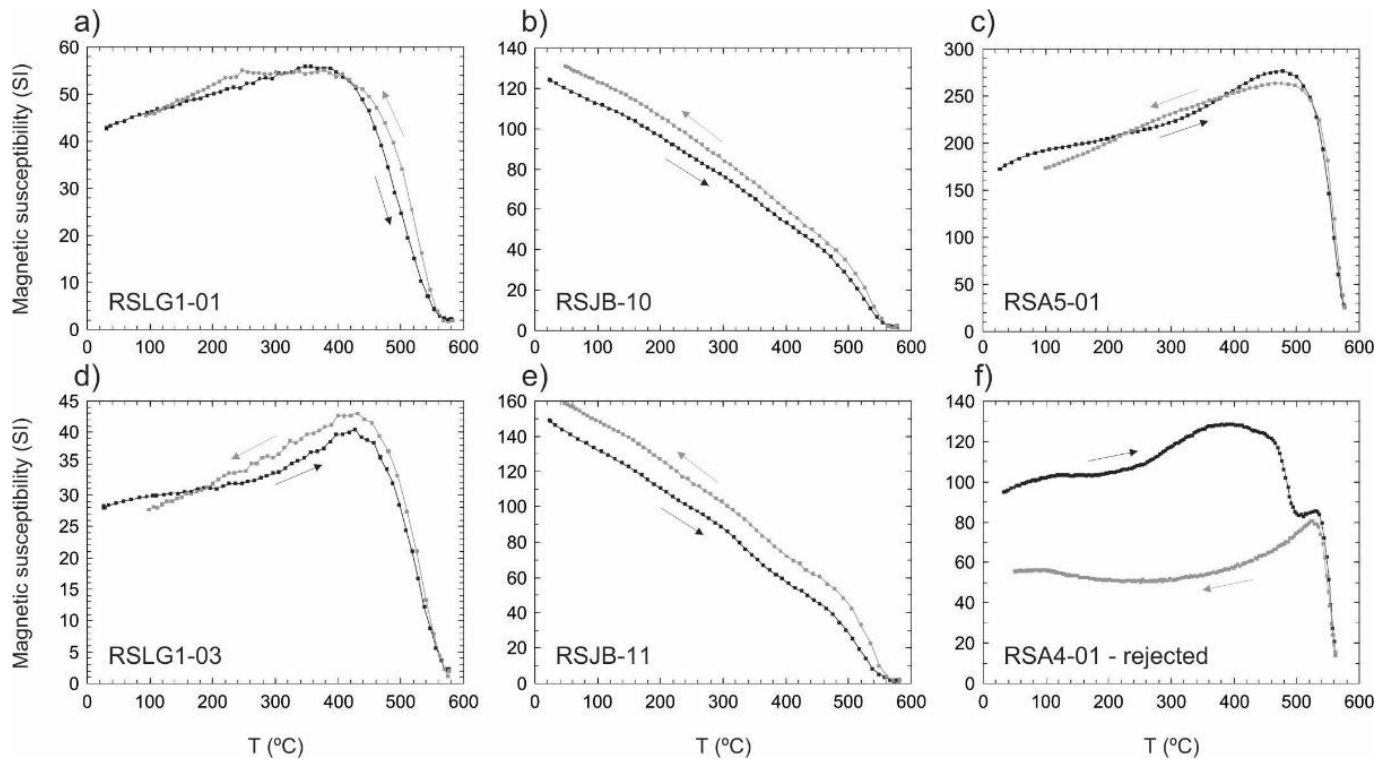

Figure 2.2.2: Curves of low-field magnetic susceptibility against temperature measured during heatingcooling cycles. (a-e) Examples of reversible curves indicating satisfactory magnetic stability during thermomagnetic experiments; these fragments were retained for archeointensity determinations. (f) Sample with an irreversible behavior that did not pass pre-selection (extracted from Poletti et al., 2016). 


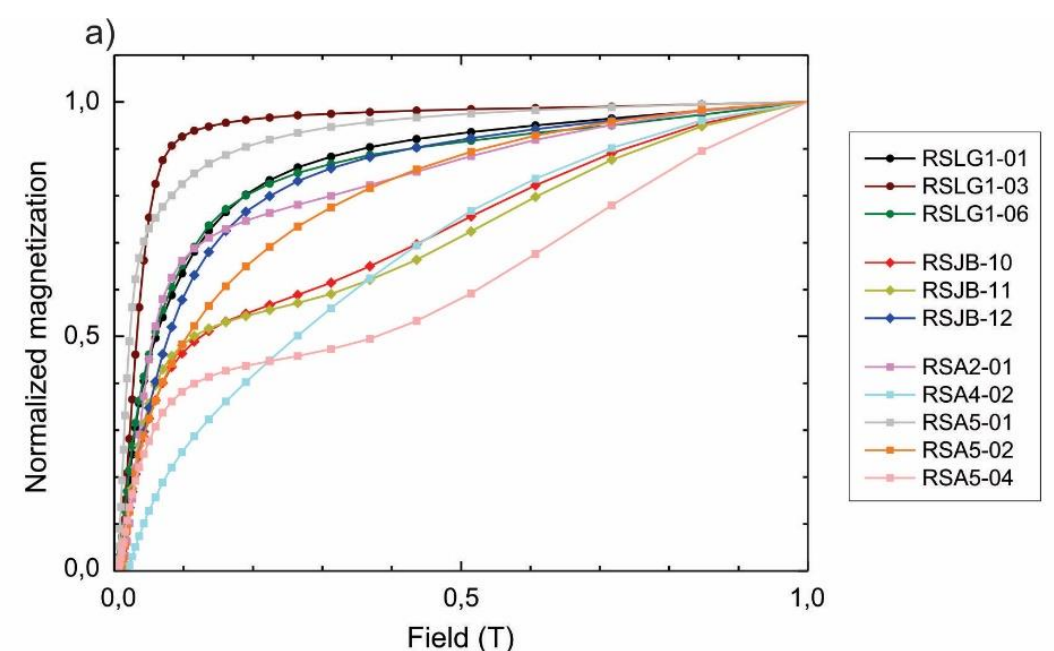

b)

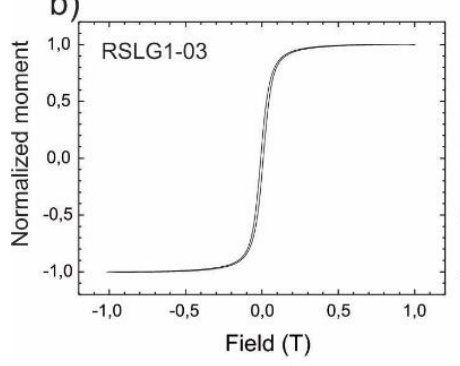

C)
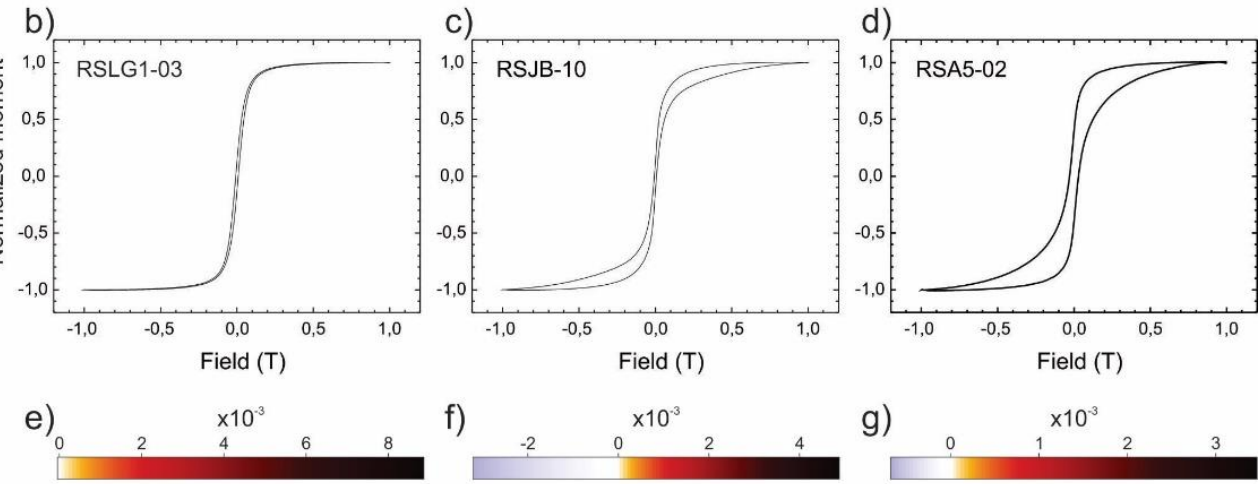

g)
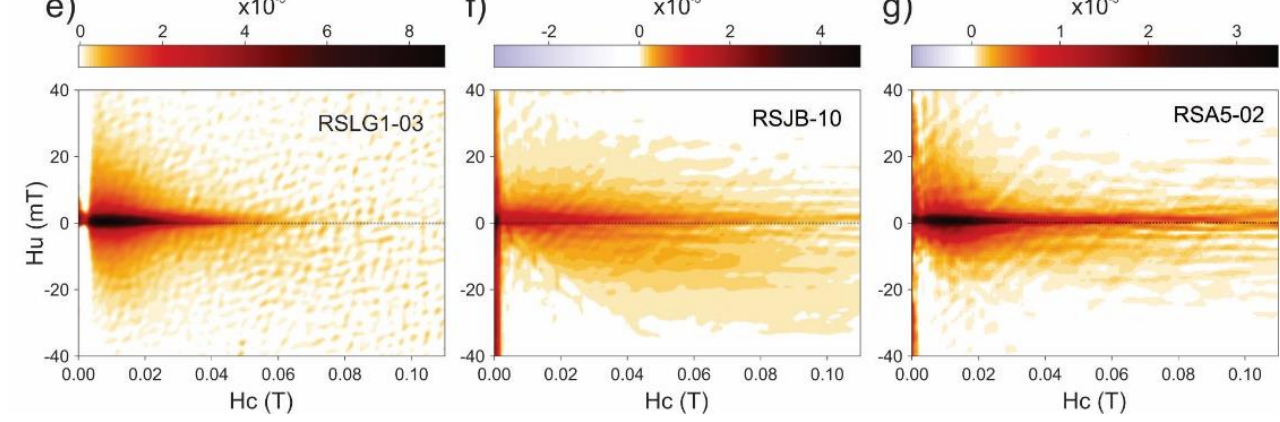

Figure 2.2.3: IRM acquisitions curves, hysteresis loops and FORC diagrams. (a) IRM acquisition curves for all studied fragments normalized to unit. (b-d) represents three characteristic hysteresis loops, where (b) exemplifies a narrow hysteresis loops and (c) and (d) wasp-waisted hysteresis loops. (e-g) FORC diagrams for the same fragments (smoothing factors 5-6) (extracted from Poletti et al., 2016).

IRM and hysteresis curves can be separated into three main types. The first one shows IRM acquisition curves saturated at fields up to $\sim 0.3$ T (e.g. RSLG1-03 in Fig. 2.2.3a). This indicates that the magnetization is carried by a low-coercivity magnetic phase, typically Ti-poor titanomagnetite in pseudo-single domain state. This interpretation is corroborated by their narrow hysteresis loops (Fig. 2.2.3b) and maximum NRM demagnetization temperature at $550{ }^{\circ} \mathrm{C}$. The second one shows concave-up IRM acquisition curves that do not saturate up to $1 \mathrm{~T}$ (e.g. RSA5-02 in Fig. 2.2.3a). These samples show wasp-waisted hysteresis loops (Figs. 2.2.3c) (Roberts et al., 1995). This behavior is characteristic of a mixture between low and high-coercivity phases with 
varying proportions among the fragments. Finally, the third one shows IRM acquisition curves with a concave-down behavior resulting from the presence of two very distinct phases - one that saturates below 0.1-0.3 $\mathrm{T}$ and another saturating at much higher fields above $1 \mathrm{~T}$ (RSA2-01 in Fig. 2.2.3a). This is likely due to the presence of magnetic minerals with contrasting coercivities, such as titanomagnetite and hematite. The corresponding hysteresis loops are typically wasp-waisted (Fig. 2.2.3d).

FORC diagrams for the three abovementioned specimens are presented in Figures 2.2.3e-2.2.3g. All fragments exhibit a long distribution along the $\mathrm{Hc}$ axis for $\mathrm{Hu}=0$, indicating a predominance of non-interacting single domain to pseudo-single domain state grains. In addition, samples RSJB-10 and RSA5-02 show a wide vertical distribution close to the origin of the Hc axis typical of superparamagnetic behavior (Roberts et al., 2014).

\subsubsection{Double-heating experiments}

Intensity measurements were performed on 53 specimens cut from 24 fragments, comprising three Jesuit Mission sites from South Brazil. Results per specimen are presented in Supplementary table A2.2.2 (supplementary material, Annex 1). A total of 24 specimens (11 fragments) passed selection criteria corresponding to a success rate of 45\% (Table 2.2.1). Figure 2.2.4a-2.2.4f displays six representative examples of successful intensity determination with measurements reported in Arai diagrams and orthogonal demagnetization plots. This figure shows that the intervals chosen for intensity estimation range from a minimum of $20-250{ }^{\circ} \mathrm{C}$ to a maximum of $400-575^{\circ} \mathrm{C}$ consistent with Tipoor magnetite being the main magnetic carrier in the ceramics. This interval always corresponds to a linear segment in the vectorial diagram. Eleven specimens were rejected due to a rapid demagnetization comprising more than $65 \%$ of their NRM at temperatures below 100-150 ${ }^{\circ} \mathrm{C}$ (Supp. fig. A2.2.1a-A2.2.1b; supplementary material). Eighteen specimens were rejected because they do not meet the selection criteria $\delta \mathrm{CK}, \delta$ pal, $\delta \mathrm{TR}$ and MAD defined above (Supp. fig. A2.2.1c-A2.2.1d; supplementary material).

It is worth mentioning that we used Paterson et al. (2014) limits for specimen selection criteria, but intensity determinations retained here would pass much more stringent criteria (see Supplementary table A2.2.2). For example, all retained specimens show $\mathrm{N} \geq 12$, whereas the minimum required is 4 . Values of NRM fraction used for intensity estimation (f) were always above 0.6 but for specimen RSA4-02-50 ( $f=0.39$ ), with a minimum required of 0.35 . Standard error of the slope $(\beta)$ is between $0.6 \%$ and 
$1.6 \%$ and quality factor $(\mathrm{q})$ is always above 11 . The associated directions have MAD < $9^{\circ}$ (with only two values above $5^{\circ}$ ) and $\alpha<5^{\circ}$. Alteration parameters as monitored by pTRM checks show $\delta \mathrm{CK}<6.5$ and $\delta$ pal $<12$. Multidomain effects are also negligible as indicated by $\delta \mathrm{TR}<5$. In fact, the strong similarity between our data and the distribution expected for SD grains as modeled by Paterson et al. (2012) suggest that we are dealing with near ideal magnetic recorders.
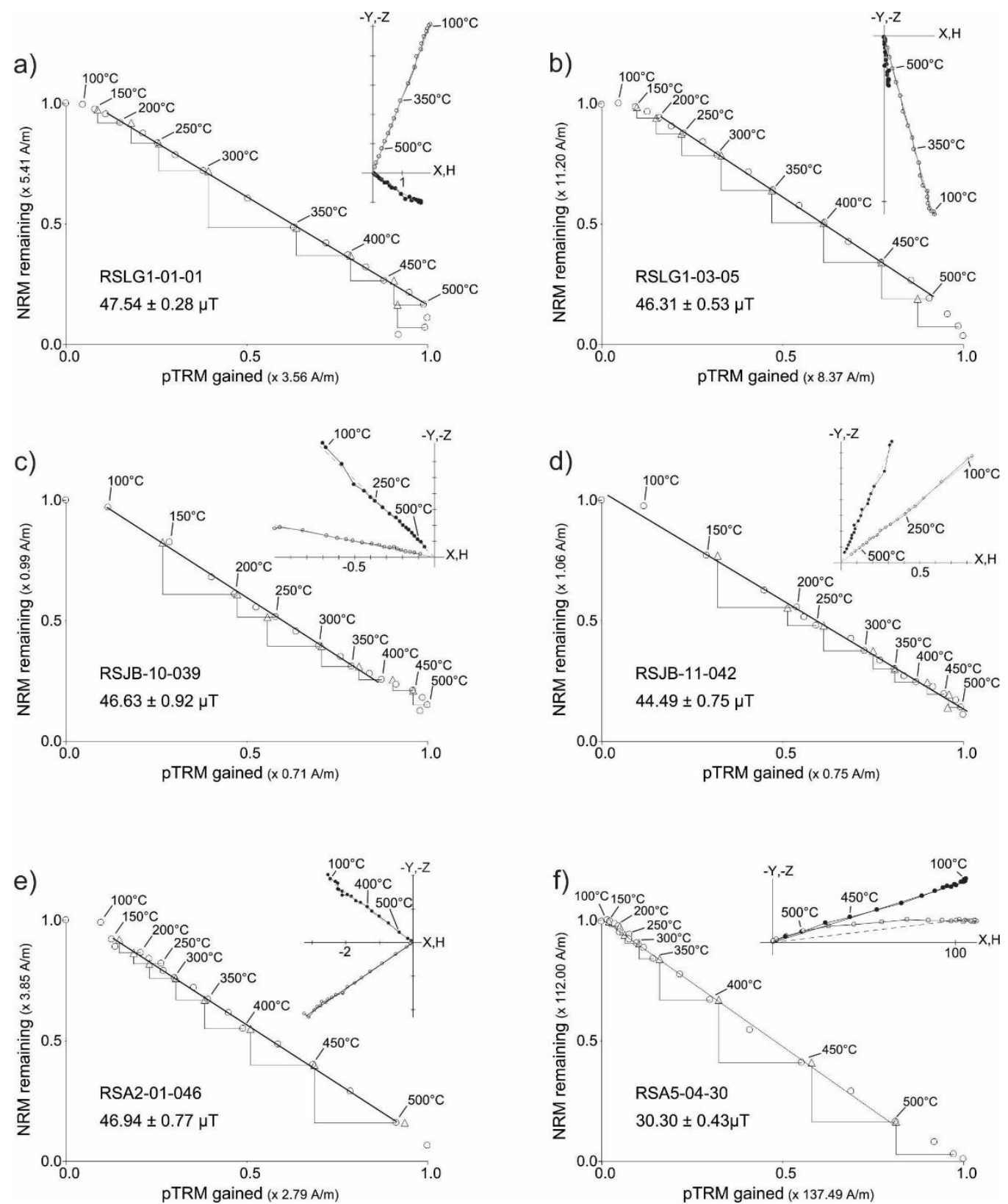

Figure 2.2.4: Arai diagrams. (a-f) Six representative examples of Arai diagrams with their respective orthogonal diagram. In Arai diagrams circles represent NRM remaining against pTRM gained and triangles show pTRM checks performed every two temperature steps. In the orthogonal diagrams, black and gray circles indicate vector end points projected onto horizontal and vertical planes, respectively (arbitrary specimen coordinate system) (extracted from Poletti et al., 2016). 


\subsubsection{Anisotropy and cooling-rate corrections}

TRM anisotropy effects were corrected according to the protocol described in Hartmann et al. (2010). Corrections using the ATRM@350 $\mathrm{C}$ tensor were applied to five specimens (RSLG1-06-10, RSJB-10-39, RSJB-10-40, RSJB-12-45, RSA5-04-30). All other specimens were corrected using the ATRM@500 $\mathrm{C}$ tensor (Supplementary table A2.2.2). Correction factors varied from zero to $23 \%$. Different anisotropy correction factors can be observed between specimens from the same fragments since we deliberately placed them orthogonal to each other during the experiment to enable consistency tests. We use the specimen with the highest correction factor (RSA5-04-2, $23 \%$ ) and a sister specimen (RSA5-04-29, 9\%) to illustrate the consistency test. Before correction, intensity estimates for RSA5-04-30 and RSA5-04-29 were 15\% different (33.2 $\mu \mathrm{T}$ and $38.9 \mu \mathrm{T}$ ). After correction the difference was reduced to 4\% (Supplementary table A2.2.2) with anisotropy-corrected intensities of $40.8 \mu \mathrm{T}$ and $42.4 \mu \mathrm{T}$, respectively. Cooling rate correction experiments were successful for all fragments and provided correction factors between $-2 \%$ to $-19 \%$. After anisotropy and cooling-rate corrections, a much better consistency between results at fragment level and at site level can be observed (Supplementary table A2.2.2).

Several authors have attempted to avoid the time-consuming anisotropy correction either by imparting the laboratory field along the ancient field (e.g. Rogers et al., 1979; Aitken et al., 1981) or by averaging intensities acquired in mutually orthogonal directions by different specimens of a given fragment (Goguitchaichvili et al., 2012). The first method has been successfully tested extensively. Our data can be used to test the second approach. For that we calculated for each specimen independent intensities for axes $+X$, $-\mathrm{X},+\mathrm{Y},-\mathrm{Y},+\mathrm{Z}$ and $-\mathrm{Z}$ between $350{ }^{\circ} \mathrm{C}$ and $500{ }^{\circ} \mathrm{C}$ with the data used to estimate ATRM@350 ${ }^{\circ} \mathrm{C}$ and ATRM@500 ${ }^{\circ} \mathrm{C}$ tensors. We restricted our analyses to non-altered specimens presenting at least $35 \%$ of demagnetization in this temperature interval (Fig. 3.2.4f). For instance, specimen RSA5-04-30 produced intensities for the six different axes varying between $27.8 \mu \mathrm{T}(+\mathrm{Z})$ and $33.9 \mu \mathrm{T}(+\mathrm{X})$ with a resulting mean at $30.1 \pm 2.3 \mu \mathrm{T}$, which is very close to the $30.3 \mu \mathrm{T}$ value obtained before correction by the analysis of the Arai plot. This value is significantly different from the anisotropy-corrected one at 39.9 $\mu \mathrm{T}$, which is internally consistent at fragment and site levels (Supp. table A2.2.2). Similar results, with smaller or greater differences were produced for the rest of our database (Supp. table A2.2.2). Therefore, we prove that the average of six orthogonally oriented specimens does not correct for the TRM anisotropy effect. 
Table 2.2.1: Archeointensity results obtained for Jesuit Missions from South Brazil (extracted from Poletti et al., 2016).

\begin{tabular}{llllllllll}
\hline Site name & Site ID & $\begin{array}{l}\text { Lat } \\
\left({ }^{\circ} \mathrm{S}\right)\end{array}$ & $\begin{array}{l}\text { Lon } \\
\left({ }^{\circ} \mathrm{W}\right)\end{array}$ & Material $^{\mathrm{a}}$ & $\begin{array}{l}\text { Age }^{\mathrm{b}} \\
(\mathrm{AD})\end{array}$ & $\begin{array}{l}N \text { frag } \\
\text { used (total) }\end{array}$ & $\begin{array}{l}n \text { spec } \\
\text { used (total) }\end{array}$ & $\begin{array}{l}\text { Intensity } \\
(\mu \mathrm{T})\end{array}$ & $\begin{array}{l}\mathrm{VADM}^{22} \\
\left(\mathrm{x} 10^{22} \mathrm{Am}^{2}\right)\end{array}$ \\
\hline $\begin{array}{l}\text { São Luiz Gonzaga } \\
\text { reduction }\end{array}$ & RSLG & 28.4 & 55.0 & $\mathrm{pt}$ & $1657-1687$ & $3(3)$ & $6(6)$ & $40.2 \pm 2.4$ & $8.03 \pm 0.50$ \\
$\begin{array}{l}\text { São João Batista } \\
\text { reduction }\end{array}$ & RSJB & 28.5 & 54.4 & $\mathrm{pt}, \mathrm{bk}$ & $1667-1697$ & $3(4)$ & $6(8)$ & $39.1 \pm 1.6$ & $7.80 \pm 0.31$ \\
$\begin{array}{l}\text { Santo Ângelo } \\
\text { reduction }\end{array}$ & RSA & 28.3 & 54.3 & $\mathrm{pt}, \mathrm{bk}, \mathrm{t}$ & $1676-1706$ & $5(17)$ & $12(39)$ & $41.1 \pm 1.48 .21 \pm 0.28$ \\
\hline
\end{tabular}

a pt - pavement tile; bk - brick; $\mathrm{t}$ - tile.

b Historical context. Lat - latitude. Lon - longitude. $\mathrm{N}$ frag - number of fragments. $\mathrm{N}$ spec - number of specimens. VADM - virtual axial dipole moment

\subsubsection{Mean intensities for Jesuit Missions}

Archeointensities were derived for each Jesuit Mission in south Brazil by averaging the mean intensities obtained at fragment level (Table 2.2.1 and Supp. table A2.2.2). Results are similar within error for the three studied reductions. São Luiz Gonzaga reduction (1657-1687 AD) yields an intensity of 40.2 $\pm 2.4 \mu \mathrm{T}$, São João Batista reduction (1667-1697 AD) yields an intensity of $39.1 \pm 1.6 \mu \mathrm{T}$, and Santo Ângelo reduction (1676-1706 AD) yields an intensity of $41.1 \pm 2.0 \mu \mathrm{T}$.

\subsubsection{Discussion}

\subsubsection{Evaluation of South American archeomagnetic data}

In order to compare our results with the data available for the rest of the continent we decided to assess first the reliability of the current South American database. For that we evaluated all entries for the past two millennia available for the continent in GEOMAGIA50 (Brown et al., 2015) as well as recently three published studies not yet incorporated in that database (Roperch et al., 2014, 2015; Goguitchaichvili et al., 2015). The period investigated comprises the past 2000 years and includes the arrival of the South Atlantic Geomagnetic Anomaly (SAGA) over South America (Hartmann and Pacca, 2009) as well as rapid regional paleointensity variations reported for different regions of the northern hemisphere (De Groot et al., 2013). For the interval of interest the data are largely concentrated in the northern hemisphere (Fig. 2.2.5). The temporal distribution of the data is also irregular both globally and locally (Fig. 2.2.6) with a predominance of intensity data over directional data in South America (Fig. 2.2.6b). Presently there are 203 archeointensity data for South America reported in fifteen published studies (Table 2.2.2). We evaluated these data taking into account the reliability of the methods used to estimate archeointensities, the quality of individual data in face of 
the current standards embodied in the criteria recently defined by Paterson et al. (2014) and the internal consistency of each entry.

Table 2.2.2: Evaluation of methods and protocols in the archaeointensity database of South America for the past two millennia (extracted from Poletti et al., 2016).

\begin{tabular}{|c|c|c|c|c|c|c|c|c|c|c|}
\hline \multirow{2}{*}{$\begin{array}{l}\text { Reference } \\
\text { ID }\end{array}$} & \multirow[t]{2}{*}{ Country } & \multirow{2}{*}{$\begin{array}{l}\text { Material } \\
\text { ID }\end{array}$} & \multirow{2}{*}{$\begin{array}{l}\text { magnetic } \\
\text { mineralogy } \\
\text { check }\end{array}$} & \multirow{2}{*}{$\begin{array}{l}\text { Method } \\
\text { PI }\end{array}$} & \multicolumn{2}{|l|}{ pTRM } & \multicolumn{2}{|l|}{ Corrections } & \multirow{2}{*}{$\begin{array}{l}\text { Approved } \\
\text { by the } \\
\text { criteria? }\end{array}$} & \multirow{2}{*}{$\begin{array}{l}\text { Obs } \\
\text { ID }\end{array}$} \\
\hline & & & & & Check & Tail check & Cooling rate & Anisotropy $^{a}$ & & \\
\hline 1 & Peru & 101,103 & yes & $\mathrm{TT}$ & no & no & no & no & no & - \\
\hline 2 & Peru & 102 & yes & TT & yes & no & no & no & no & 201 \\
\hline 3 & Peru & 102 & no & $\mathrm{SH}$ & - & - & no & no & no & 202 \\
\hline 4 & Peru & 102 & no & MW & no & no & no & yes & no & 202 \\
\hline 5 & Peru & 101 & yes & GM & - & - & - & no & no & - \\
\hline 6 & $\begin{array}{l}\text { Peru/ } \\
\text { Bolivia }\end{array}$ & 102,104 & yes & TT & no & no & no & no & no & 203 \\
\hline 7 & $\begin{array}{l}\text { Peru/ } \\
\text { Bolivia }\end{array}$ & 102 & yes & TT & no & no & no & no & no & - \\
\hline 8 & $\begin{array}{l}\text { Ecuador/ } \\
\text { Bolivia }\end{array}$ & 102 & no & TT & no & no & no & no & no & - \\
\hline 9 & Brazil & 101 & yes & TT / TR & yes & yes & yes & yes & yes & - \\
\hline 10 & Brazil & 101 & yes & TT / TR & yes & yes & yes & yes & yes & - \\
\hline 11 & Argentina & 102 & yes & TT & yes & no & yes & yes & yes & - \\
\hline 12 & Argentina & 102 & yes & $\mathrm{TT}$ & yes & no & yes & no & no & 204 \\
\hline 13 & Argentina & $\begin{array}{l}101,102, \\
105\end{array}$ & yes & TT & yes & no & yes & yes & yes & 204 \\
\hline 14 & Chile & 106 & yes & TT & yes & no & yes & yes & yes & 202 \\
\hline 15 & Chile & 106 & yes & TT & yes & no & yes & yes & yes & 202 \\
\hline This study & Brazil & 101,105 & yes & TT & yes & yes & yes & yes & yes & - \\
\hline
\end{tabular}

Reference ID: 1 - Kono et al . (1986); 2 - Yang et al. (1993); 3 - Gunn and Murray (1980); 4 - Shaw et al. (1996); 5 - Games (1977); 6 - Lee (1975); 7 - Nagata et al. (1965); 8 - Kitazawa and Kobayashi (1968); 9 - Hartmann et al. (2010); 10 - Hartmann et al. (2011); 11 - Goguitchaichvili et al. (2011); 12 Goguitchaichvili et al. (2012); 13 - Goguitchaichvili et al. (2015); 14 - Roperch et al. (2014); 15 - Roperch et al. (2015).

Material ID: 101 - bricks; 102 - ceramics; 103 - archeological fragments; 104 - baked clay; 105 - tile; 106 - historic basalt.

Observation ID: 201 - TRM anisotropy effect shown to be negligible; 202 - pTRM tail checks were not applied, but the curvature of Arai diagram was evaluated; 203 - different variations of the original ThellierThellier method were tested; 204 - anisotropy correction was replaced by the arithmetic mean of intensities acquired in six orthogonally-oriented sister specimens; 205 - cooling rate correction was performed with a slow cooling time of three hours only; 206 - anisotropy tensors were not calculated from specimens where intensities were estimated but for sister specimens.

Glossary: PI - paleointensity; TT - modified Thellier-Thellier (Coe, 1967); SH - Shaw (1974); GM Games (1977); MW - microwave (Shaw et al., 1996); TR - triaxe (Le Goff and Gallet, 2004).

${ }^{\text {a }}$ Correction from thermoremanent anisotropic tensor or re-magnetizing the sample in the same direction as the NRM. 


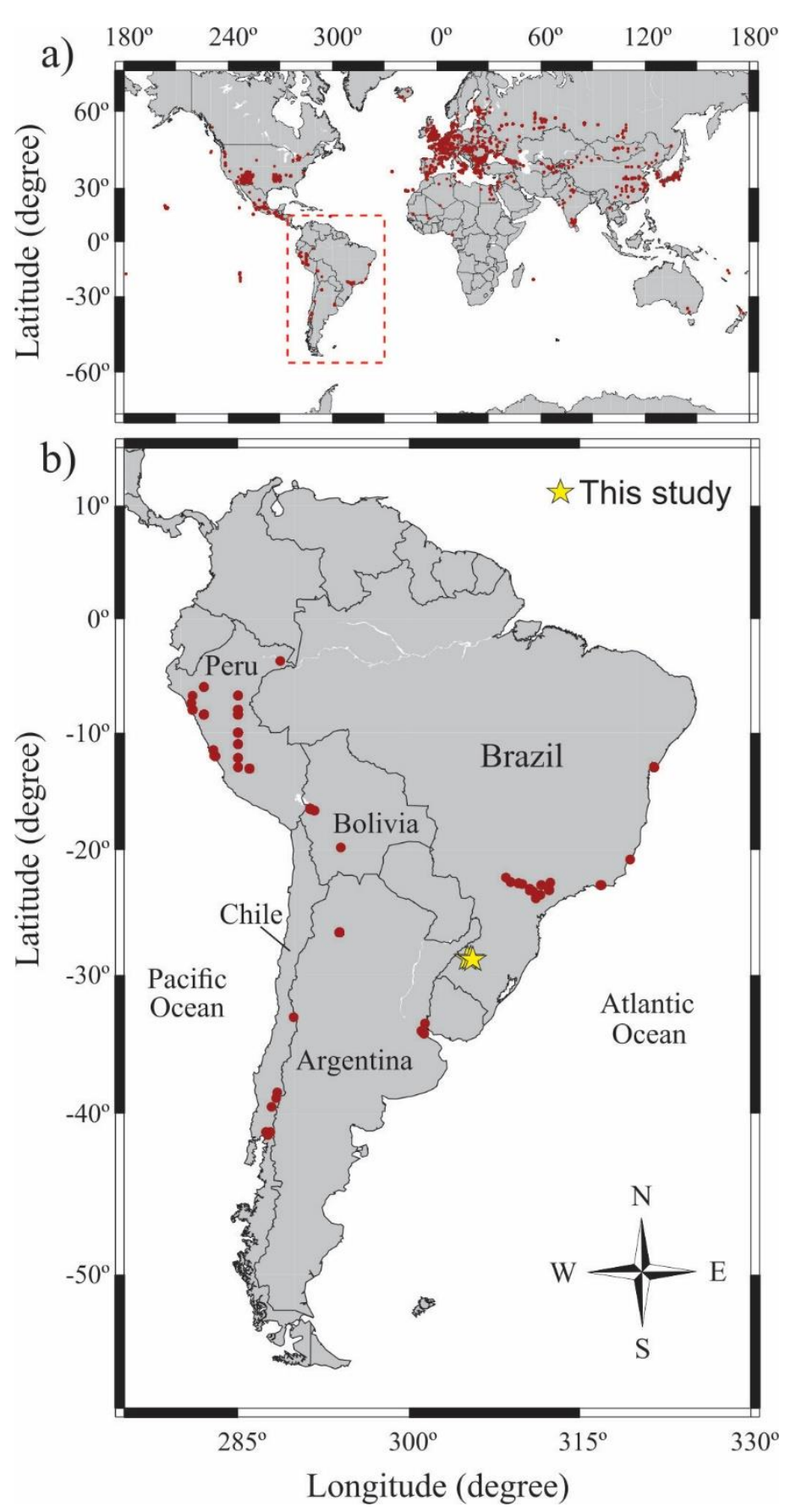

Figure 2.2.5: Distribution of archeomagnetic sites for the last two millennia (a) in the world and (b) in South America. Stars represent location of Jesuit reductions studied here (extracted from Poletti et al., 2016).

In evaluating the methodology of previous works, we considered (Table 2.2.2): (1) the archeointensity method (and protocols) used, (2) the type of material investigated and the nature of the magnetic mineralogy (if it was investigated). In case of doubleheating techniques, we also considered whether: (3) additional steps were used to check for thermochemical alteration and the influence of multi-domain grains (pTRM check and pTRM tail check), and (4) cooling-rate and anisotropy corrections were made. 


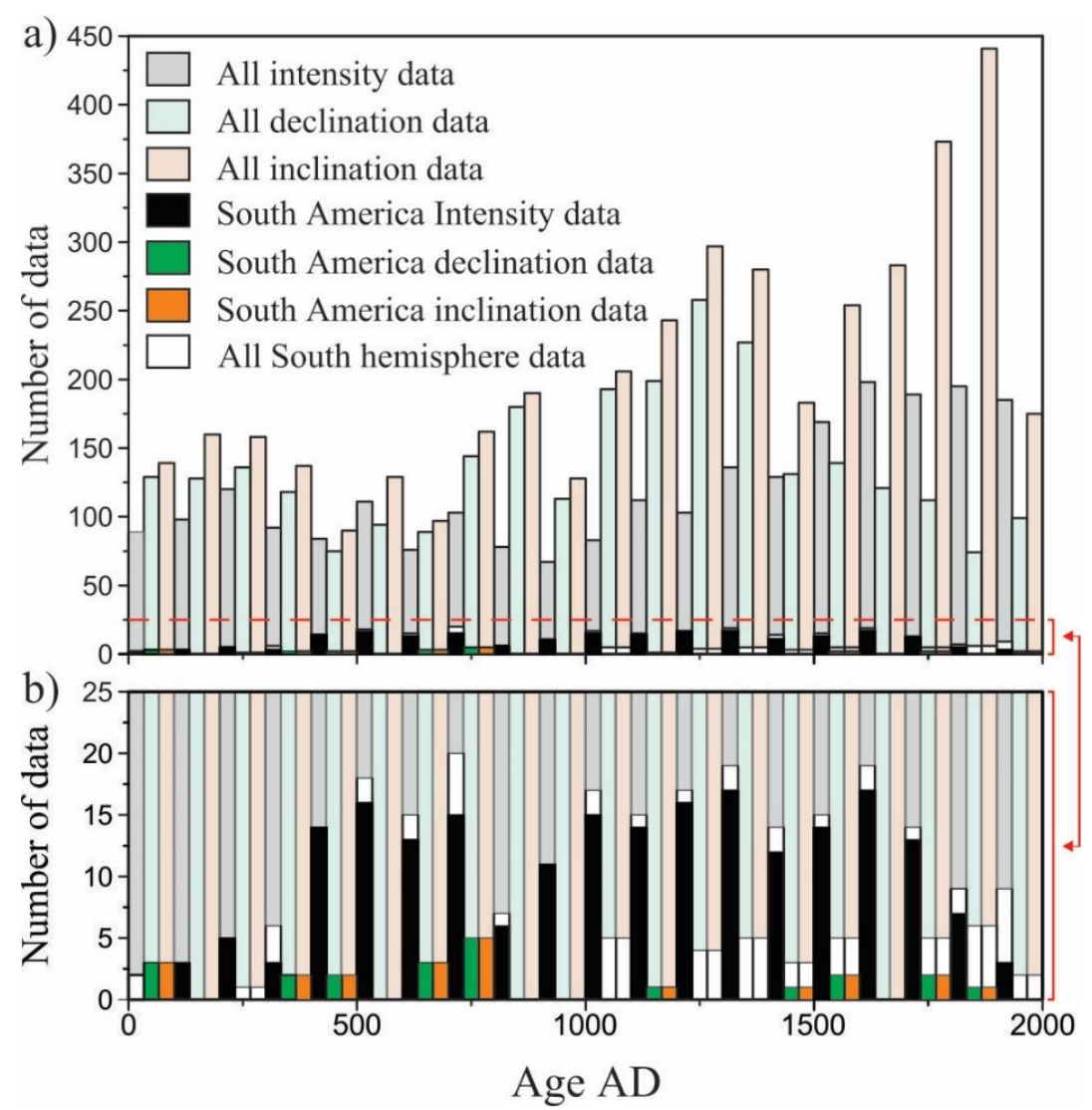

Figure 2.2.6: Archeomagnetic database distribution through time for (a) the world and (b) re-scaled for South America. Note the dominance of directional data in the world database, and the dominance of intensity data for South America (extracted from Poletti et al., 2016).

Two studies were performed using Shaw-type experiments (Shaw, 1974) in ceramics from Peru, corresponding to a total of 50 intensity estimates (Games, 1977 and Gunn and Murray, 1980). The Shaw method uses only one step of TRM acquisition and compares the alternating field demagnetization patterns of this artificial TRM with the NRM. Before and after TRM acquisition the sample acquires an anhysteretic remanence (ARM) that is used to calibrate the TRM-NRM relation. This assumes implicitly that TRM and ARM have a similar behavior under AF demagnetization. Yu et al. (2003) demonstrate that this assumption is not valid. Moreover, Games (1977) and Gunn and Murray (1980) did not incorporate tests to investigate alteration during the experiments (e.g. Tsunokawa and Shaw, 1994). Besides involving significantly less heating time, this method does not prevent completely thermochemical alteration as demonstrated by Valet and Herrero-Bervera (2000). For these reasons, all results obtained in these two studies were discarded (Table 2.2.2).

One study also performed on ceramics from Peru reported 13 intensity estimates obtained with the microwave method (Shaw et al., 1996). In this method, the heating steps 
are replaced by microwave excitation of magnetic grains. Recently, Poletti et al. (2013) showed that cooling-rate effects and thermochemical alteration could affect microwave archeointensity estimates, overestimating the results by $25 \%$ in some cases. Because of that a cooling-rate correction (Poletti et al., 2013) and pTRM checks (Coe et al., 1978) are necessary to validate the results obtained with this technique. Since none of these were provided in the original study of Shaw et al. (1996) these results were also rejected (Table 3.2.2).

Most studies used the Thellier-Thellier method and its variations, but several of them fail in providing the necessary tests and corrections. The works of Nagata et al. (1965), Kitazawa and Kobayashi (1968), Lee (1975) and Kono et al. (1986) were performed before the tests and corrections used now routinely in archeointensity experiments were established. They do not present pTRM checks, pTRM tail checks, cooling-rate and anisotropy corrections and were consequently discarded (Table 2.2.2). Yang et al. (1993) presented pTRM checks but did not correct results for cooling-rate or anisotropy effects and was also rejected (Table 2.2.2). For one recent work on Argentina, anisotropy corrections were tentatively circumvented by averaging the intensity estimates of six sister specimens positioned orthogonal to each other (Goguitchaichvili et al., 2012). This protocol assumes implicitly that the anisotropy is constant throughout the artifact, and this is not necessarily true (Veitch et al., 1984). But even if the anisotropy tensor is exactly the same throughout the fragment, replacing the tensor-based correction by the arithmetic mean of intensities is, in principle, wrong. It will simply produce the mean of six uncorrected values (see above). Finally, based on the analysis of the methods used, we are left with six datasets obtained with variants of the Thellier-Thellier method that provide all the necessary checks and corrections and were thus considered for further analyses (Hartmann et al., 2010, 2011; Goguitchaichvili et al., 2011, 2015; Roperch et al., 2014, 2015). Note that in some cases the temperature intervals where intensities were determined are below the temperature where correction factors were obtained. In such cases, corrections are meaningless as correctly stated by Goguitchaichvili et al. (2011). Therefore, in our compilation we accepted only the intensity estimates obtained in a temperature interval comprising that of cooling-rate and anisotropy corrections. Sitemeans were recalculated on this basis and are given in Supplementary table A2.2.3.

We can also evaluate the datasets in terms of the criteria used to select each intensity estimate. Currently, especially after Paterson et al. (2014), it is crucial that parameters used to select paleointensity results are explicitly presented and discussed. 
Selection can be easily done using available packages for paleointensity estimates (e.g., ThellierTool 4.0 of Leonhardt et al., 2004). Most studies present only a small number of the parameters recently proposed in the literature to discriminate reliable data (Supplementary table A2.2.4). None of the remaining results was discarded based on these criteria only.

We further analyzed the internal coherence of the data at the fragment and site level. Our criteria stated in section 2.3 above assumes that a mean intensity at fragment level is retained only when the difference between individual values is less than $5 \%$ after corrections and at least two independent intensities are obtained for each fragment. At the site level, a total mean is calculated from at least three fragments and the standard deviation of the mean is less than $10 \%$. Hartmann et al. $(2010,2011)$ used the same criteria and all their results were therefore retained in our compilation. All results from Roperch et al. $(2014,2015)$ also comply with these criteria since each rock specimen can be considered to be equivalent to an archeological fragment. Since the other selected studies did not apply such a stringent criteria in calculating the site mean, we decided to accept results that have at least 5\% coherence at fragment level after corrections (Supplementary table A2.2.3). According to this criterion we maintained four results from Goguitchaichvili et al. (2011) and two from Goguitchaichvili et al. (2015).

\subsubsection{Trends and gaps of high-quality archeointensity data for South America}

Figure 2.2.7a shows all available data for the past two millennia in South America plotted as virtual axial dipole moment (VADM) against time. Empty grey circles represent data obtained by older studies (Nagata et al., 1965; Kitazawa and Kobayashi, 1968; Lee, 1975; Games, 1977; Gunn and Murray, 1980; Kono et al., 1986; Yang et al., 1993; Shaw et al., 1996). We represented in color all studies performed since 2010, which correspond to those published after the 14-years gap in data generation for the region. For these data, error bars are given for VADM and age estimates. Taken together the whole dataset roughly follows the available field models until 1200 AD. Prior to that, there are strong discrepancies in the data (and models), particularly for the 800-1100 AD period when estimates depart by $\sim 8 \times 10^{22} \mathrm{Am}^{2}$. It is also worth noting extremely high values observed at 1650-1700 AD from Argentina (Goguitchaichvili et al., 2011). These results depart significantly from the models, which are considered to be well constrained for this time interval (see discussion in Korte et al., 2011; Roperch et al., 2015). They also differ significantly by $\sim 5 \times 10^{22} \mathrm{Am}^{2}$ from those produced here for the same age interval. 

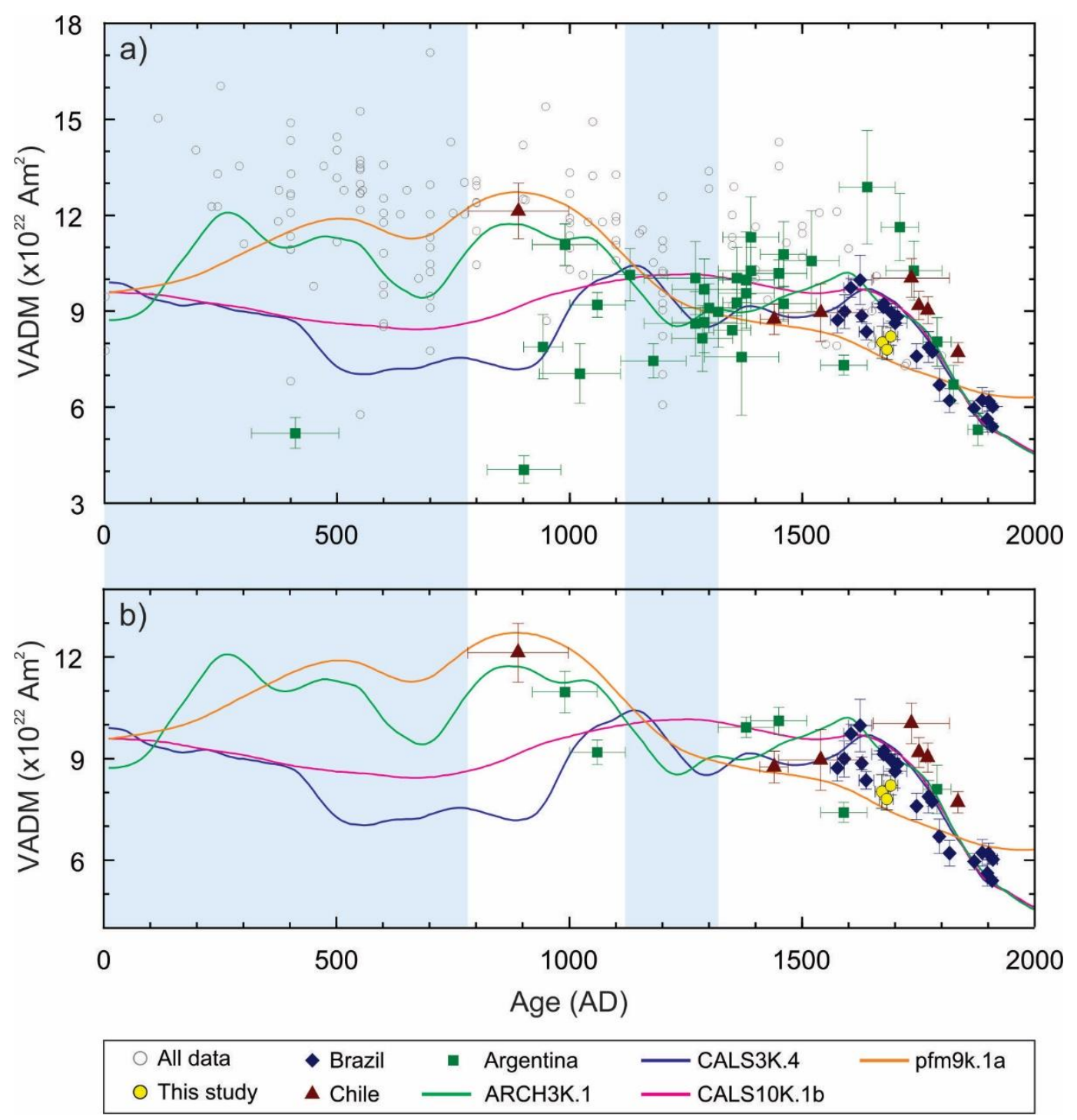

Figure 2.2.7: VADM data for South America in the past two millennia (a) before and (b) after data selection. Empty grey circles represent data obtained by older studies and colored symbols represents data obtained in studies performed since 2010. Yellow circles represents VADM estimates obtained in this study. Error bars were omitted for older studies to facilitate visualization. Lines represent four different field models (Korte et al., 2009, 2011, Korte and Constable, 2011; Nilsson et al., 2014). Light blue areas indicate gaps in the archeointensity database after filtering out less reliable results (extracted from Poletti et al., 2016).

Figure 2.2.7b shows the data after filtering results that either present methodological problems or are not internally consistent (Table 2.2.2 and Supp. table A2.2.3). It comprises 36 data from previous studies plus the three reported here. Two main gaps at 0-800 AD and 1100-1300 AD can be identified in the dataset after filtering out less reliable results. Therefore, the rapid variations observed in other parts of the globe (De Groot et al., 2013) cannot be verified in South America because of the noise inherent 
to the unfiltered dataset and the lack of high quality estimates covering sufficient time span. Three data correspond to older periods of time with ages within 800-1100 AD. Two of them overlap within error models ARCH3K.1 (Korte et al., 2009) and pfm9k.1a (Nilsson et al., 2014), whereas one data does not match any model (Fig. 2.2.7b). ARCH3K.1 is based only on archeointensity data, whereas pfm9k.1a prioritize sedimentary data. The filtered data within the last 700 years match the younger, welldefined sector of the models except for one entry from Argentina that might be misdated (see below). Figure 2.2.8 shows intensity estimates for the past 700 years, including our results. Also represented are some archeointensity models. Data from Chile, Argentina, SE and NE Brazil were relocated to the latitude of Jesuit Missions $\left(28.4^{\circ} \mathrm{S}\right)$ assuming an axial dipolar field. Our data covers the period between 1657 and $1706 \mathrm{AD}$ and fit into the trend defined by data from SE-Brazil (Hartmann et al., 2011) and Argentina (Goguitchaichvili et al., 2015), thus helping to fill the gap left by the previous surveys. One Argentinian data plot away from the whole database. It corresponds to one fragment collected at Santa Catalina de Siena convent which was built between 1750-1800 AD and the pottery sampled was considered to be post XVII century by the local archeologists (Goguitchaichvili et al., 2015). The authors preferred instead a radiocarbon age of $419 \pm$ $84 \mathrm{BP}$, essentially because it eventually matches an archeomagnetic dating of 1504-1596 AD. We rerun the archeomagnetic dating software of Pavon-Carrasco et al. (2011) with the archeointensity value of $39.4 \pm 1.6 \mu \mathrm{T}$ for Santa Catalina de Siena location using the CALS3K.3 model and obtained only one age at 1793-1840 AD (not 1504-1596 AD). This age is fully compatible with the historical record of convent's construction between 1750$1800 \mathrm{AD}$ and makes the data compatible with the rest of the database.

The combined S Brazil and relocated SE-Brazil+Argentina data plot below most field models. They follow the general trend defined by ARCH3K.1, CALS3K.4 and CALS10K.1b models (Korte et al., 2009, 2011; Korte and Constable, 2011) and depart from the pfm9k.1a model (Nilsson et al., 2014). This is a consequence of the way these studies have calculated the most recent part of the models. In the first three models, largescale agreement with the robust gufm1 historical model of Jackson et al. (2000) has been enforced for 1650-1990 AD. In contrast, model pfm9k.1a was obtained dominantly from sedimentary records and does not observe the same constraints for the recent past (Nilsson et al., 2014). S+SE-Brazil+Argentina results also plot systematically below the relocated data from NE Brazil and Chile. Relative to the studied region, NE Brazil results are located $\sim 15^{\circ}$ to the north and results from Chile are located $\sim 10^{\circ} / 15^{\circ}$ to the south/west 
(Fig. 2.2.5). We interpret these differences in line with Hartmann et al. (2011) and suggest they are likely due to complexities in the geometry of the field in South America for the considered period not appropriately accounted by the simple axial dipole model used in relocating the data. In principle, this implies that from the beginning of the XVII century the South Atlantic Geomagnetic Anomaly (or other important non-dipolar feature of the field) was already stronger over South America than current models suggest.

\subsubsection{Conclusions}

We obtained high-quality results for Jesuit reductions in South Brazil that include all available checks and corrections. An experimental test for the 6-specimen average anisotropy correction technique was performed for the first time and proves that it does not correct for the TRM anisotropy effect. Archeointensity data for São Luiz Gonzaga (40.2 $\pm 2.4 \mu \mathrm{T}$ at 1657-1687 AD), São João Batista (39.1 $\pm 1.6 \mu \mathrm{T}$ at 1667-1697 AD), and Santo Ângelo $(41.1 \pm 2.0 \mu \mathrm{T}$ at 1676-1706 AD) increase the number of high-quality estimations for South America by $10 \%$. These data follow the same trend of previously published results from SE Brazil and help in defining a combined S+SE Brazil archeointensity curve.

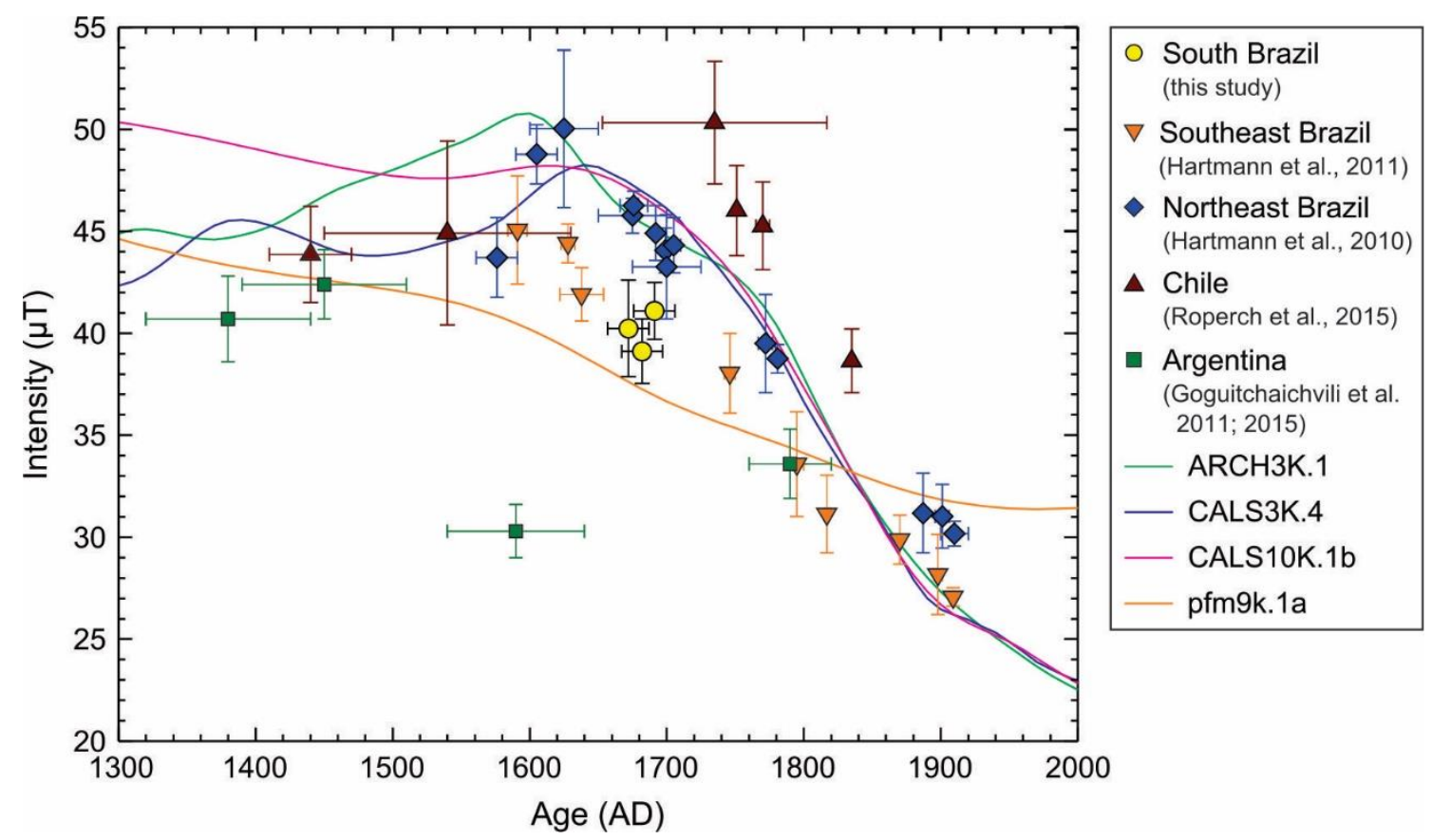

Figure 2.2.8: Geomagnetic field intensity variation defined by high-quality South American data for the past 600 years. Yellow circles represents archeointensity estimates obtained from this study. Other symbols represents archeomagnetic data obtained from other recent studies; all of them were relocated to a latitude of $28.4^{\circ} \mathrm{S}$. Lines represents four different field models (extracted from Poletti et al., 2016). 
The analysis of the current archeointensity database for South America, that comprises 205 data reported in fifteen studies (plus the three data published here), shows that most results do not conform to current quality standards for archeointensity estimates. Data were rejected largely due to problems in the methods used in estimating the intensity of the ancient field, but also because they do not fit minimum standards in statistical parameters used to evaluate the data. After filtering for quality the database was reduced dramatically to 39 results, which were predominantly obtained with variants of the Thellier-Thellier method including all the necessary checks and corrections and show internal consistency. The high-quality data are concentrated within the last 700 years, with three entries at 800-1100 AD, and exhibit two major gaps for times prior to $800 \mathrm{AD}$ and for 1100-1300 AD. They cover only Brazil, Chile and Argentina with no reliable data for the center, north and northwestern sectors of the continent. Given the complexities of the field in South America, and the need to verify rapid variations recently observed in other continents, we consider that new data of similar standards must be obtained to cover preferentially these spatial and temporal gaps.

\section{Acknowledgments}

This work was partially funded by grants \#2013/16382-0 and \#2010/10754-4 São Paulo Research Foundation (FAPESP), CAPES AUXPE 2043/2014 and CNPq grant 454609/2014-0 to GAH and CNPq-PQ 304934/2014-3 to RIFT. Plinio Jaqueto helped in magnetic mineralogy measurements. We thank Prof. Igor Pacca for suggesting the Jesuit Missions as an archeointensity target. A pre-submission reading by Andrew Biggin and two editorial reviews by Greig Paterson and an anonymous colleague helped in improving the paper. 


\title{
2.3. New archeointensity data from South Brazil and the influence of the South Atlantic Anomaly in South America
}

\author{
Gelvam A. Hartmann ${ }^{1}$, \\ $\underline{\text { Wilbor Poletti }^{2}}$, Ricardo I.F. Trindade ${ }^{2}$, Lucio Menezes Ferreira ${ }^{3}$, Pedro Sanches ${ }^{4}$
}

${ }^{1}$ Instituto de Geociências, Universidade Estadual de Campinas, Rua Carlos Gomes, 250, 13083-855, Campinas, Brazil. ${ }^{2}$ Departamento de Geofísica, Instituto de Astronomia, Geofísica e Ciências Atmosféricas, Universidade de São Paulo, Rua do Matão, 1226, 05508-090, São Paulo, Brazil. ${ }^{3}$ Departamento de Antropologia e Arqueologia, Instituto de Ciências Humanas, Universidade Federal de Pelotas, Pelotas, Rio Grande do Sul, Brazil. ${ }^{4}$ Departamento de Museologia, Conservação e Restauro, Instituto de Ciências Humanas, Universidade Federal de Pelotas, Pelotas, Rio Grande do Sul, Brazil.

\begin{abstract}
We obtained six new high-quality archeointensity results for the Pelotas city region, in South Brazil with ages ranging from 1790 to $1943 \mathrm{CE}$. Archeointensity measurements were performed with the double heating technique, including partial termoremanent magnetization (pTRM) checks and pTRM tail-checks. Measurements were corrected from anisotropy of TRM and cooling-rate. Archeological sites providing successful results comprised: Charqueada Santa

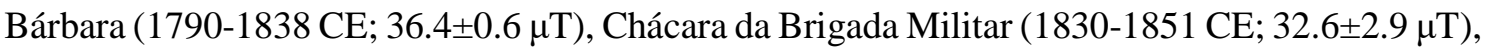

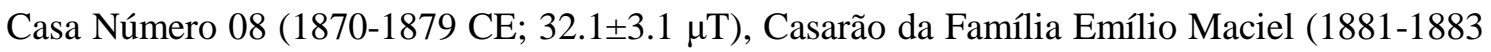

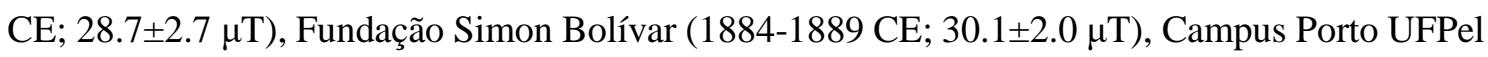
(1942-1943 CE; 27.8 $\pm 2.0 \mu \mathrm{T}$ ). Two other sites did not provide meaningful results. The new data complement previous results obtained in South and Southeast Brazil, Argentina and Chile and provide additional evidence for the rapid decay of the field in the region. In addition, it demonstrates the gradual increase in the contribution of non-dipolar components in the geomagnetic field of South America since $1800 \mathrm{CE}$, therefore tracking the arrival of the South Atlantic Anomaly to these times.
\end{abstract}

Keywords: Archeomagnetism; Archeointensity; South America; South Atlantic Anomaly. 


\subsubsection{Introduction}

The processes operating in the Earth's core can be studied through the variations of the geomagnetic field, which is recorded nowadays by observatories and satellites and has been recorded in the past on sediments, volcanic rocks and archeological material (Hulot et al., 2010). Tracing the field in the past at the centennial and millennial timescale (i.e., the archeomagnetic timescale) is important in improving geomagnetic field models (e.g., Korte et al., 2011; Licht et al., 2013) and also for field forecast analyses (e.g., Aubert, 2015; Tangborn and Kuang, 2018). While recent data from observatories and satellites cover the Earth more uniformly, the distribution of archeomagnetic data across the globe is very inhomogeneous with almost all data coming from the northern hemisphere, particularly from Europe and Asia (Brown et al., 2015). Yet, the southern hemisphere is the one presenting the highest variability for the past millennia (Constable et al., 2016). It is also the region comprising the South Atlantic Anomaly (SAA), the largest geomagnetic field anomaly on the globe covering the South Atlantic and also part of South America, where the lowest magnetic intensities are found (Hartmann and Pacca, 2009; Finlay et al., 2010; Aubert, 2015; Terra Nova et al., 2017). The SAA is presently located in Southern Brazil and its low-field intensities are credited to the presence of strong non-dipole fields (Hartmann and Pacca, 2009), which is a consequence of the reversed flux patches (RFP) on the core-mantle boundary beneath the region (Terra-Nova et al., 2017). Some studies suggest that SAA is a persistent field feature in South Atlantic for periods longer than historical times (Tarduno et al., 2015; Shah et al., 2016). But, the beginning of the influence of strong non-dipole fields at the centennial-scale evolution in South Atlantic region, could give important information about the recurrence of SAA at longer timescales.

Efforts have been made to constrain time evolution of SAA in both sides of Atlantic Ocean from archeomagnetic point of view. In Africa, important results both from directional and intensity data were obtained last years (e.g. Casas et al., 2008; GomézPaccard et al., 2012; Neukirch et al., 2012; Mitra et al., 2013; Donadini et al., 2015; Osete et al., 2015; Tarduno et al., 2015; Kapper et al., 2017; Hare et al., 2018), in order to describe secular variation of SAA; most of them, indicate a rapidly westward drift accompanied to a decrease in field intensity for the past few centuries (e.g. Tarduno et al., 2015). In South America, in an attempt to improve the archeomagnetic database, several studies were performed in the past decade addressing the variability of the field in the region in the past millennia (Hartmann et al., 2010, 2011; Goguitchaichvili et al., 
2011, 2015; Roperch et al., 2014, 2015; Poletti et al., 2016; Di Chiara et al., 2017). A critical assessment of the South American archeointensity database selected only 39 highquality data for the region, most of them within the past 700 years (Poletti et al., 2016). The dataset comprise results from Brazil, Argentina and Chile. Significant differences are observed between archeointensities from SE Brazil and Argentina and the rest of South America, which were interpreted as due to the influence of the SAA, which cover these sectors of the continent.
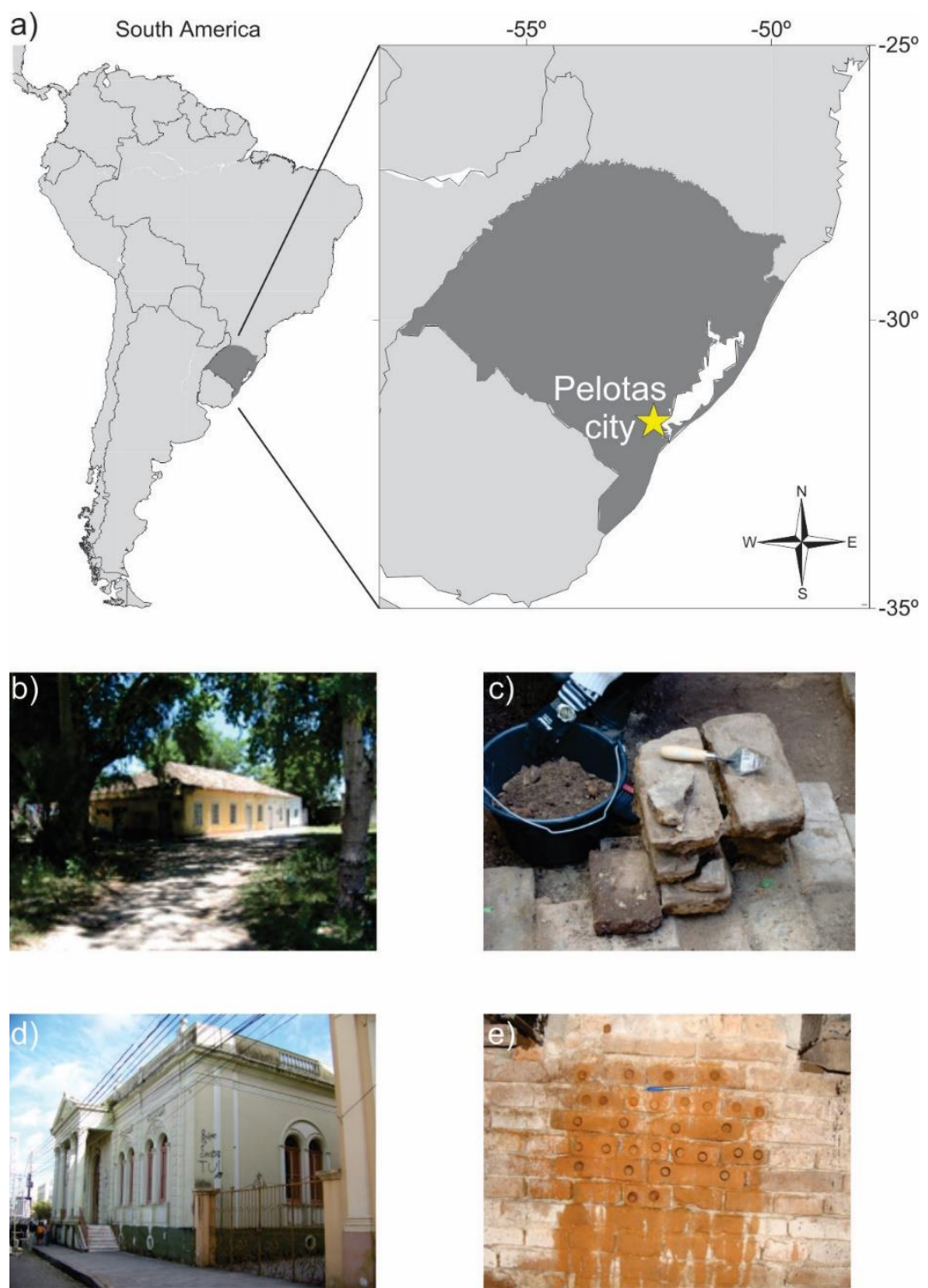

Figure 2.3.1: Location and examples of sampled sites. (a) On left side of the panel is the map of South America, where dark grey area represents the Rio Grande do Sul State; on right side of the map there is a zoon indicating the Pelotas city, South Brazil, where archeomagnetic sites were sampled (yellow star). (b, c) Charqueada Santa Bárbara $(\mathrm{CSB} 1+2)$ farmhouse and examples of sampled brick fragments from the basement of CSB1+2, respectively. (d, e) Casarão da Família Eliseu Maciel (FEM) house and brick cores sampled from the basement of FEM, respectively (extracted from Hartmann et al., submitted). 
Here we present six new high-quality archeointensity data from Pelotas city (Fig. 2.3.1a), South Brazil, located close to the present-day minimum of the SAA. These data, together with the previously reported results for Jesuit Missions and northern Argentina allow us to discuss more thoroughly the effects of rapid field variations in the region, and the eventual role of regional non-dipolar components on the geomagnetic field observed over South American in the past centuries.

\subsubsection{Archeological context and sampling}

Brazil was the last country in the western world to abandon the black slavery system. In South Brazil, black slavery started at around $1730 \mathrm{CE}$ and accelerated in the coming decades (Cardoso, 2003). One of the most important slavery system in South Brazil was placed in Pelotas region $\left(31.8^{\circ} \mathrm{S}, 52.3^{\circ} \mathrm{W}\right)$, near the South Atlantic Ocean (Fig. 2.3.1a). This slavery main d'ouvre was the motor of a very successful jerky beef industry in the XVIII century (Gutierrez, 2001; Funari e Ferreira, 2016), which included 40 farms at the banks of the Pelotas River. All of them operated from the middle XVIII until the beginning of the $\mathrm{XX}$ century.

Table 2.3.1: Archeological and architectural IDs (details in Supplementary table A3.2.1) and archeointensity results of the studied sites from Pelotas, South Brazil $\left(31.8^{\circ} \mathrm{S}, 52.3^{\circ} \mathrm{W}\right)$ (extracted from Hartmann et al., submitted).

\begin{tabular}{lllll}
\hline Site & $\begin{array}{l}\text { Age interval } \\
(\mathrm{CE})\end{array}$ & $\begin{array}{l}\mathrm{N} \\
\text { fragment }\end{array}$ & $\begin{array}{l}\mathrm{n} \\
\text { specimen }\end{array}$ & $\begin{array}{l}\text { Fmean } \pm \sigma \mathrm{F} \\
(\mu \mathrm{T})\end{array}$ \\
\hline $\begin{array}{l}\text { Charqueada Santa Bárbara } \\
\text { (CSB1+2) }\end{array}$ & $1790-1838$ & $6(9)$ & $12(18)$ & $36.4 \pm 0.6$ \\
$\begin{array}{l}\text { Chácara da Brigada Militar (CBM) } \\
\text { Casa Número 08 (C08) }\end{array}$ & $1830-1851$ & $3(5)$ & $6(10)$ & $32.6 \pm 2.9$ \\
$\begin{array}{l}\text { Casarão da Família Emílio Maciel } \\
\text { Sede dos Conselhos Universitários } \\
\text { da UFPEL) (FEM) }\end{array}$ & $1881-1883$ & $3(5)$ & $6(10)$ & $28.7 \pm 2.7$ \\
$\begin{array}{l}\text { Fundação Simon Bolivar (Antigo } \\
\text { Casarão da Faculdade de Turismo } \\
\text { da UFPEL) (FSB) }\end{array}$ & $1884-1889$ & $5(6)$ & $10(12)$ & $32.1 \pm 3.1$ \\
& & & & \\
& & & & \\
Campus Porto da UFPEL (CPU) & $1942-1943$ & $4(5)$ & $8(10)$ & $27.8 \pm 2.0$ \\
$\begin{array}{l}\text { Grande Hotel (GH) } \\
\begin{array}{l}\text { Prédio 2 do Instituto de Ciências } \\
\text { Humanas (ICH2) }\end{array}\end{array}$ & $1924-1928$ & $0(14)$ & - & - \\
\hline
\end{tabular}


The Southern of Rio Grande do Sul State, where the city of Pelotas is located, was a major slavery centre. At the beginning of eighteenth century, with the end of disputes between the Portuguese and Spanish crowns, the Portuguese founded colonies in Rio Grande do Sul State. Later, in the plains of the region, they installed a series of farms for the commercial production of jerky beef on the banks of several rivers. These farms propitiated the emergence of an ostentatious elite and a rich urban centre articulated with the import and export networks of the period. On average, each farm had sixty slaves. As in other regions of the world, the slave system in the Southern of Rio Grande do Sul State worked out as an elite political strategy. Slaving facilitated both urbanization and political centralization; it underpinned the rise of an elite class; it flowed new trade wealth to the local societies; and, it lured a larger settled population (Funari and Ferreira, 2016).

Our sampling comprises 112 architectural brick fragments from eight buildings (sites), including two farmhouses and six historical buildings from the Pelotas city. Between five and fourteen independent brick fragments were collected per site (Table 2.3.1). The sites were sampled regarding their importance and history for Pelotas region (Gutierrez, 2001; Funari e Ferreira, 2016). Ages for each site was based on historical archives retrieved from documents concerning the construction and uses of the selected buildings. These documents allow us to determine accurate and consistent ages for the collected sites; in most cases, age uncertainties are less than 21 years (only one site present age uncertainty within 48 years). For example, from the Charqueada Santa Bárbara (CSB1+2) jerky beef farm (Fig. 2.3.1b), we collected brick fragments from the basement of the main building (Fig. 2.3.1c), avoiding any indication of alteration during their occupation. For the Casarão da Família Eliseu Maciel (FEM) house (Fig. 2.3.1d), age interval is very precisely determined from the historical documents, with the exact dates of the launching of the cornerstone (July 16, 1881) and inauguration (April 22, 1883); in this building we sampled 15 bricks (30 cores) using a portable drill from the basement of the house (Fig. 2.3.1e, Table 2.3.1).

\subsubsection{Rock magnetic and archeointensity experiments}

\subsubsection{Rock magnetic experiments}

All rock magnetic and archeointensity measurements were performed at the Laboratório de Paleomagnetismo of Universidade de São Paulo (USPmag). Rock magnetic characterization was carried out in order to determine the magnetic mineralogy and the thermal stability upon heating. Thermomagnetic cycles were performed on each 
fragment of our archeological collection. The reversibility between heating and cooling curves was used for selecting fragments with good thermal stability for further archeointensity experiments (see below). Heating-cooling cycles of low-field magnetic susceptibility from room temperature up to $\sim 550-600{ }^{\circ} \mathrm{C}$ were performed in air using a Kappabridge KLY4 coupled with a CS3 furnace system (Agico Ltd.). Note that this maximum temperature corresponds to the maximum temperature used for archeointensity measurements (see below).

Hysteresis loops, isothermal remanent magnetization (IRM) acquisition curves and back-field measurements were performed at room temperature with a peak field of 1 T in a VSM MicroMag 3900 (Princeton Measurements Corp.). Additionally, we carried out first order reversal curves (FORC) in order to further characterize domain structure, magnetic interactions and coercivity spectra on four representative samples of our archeological collection. FORC measurements were performed at room temperature after 200 reversal curves with an averaging time of $200 \mathrm{~ms}$ and using the input parameters of Egli et al. (2010) $(\mathrm{Hc} 1=0 \mathrm{mT}, \mathrm{Hc} 2=110 \mathrm{mT} ; \mathrm{Hu} 1=-40 \mathrm{mT}$, Hu2 $=+40 \mathrm{mT} ; \delta \mathrm{H}=0.99$ $\mathrm{mT})$. FORC diagrams were computed using the FORCinel software with a smoothing factor of 5-6 (Harrison and Feinberg, 2008).

\subsubsection{Archeointensity experiments}

Archeointensity experiments were performed using the classical Thellier and Thellier (1959) double-heating paleointensity method, with modifications proposed by Coe (1967). The Coe (1967) approach of Thellier and Thellier (1959) method consists of increasing double heating-cooling temperature steps, first Zero-field step for demagnetization of the natural remanent magnetization (NRM) and then with an In-field step for partial thermoremanent magnetization (pTRM) acquisition (hereafter TT-ZI protocol). Experiments were carried out between $100{ }^{\circ} \mathrm{C}$ and $575{ }^{\circ} \mathrm{C}$, with temperature intervals of $50^{\circ} \mathrm{C}$ from $100{ }^{\circ} \mathrm{C}$ to $150^{\circ} \mathrm{C}$ and $25^{\circ} \mathrm{C}$ afterwards. For pTRM acquisition, a laboratory field of $35 \mu \mathrm{T}$ was applied parallel to an arbitrary Z-axis of the specimen. Heating-cooling cycles were performed in air during $30 \mathrm{~min}$ each for both Zero-field and In-field steps. Thermochemical alteration was monitored with an additional In-field step (pTRM check) at lower temperatures, determined every two ZI steps (Coe et al., 1978). Multidomain effect was screened out by including five additional Zero-field steps at 200 ${ }^{\circ} \mathrm{C}, 300{ }^{\circ} \mathrm{C}, 350{ }^{\circ} \mathrm{C}, 400{ }^{\circ} \mathrm{C}$ and $500{ }^{\circ} \mathrm{C}$ (pTRM-tail checks; Riisager and Riisager, 2001). From each fragment, we prepared three cubic specimens of $1 \mathrm{~cm}$ side, two for 
archeointensity determinations and one for the cooling-rate experiment. Heating-cooling cycles were performed in a programmable ASC Scientific single-chamber oven with an inducing field coil. Magnetization measurements were obtained with a horizontal SRM 755-1.65 UC SQUID magnetometer (2G Enterprises) housed into the magnetically shielded room of USPmag, with ambient field $<500 \mathrm{nT}$.

Anisotropy of thermoremanent magnetization (ATRM) and cooling rate (CR) effects are known to affect archeointensity determinations and their corrections need to take into account (Veitch et al., 1984; Genevey and Gallet, 2002; Poletti et al., 2013). ATRM corrections were estimated at $350{ }^{\circ} \mathrm{C}$ and $500{ }^{\circ} \mathrm{C}$ through pTRM acquisition along six successive positions $(\mathrm{X},-\mathrm{X}, \mathrm{Y},-\mathrm{Y}, \mathrm{Z}$ and $-\mathrm{Z})$, following the same procedure described by Hartmann et al. (2010, 2011) and Poletti et al. (2016). In both temperatures, a correction factor was then computed following Veitch et al. (1984). ATRM correction at $350{ }^{\circ} \mathrm{C}$ was applied only when the NRM fraction removed at $350{ }^{\circ} \mathrm{C}$ was higher than $40 \%$. The remaining samples were corrected using the tensor ATRM obtained at $500{ }^{\circ} \mathrm{C}$. The CR correction factor was estimated using an additional unheated specimen. The CR protocol involves three pTRM acquisition steps: a rapid cooling, a slow cooling and a final rapid cooling. Each rapid cooling takes $30 \mathrm{~min}$, whereas the slow cooling takes 12 h. The slow cooling step was performed introducing thermal insulators into the oven and turning off the cooling fan. When the difference between the two rapidly acquired TRMs is within $5 \%$ we consider that thermochemical alteration is negligible. In this case, a CR correction factor can be computed that corresponds to the ratio between the average of the two rapidly acquired TRMs to the slowly acquired TRM. The temperature at which the cooling-rate experiments were performed was carefully chosen for each fragment to ensure that at least $50 \%$ of the NRM was used and no alteration was detected during TTZI experiments.

The quality of the intensity estimations was assessed through the strict selection criteria previously applied by Hartmann et al. (2010, 2011) and Poletti et al. (2016). At specimen level: a minimum of 4 temperature steps, comprising at least $35 \%$ of NRM; standard error of the line slope below 15\%; overall quality index (q) above 5; maximum angular deviation (MAD) of remanence vector below $10^{\circ}$; angular difference between anchored and free-floating best-fit directions below $15^{\circ}$; maximum difference of normalized pTRM checks $(\delta \mathrm{CK})$ smaller than $9 \%$; the normalized ratio of alterationcorrected to non-corrected estimates ( $\delta$ pal) smaller than $18 \%$; maximum difference of normalized pTRM-tail $(\delta T R)$ checks below 20\%. At fragment level: difference between 
individual intensities per fragment is less than 5\% after ATRM correction; alteration from CR experiments is below 5\%; at least two independent estimates from each fragment. At site level: at least three fragments from the same site must provide intensities within $10 \%$ of the standard deviation.

\subsubsection{Results}

\subsubsection{Rock magnetism}

Thermomagnetic curves for $54 \%$ of all samples of our archeological collection were fully reversible. For two sites $(\mathrm{GH}, \mathrm{ICH} 2)$ curves were not reversible, consequently they were not considered for archeointensity experiments (Table 2.3.1 and Supp. table A3.2.1). The remainder six sites (CO8, CBM, CPU, CSB1+2, FEM, FSB) presented a success rate in thermomagnetic curves of $56 \%$ providing a total of 47 fragments for archeointensity measurements. Figure 2.3.2 shows that reversible curves were obtained even in weakly magnetic samples (sites CSB1-03, CBM-02, FEM-15). Susceptibility decay occurs always after $480{ }^{\circ} \mathrm{C}$, with the Curie/Néel temperature varying from $490{ }^{\circ} \mathrm{C}$ to $580{ }^{\circ} \mathrm{C}$ for most samples.
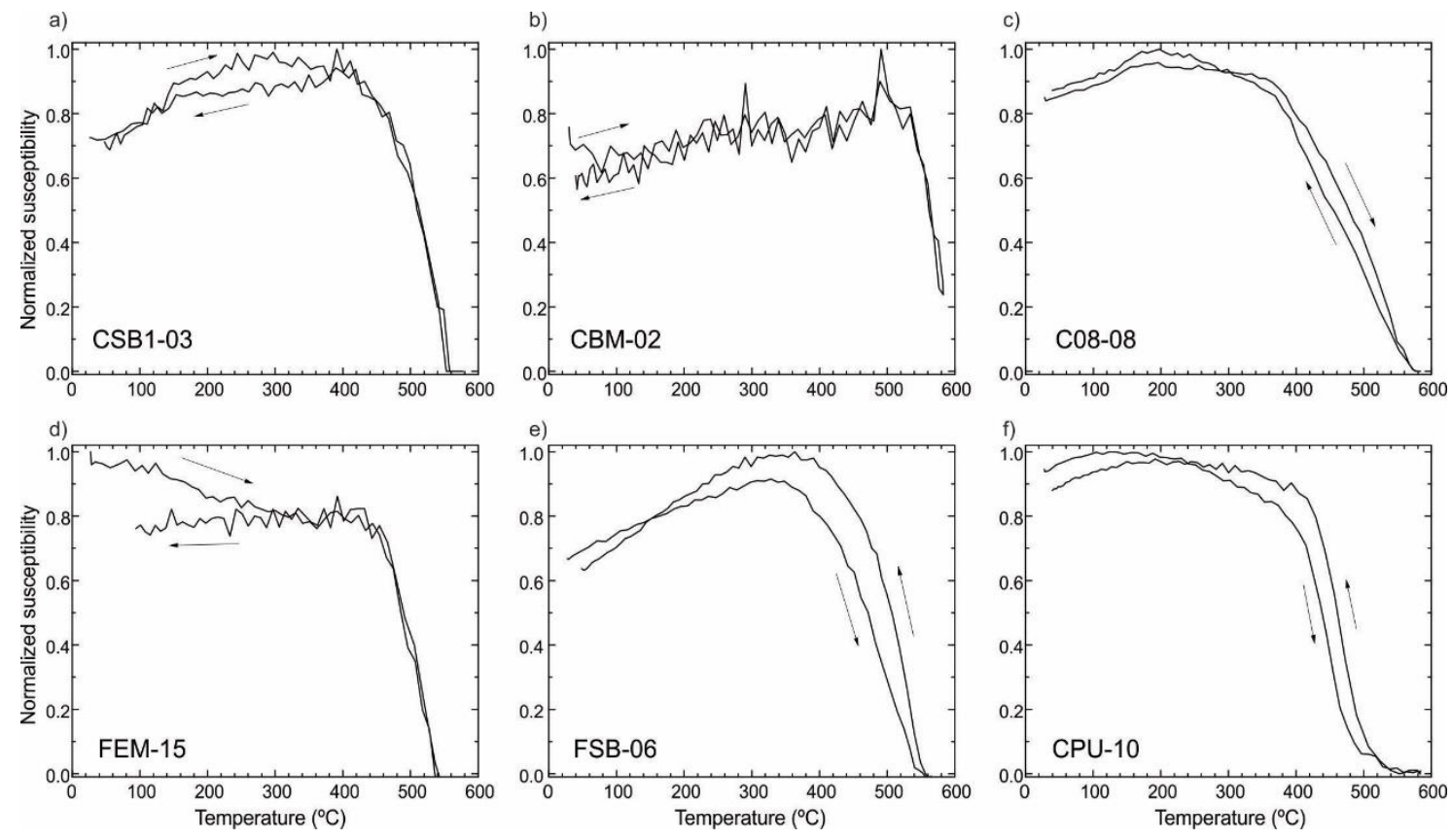

Figure 2.3.2: Thermomagnetic curves (low-field magnetic susceptibility against temperature) during heating-cooling cycles. (a-f) Examples of reversible curves indicating satisfactory magnetic stability during thermomagnetic experiments for each successful site. CSB1+2: Charqueada-Santa Barbara (1790-1838 CE), CBM: Chácara da Brigada Militar (1830-1851 CE), C08: Casa Número 08 (1870-1879 CE), FEM: Casarão da Família Emílio Maciel (1881-1883 CE), FSB: Fundação Simon Bolívar (1884-1889 CE), CPU: Campus Porto UFPel (1942-1943 CE) (extracted from Hartmann et al., submitted). 

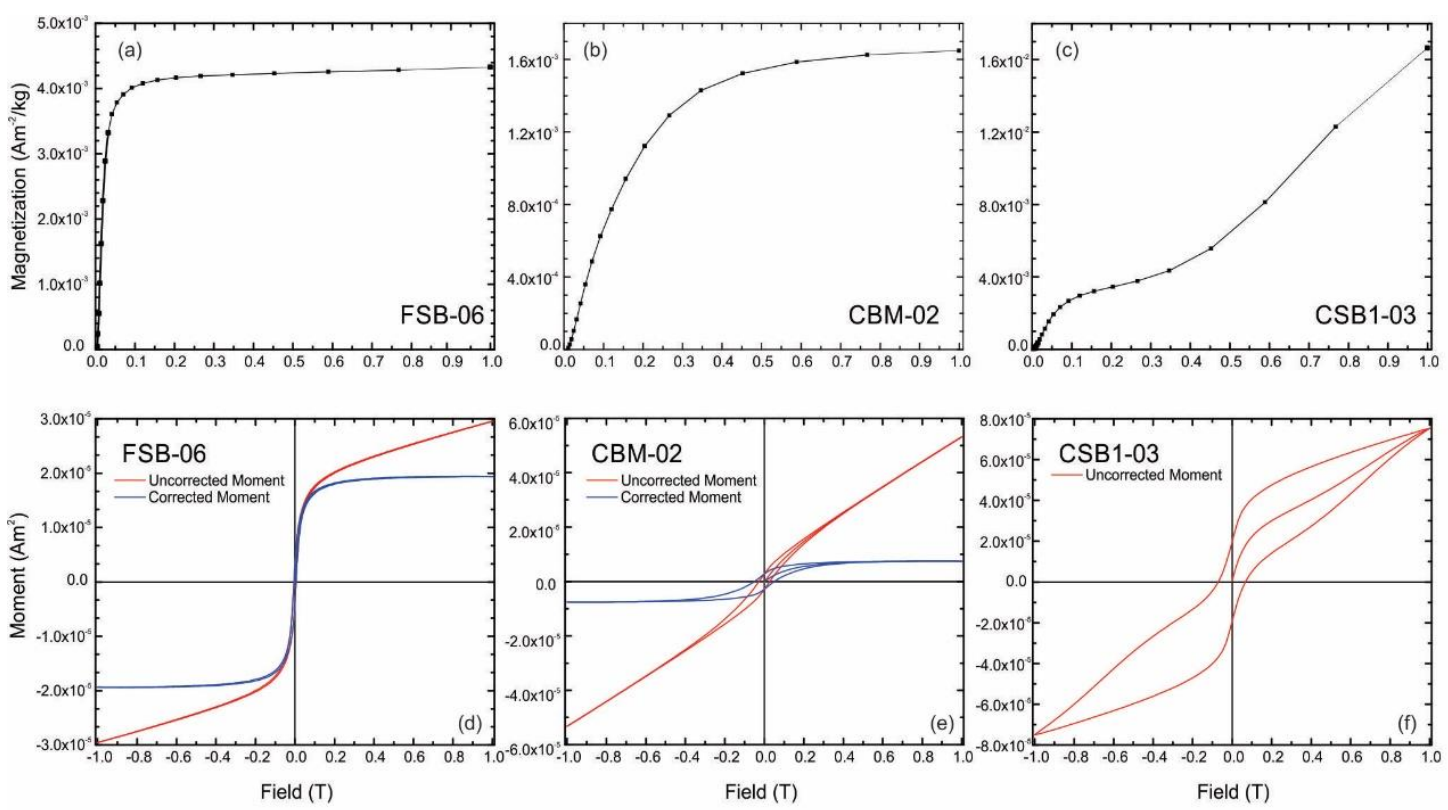

(g) FSB-06

(h) CBM-02

(i) CSB1-03
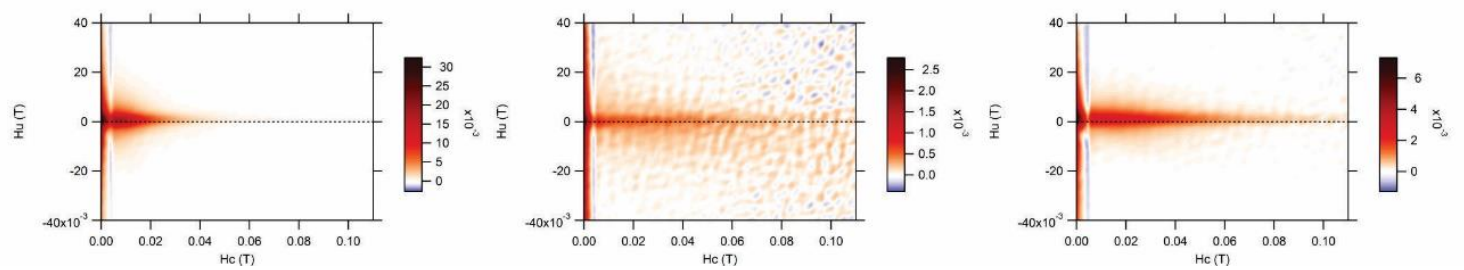

Figure 2.3.3: Examples of IRM acquisitions curves (a-c), hysteresis loops (d-f) and FORC diagrams (g-i) for typical samples from sites FSB, CBM and CSB1+2 sites. FORC diagrams were performed with smoothing factors 5-6 (extracted from Hartmann et al., submitted).

Stepwise IRM acquisition curves show different behaviours for the six studied sites (Fig. 2.3.3 and Supp. fig. A3.2.1). Figures 2.3.3a-2.3.3c present the three endmembers of IRM curves. In sample FSB-06, remanence increases rapidly at $300 \mathrm{mT}$ but does not attain saturation. For sample CBM-02, remanence increases slower than in FSB06 and saturation is not attained at the maximum field of 1 T. Finally, sample CSB1-03 typically shows a mixed pattern, with an initial fast increase in remanence being followed by a steady slow increase, being far from saturation at $1 \mathrm{~T}$. These samples are characterized, respectively, by low-coercivity narrow-waisted (Fig. 2.3.3d), moderate coercivity (Fig. 2.3.3e), and wasp-waisted (Fig. 2.3.3f) hysteresis loops. Together with the thermomagnetic results, this suggests that the main magnetic carriers are magnetite (FSB-06), hematite (CBM-02) or the mixture of these two magnetic phases (CSB1-03). FORC diagrams (Fig. 2.3.3g-2.3.3i) are typical of single-domain weakly interacting grains, with a ridge along the Hu origin line and low vertical spread (Roberts et al., 2014). 


\subsubsection{Archeointensity}

After eliminating samples with non-reversible thermomagnetic curves and very weak natural remanence intensity, 36 fragments were retained for TT-ZI analysis (Table 2.3.1 and Supp. table A3.2.1 and A3.2.2). Intensity analysis were interpreted only over the linear parts of Arai diagrams and their corresponding vectorial plots. Figure 2.3.4a2.3.4f shows examples of Arai and vectorial diagrams of successful specimens for the six sampling sites considered for archeointensity measurements. Intensities were estimated at temperatures varying from $100-375{ }^{\circ} \mathrm{C}$ to $425-575^{\circ} \mathrm{C}$. The standard error of the slope ranges from 0.13 to $1.43 \mu \mathrm{T}$, for NRM fractions between $43 \%$ and $89 \%$ and using from 6 to 19 temperature steps (Fig. 2.3.4 and Supp. table A3.2.2) In the considered interval the remanence vector is always unidirectional as attested by MAD values below $4.8^{\circ}$. At this stage, only four fragments (CSB2-04, C08-07, FEM-03, CSB2-16) were rejected from our analysis due to the high thermochemical alteration indicated by high $\delta \mathrm{CK}$ and $\delta$ pal values. The high success rate obtained in the archeointensity experiments can be attributed to our choice of measuring only fragments that presented a good reversibility in thermomagnetic curves.

ATRM and CR corrections were performed in all fragments retained for archeointensity measurements. Six fragments were rejected due to thermochemical alteration during either ATRM (CBM-01, FSB-02) or CR (CSB1-04, CBM-05, FEM-05, CPU-12) measurements. ATRM was obtained at two different temperatures $\left(350{ }^{\circ} \mathrm{C}\right.$ and $500{ }^{\circ} \mathrm{C}$ ) in order to better evaluate and correct for this effect (see above). Figure 2.3.5a shows the ATRM degrees $(\mathrm{K} 1 / \mathrm{K} 3)$ obtained for the retained specimens. The histogram indicates that $\sim 81 \%$ (42 specimens) present a weak ATRM degree with values varying from 1.0 to 1.15 , while the remaining 10 specimens are more anisotropic presenting ATRM degree values between 1.15 and 1.55. This anisotropic behavior seems to be common in bricks, as already observed in other studies (e.g. Genevey et al., 2008; Kovacheva et al., 2009; Hartmann et al., 2010; 2011; Osete et al., 2015; Poletti et al., 2016). The CR correction was performed in one fresh specimen from each retained fragment, after the archeointensity experiments. TRM overestimate varies from $\sim 1 \%$ to $\sim 20 \%$, but most fragments present values around 9\% (Fig. 2.3.5b). This result is also very similar to those obtained in other studies on bricks from Northeast and Southeast Brazil (Hartmann et al., 2010; 2011; Poletti et al., 2013) for which different cooling times were applied (e.g. $5 \mathrm{~h}, 10 \mathrm{~h}$ and $25 \mathrm{~h}$ ). In addition, we observe that the TRM overestimates also 
are similar to those estimated for bricks and pavement tiles from Jesuit Missions in South Brazil (Poletti et al., 2016).

Consistency of intensity results has improved significantly after ATRM and CR corrections, with differences within fragment and within site being reduced to $0.08-4.83 \%$ and $1.53-9.54 \%$, respectively (Supp. table A3.2.2). The success rate considering only samples which passed our strict selection criteria corresponds to $\sim 72 \%$ (26 fragments, 52 specimens). Intensity values vary from $36.4 \mu \mathrm{T}(\mathrm{CSB} 1+2)$ to $27.8 \mu \mathrm{T}(\mathrm{CPU})$ (Table 2.3.1 and Supp table A3.2.1 and A3.2.2).
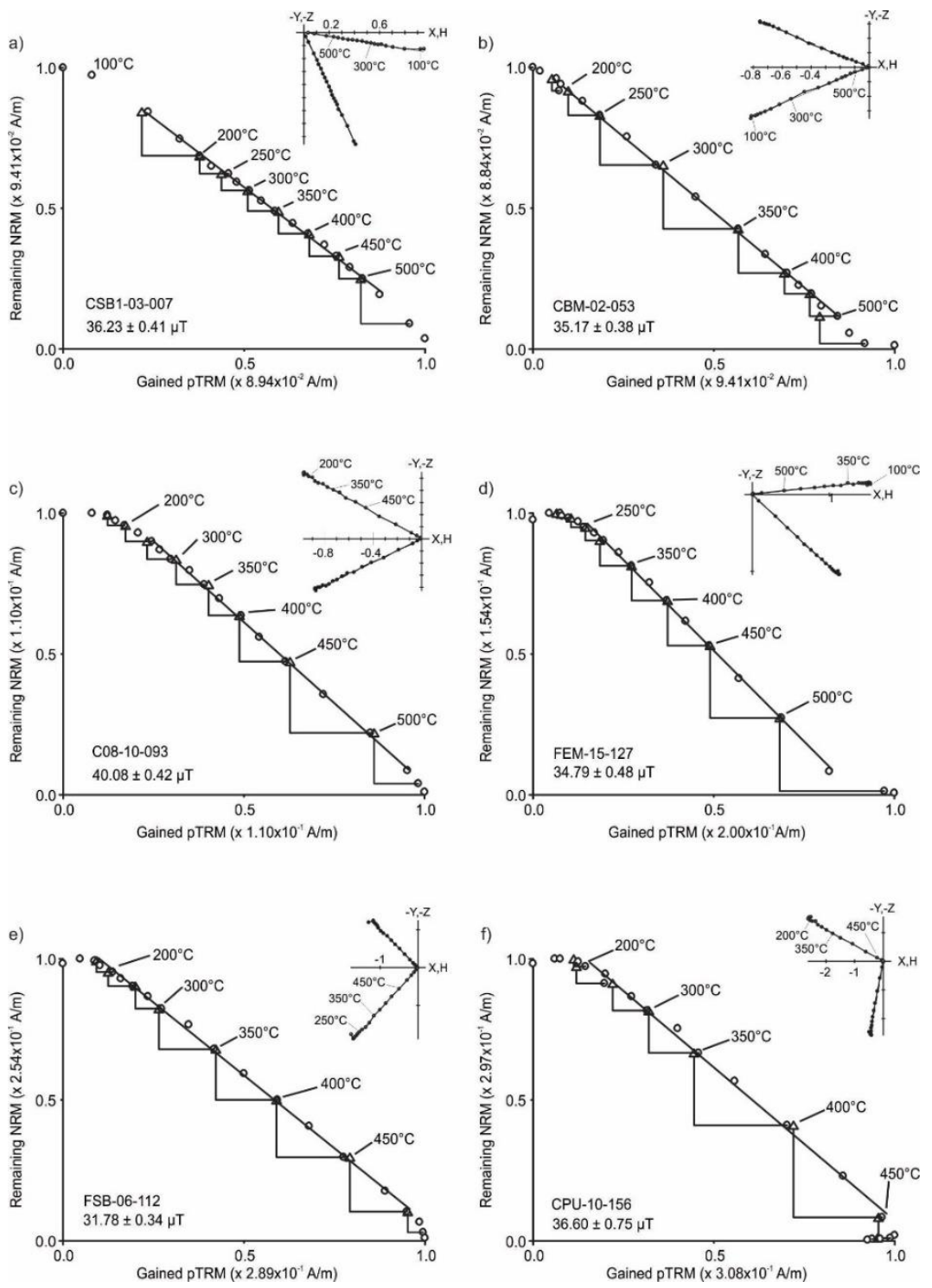

Figure 2.3.4: Arai diagrams for six representative examples of Arai diagrams with their respective orthogonal diagram. In Arai diagrams empty circles represent NRM remaining against pTRM gained and triangles show pTRM checks performed every two temperature steps. In the orthogonal diagrams, black and gray circles indicate vector end-points projected, respectively, onto horizontal and vertical planes in an arbitrary specimen coordinate system (extracted from Hartmann et al., submitted). 

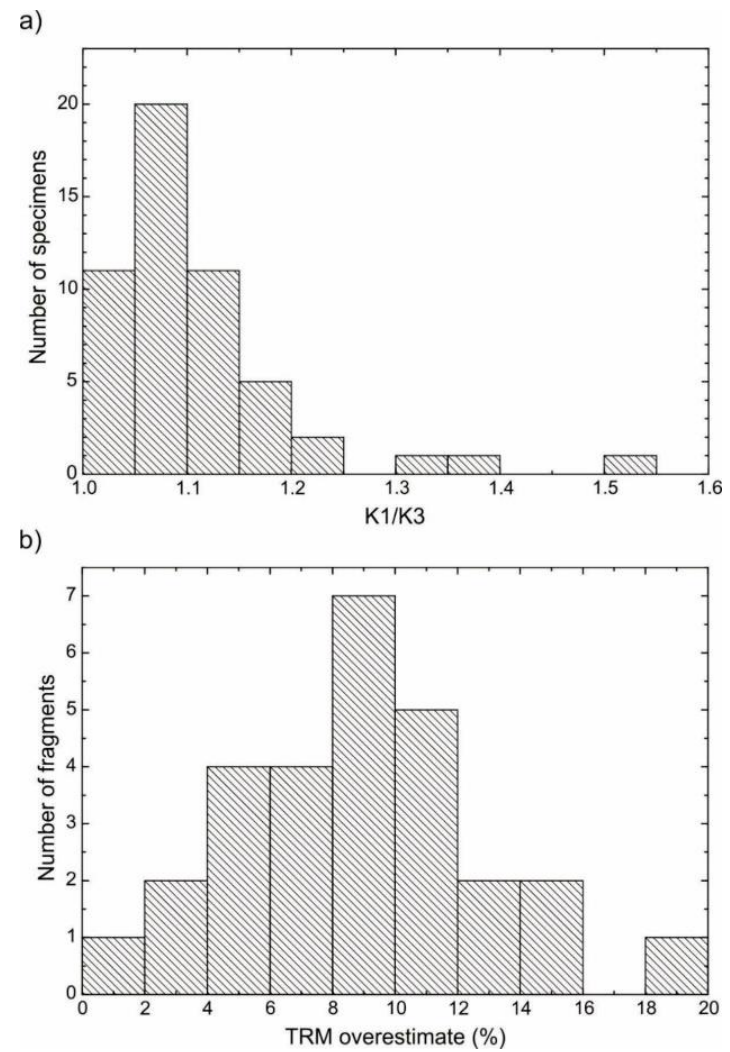

Figure 2.3.5: Histograms for anisotropy and cooling rate correction. (a) TRM anisotropy degrees obtained for all retained specimens (K1: maximum anisotropy axis, K3: minimum anisotropy axis), (b) TRM overestimates (in percentage relative to the original intensity value) considering the slow cooling time of $\sim 25 \mathrm{~h}$ (extracted from Hartmann et al., submitted).

\subsubsection{Discussion}

The data for South America in the 1500-2000 CE interval comprises sectors located close and away from the SAA. The raw dataset for this time period includes 67 intensity data, including the data acquired in this work. However, as pointed out by Poletti et al. (2016), most of these data does not comply to minimum quality standards. We recall the selection criteria used by those authors to filter the archeointensity data: (i) age uncertainty of archeological sites below 100 years; (ii) archeointensity data determined from classical double-heating method of Thellier-Thellier (and their variants); (iii) pTRM checks for monitoring thermochemical alteration; (iv) checking for alteration of multidomain grain effects on paleointensity experiments; (v) effect of ATRM accounted; (vi) $\mathrm{CR}$ correction to consider the difference between lab and natural cooling times; (vii) standard deviation of average intensity less than $15 \%$. Considering these criteria, we retained here 32 data selected by Poletti et al. (2016) plus the new six entries reported here, comprising 38 intensity means from Brazil, Argentina and Chile between 15002000 CE. These results are shown in Figure 6 (see also Supplementary table A3.2.3). 

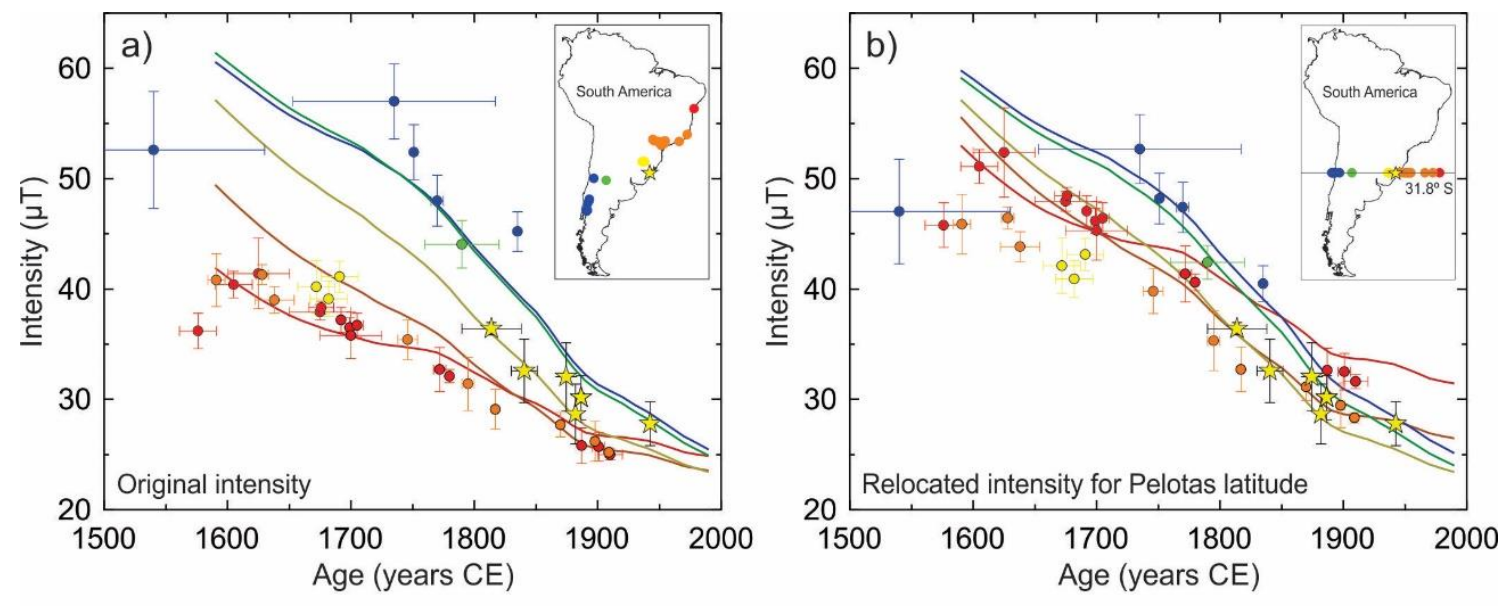

\begin{tabular}{|c|c|}
\hline gufm1 & Data \\
\hline NE Brazil & - NE_Brazil A Argentina \\
\hline _ SE_Brazil & $\begin{array}{l}\text { SE_Brazil } \\
\text { (Hartmann et al., 2011) }\end{array}$ Chile $_{\text {(Roperch et al., 2015) }}^{\text {Con }}$ \\
\hline $\begin{array}{l}\text { Argentına } \\
\text { Chile }\end{array}$ & - $\begin{array}{l}\text { S_Brazil } \\
\text { (Poletti et al., 2016) }\end{array}$ \\
\hline
\end{tabular}

Figure 2.3.6: Geomagnetic field intensity variation defined by high-quality South American data for the past 500 years. Yellow stars represent archeointensity estimates obtained from this study. Other symbols represent archeomagnetic data obtained from other recent studies. In (a) the original intensity estimates are represented according to the respectively latitude and in (b) all of them were relocated to a latitude of Pelotas city $\left(31.8^{\circ} \mathrm{S}\right)$. Continuous lines represent the gufm1 model (extracted from Hartmann et al., submitted).

The six new site-mean intensity values from Pelotas describe a continuous decreasing trend during historical times in South Brazil from 1790-1943 CE (Fig. 2.3.6). Together with results recently obtained for the Jesuit Missions from South Brazil dating between 1657-1706 CE (Poletti et al., 2016), we can trace the evolution of the geomagnetic field in the region since the beginning of the 17th century. While the results from Jesuit Missions plot below the gufm1 model, the new data reported here fit the gufm1 model (Jackson et al., 2000) within error. From 1815 to 1940 CE, the intensity data for the Pelotas region shows an average rate variation of about $0.072 \mu \mathrm{T} / \mathrm{year}$. Considering the whole database for South America, intensity values vary from $58.2 \mu \mathrm{T}$ (Chile) to $27.8 \mu \mathrm{T}$ (S Brazil). Chilean data plot systematically above the results from other sectors of the continent, and also plot above the gufm1 model. Results from NE Brazil, like those from Pelotas, overlap the gufm 1 model within experimental error. Finally, the results from SE Brazil and Jesuit Missions are below the gufm1 model except for the results for mid-nineteenth century. All data show a general decay trend of intensity with time of $0.076 \mu \mathrm{T} / \mathrm{year}$, similar to that defined by the data from Pelotas. This average rate is also similar to that determined by Hartmann and Pacca (2009) and Terra-Nova et al. 
(2017) for the SAA minimum intensity. In addition, for the period between $\sim 1840-1950$ CE, the non-dipolar contribution reaches about $40-50 \%$ of the total field (Hartmann and Pacca, 2009; Hartmann et al., 2011), which supports the idea of a strong influence of the SAA in this region since the 19th century at least, the minimum of the anomaly reaching the South and Southeast of Brazil at the early 20th century.

When did such a significant non-dipolar contribution start in South America? Based on our dataset, we can explore further the evolution of the non-dipolar part of the geomagnetic field. Our first step was to perform a qualitative analysis from the reduction of the magnetic intensity data for the same latitude, considering a dipolar field. For this, we relocated all high-quality archeointensity data from South America to the Pelotas city latitude. Interestingly, the data show a common decreasing trend, which reflects the continuous decay of the geomagnetic axial dipole on a millennial scale (Poletti et al., 2018). However, they have small differences between them, suggesting that there is a significant non-dipole component acting in the region (Fig. 2.3.6b).

Subsequently, we performed a quantitative evaluation in order to describe the variation of the non-dipolar influence in South America during the historical period. For that, we subtracted the estimated intensity for each site $\left(\mathrm{B}_{\text {archeo}}\right)$ from the intensity at the same latitude associated only to the dipole component of the gufm1 ( $\left.\mathrm{B}_{|\mathrm{g} 10|}\right)$ model modified by Poletti et al. (2018), i.e. $\mathrm{B}_{\text {archeo }}-\mathrm{B}_{|\mathrm{g} 10|}$. The $\mathrm{B}_{|\mathrm{g} 10|}$ was obtained from:

$$
B_{|g 10|}=\frac{\left|g_{10}\right| a^{3}}{r^{3}}\left(1+\cos ^{2} \theta\right)^{\frac{1}{2}}
$$

where $r$ is the Earth's radius, $a$ is the distance where the field was estimated (in our case at the surface of the planet, $a=r)$, and $\theta$ is co-latitude. A zero value for $\left(B_{\text {archeo }}-B_{|g 10|}\right)$ indicates the intensity is related exclusively to the dipolar field. Significant deviations from zero would point to important contributions from non-dipolar terms to the measured intensity. The results are shown in Figure 2.3.7 together with curves representing the subtraction of the total intensity to the dipolar-only intensity estimated from the modified gufm1 model. Some tests using the original gufm1 model (Jackson et al., 2000) provided similar results (Supp. table A3.2.3). The horizontal dark and light grey swaths in the Figure 2.3.7 represent $\pm 1 \bar{\beta}$ and $\pm 3 \bar{\beta}$, respectively, i.e. one and three times the deviation of the mean of all archeointensity data entries shown. 


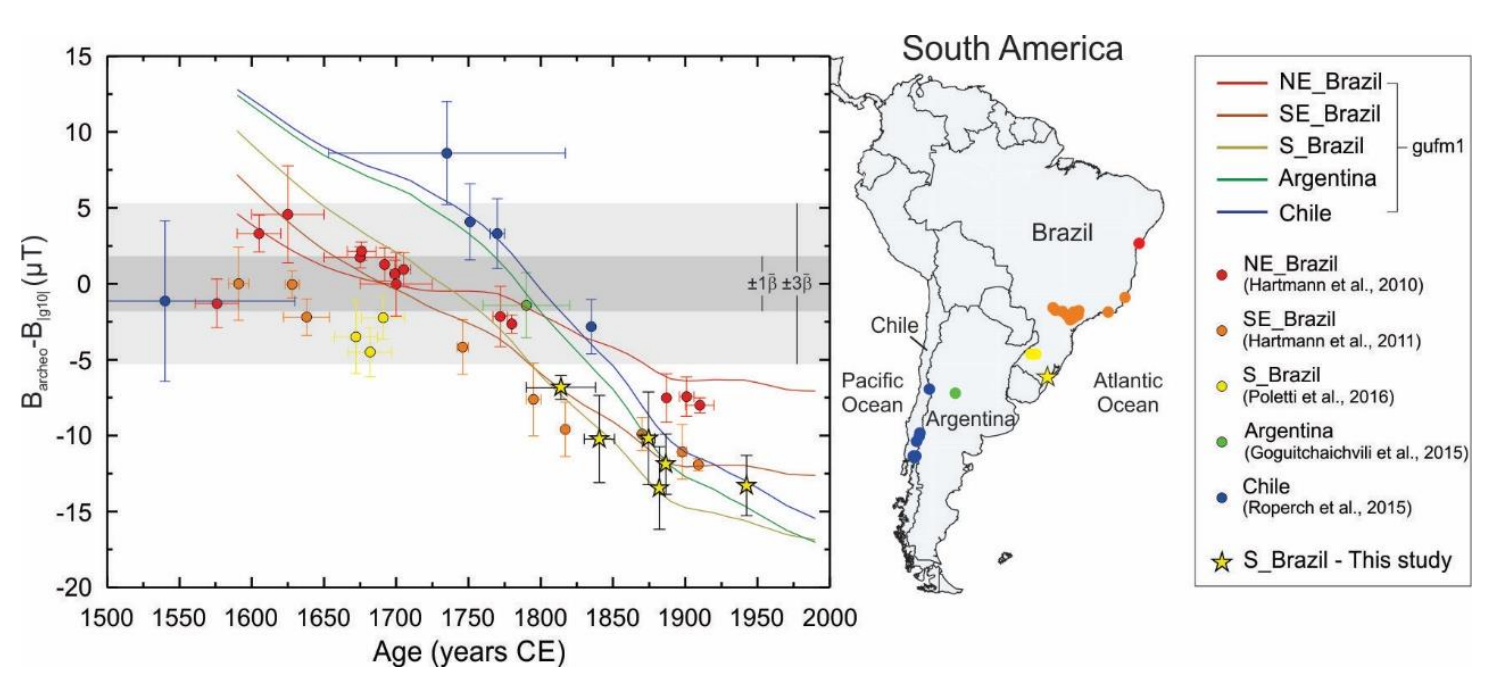

Figure 2.3.7: Non-dipolar contributions to geomagnetic field intensity. Symbols represent local intensity minus the intensity associated only to the dipole component of the gufm1 (B $|\mathrm{g} 10|)$ model modified by Poletti et al. (2018). Continuous lines represent the total intensity minus the dipolar-only intensity estimated from the modified gufm1 model. The dark and light grey areas correspond to $\pm 1 \beta^{-}$and $\pm 3 \beta^{-}$of the mean of archeointensity data errors, respectively. The map shows the location of archeointensity sites considered in our analysis (extracted from Hartmann et al., submitted).

The models predict an increasing influence of non-dipolar contributions to the intensity from NE-Brazil region to S-Brazil, Chile and Argentina (Fig. 2.3.7). This behaviour is accompanied by the high-quality archeointensity data, including the six new results reported here, and is attributed to the influence of the SAA, whose effects have been traced back until the 19th century. Our results suggest that the influence of nondipolar contributions on South America, and likely that of the SAA, starts much earlier at around $1700 \mathrm{CE}$, when a marked trend can be observed in the $\left(\mathrm{B}_{\text {archeo }}-\mathrm{B}_{|\mathrm{g} 10|}\right)$ values, but it becomes significant (beyond the $\pm 3 \bar{\beta}$ of our archeointensity data) at around $1800 \mathrm{CE}$. These results demonstrate quantitatively some previous qualitative assessments of the archeointensity data in South America that provided hints on an earlier influence of the SAA in the continent (Hartmann et al., 2010; 2011; Poletti et al., 2016).

\subsubsection{Conclusions}

We obtained high-quality results for six archeological sites in the Pelotas city region, in South Brazil with ages ranging from 1790 to 1943 CE. These data permitted to better reconstruct the decreasing trend of the geomagnetic field in the region, complementing previous results obtained in Northeast, Southeast and South Brazil, Argentina and Chile. The new data is located close to the minimum of the SAA and 
allowed us to access more thoroughly the effects of the anomaly through time. By separating the dipolar and non-dipolar contributions to the archeointensities both in the data and in the models for the past five centuries, we demonstrate that the influence of the SAA is present since $1800 \mathrm{CE}$, and has probably started as early as $1700 \mathrm{CE}$. New archeointensity data on western Brazil, Paraguay and Argentina would help in better constraining the evolution of the anomaly through time.

\section{Acknowledgments}

This work was partially funded by grants of CAPES AUXPE 2043/2014 and CNPq (454609/2014-0; 306527/2017-0) to GAH, grants \#2013/16382-0 and \#2016/22960-4 to WP of São Paulo Research Foundation (FAPESP), and CNPq-PQ 304934/2014-3 to RIFT. 


\title{
2.4. Continuous millennial decrease of the Earth's magnetic axial dipole
}

\author{
Wilbor Poletti $^{1,2}$,
}

Andrew J. Biggin ${ }^{2}$, Ricardo I.F. Trindade ${ }^{1}$, Gelvam A. Hartmann ${ }^{3}$ and Filipe Terra-Nova ${ }^{4}$

${ }^{1}$ Universidade de São Paulo, Instituto de Astronomia, Geofísica e Ciências Atmosféricas, Departamento de Geofísica, Laboratório de Paleomagnetismo - USPMag, Rua do Matão, 1226, 05508-090, São Paulo, Brazil; ${ }^{2}$ Geomagnetism Laboratory, Department of Earth, Ocean and Ecological Sciences, University of Liverpool, Liverpool, UK; ${ }^{3}$ Instituto de Geociências, Universidade Estadual de Campinas, Rua João Pandiá Calógeras, 51, 13083-870, Campinas, Brazil; ${ }^{4}$ CNRS, Université de Nantes, Nantes Atlantiques Universités, UMR CNRS 6112, Laboratoire de Planétologie et de Géodynamique, 2 rue de la Houssinière, F-44000 Nantes, France

\begin{abstract}
Since the establishment of direct estimations of the Earth's magnetic field intensity in the first half of the nineteenth century, a continuous decay of the axial dipole component has been observed and variously speculated to be linked to an imminent reversal of the geomagnetic field. Furthermore, indirect estimations from anthropologically made materials and volcanic derivatives suggest that this decrease began significantly earlier than direct measurements have been available. Here, we carefully reassess the available archaeointensity dataset for the last two millennia, and show a good correspondence between direct (observatory/satellite) and indirect (archaeomagnetic) estimates of the axial dipole moment creating, in effect, a proxy to expand our analysis back in time. Our results suggest a continuous linear decay as the most parsimonious long-term description of the axial dipole variation for the last millennium. We thus suggest that a break in the symmetry of axial dipole moment advective sources occurred approximately 1,100 years earlier than previously described. In addition, based on the observed dipole secular variation timescale, we speculate that the weakening of the axial dipole may end soon.
\end{abstract}

Keywords: geomagnetism; archaeointensity; axial dipole; archaeomagnetic dataset; data selection criteria. 


\subsubsection{Introduction}

The continuous intensity record of the Earth's magnetic field was started in 1833 CE by Carl Friedrich Gauss, enabling the precise direct recording of the full geomagnetic vector for the past 184 years (e.g. Kono, 2007). Nonetheless, ancient civilizations, when baking pottery, were also inadvertently recording the Earth's magnetic field. This archaeomagnetic record can be retrieved from ancient baked clay (and from historical lavas) using laboratory techniques developed more than one hundred years ago (Folgheraiter, 1899), that were subsequently significantly improved (Thellier and Thellier, 1959; Coe, 1967; Coe et al., 1978; Aitken et al., 1988; Shaw et al., 1996; Riisager and Riisager, 2001; Yu et al., 2004; Le Goff and Gallet; 2004). Archaeomagnetism provides information about geomagnetic field variations thousands of years before the "Gauss era" and can help in unveiling the processes operating in the Earth's core at timescales longer than the past 184 years (e.g., Dumberry and Finlay, 2007; Amit et al., 2011; Sanchez et al., 2016; Terra-Nova et al., 2015; 2016).

Variations observed in intensity data from observatories, satellites, volcanic lavas, and archaeological artifacts can be linked to the main component of the geomagnetic field (e.g., Jackson et al., 2000; Olson and Amit, 2006; Gubbins et al., 2006; Finlay, 2008; Korte et al., 2009; Korte and Constable, 2011; Suttie et al., 2011; Licht et al., 2013; Nilsson et al., 2014; Pavon-Carrasco et al., 2014), which originates from the movement of the outer core's conductive fluid and is dominated by the axial dipole component. Thanks to the continuous direct records over a wide spatial coverage during the Gauss era, it was possible to describe the geomagnetic dipole variation in detail for the past 184 years (e.g., Jackson et al., 2000; Gillet et al., 2013; Finlay et al., 2015). For this period, the decay rate of the axial dipole is, on average, about $15 \mathrm{nT} / \mathrm{yr}$, with decadal fluctuations (Jackson et al., 2000; Finlay et al., 2015). Prior to the Gauss era, the Earth's magnetic field record provided by archaeomagnetism is still scarce both temporally and spatially (Genevey et al., 2008, Donadini et al., 2009, Brown et al., 2015; Poletti et al., 2016). Yet, it is sufficiently robust for the description of local, rapid variations (de Groot et al., 2013; Genevey et al., 2016). It is also the only means to analyze geomagnetic axial dipole evolution on millennial timescales.

Several datasets of full vector archaeomagnetic data exist (e.g., Brown et al., 2015; Arneitz et al., 2017b). From such datasets, different descriptions of global variations of the geomagnetic axial dipole have emerged (e.g., Valet et al., 2008; Genevey et al., 2008, Knudsen et al., 2008, Usoskin et al., 2016). However, although such efforts have 
produced useful and detailed descriptions of millennial timescale variations, they have tended to avoid making links between surface observations and Earth' core process. Furthermore, due to fundamental differences between the magnetic intensity records obtained by direct and indirect measurements (e.g., spatial and temporal coverage, experimental errors) (Arneitz et al., 2017a), the geomagnetic axial dipole variations are usually described independently for two distinct periods: before and after $1840 \mathrm{CE}$ and there have been few attempts to critically compare and integrate them. From 1840 to today, the axial dipole variations are robust, meanwhile for the period of 1590-1840 CE, the widely utilized historical field model gufm1 (Jackson et al., 2000) uses an arbitrary extrapolation of the axial dipole intensity from the Gauss era, whereas estimations incorporating only archaeointensity data tend to favor a rather flat decay of the axial dipole field (Gubbins et al., 2006; Finlay, 2008; but also see Suttie et al., 2011).

In this work, we present a new description of geomagnetic axial dipole variations before the Gauss era by evaluating the Axial Dipole Moment (ADM) and Virtual Axial Dipole Moment (VADM) obtained from archaeointensity data for the entirety of the last two millennia. To do so, we accepted only high-quality archaeointensity estimates into our evaluation, and attempted to assess these data using a minimum number of linear trends. Our compilation indicates a significant shift in the trend of the axial dipole strength around the interval 550-750 CE, initiating a continuous decay in the same order of magnitude of the Gauss era up to the present. We attribute this shift to fundamental changes in geodynamo workings in the last millennium, ultimately attempting to link the archaeointensity record to dynamical processes within Earth's outer core.

\subsubsection{Methods}

\subsubsection{Datasets}

Thellier and Thellier (1959) defined the original double-heating protocol (TT) which today incorporates checks for alteration (Coe et al., 1978) and multi-domain effects (e.g., Riisager and Riisager, 2001), as well as corrections for the effects of magnetic anisotropy (e.g., Rogers et al., 1979) and for the fast cooling-rates applied in the laboratory (e.g., Fox and Aitken, 1980). Other methods such as the Microwave (MW; Shaw et al., 1996) and Triaxe (TR; Le Goff and Gallet, 2004) have also been developed and their results have been systematically compared one to each other, thus increasing our confidence in the results (e.g., TT-TR: Le Goff and Gallet, 2004; Gallet and Le Goff, 2006; Genevey et al., 2009; Hartmann et al., 2010; 2011; TT-MW: Shaw et al., 1999; Hill 
et al., 2002a; 2002b; Casas et al., 2005; Stark et al., 2010; Ertepinar et al., 2016; TT-TRMW: Poletti et al., 2013). A detailed historical and physical description of the ThellierThellier method and its modifications was put forward by Dunlop (2011).

GEOMAGIA50.v3 (Brown et al., 2015) is a comprehensive database comprising 14,645 data (declination, inclination, and intensity) from archaeological artifacts and volcanic material, obtained over the past half century. In our analysis we used a catalogue of archaeointensities from the GEOMAGIA50.v3 database, and some other data recently published that were not incorporated into the collection at the time of our analysis (Supp. table A4.2.1). The time window investigated was the past two millennia as this period shows the best temporal and spatial coverage.

\subsubsection{Selection criteria}

Data selection was performed by checking if current laboratory criteria were satisfied (e.g., Poletti et al., 2016). We considered seven factors in our assessment of the archaeointensity data when considering the archaeological material. The factors were applied following the sequence in which they are presented below:

i) Age uncertainty. For this study, we accepted data with age uncertainty less than or equal to 100 years $\left(\sigma_{\text {age }} \leq 100\right)$. This rather strict choice was made to enable the comparison between archaeomagnetic and observatory/satellite data in the Gauss era (i.e., 184 years). Data were not filtered by the dating technique (except for archaeomagnetic dating);

ii) The archaeointensity method used and the protocol adopted. We only accepted intensity data performed exclusively with the classical double-heating method at room-temperature (Thellier-Thellier, 1959) in one of its modified versions (TT) (Coe, 1967; Aitken et al., 1988; Yu et al, 2004), the microwave method (MW) (Shaw et al., 1996; Hill and Shaw, 1999), or the high-temperature Triaxe method (TR) (Le Goff and Gallet, 2004). Our choice was based on palaeointensity methods that perform a gradual and progressive replacement between the magnetizations acquired from the nature and laboratory. The results obtained from these three specific methods are more likely to be high-quality and concordant as highlighted by several works published in the last few decades (e.g., Hill et al., 2002a; Genevey et al., 2009; Poletti et al., 2013); 
iii) Additional steps to check alterations during the experiment. For TT and MW, we required additional steps in the laboratory protocol, referred to as pTRM checks, to monitor possible (thermo)chemical alterations during the gradual increase of temperature (TT) or power (MW) steps on the experiment (Coe et al., 1978). For TR, these additional steps are unnecessary (Le Goff and Gallet, 2004);

iv) Evaluation of the influence of multi-domain (MD) grains. We required at least one test-type to verify possible MD grains influence (e.g., Riisager and Riisager, 2001; Krása et al., 2003; Yu et al., 2004), in order to avoid the violation of the principles of additivity and reciprocity, which are part of the backbone of the Thellier-Thellier method (Yu and Dunlop, 2003; Dunlop, 2011);

v) Anisotropy thermoremanent magnetization (ATRM) correction. We accepted only data largely unbiased by anisotropy effects either by having the laboratory field applied in a direction within 10 degrees of the principal component of the natural remanent magnetization (NRM) (Rogers et al, 1979; Aitken et al., 1981), or by the correction of the tensor of ATRM being obtained experimentally and calculated through the formulation proposed by Veich et al. (1984). Although there are other ways to correct the ATRM effect, for example, through the tensor obtained from measures of anhysteretic remanent magnetization (ARM) or magnetic susceptibility (MS), we restrict our analysis to results that take into account the same physical basis between anisotropy correction and Thellier-Thellier method (see ii). Data corrected by the ATRM effect using ARM or MS technique implicitly assume equivalence between the pairs of anisotropy tensors TRM-ARM or TRM-MS, which are not always true (Stephenson et al., 1986; Yu et al., 2003), although we acknowledge the need for further advances in this topic.

vi) Cooling rate correction. We accepted only archaeointensity data that were corrected for cooling rate effects following the experimental procedure described by Chauvin et al. (2000) and Genevey and Gallet (2002) for data from TT, and Poletti et al. (2013) for data from MW, in order to avoid possible bias in the final archaeointensity result due to the difference between natural (NRM) and experimental (pTRMs imparted) cooling times (e.g., Fox and Aitken, 1980; Dodson and MaClellend-Brown, 1980; Halgedhal et al., 1980; Biggin et al., 2013). All results from TR were accepted without 
this correction, since TR routinely produces results consistent with cooling ratecorrected TT and MW estimates (e.g., Genevey et al., 2009; Hartmann et al., 2010; 2011; Poletti et al., 2013);

vii) Standard deviation of final archaeointensity estimates. We only accepted data with standard deviation up to $15 \%$ of the mean intensity (Paterson et al., 2014), and a minimum of three samples/specimens $(\mathrm{N} \geq 3)$ per age.

In archaeointensity works, there are the designations "sample/specimen", "fragment" and "site", which are employed to distinguish the data acquired from laboratory measurements from the raw materials utilized, as well as for the calculation/presentation of the final archaeointensity results. Although there is a consensus about the term site, which is the final value of the magnetic intensity from a specific location for a given age (e.g., magnetic intensity for an archaeological ruin or destruction level that represents a specific period, magnetic intensity for a specific lava flow, etc.), there is no uniformity of nomenclature in relation to the other terms, which in turn are used in the calculations of the means. Thus, there are several ways in which the calculated mean from measured data in the laboratory is associated with a site (e.g., mean of several samples/specimens from a single fragment, mean of several fragments with a single sample each, mean of several fragments with several samples each, etc). We understand that the result of a site can be given by the mean value obtained from the results of at least three independent fragments; that the result of each fragment is given by the mean value from the results of at least two independent samples/specimens extracted from the same fragment in question; and that the result of each sample/specimen is given by the value obtained in the laboratory, processed, analyzed, approved by current selection criteria (e.g., Paterson et al., 2014), and corrected for the possible anisotropy and cooling rate effects (e.g., Genevey et al., 2009; Hartmann et al., 2010; 2011; Poletti et al., 2016). Due to the non-uniformity about the nomenclatures described, we did not distinguish between the results presented as site in our assessment. However, it is important to emphasize that our final results already have strong restrictions due to the previously applied selection criteria (i-vi). Finally, we suggest that future work should include more details about the distinction made between site, fragment and sample/specimen. 
For volcanic rocks we applied the same selection criteria as for data obtained from archaeological materials with some exceptions. In criterion ii) the pseudo-Thellier method proposed for volcanic rocks (de Groot et al., 2013) (only 18 entries) were also accepted; in criterion v) an ATRM correction was not required; in criterion vi) the cooling rate correction was neglected once its effect has been shown to be very small for the assemblages of PSD and interacting SD grains that are most commonly found in lavas (Biggin et al., 2013).

\subsubsection{ADMs and VADMs}

From filtered archaeointensity data $\left(\mathrm{B}_{\text {indirect }}\right)$, axial dipole moments $(\mathrm{ADMs}$ indirect $)$ are calculated using the theorem of Hulot et al. (1997), following the strategy applied by previous works (Gubbins et al., 2006; Genevey et al., 2009; Hartmann et al., 2011), described as:

$\mathrm{g}_{1}^{0}(\mathrm{t})_{\text {indirect }}=\mathrm{g}_{1}^{0}(\mathrm{t})_{\text {field model }} \frac{\mathrm{B}(\lambda, \varphi, \mathrm{t})_{\text {indirect }}}{\mathrm{B}(\lambda, \varphi, \mathrm{t})_{\text {field model }}}$

where $\lambda, \varphi$, and t, represent longitude, latitude and age, respectively; the field models used are gufm1 (Jackson et al., 2000) for 1590 $\leq \mathrm{t} \leq 1990$ and CHAOS-5 (Finlay et al., 2015) for $1997<t \leq 2015$. Then, the absolute intensities of $g_{1_{\text {indirect }}^{0}}$ from archaeointensity estimates are calculated by:

$$
\mathrm{B}_{\mathrm{g}_{\text {indirect }}^{0}}=\frac{\mathrm{g}_{\text {indirect }}^{0} \mathrm{a}^{3}}{\mathrm{r}^{3}}\left(1+3 \cos ^{2} \theta\right)^{\frac{1}{2}}
$$

where $r$ is the mean Earth radius, $\theta$ is the co-latitude, and $a$ is the mean radial distance from the Earth's center; for Earth surface estimation, we can approximate a by r. Finally, for this case, $\mathrm{ADM}_{\text {indirect }}$ are estimated (in $\times 10^{22} \mathrm{Am}^{2}$ ) by:

$$
\mathrm{ADM}_{\text {indirect }}=\frac{4 \pi \mathrm{r}^{3}}{\mu_{0}} \mathrm{~B}_{\mathrm{g}_{\text {indirect }}^{0}}\left(1+3 \cos ^{2} \theta\right)^{-\frac{1}{2}}
$$

where $\mu_{0}$ is the permeability of free space. Note that the insertion of equation (2.4.2) into equation (2.4.3) eliminates the dependence with the co-latitude, transforming it in a direct relation between $\mathrm{ADM}_{\text {indirect }}$ and $\mathrm{g}_{1}^{0}$. Virtual axial dipole moments (VADMsindirect) are 
calculated (in $\times 10^{22} \mathrm{Am}^{2}$ ) using equation (3.4.3), replacing $\mathrm{ADM}_{\text {indirect }}$ by VADM indirect and $\mathrm{B}_{\mathrm{g}_{\text {indirect }}^{0}}$ by $\mathrm{B}_{\text {indirect }}$.

\subsubsection{Linear regression applied to the selected dataset}

There are several statistical methods to infer the geomagnetic axial dipole variations through time from intensity data (e.g., splines, polynomials, moving averages). We decided to use linear regression in order to simplify the description of the geomagnetic dipole variations, thus providing a common solution across the longest possible period within the last two millennia; and also to correlate the variations described by direct and indirect data, considering their respective resolutions. We justify our parsimonious model on the grounds of four main (general) points: i) linear fits have proved to be sufficient to account for archaeomagnetic and historical data within their estimated errors during the historical period (Gubbins et al., 2006; Finlay, 2008); ii) a robust linear fit that describes the dataset taking into account all experimental errors will ignore any rapid, local variations; iii) at the point where the linear model no longer satisfies the dataset, it suggests that there has been a change in the general trend; iv) with a model (mathematical function) it is possible to make quantitative comparisons in relation to the physical models that may describe, for example, core features (e.g., Jackson, 2003). Therefore, if linear regression is statistically satisfied, this may provide us with insights into links between long-term (millennial) geomagnetic dipole variations recorded at Earth's surface and core physical mechanisms.

In this light, we describe the strategy employed in this work as follows. First an expression regarding the variations of the geomagnetic axial dipole as a function of time is defined as:

$g_{1}^{0}(t)=\alpha t+\beta+f(t)$

where $f(t)$ represents all nonlinear variations of $g_{1}^{0}$ as a function of time, and $t$ is the time in years $(C E)$ defined for the interval $0 \leq t \leq t_{c y}$, where $t_{c y}$ is the current year. Since $f(t)$ is an unknown function and represents the manifestation of several mechanisms operating in the Earth's core, its modelling requires more sophisticated physical/mathematical approach as well as a large number of data. However, if we assumed the hypotheses that short-period variations of $\mathrm{f}(\mathrm{t})$ can be minimized through average trends in restricted time 
windows (e.g., 15nT/yr for the last 150 years; Jackson et al., 2000; Finlay et al., 2015), we can represent the variation of the geomagnetic axial dipole as:

$\mathrm{g}_{1}^{0}\left(\mathrm{t}_{\mathrm{sp}}\right) \approx \alpha \mathrm{t}_{\mathrm{sp}}+\beta$

where $t_{s p}$ represents the time for a sub period between 0 and $t_{c y}$, and $\alpha$ and $\beta$ represent the angular and linear coefficients. In addition, we have $\dot{\mathrm{g}}_{1}^{0}\left(\mathrm{t}_{\mathrm{sp}}\right)=\alpha$.

From equation 2.4.5 we can calculate linear regressions for datasets belonging to different time windows. From an appropriated linear regression method, which provides both $\alpha$ and $\beta$ values and their respective uncertainties ( $\sigma \alpha$ and $\sigma \beta)$, it is possible to obtain a set of $\gamma$ linear solutions for each sub period $t_{\text {sp }}$, which can be written as:

$L=\left\{\gamma_{1}, \gamma_{2}, \ldots, \gamma_{n}\right\}$

where each $\gamma \in \mathrm{L}$ represents a solution with a specific value of $\alpha \pm \sigma \alpha$ and $\beta \pm \sigma \beta$, and $\mathrm{n}$ represents the number of solutions belongings to the set $\mathrm{n} \rightarrow \infty$, since $\{\alpha, \beta, \sigma \alpha, \sigma \beta\} \in$ $\mathbb{R})$. Fixing a sub period with a time window $\left(T_{w}\right)$ that minimizes $f(t)$, it is possible to perform successive linear regressions in order to cover the entire period between 0 and $\mathrm{t}_{\mathrm{cy}}$. Thus we can find a subset of linear solutions (S) given by the intersection of the largest number of sets $L$ (i.e., $S=L_{1} \cap L_{2} \cap \ldots \cap L_{m}$ ). Finally, from a priori information of the geomagnetic field, it is feasible to refine the number of linear solution $\gamma \in S$ that represents the linear variation of the geomagnetic axial dipole for the longest period between 0 and $t_{c y}$. The advantages of this approach are: $\left.i\right)$ it tends to minimize the effect of rapid variations of $f(t)$, thus restricting the scenario of signals from mechanisms that operate in the Earth's core; and ii) it is sufficiently robust to define a period in which the variations represented by equation 3.4 .5 is valid, by using the condition $S \cap L=\emptyset$, i.e., it is sufficient to capture the period in which there is no significantly influence of nonlinear variations expressed by $f(t)$ for long periods (millennial scale), further restricting the scenario of physical mechanisms responsible for geomagnetic axial dipole variations as a function of time for the last millennium. In this work the value of $g_{1}^{0}(2015)$ from CHAOS 5 (Finlay et al., 2015) will be used to estimate $\beta$ and gufm1 (Jackson et al., 2000) will be used to refine the $\alpha$ value. 
To calculate the linear regressions, we employ the following strategy. Initially, for the data belonging to Gauss era (1840-2009 CE) we computed a linear regression and its respective "reduced residual" (RR). The $R R$ is defined by $\left[y-y_{a}(x)\right] /$ $\sqrt{\left[\left(\sigma_{\mathrm{y}}\right)^{2}+\left(\alpha \sigma_{\mathrm{x}}\right)^{2}\right]}$, where $\mathrm{y}_{\mathrm{a}}(\mathrm{x})=\alpha \mathrm{x}+\beta$ is an interpolated linear function and $\sigma_{\mathrm{y}}$ and $\sigma_{\mathrm{x}}$ are uncertainties of (V)ADM and age, respectively. The fitting parameters were obtained from the dataset into a fixed limit of \pm 3 of $R R$ in order to refine the uncertainties of the linear model $\left(\sigma_{\alpha}\right.$ and $\left.\sigma_{\beta}\right)$, assuming that "y" (VADM and ADM) and "x" (age of thermoremanent magnetization of the material) are variables with independent uncertainties (Bevington and Robinson, 2003). The described procedure was repeated for multiple earlier intervals spanning an arbitrary time period such that each contained the same number of data of the Gauss era (48 data). The end dates of each interval were 50 years apart $(1959,1909$, etc) but the start date was determined solely by the requirement to have 48 data within the interval. Interval lengths therefore varied from 107 (between 1600 and $1707 \mathrm{CE}$ ) to 450 (between 0 and $450 \mathrm{CE}$ ) years. It is worth noting that the time window used for each linear regression and the shift by 50 years is sufficient to average typical rapid time-variations of the larger scale part of the geomagnetic field (Hulot and Le Mouël, 1994; Lhuillier et al., 2011).

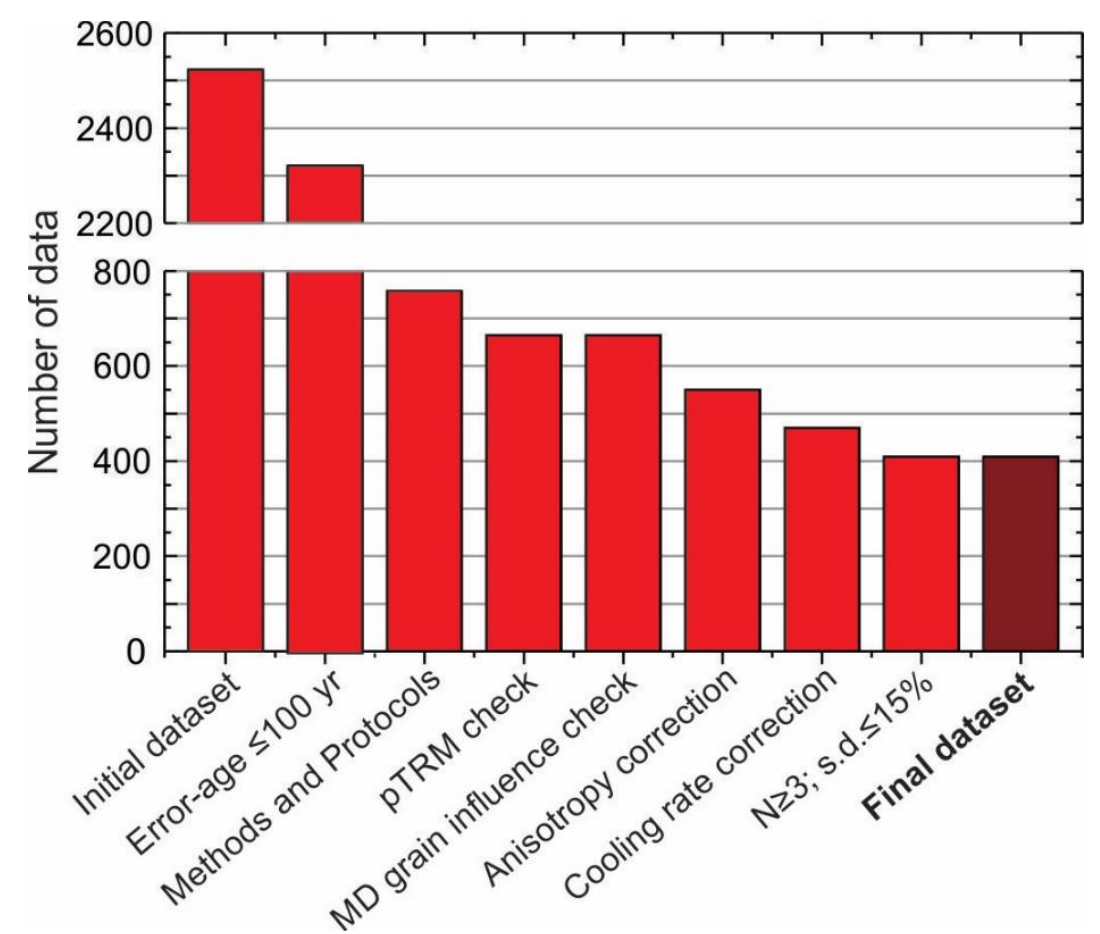

Figure 2.4.1: Summary of remaining datasets after the application of each selection criterion (see Methods) (extracted from Poletti et al., 2018). 

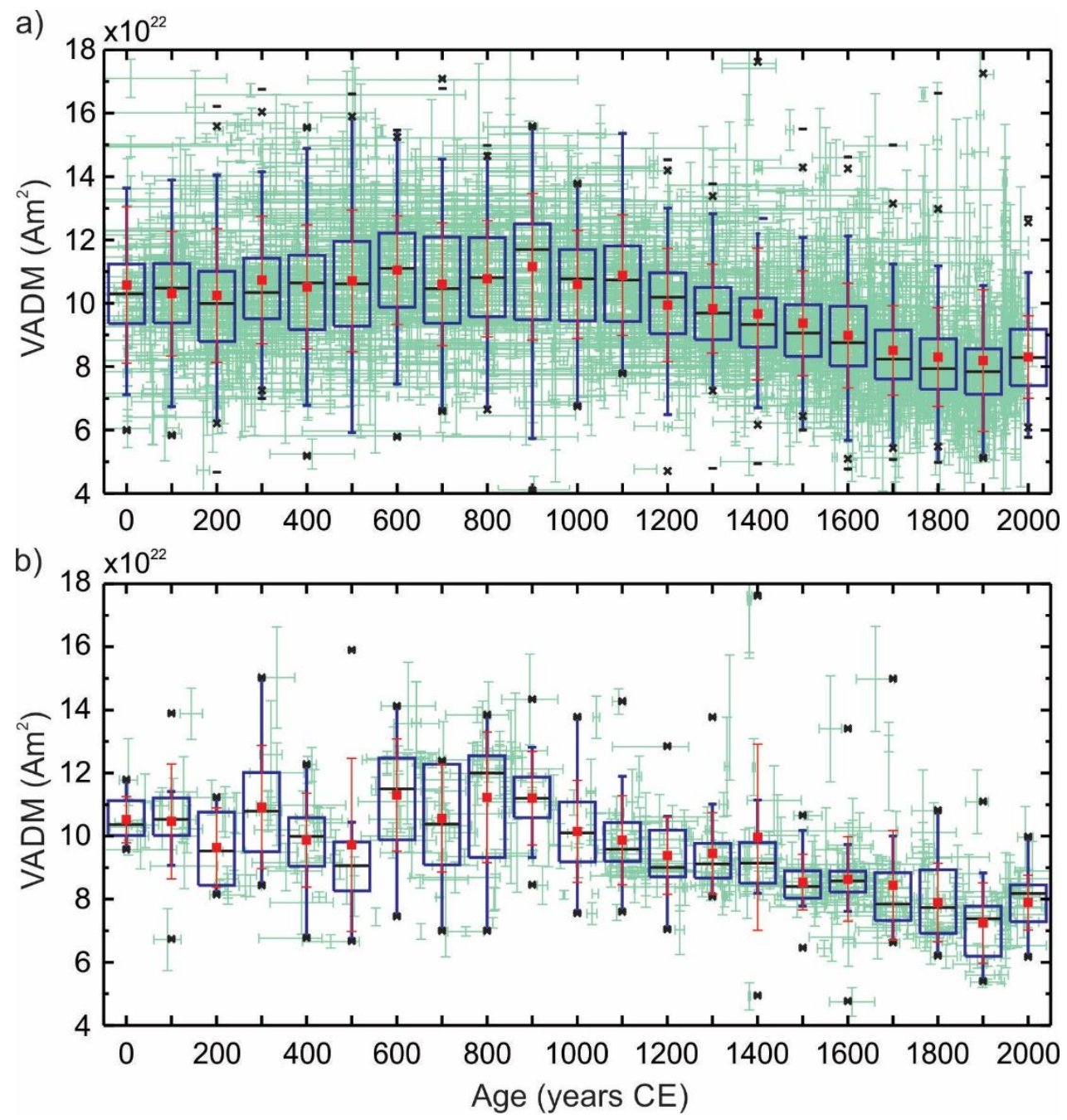

Figure 2.4.2: Archaeointensity data for the last two millennia. Box-and-whisker plots of 100 -years-subsets of the archaeointensity data are represented in blue and black, mean and standard deviation for the same subsets are represented in red, and age-intensity uncertainties of all dataset are represented in light green. a) represents the complete dataset, and b) the filtered dataset (extracted from Poletti et al., 2018).

\subsubsection{Results}

\subsubsection{Filtered archaeointensity database}

We applied the data selection criteria for the time-window between 0 and 2009 $\mathrm{CE}$, comprising all results obtained from archaeological artifacts and volcanic rocks. From a total of 2,532 data, only 413 entries from 62 published papers fulfill the selection criteria (Fig. 2.4.1; Supp. table A4.2.1). These include 290 data from archaeological artifacts and 123 data from volcanic material. Regarding to the initial number of data, the selection criteria that excluded the largest number of entries was the archaeointensity method and protocols adopted (62\%). In contrast, the criteria responsible to verify if there was previous investigation regarding MD grains influence did not exclude any data. The 
criteria about age uncertainties excluded $8 \%$ of the initial dataset; the criteria regarding thermo(chemical) alterations during the experiment excluded 3.7\%; the criteria about anisotropy and cooling rate corrections excluded $4.6 \%$ and $3.2 \%$, respectively; and the criteria that evaluated the final result excluded $2.6 \%$ of the initial catalog (Fig. 2.4.1).

Figure 2.4.2 shows the means and medians for the non-filtered (Fig. 2.4.2a) and filtered (Fig. 2.4.2b) datasets, as well as the age and intensity uncertainties of each data. For the original dataset (Fig. 2.4.2a), disregarding the uncertainties of individual measurements (i.e., box-and-whisker plot), there is a greater smoothing of the virtual axial dipole variations for the last 2,000 years. This comes as no surprise, since the means and medians were estimated from a cloud of many values within a restricted range. Applying the selection criteria reduces the smoothness of the variation prior to $1000 \mathrm{AD}$ but enhances how well the trend is defined in the later part of the record whilst maintaining its shape (Fig. 2.4.2b).
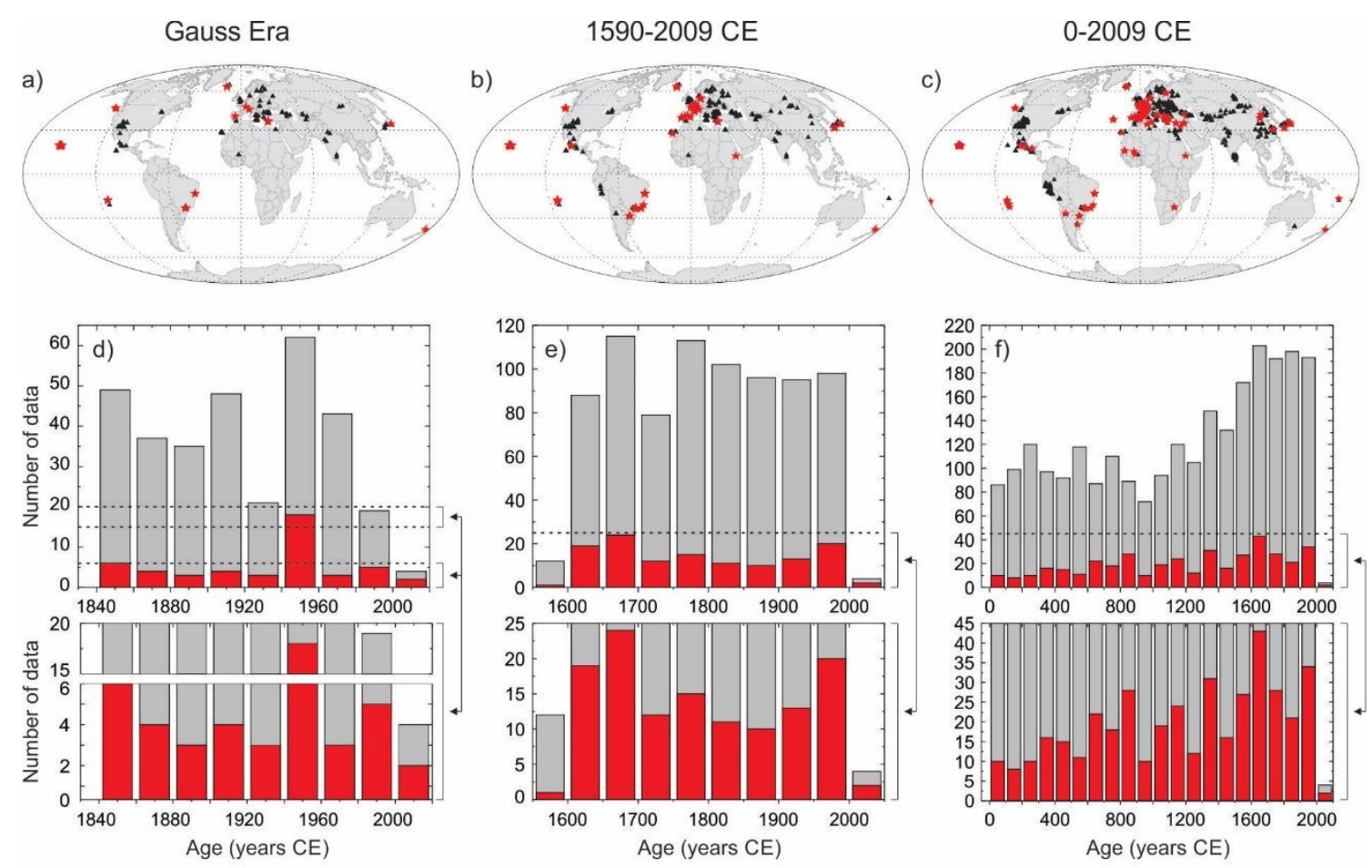

All archaeointensity data

$\star$ Filtered archaeointensity data

Figure 2.4.3: Spatiotemporal distribution of the archaeointensity database for the last two millennia. Maps (a-c) show the geographic data distribution, where triangles (black) indicate all dataset, and stars (red) only selected data (more details in the main text). Histograms (d-f) show the distribution of age, where grey bars represent all dataset, and red bars the filtered dataset. (a, d) represent the distribution for the Gauss era (after $1840 \mathrm{CE}$ ), (b, e) for the "historical period" (after $1590 \mathrm{CE}$ ), and (c, f) for the last two millennia (extracted from Poletti et al., 2018). 
Figure 2.4.3 shows the spatial (Fig. 2.4.3a, 2.4.3b and 2.4.3c) and temporal (Fig. 2.4.3d, 2.4.3e and 2.4.3f) distribution of the archaeointensity data for the last two millennia. The representations were divided into three distinct periods that will be explored throughout the work: between 1840 and 2009 CE (Gauss era) (Fig. 2.4.3a and 2.4.3d), 1590 and 2009 CE (Fig. 2.4.3b and 2.4.3e), and 0 and 2009 CE (Fig. 2.4.3c and 2.4.3f). Although there is a greater concentration of data in Europe, it is important to note that, even after data selection, the same relative geographic distribution remained (Fig. 2.4.3a, 2.4.3b and 2.4.3c). The temporal distribution of the data provides a good coverage for the three averaged periods, albeit with some peaks in the number of data (e.g., 19401960 CE, 1600-1700 CE).
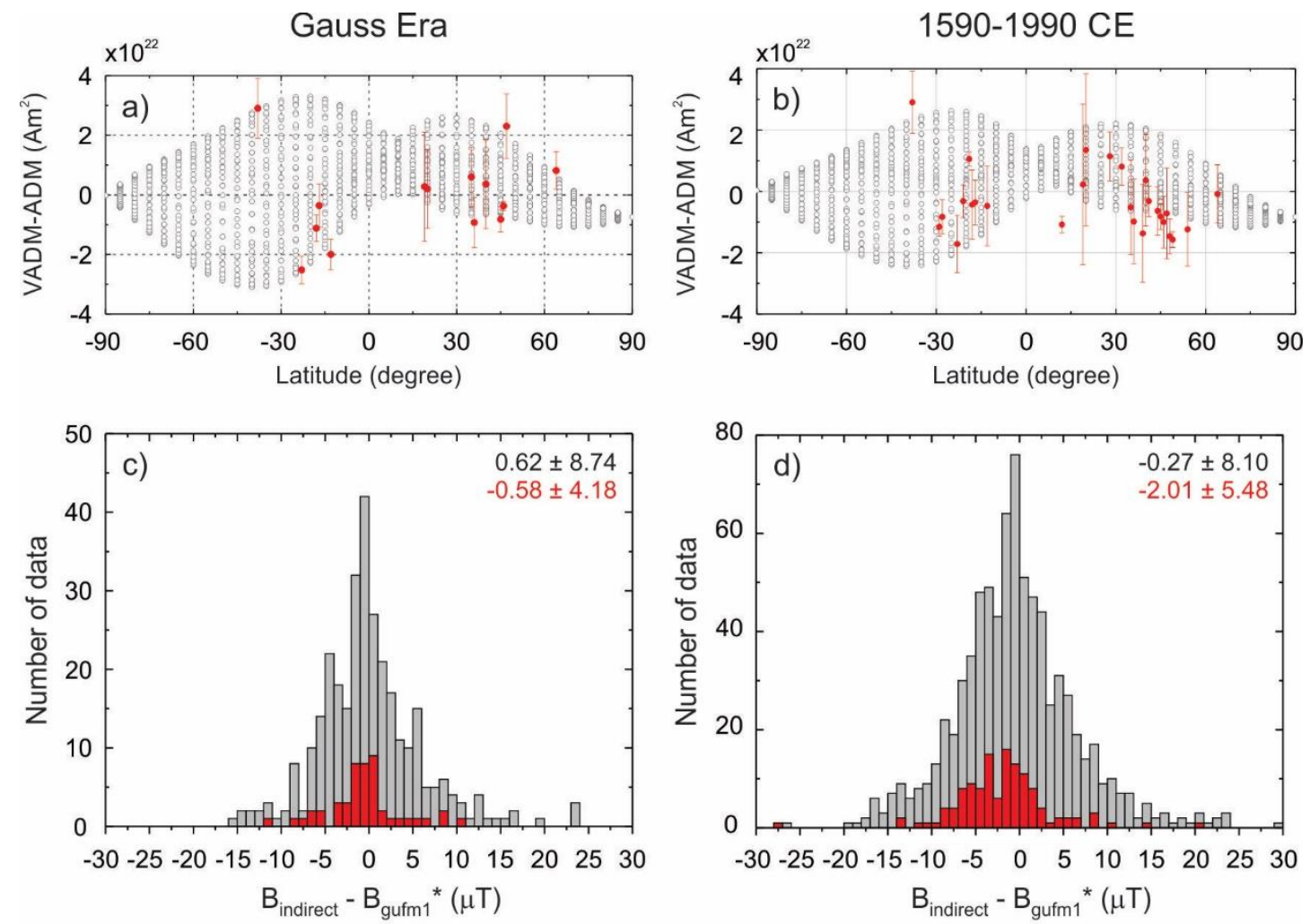

○ VADM and ADM from gufm1 - VADM from archaeointensity data and ADM from gufm1

All archaeointensity data

Filtered archaeointensity data

Figure 2.4.4: Latitudinal influence and intensity consistency of the archaeomagnetic dataset when compared with gufm1. (a-b) show the variation of the intensity for different latitudes, where opened circles (gray) represent data from gufm1, given by the averaged intensity of 36 data for every 10 degrees of longitude equally-spaced; and closed circles (red) represent the averaged intensity in a latitudinal-degreespaced of the filtered archaeointensity data (see Methods). Histograms show the distribution of the difference between the absolute archaeointensity data obtained from laboratory and: (*) gufm1 (Jackson et al., 2000) for 1590-1990 CE, and CHAOS-5 (Finlay et al., 2015) for 1990-2009 CE (extracted from Poletti et al., 2018). 


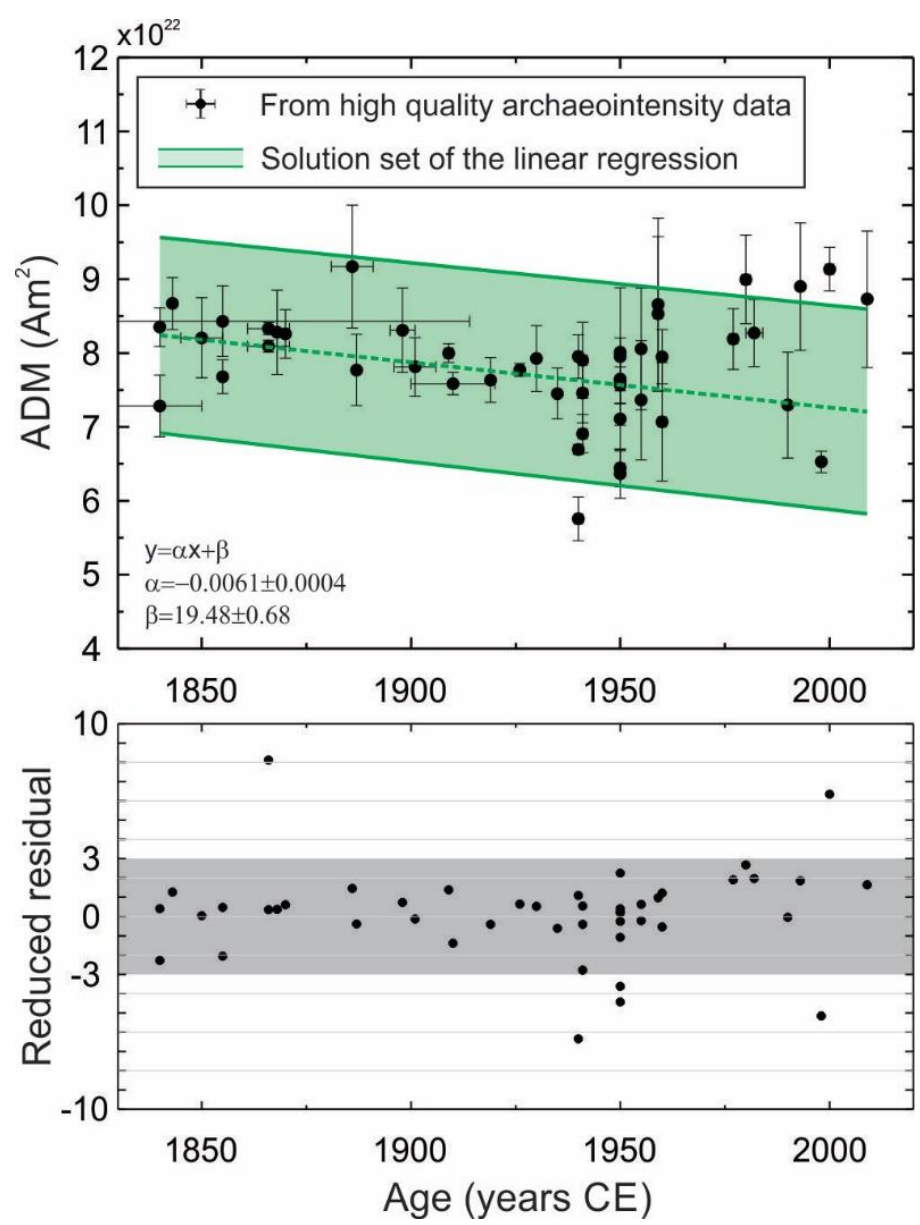

Figure 2.4.5: Linear regression of the high-quality archaeointensity dataset for the Gauss era. Up graphic shows the filtered intensities converted into $\mathrm{ADM}_{\text {indirect }}$ values as a function of age of the natural thermoremanent magnetization. Green shaded area represents the set of linear solutions obtained from the dataset into a limit of $\pm 3 \mathrm{RR}$, as represented by gray area in the below graphic (see Methods). Continuous and dashed green lines represent the average and extremes of the linear solution set, respectively (extracted from Poletti et al., 2018).

Considering the similarity of the spatial distribution and the good temporal coverage of the selected data for the three periods described above, the results were compared with the gufm 1 and CHAOS 5 models (Jackson et al., 2000; Finlay et al., 2015) for the periods 1840-2009 CE (Gauss Era) and 1590-2009 CE. The main objectives of this comparison were to test the latitudinal distribution of the data, since this variation has a direct influence on the magnetic intensity estimates (e.g., Campuzano et al., 2015), as well as to test the compatibility between the high-quality archaeointensity values and the historical field models (Fig. 2.4.4). Figure 2.4.4a and 2.4.4b show the mean VADM-ADM values from archaeointensity data (each point represents the averaged intensity in a latitudinal-degree-spaced) and from the gufm1 (each point is given by the averaged intensity of 36 data in a longitudinal-equally-spaced distribution, represented every five 
degrees of latitude). Although there is a greater concentration of data in the northern hemisphere ( $72.9 \%$ and $\sim 73.2 \%$ for Gauss era and 1590-2009 CE, respectively), it is important to note that they are distributed in a range of $\sim 100$ degrees ( -38 to 64 degrees) of latitude. In addition, considering the uncertainties of the measurements, the difference between VADM and ADM presents values close or equal to zero. Also, almost all data (except one result) show a good correspondence with gufm1 for both temporal averages.
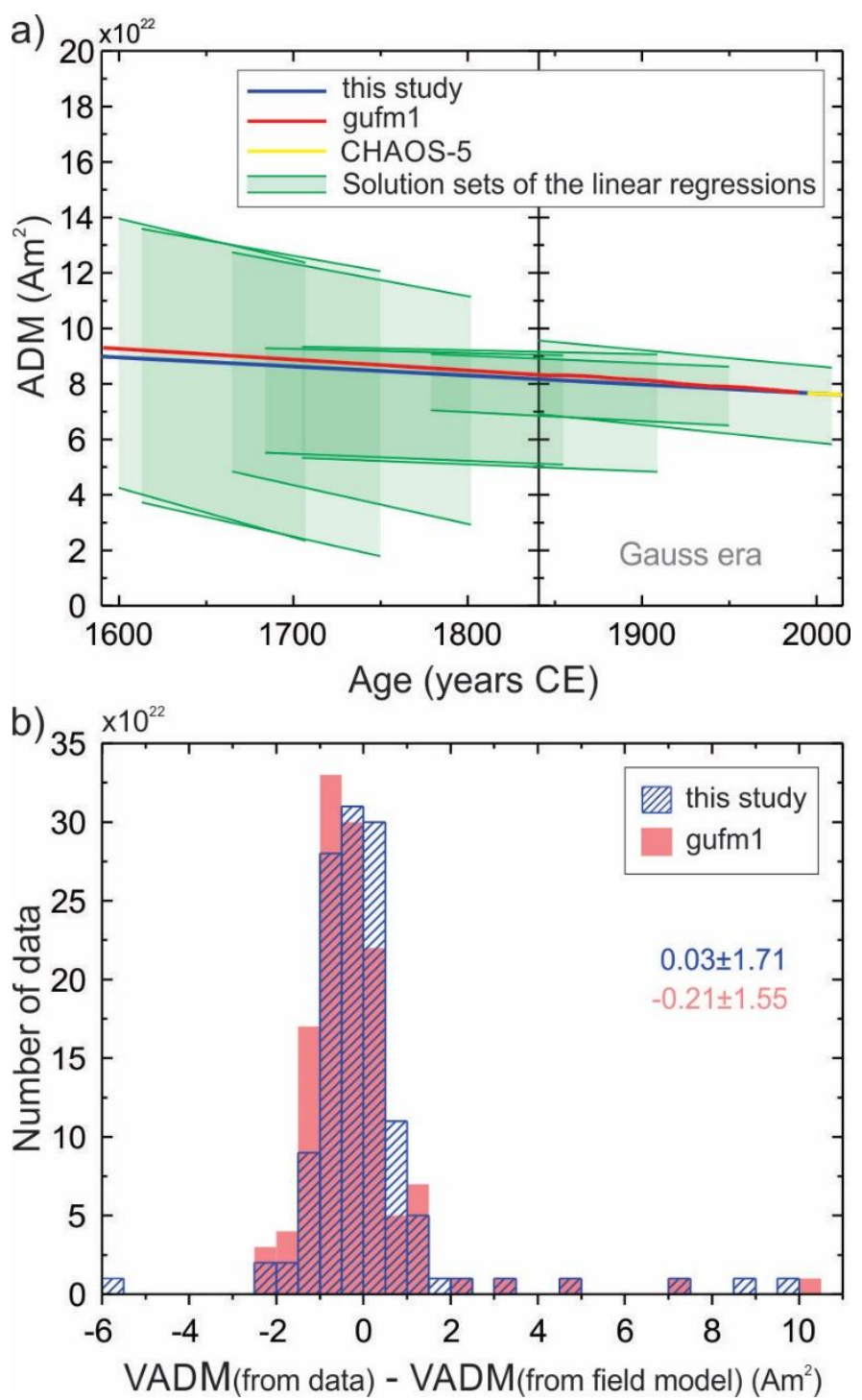

Figure 2.4.6: Continuous decrease of the geomagnetic axial dipole for the last four centuries. (a) Seven linear solutions sets for the last four centuries are represented in light green shaded area; continuous green lines represent the extremes of each linear solution set. Yellow and red lines represent the ADM of CHAOS5 and gufm1, respectively. Blue line represents the common linear solution for the sets of linear regressions, obtained exclusively from archaeointensity data. (b) Normal distributions of the difference between

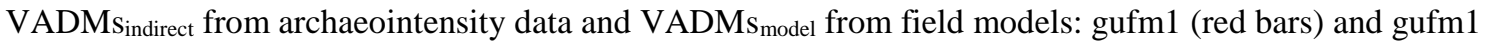
with it original axial dipole coefficient replaced (and the others coefficients recalibrated) by the linear trend proposed here (blue bars) (extracted from Poletti et al., 2018). 
For the same periods, the archaeointensity results were compared to expected values from gufm1 and CHAOS 5 (simplified by $B_{\text {gufm1 }}$; Jackson et al., 2000; Finlay et al., 2015) and the resulting distributions of the residuals plotted in figure $2.4 .4 \mathrm{c}$ and 2.4.4d. In both cases the selected data show less scatter than the original unfiltered data. A symmetric distribution within one standard deviation of zero was observed for both subsets $(-0.58 \pm 4.18$ and $-2.01 \pm 5.48 \mu \mathrm{T})$, indicating a good concordance between measured data and the historical field models. In order to test all possible scenarios regarding to the differences between archaeointensity and gufm1 data, we repeated the same comparison taking into account experimental and age uncertainties of the indirect results, where a normal distribution with standard deviation covering the zero was also observed (Supp. fig. A4.2.1a to A4.2.1i). In addition, we performed a Monte Carlo approach by using a homogeneous distribution for the intensity and age uncertainties, and again the averaged residual shows values close to zero for both periods (Supp. fig. A4.2.2). This high-quality and historical-model-comparable catalogue is the main basis for our analysis of the temporal variation of the geomagnetic axial dipole.

\subsubsection{The geomagnetic ADM for the last four centuries}

Filtered intensity estimates for the Gauss era comprise 48 data timegeographically distributed (Fig. 2.4.3a and 2.4.3d; Supp. table A4.2.1). These data were converted into $\mathrm{ADM}_{\text {indirect }}$ values from the theorem of Hulot et al. (1997) (see Methods). It is worth noting that this theorem requires a complete geometric coverage of the magnetic field on the globe. Therefore, we computed the $\mathrm{ADM}_{\text {indirect }}$ values from archaeointensity data using gufm1 (Jackson et al., 2000) for 1840-1990 CE and CHAOS5 (Finlay et al., 2015) for 1997-2015 CE, since they are well-established field models available for these respective periods. Then a linear regression was performed from converted $\mathrm{ADM}_{\text {indirect }}$ data, resulting in a set of linear solutions for this particular time interval. In our analyzes, the linear solution set is given by the uncertainties of $\alpha$ and $\beta$ of a linear function type; in our case $y(x)=\alpha x+\beta$ with y representing (virtual) axial dipole moment and $\mathrm{x}$ the age of the thermoremanent magnetization of the material (Fig. 2.4.5;

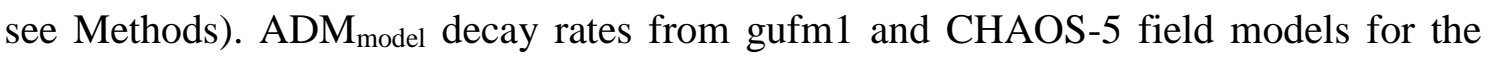
Gauss era fall well within our linear solution set (Fig. 2.4.6a).

Similarly, for the 1590 and $1840 \mathrm{CE}$ time interval, we converted 81 high-quality

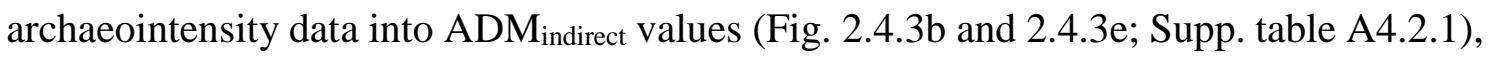
using gufm1 for 1590-1840 CE. Subsequently, six linear regressions were calculated 
individually using the same number of data for the Gauss era, every 50 years before 2009 CE (Fig. 2.4.6a, see Methods). All solution sets comprise the ADMmodel decay rate from gufm1. Between $1600 \mathrm{CE}$ and $1800 \mathrm{CE}$ the sets of linear solutions have greater uncertainties than those obtained for more recent periods. This is due to the sensitivity of linear regressions to uncertainties of age and axial dipole moment. For example, Schnepp et al. (2009) presented 25 archaeointensity results from oven floors collected in Germany. From these, 10 sites dated for $1665 \pm 85 \mathrm{CE}$ show intensity values over a wide range from $59.7 \pm 2.9$ to $44.1 \pm 3.3$. So, despite the excellent quality of individual archaeointensity estimates their relatively high age uncertainties and range in the intensity results strongly influence our regressions. Notwithstanding, the removal of these data reduces the uncertainties of regressions, but does not change any features or trends. For this reason, we decided to keep them into our analyses.

When we consider the whole filtered archaeointensity dataset comprising the past four centuries, the data are normally distributed, but the mean is slightly offset relative to intensity estimates of the gufm1 model (Fig. 2.4.4d). The same behaviour is observed when this archaeointensity catalogue is converted into VADM $\mathrm{V}_{\text {indirect }}$ values and compared with gufm1 (Fig. 2.4.6b). It is important to note that several studies have emphasized poor accuracy at the values calculated by gufm1, especially for the pre-Gauss era (e.g., Le Goff and Gallet, 2017). However, the comparisons performed in this work between highquality archaeointensity data and those calculated by gufm 1 present, on average, a satisfactory correspondence (Fig. 2.4.4c, 2.4.4d and Fig. 2.4.6b), since the mean residual covers the zero value within one standard deviation. Although there is a need to generate models with greater accuracy in the calculation of the complete vector of the Earth's magnetic field, the gufm 1 remains the most robust full-vector magnetic field model for the historical period. Thus, we use the gufm 1 and CHAOS-5 for the Gauss era and gufm1 for the period 1590-1990 CE in an attempt to capture a linear trend exclusively from archaeointensity data, which represents the average variation of the axial dipole for the historical period; and also minimizes the slightly offset of the mean residual between indirect data and model.

The mean linear trend given by the slope from the gufm1 and CHOS-5 models (i.e., $\sim 15 \mathrm{nT} / \mathrm{yr}$ ) is one of several possible solutions that belong to the set of linear solutions between 1590 and 2009 AD (i.e., $\gamma_{\text {gufm1 and CHAOS-5 }} \in$ S) (Fig. 2.4.6a). However, there are many other slopes that satisfy the condition $\gamma \in S$ for this period. To determine a single linear solution that better represent the average decrease of the geomagnetic axial 
dipole, we firstly: i) fix the ADM for $2015 \mathrm{CE}$ at $7.61 \times 10^{22} \mathrm{Am}^{2}$ (Finlay et al., 2015), in order to restrict the $\beta$ value in the equation 2.4.5; and ii) find a slope $(\gamma)$ that minimizes the difference between absolute data from laboratory and model in order to obtain a normal distribution of the residual centered on zero value. To obtain (ii), we replaced the $\mathrm{g}_{1}^{0}$ coefficient of gufm 1 by those extracted from linear solutions trends, and then we recalibrate all coefficients following the strategy showed by Whaler and Holme (2011):

$\mathrm{g}_{\text {new }}^{\mathrm{m}}=\mathrm{g}_{\mathrm{l}_{\text {gufm } 1}^{\mathrm{m}}} \mathrm{g}_{1_{\text {arch }}}^{0} / \mathrm{g}_{1_{\text {gufm1 }}}$

and

$\mathrm{h}_{\mathrm{l} \text { new }}^{\mathrm{m}}=\mathrm{h}_{\mathrm{l}_{\text {gufm } 1}^{\mathrm{m}}} \mathrm{g}_{1_{\text {arch }}}^{0} / \mathrm{g}_{1_{\text {gufm} 1}}^{0}$

where 1 and $m$ represent degree and order, respectively. Finally, the best linear fit found is indicated as a blue continuous line in Figure 2.4.6a (relative to the residual represented with the same colour in Figure 2.4.6b) and corresponds to an intensity decay rate of 12.5 nT/yr.

In order to statistically test the slope of $12.5 \mathrm{nT} / \mathrm{yr}$ obtained for the period between 1590 and 2009 CE, we performed 100 simulations in which $60 \%$ of 129 archaeointensity data were randomly selected, and then we calculated the $95 \%$ bootstrapping confidence intervals ( $\mathrm{N}=1999)$ (Hammer et al., 2001) for each linear regression, and also evaluated the residuals between the mean linear fit and i) the data used to compute the linear fit; and ii) the data that were not used to compute the linear fit. Then we observe that the slope obtained above is statistically robust (Supp. fig. A4.2.3a) and that both residuals show a normal distribution within one standard deviation of zero (Supp. fig. A4.2.3b). Therefore, the linear solution obtained exclusively by archaeointensity data apparently emerges as a robust solution to describe the average ADM decay trend for the historic period.

\subsubsection{The geomagnetic ADM for the last two millennia: VADM application as a proxy}

Does the linear trend obtained for the past four centuries also describe the geomagnetic axial dipole further back in time? To address this question, we first need to test whether we are able to safely use VADM as a "proxy" of ADM. 

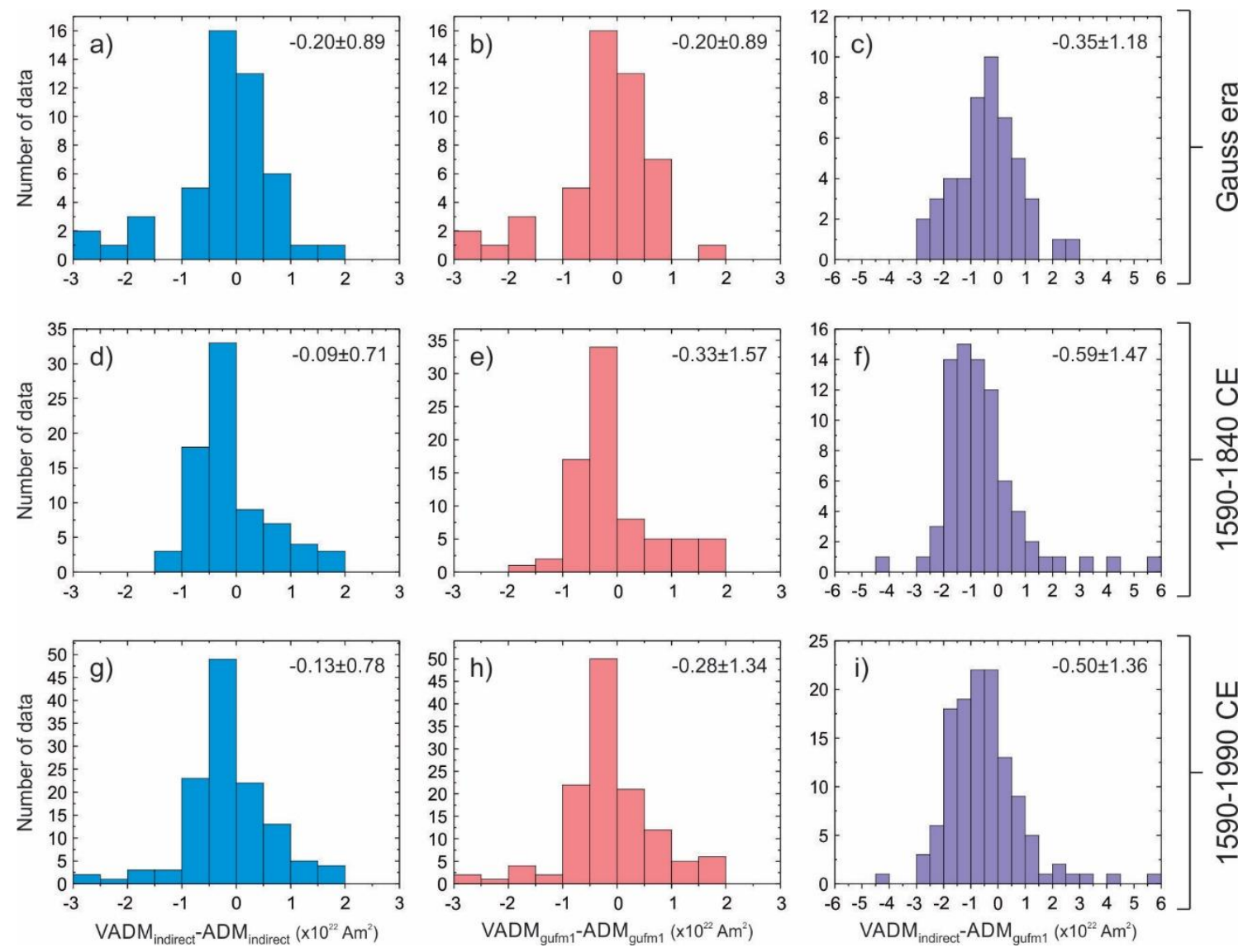

Figure 2.4.7: Correlations between ADMs and VADMs from archaeointensity data and gufm1. Normal distribution of the difference between VADMs and ADMs for: (a, d, g) only archaeointensity data, (b, e, h) only gufm1 with same time-space coverage, and (c, f, i) archaeointensity data (VADM) and gufm1. The comparisons were separated into the periods: (a, b, c) Gauss era, (d, e, f) 1590-1840 AD, and (g, h, i) 15901990 CE (extracted from Poletti et al., 2018).

In order to estimate the error arising from our use of VADMsindirect in the preGauss era instead of values of ADMsindirect calculated from theorem of Hulot et al. (1997), we compare the distributions of ADMs (both those calculated using Hulot et al.'s theorem from archaeointensity data and those taken directly from gufm1 and CHAOS-5) and VADMs (both those taken from archaeointensity data and from gufm1 and CHAOS-5), for the periods 1840-1990 CE, 1590-1840 CE and 1590-1990 CE (Fig. 2.4.7). In all cases, the residuals distributions between VADM and ADM are centered close to zero and wellinside of one standard deviation. We conclude that, although the (V)ADMsindirect are marginally offset to lower values than the ADMsmodel (Fig. 2.4.8a), they nevertheless provide a useful proxy for the Gauss era, as well as for the entire historical period.

In order to test whether the geographical distribution of the entire dataset used here is sufficient to define ADMs over the last two millennia, we segmented this into 150 
years intervals (taken as the same duration as the Gauss era time interval belonging to gufm1 - 1840-1990 CE), and then for each sub-period we re-sampled VADMs model $_{\text {from }}$ gufm1 (1840-1990 CE) taking into account the longitudes and latitudes of each of the archaeointensity data from the preceding time intervals (Supp. fig. A4.2.4). Afterwards we calculated the normal distribution of the difference between the re-sampled VADMs $s_{\text {model }}$ and the ADMsmodel from gufm1 (Supp. fig. A4.2.4). For all segments, the obtained peak of the VADM-ADM distributions was close to and within one standard deviation of the zero value. This suggests that, presuming variability with the Gauss era is reasonably representative of that for the last 2,000 years, the geographical distribution of $\mathrm{VADM}_{\text {indirect }}$ data in the intervals prior to 1840 would be sufficient to adequately describe the main trend of $\mathrm{ADM}$ in the post-1840 interval and that the limited geographical distribution of $\mathrm{VADM}_{\text {indirect }}$ estimates prior to 1840 should not be a barrier to defining ADM variations.

Additionally, we show that the trend of (V)ADM $\mathrm{Andirect}_{\text {from the archaeointensities }}$ in the gufm1 time period is close to that of the $\mathrm{ADM}_{\text {model }}$ taken from gufm1 and falls within one standard deviation of the $\mathrm{VADM}_{\text {model }}$ values from gufm1 in a degree-spaced coverage around the globe for each year (64,800 estimations per year) (Fig. 2.4.8a). Finally, we tested the influence of the linear trend from this study (section 2.4.3.2) in the original gufm1 (Jackson et al., 2000) by placing it into the gufm1 (equations 2.4.7 and 2.4.8), and then calculating the average of the radial component of the magnetic intensity at the core-mantle boundary (CMB) (Fig. 2.4.8b-f). The average field at the CMB shows similar geometry and maximum differences of $0.012 \mathrm{mT}$ for Gauss era (Fig. 2.4.8d) and 0.016 mT for 1590-1990 CE (Fig. 2.4.8g). These comparisons converge in showing that $\mathrm{VADM}_{\text {indirect }}$ is expected to be a good proxy for $\mathrm{ADM}_{\text {indirect }}$ suitable for ascertaining variations on timescales longer than 150 years in the axial dipole over the last 2,000 years.

We therefore proceeded back in time with the linear regressions using groups of 48 data (i.e., the same number used for the Gauss era), every 50 years, over the pre-gufm 1 period (Fig. 2.4.9). The 26 sets of linear regressions include a total of 275 high-quality archaeointensity data (Supp. table A4.2.1), belonging to the range of 0-1590 CE. Linearly extrapolating the previous linear trend back $1590 \mathrm{CE}$ we found that it is a common solution (that satisfy $\gamma \in \mathrm{S}$ ) for 18 sets of solutions, being consistent until the period between $550 \mathrm{CE}$ and $750 \mathrm{CE}$ (Fig. 2.4.9). The period 550-750 CE marks the interval of two consecutive sets of linear solutions where the linear fit is a solution for the last time (550-800 CE) and where it fails for the first time (475-750 CE). Thus, for the last 
millennium, the single linear regression with slope $12.5 \mathrm{nT}\left(\sim-0.0032 \times 10^{22} \mathrm{Am}^{2}\right)$, intercept $7.61 \times 10^{22} \mathrm{Am}^{2}$ at $2015 \mathrm{CE}$ (Finlay et al., 2015) and valid for the period 7502015 CE (hereafter called by archaeo_adm1.3k), appears to be a useful description of the long-term variations of the geomagnetic axial dipole and one that differs substantially from existing models in the interval 750-1200 CE (Fig. 2.4.10).

\subsubsection{Discussion}

\subsubsection{Effects of small spatial and temporal variations}

Some studies have consistently reported rapid local variations of the geomagnetic field for the past two millennia. For example, de Groot et al. (2013) studied lava flow sequences from Hawaii and reported a rapid increase in geomagnetic field strength of about $15 \mu \mathrm{T}$ between $\sim 850$ and $925 \mathrm{CE}(\sim 200 \mathrm{nT} / \mathrm{yr})$, followed by a rapid decrease at $\sim 1150$ CE ( 190 nT/yr). For Western Europe, Genevey et al. (2016) and Gómez-Paccard et al. (2016) used high-quality archaeointensity data to argue for a rapid decrease in geomagnetic field strength of $\sim 100 \mathrm{nT} / \mathrm{yr}$ between 800 and $1050 \mathrm{CE}$. Rapid variations have also been reported for older periods, including dramatic field intensity spikes in southern Israel reported by Shaar et al. $(2011,2016)$. These rapid variations have been attributed to local anomalies caused by dynamic processes at the CMB (e.g., Livermore et al., 2014; Davies and Constable, 2017). A complete assessment of these variations would require a more complete coverage of the globe with high-quality archaeointensity data, particularly in the southern hemisphere where the field may be more time-dependent (Constable et al., 2016) but which is underrepresented in the archaeomagnetic database. Our analysis tends to eliminate rapid local variations, thus describing only the long-term variations of the axial dipole field strength.

Our analysis also tends to average out the small amplitude variations of $\mathrm{ADM}_{\text {model }}$ derived from observatory and satellite data that are taken into account in, for example, gufm1 and CHAOS-5 models (Jackson et al., 2000; Finlay et al, 2015; Fig. 2.4.6a and Fig 2.4.9). Some studies reported that regional high-quality archaeointensity data have sufficient resolution to suggest oscillatory behavior of the geomagnetic axial dipole (Genevey et al., 2009; Hartmann et al., 2011). However, given the inherent experimental errors and limited geographical coverage, we suggest that the current global archaeointensity dataset, on average, cannot reproduce small fluctuations in the geomagnetic axial dipole. 

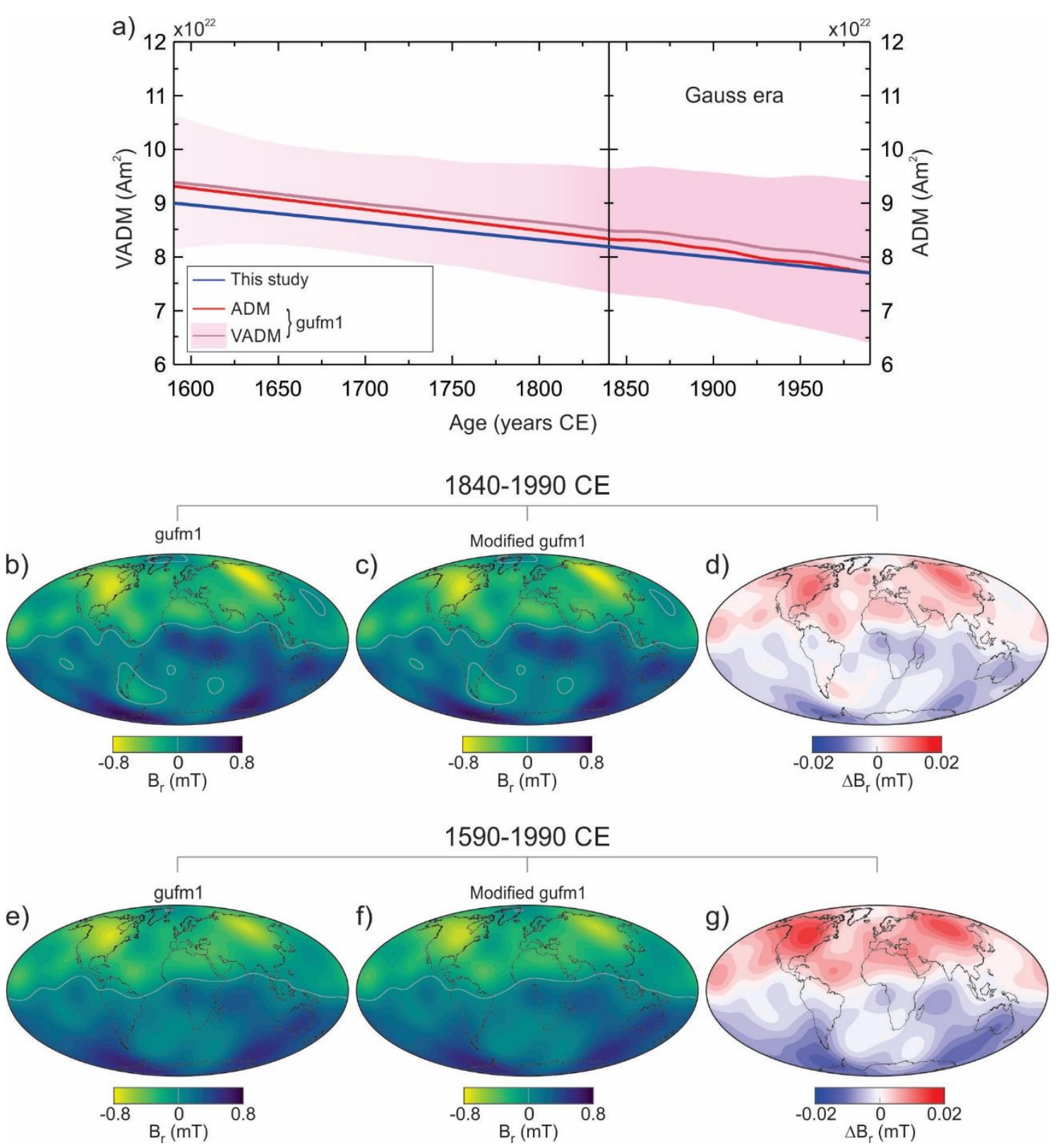

Figure 2.4.8: VADMs and ADMs from archaeointensity data and gufm1, and implications for the intensity variations at CMB. (a) Pink line and area represent averages and standard deviations, respectively, of VADMsmodel values produced from intensity measurements taken from gufm1 (which is constrained by intensity data only since 1840), with a degree-spaced coverage around the globe for each year between 1590 and 1990 CE. Red line represents the $\mathrm{ADM}_{\text {model }}$ of gufm1. Blue line represents the linear trend obtained exclusively from archaeointensity data. Note that the maximum discrepancy between this study's $\mathrm{ADM}$ and the gufm1 in the Gauss era (for which the latter is well-constrained) is $0.15 \times 10^{22} \mathrm{Am}^{2}(\sim 1.8 \%$ of the total). (b), (c), (e) and (f) represent the average radial magnetic field intensity for 1840-1990 CE and 1590-1990 CE periods. (b) and (e) were computed using gufm1. (c) and (f) were computed using gufm1 with it original axial dipole coefficient replaced (and the others coefficients recalibrated) by the linear trend proposed here. (d) and (g) provide the residuals between the averages of radial intensity at CMB calculated from gufm1 and the modified gufm1 (extracted from Poletti et al., 2018). 


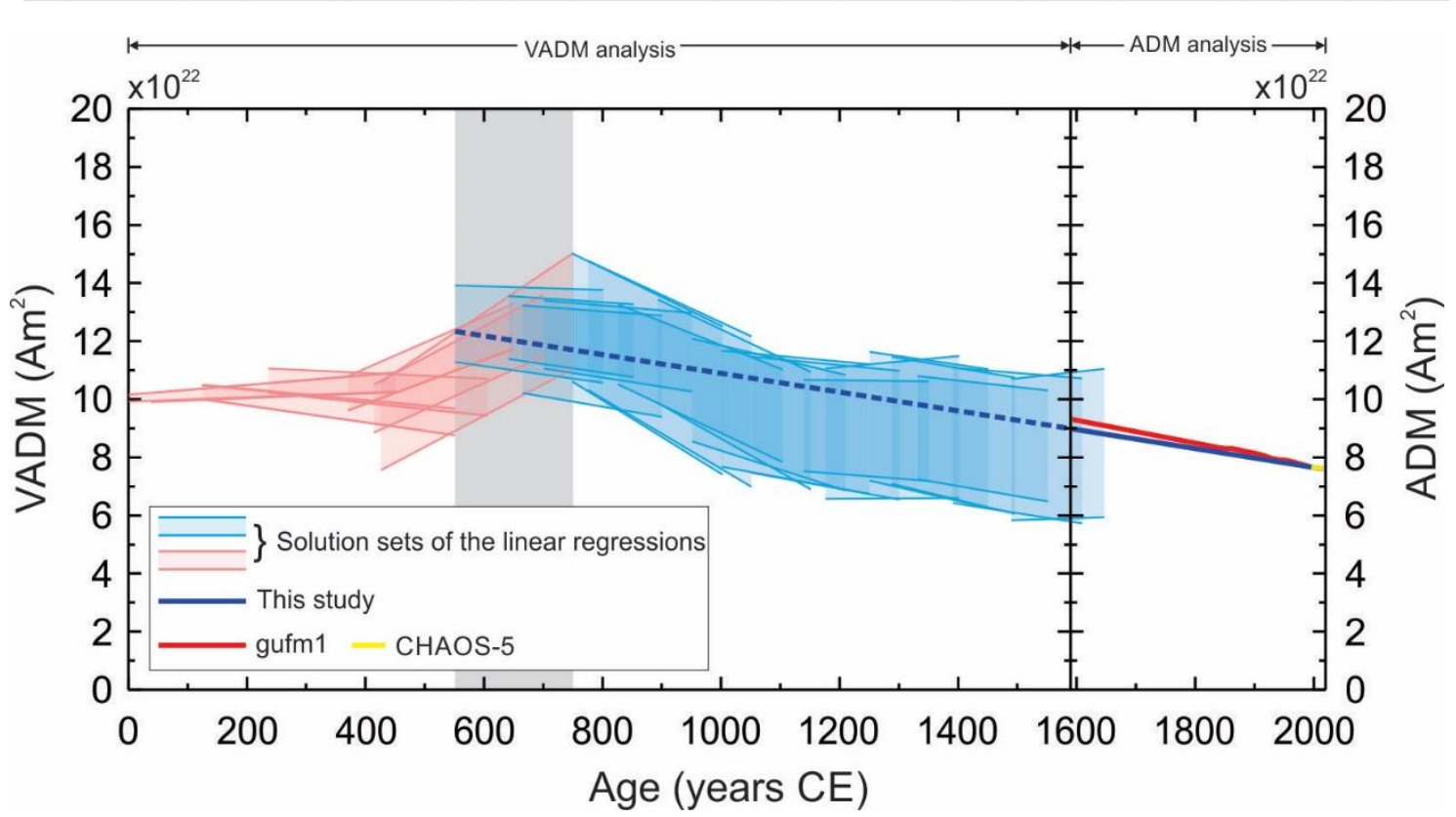

Figure 2.4.9: Continuous decrease of the geomagnetic axial dipole for the last millennium. Twenty six linear solutions sets for the last are represented in pink and light blue shaded area; continuous pink and light blue lines represent the extremes of each linear solution set. Yellow and red lines represent the $\mathrm{ADM}_{\text {model }}$ of CHAOS-5 and gufm1, respectively. Continuous blue line represents the linear trend obtained exclusively from archaeointensity data (this study); and dashed blue line represents it linear extrapolation. The period indicated by the gray area marks the interval of the last linear regression in which the linear extrapolation is a solution and the first that it fails. Just to facilitate visualization, the sets of linear regressions represented in light blue are those that contain the linear trend as the solution, and the sets represented by pink are those that do not contain it (extracted from Poletti et al., 2018).

\subsubsection{Comparison between archaeo_adm1.3k and geomagnetic field models}

When the archaeo_adm1.3k is compared with historical models, some differences can be related to data quality instead of Earth's core dynamics. Between 1590 and 1840 CE some models described the ADM evolution by a linear trend. For example, gufm1 (Jackson et al., 2000) used a linear extrapolation from the main trend of the Gauss era, Gubbins et al. (2006) proposed a linear regression from 315 non-filtered archaeointensity data, and Finlay (2008) suggested a linear trend given by the best fit from inversion of the same 315 archaeointensity data (Fig. 2.4.10a). The models of Gubbins et al. (2006) and Finlay (2008) suggested a shift in decay trend at $1840 \mathrm{CE}$, which is a recurrent feature of the differences between direct and indirect estimates (Suttie et al., 2011). Here, using only high-quality archaeointensity data to describe the ADM time-evolution, the shift in decay at 1840 is suppressed. Our estimates of ADM before $1840 \mathrm{CE}$ differ from the flat evolution proposed by Gubbins et al. (2006) and Finlay (2008). Instead, we suggest an earlier start in the decay of the ADM. 
Greater time-period models obtained by different data sets and modeling strategies also show significant differences regarding archaeo_adm1.3k (Fig. 2.4.10a). We compare our main result with the CALS3k series of field models (Korte et al., 2009; Korte and Constable, 2011), and with the A_FM_M and ASDI_FM_M models, which are the mean models of ensemble of time-varying archaeomagnetic field models (Licht et al., 2013). The CALS3k and the ASDI_FM_M field models are constructed from archaeological, volcanic and sedimentary data, whereas A_FM_M only uses archaeointensity data. For better visualization, all millennial models used in our comparison had their ADM' curves smoothed using a larger smooth factor in a sequence of third-order polynomials continuous up to the second derivative (de Born, 1978) (Fig. 2.4.10a). Besides differences in the main trend between the archaeo_adm1.3k and the mentioned models, in the specific period 550-900 CE the CALS3k models present a low of the ADM, being opposite to the peak described here. The Licht et al,' models show intermediate values of ADM for this period.

Other descriptions regarding the variations of the geomagnetic axial dipole were presented through VADM curves computed using temporal and spatial averaging (e.g., Valet et al., 2008; Genevey et al., 2008; Knudsen et al., 2008; Usoskin et al., 2016) (Fig. 2.4.10b). From a non-filtered archaeointensity database, Valet et al. (2008) proposed a third-degree polynomial function model to describe the variation of the $(\mathrm{V}) \mathrm{ADM}_{\text {indirect }}$ for the last 2,000 years, from a running-window approach using time-averaged data over 100 years and shifted by 25 years. They argued that time-averaged windows of 100 years are enough to attenuate non-dipolar contributions. The result from Valet et al.'s work shows a peak of (V)ADM values at about $700 \mathrm{CE}$, followed by a decrease up to the present. Knudsen et al. (2008) adopted a running-window approach to calculate the VADM variations during the entire Holocene. They presented a least-square fit from timeaveraged data using 500 year long sliding windows shifted by 100 years (between -2000 and $2000 \mathrm{CE}$ ). The description put forward by Knudsen et al.'s VADM curve shows a similar behavior to that described in Valet et al.'s paper, with relatively lower values beginning from a peak in the VADM at about 700 CE. Genevey et al. (2008) proposed a VADM evolution for the last 10,000 years. Their results are given by time-averaged data using 200 year long sliding windows shifted by 100 years (between -1000 and $2000 \mathrm{CE}$ ), and show a peak in VADM values between 300 and $400 \mathrm{CE}$, and the beginning of the VADM decrease at about 1200 CE. Similarly, Usoskin et al. (2016) presented a description of VADM from time-averaged data using 200 year long sliding windows 
shifted by 10 years (between -1500 and $2000 \mathrm{CE}$ ), using the newly updated database GEOMAGIA50.v3 (Brown et al., 2015). Usoskin et al.'s work provides a VADM curve with variations similar to that presented by Genevey et al. (2008), but with relatively lower mean values for the period 0-1440 CE. For the last nine centuries, our results, which were obtained through regressions by different time-windows with each individual endpoints regularly spaced by 50 years, are in agreement with that proposed by Valet et al.'s, Genevey et al.'s, Knudsen et al,' and Usoskin et al.'s works, and emerge as a simplification of all them. Before $900 \mathrm{CE}$ the archaeo_adm1.3k presents a unique trend that started between 550 and $750 \mathrm{CE}$. This reinforces that, for the last two millennia, the current models tend to lose information about the variation of the geomagnetic axial dipole, even if it is not possible to state specifically the cause.

A promising approach to combine short and long-term changes in axial dipole intensity into a complete description of the geodynamo has been put forward by Sanchez et al. (2016). These authors constructed a geomagnetic field model for the last three millennia using non-filtered archaeomagnetic data and prior information from geodynamo simulations (Aubert et al., 2013). Their geomagnetic axial dipole presents an average decay of $\sim 7 \mathrm{nT} / \mathrm{yr}$ for the last millennium, which differs from the result obtained here (12.5 nT/yr). In view of the new methodological approach presented by Sanchez et al' model, we tentatively suggest that the use of only high-quality archaeointensity data may improve attempts to describe physical processes of the Earth's core, which drive global millennial features of the field.

\subsubsection{Implications for core dynamics}

The average rate of geomagnetic axial dipole decay for the last 184 years is $\sim 15$ nT/yr (Jackson et al., 2000; Finlay et al, 2015). For this period, Finlay et al. (2016) combined geomagnetic field models (Gillet et al., 2013) and equatorially symmetric core flow models (e.g. Pais and Jault, 2008; Amit and Pais, 2013; Aubert, 2014; Gillet et al., 2015) to attribute the axial dipole decay to symmetry breaking in advection sources in the Southern Hemisphere. They showed that the drift of an intense normal polarity flux path equatorward, which diminishes the ADM (e.g. Olson and Amit, 2006), is unbalanced by any other significant advection source, causing the ADM decrease. According to our analysis, the intensity of the Earth's magnetic axial dipole had an average decay rate of $12.5 \mathrm{nT} / \mathrm{yr}$ from $~ 750 \mathrm{CE}$ to present, beginning after a clear change in the trend of the geomagnetic axial dipole (Fig. 2.4.9). Therefore, we have provided evidence for a 
continuous linear decay comparable in order of magnitude with the average rate for the Gauss era (e.g., Jackson et al., 2000; Finlay et al., 2015; Finlay et al., 2016). Consequently, we suggest an early break in the symmetry of the ADM advection sources in the Earth's core at about $750 \mathrm{CE}$.

According to our analysis, the ADM has been decreasing at roughly the rate of present-day for the past $\sim 1,265$ years. This corresponds to estimations of axial dipole secular variation (SV) time-scales ( 1,000 years) recently observed by Amit et al. (2017). This SV timescale represents the reorganization time of the axial dipole (Hulot and LeMouël, 1994). Based on the similarity between our estimate of ADM decrease period and the axial dipole SV timescale (Amit et al., 2017), we speculate that the ADM decrease may reach its end soon.

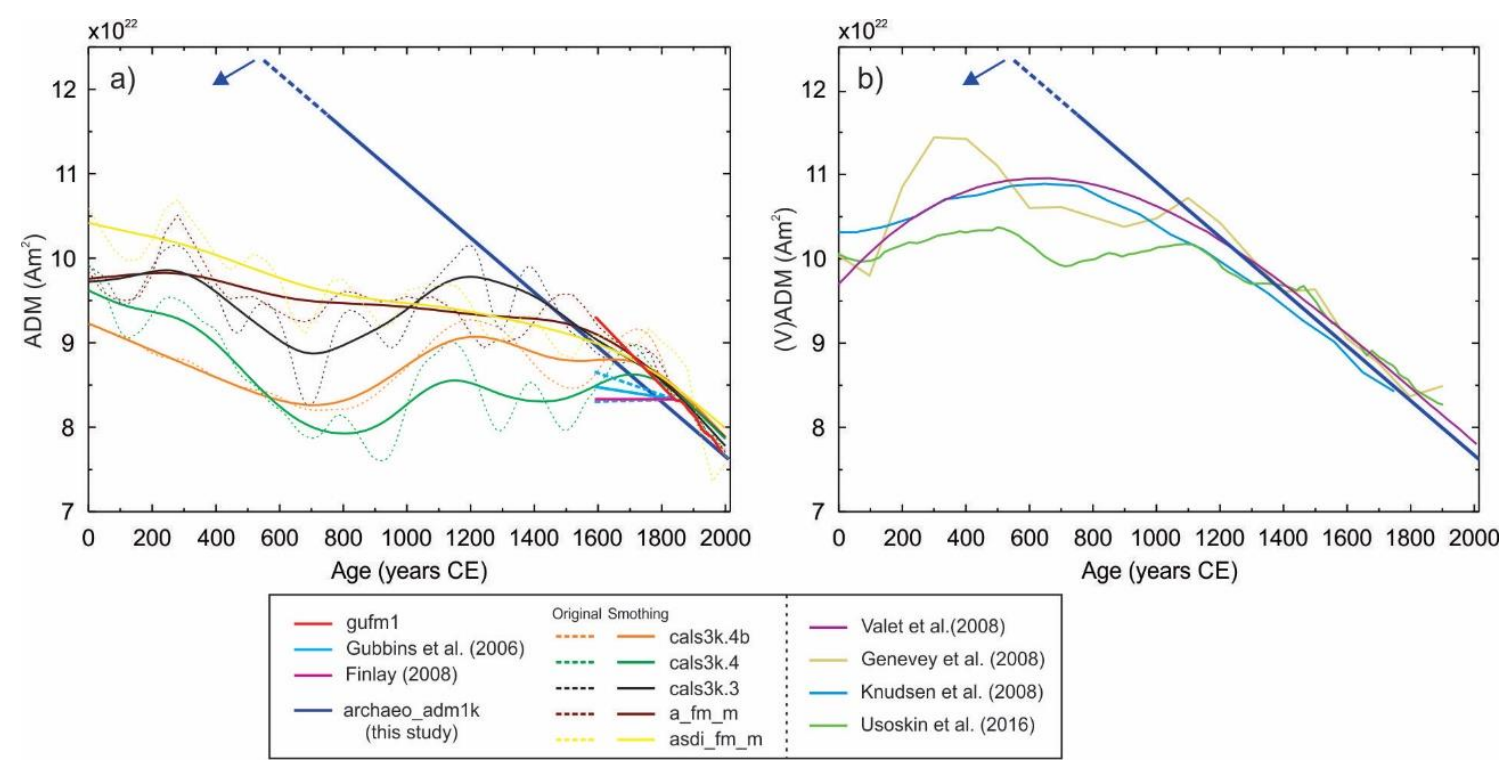

Figure 2.4.10: Comparison between the continuous linear trend decreases (archaeo_adm1.3k) with (a) geomagnetic field models and (b) VADM curves computed using temporal and spatial averaging. For the

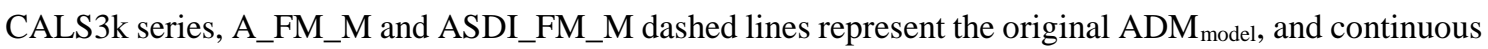
line the smoothed trend. Dashed lines for Gubins et al.'s model represent the uncertainties. Dashed line for archaeo_adm1.3k represents the interval that the linear trend is a solution for the last time and fail for the first time (details in the main text). The arrow indicates the possible trend before 550-750 CE (see also Fig. 3.4.9) (extracted from Poletti et al., 2018).

\subsubsection{Conclusions}

From a careful analysis of the current archaeointensity dataset we propose a welldefined linear trend that describes the variation of the geomagnetic axial dipole for the last millennium: archaeo_adm1.3k. The main conclusions of this work are: 
i) The comparison between the data obtained by direct and indirect measurements during the Gauss era allowed the analysis of the axial dipole to be extrapolated back in time for two millennia.

ii) The shift in the trend of the geomagnetic axial dipole variation at $1840 \mathrm{CE}$ described by previous studies (Gubins et al., 2006; Finlay, 2008) is a biased feature of the difference between direct and indirect measurements;

iii) Considering the last 2000 years, at approximately $750 \mathrm{CE}$ there was a peak of intensity of the axial dipole followed by a quasi-constant decrease, which is not captured by millennial models.

iv) If the recent decay of the Earth's magnetic axial dipole is caused by asymmetry in the advective sources then this commenced within the interval 550-750 CE.

v) Comparable duration of the dipole decay and the ADM SV timescale suggests that this event may be reaching its end soon.

\section{Acknowledgements}

Richard Holme and Hagay Amit are thanked for pre-submission readings and discussions that helped in improving the paper. We thank two anonymous reviewers for their helpful and constructive comments. W.P. thanks the São Paulo Research Foundation (FAPESP) (grant \#2013/16382-0). A.J.B. acknowledges a NERC standard grant (NE/P00170X/1) and funding from The Leverhulme Trust. G.A.H. thanks CAPES (grant AUXPE 2043/2014) and CNPq (grant 454609/2014-0). F.T-N. thanks The National Council for Scientific and Technological Development (CNPq/Brazil) (grant 206997/2014-0). 


\section{Chapter 3}

\section{Synthesis and perspectives}

Throughout the development of my $\mathrm{PhD}$ project, which resulted in this thesis, I have had the pleasure of exploring a significant range of research topics about the Earth's magnetic field. The main contributions of this thesis, as well as the immediate implications and perspectives, will be summarized below.

\subsection{Contributions for archaeointensity methods}

\subsubsection{Microwave archaeointensity method}

The first part of the project was essentially methodological. In Poletti et al (2013), archaeointensity measurements were performed on archaeological materials using the Microwave method (MW - Shaw et al., 1996). The samples used were those previously investigated by Hartmann et al. (2010), coming from Northeast Brazil with ages covering the last 500 years. In Hartmann et al. (2010), they presented 14 new archaeointensity results obtained from the modified Thellier-Thellier method (TT - Coe et al., 1978; Riisager and Riisager, 2001; details in Genevey et al., 2009) and Triaxe method (TR - Le Goff and Gallet, 2004). In addition, they did a detailed investigation of the magnetic mineralogy. In this way, these well-characterized archeological materials were ideal to study with the MW method. Under this light, an extensive set of measurements was carried out, and the results obtained by the MW method presented some significant discrepancies in relation to those obtained from TT and TR methods (up to 25\%). Theoretical and experimental investigations showed that although the MW method directly excite the magnetic minerals by high-frequency microwaves, not heating the material in a conventional way, the samples were indeed heated. Consequently, once the samples are heated, they incorporate an adverse effect called cooling rate effect, which is associated to the difference between the cooling times during its manufactory and that of the heating steps during the archaeointensity experiment (e.g. Fox and Aitken, 1980; Dodson and McClelland-Brown, 1980; Halgedahl et al., 1980). To correct for this effect, Poletti et al. (2013) proposed a simple experimental procedure to be performed on sister samples (i.e., samples from a same fragment). It was observed that this cooling rate 
correction provides a concordant final result among the three methods (MW-TT-TR). It is important to emphasize that the physical theory behind the heating during MW application is still not well understood, but it is well known that it is proportional to the increase of the power integral (power x time) during the experiment. Since the equipment operates exclusively with the resonance frequency of magnetite (i.e., $14 \mathrm{GHz}$ ) (Shaw et al., 1996, 1999; Hill and Shaw, 1999, 2000; Hill et al., 2002a, 2002b), we hypothesize that since archaeological materials have a range of magnetic minerals in its composition, the absorption of the power integral by non-magnetite minerals is converted into heat.

Based on the above mentioned contribution I suggest that from now on all microwave archaeointensity estimates need to be corrected from the cooling rate effect. In addition, it would be interesting if the theoretical basis of the MW method was more explored. Thus, it would be possible to obtain a better understanding of the physics behind the interaction between high-frequency microwaves and bulk samples. Also, this would contribute to reduce the empirical character of this method.

\subsubsection{Double-heating archaeointensity method}

In Poletti et al. (2016) two methodological aspects were explored. The first one is the influence of the anisotropy of thermoremanent magnetization (ATRM) on archaeological materials and how to correct it. The second was the successful implementation of the archaeointensity methodology (TT method) at the Laboratório de Paleomagnetismo, Universidade de São Paulo, Brazil.

Since the late 1970s it has been known that ATRM has adverse effects on the final estimate of archaeointensity estimates obtained from archaeological materials (Rogers et al., 1979). Veitch et al. (1984) proposed an elegant way to correct such effect from the calculation and application of an ATRM-tensor. However, due to the significant increase in laboratory time that this procedure represents as it adds six additional heating steps to the already laborious palaeointensity routine, several researchers looked for alternative methods to correct for the anisotropy effect. The most popular ones were those that corrected the ATRM effect from tensors built through anhysteretic remanent magnetization (ARM) or magnetic susceptibility (MS) measurements. However, these approaches require some caution, since they imply in assuming that the thermoremanent magnetization (TRM) behavior is equivalent to ARM and/or MS, which is not always true (Stephenson et al., 1986; Yu et al., 2003). Therefore, the application of these alternative methods to correct ATRM effect must be accompanied by tests that 
demonstrate the correspondence between the ATRM and the ARM or MS for each studied case. Another way used by some researchers is to correct for the ATRM effect by measuring six samples extracted from a single fragment, positioned experimentally orthogonal to each other (e.g., Morales et al., 2009; Goguitchaichvili et al. 2012). Fortunately, in Poletti et al. (2016) we had the opportunity to test whether this correction methodology is appropriate or not.

Following Veitch et al. (1984), the samples studied by Poletti et al. (2016) were subjected to six additional heating steps, in a fixed laboratory field, at the temperatures of $350{ }^{\circ} \mathrm{C}$ and $500{ }^{\circ} \mathrm{C}$ for the ATRM correction. In these additional heating steps, the arbitrary adopted positions were $+\mathrm{X},-\mathrm{X},+\mathrm{Y},-\mathrm{Y},+\mathrm{Z}$ and $-\mathrm{Z}$. The different temperatures were strategically chosen in order to calculate the ATRM-tensors in samples that had at least $40 \%$ of the NRM removed. This strategy gave us, in addition, a set of measurements that enabled to test the hypothesis of the correction made from an arithmetic mean of six independent sister samples, positioned orthogonally to each other during the experiment.

To test the validity of the six orthogonal samples approach, the following procedure was adopted: i) only samples that showed a demagnetization proportional to at least $30 \%$ of NRM between $350{ }^{\circ} \mathrm{C}$ and $500{ }^{\circ} \mathrm{C}$, respectively, and complied to all selection criteria proposed by Paterson et al. (2014), were selected; ii) archaeointensity for each position $(+\mathrm{X},-\mathrm{X},+\mathrm{Y},-\mathrm{Y},+\mathrm{Z}$ and $-\mathrm{Z})$ between $350{ }^{\circ} \mathrm{C}$ and $500{ }^{\circ} \mathrm{C}$ were estimated; iii) final results were calculated from the arithmetic mean of the six results obtained in (ii); and iv) the results obtained from the arithmetic mean described in (iii) were compared with the results corrected by the method proposed by Veitch et al. (1984) for each same fragment. At the end, we show that the results obtained by the two correction methods disagree. Therefore, we prove that the ATRM correction from the arithmetic mean of six orthogonal samples is not valid (Poletti et al., 2016).

A great effort has been put forth by the paleomagnetic community to try to reduce the experiment time of the TT method. Yet, based on the above discussion, I suggest that more care should be exercised in the application of alternative methods to correct for the ATRM effect and that the six sample average method, in particular, should be abandoned.

\subsubsection{Double-heating archaeointensity method at Universidade de São Paulo, Brazil}

As previously stated, another methodological contribution from this thesis was the successful implementation of the modified Thellier-Thellier method for archaeointensity measurements in the Laboratório de Paleomagnetismo, Universidade de São Paulo. 
Before obtaining new archaeointensity estimates from unpublished materials, in Poletti et al. (2016) we also performed a series of measurements on samples remaining from the works already published by Hartmann et al. (2010 and 2011) and Poletti et al. (2013). In this way, we were able to implement and test the entire protocol of measurements and corrections, and intercalibrate the final results with those obtained at the Institut de Physique du Globe de Paris, France (Hartmann et al., 2010, 2011) and Geomagnetic Laboratory, University of Liverpool, UK (Poletti et al., 2013), therefore demonstrating that results obtained in São Paulo are of equivalent quality to those produced by some of the reference research centers in the world.

\subsection{Archaeomagnetic field intensity evolution in South America}

\subsubsection{Reassessment of the South America database}

In Poletti et al. (2016), a detailed reassessment of the available archaeointensity data for South America during the last 2000 years was carried out. For this, a list of selection criteria was established in order to retain only high-quality entries. A detailed description of this list can be found in Poletti et al. (2018). To be an important point of this thesis, the list of selection criteria used will be re-presented below according to Poletti et al. (2018, pages 73 and 74), where it reads:

“i) Age uncertainty. For this study, we accepted data with age uncertainty less than or equal to 100 years (fage $\leq 100)$. This rather strict choice was made to enable the comparison between archaeomagnetic and observatory/satellite data in the Gauss era (i.e., 181 years). Data were not filtered by the dating technique (except for archaeomagnetic dating);

ii) The archaeointensity method used and the protocol adopted. We only accepted intensity data performed exclusively with the classical double-heating method at roomtemperature (Thellier-Thellier, 1959) in one of its modified versions (TT) (Coe, 1967; Aitken et al., 1988; Yu et al, 2004), the microwave method (MW) (Shaw et al., 1996; Hill and Shaw, 1999), or the high-temperature Triaxe method (TR) (Le Goff and Gallet, 2004). Our choice was based on palaeointensity methods that perform a gradual and progressive replacement between the magnetizations acquired from the nature and laboratory. The results obtained from these three specific methods are more likely to be high-quality and 
concordant as highlighted by several works published in the last few decades (e.g., Hill et al., 2002a; Genevey et al., 2009; Poletti et al., 2013);

iii) Additional steps to check alterations during the experiment. For TT and MW, we required additional steps in the laboratory protocol, referred to as PTRM checks, to monitor possible (thermo)chemical alterations during the gradual increase of temperature (TT) or power (MW) steps on the experiment (Coe et al., 1978). For TR, these additional steps are unnecessary (Le Goff and Gallet, 2004);

iv) Evaluation of the influence of multi-domain (MD) grains. We required at least one test-type to verify possible MD grains influence (e.g., Riisager and Riisager, 2001; Krása et al., 2003; Yu et al., 2004), in order to avoid the violation of the principles of additivity and reciprocity, which are part of the backbone of the Thellier-Thellier method (Yu and Dunlop, 2003; Dunlop, 2011);

v) Anisotropy thermoremanent magnetization (ATRM) correction. We accepted only data largely unbiased by anisotropy effects either by having the laboratory field applied in a direction within 10 degrees of the principal component of the natural remanent magnetization (NRM) (Rogers et al, 1979; Aitken et al., 1981), or by the correction of the tensor of ATRM being obtained experimentally and calculated through the formulation proposed by Veich et al. (1984). Although there are other ways to correct the ATRM effect, for example, through the tensor obtained from measures of anhysteretic remanent magnetization (ARM) or magnetic susceptibility (MS), we restrict our analysis to results that take into account the same physical basis between anisotropy correction and Thellier-Thellier method (see ii). Data corrected by the ATRM effect using ARM or MS technique implicitly assume equivalence between the pairs of anisotropy tensors TRMARM or TRM-MS, which are not always true (Stephenson et al., 1986; Yu et al., 2003), although we acknowledge the need for further advances in this topic.

vi) Cooling rate correction. We accepted only archaeointensity data that were corrected for cooling rate effects following the experimental procedure described by Chauvin et al. (2000) and Genevey and Gallet (2002) for data from TT, and Poletti et al. (2013) for data from $M W$, in order to avoid possible bias in the final archaeointensity result due to the difference between natural (NRM) and experimental (pTRMs imparted) cooling times 
(e.g., Fox and Aitken, 1980; Dodson and MaClellend-Brown, 1980; Halgedhal et al., 1980; Biggin et al., 2013). All results from TR were accepted without this correction, since TR routinely produces results consistent with cooling rate-corrected TT and MW estimates (e.g., Genevey et al., 2009; Hartmann et al., 2010; 2011; Poletti et al., 2013);

vii) Standard deviation of final archaeointensity estimates. We only accepted data with standard deviation up to $15 \%$ of the mean intensity (Paterson et al., 2014), and a minimum of three samples/specimens $(N \geq 3)$ per age."

The above mentioned list of selection criteria was established for archaeological materials. In the case of geological materials (i.e., volcanic rocks) criteria (v) and (vi) were not applied (see Poletti et al., 2018).

From 205 initial data, which represents about 5\% of the world intensity data for this period, only 39 passed by the selection criteria. On the one hand, the number of values has been drastically reduced, implying in a huge gap of data for this region, both temporally and geographically (Poletti et al., 2016). On the other hand, this new list is composed only of high-quality archaeointensity data that can be used as a reference for regional studies of the Earth's magnetic field intensity variations.

Based on the analysis put forward by Poletti et al. (2016), it is evident the immediate necessity to acquire new high-quality archaeointensity results for different regions of the South America, as well as for different ages. In addition to the importance of understanding the regional field evolution, the increase in the number of data for this region is essential to better understand the field variations in the Southern Hemisphere, which presents a high secular variation and is the location of the largest and most enigmatic magnetic field anomaly of the present-day field: the South Atlantic Anomaly (SAA).

\subsubsection{New archaeointensity data for South America and implications}

Another important contribution from this thesis was the acquisition of nine new high-quality archaeointensity data from archaeological materials collected in South Brazil, covering the last 400 years. All archaeointensity data were obtained in the Laboratório de Paleomagnetismo, Universidade de São Paulo, Brazil, and obey the selection criteria listed below, extracted from Poletti et al. (2016, page 39): 
"At the specimen level, an intensity estimate is considered valid if:

- it uses a minimum of four temperature steps $(N \geq 4)$ including at least $35 \%$ of the total $N R M(f \geq 0.35)$ (Coe et al., 1978);

- standard errors of the slope are below 15\% ( $\beta \leq 0.15)$ (Selkin and Tauxe, 2000);

- the overall quality index of the paleointensity estimate is above 5 ( $q \geq 5$ ) (Coe et al., 1978);

- the intensity value is obtained along the same temperature interval in which the characteristic magnetic component was isolated with an unanchored $M A D \leq 10^{\circ}$;

- the angular difference between anchored and free-floating best-fit directions on a vector component diagram is below $15^{\circ}(\alpha \leq 15)$;

- maximum difference produced by a pTRM check normalized by the TRM is smaller than 9\% ( $\delta C K \leq 9)$ (Leonhardt et al., 2004);

- the measure of cumulative alteration determined by the ratio of the alteration-corrected intensity estimate (Valet et al., 1996) to the uncorrected estimate, normalized by the

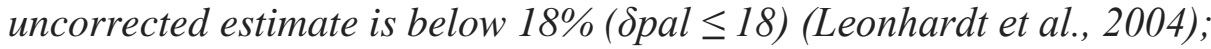

- maximum difference produced by a pTRM tail check normalized by the NRM is below $20 \%(\delta T R \leq 20)$ (Leonhardt et al., 2004).

At the fragment level, a mean intensity was retained only when:

- the difference between individual intensity values per fragment was less than 5\% after anisotropy correction;

- alteration measured by the difference between the two rapidly acquired TRMs during cooling rate experiments was less than 5\% (Hartmann et al., 2010, 2011);

- at least two independent intensities were obtained for each fragment.

At site level, a total mean was calculated by averaging results from at least three fragments and the standard deviation of the mean is less than 10\%."

From the nine new results, three of them were obtained from archaeological materials sampled from ruins of Guarani Jesuit Mission reductions, located at the triple border Brazil-Paraguay-Argentina (Poletti et al., 2016) and the remaining six come from the Pelotas city, Rio Grande do Sul, Brazil, from archaeological sites of jerky beef farms (Hartmann et al., Submitted). The compilation of these new results provided a new intensity curve of archaeointensity as a function of time for South Brazil, thus expanding 
in latitude the works of Hartmann et al. (2010 and 2011) in Northeast and Southeast Brazil.

The southern region of Brazil covers a strategic area and enables us to investigate the SAA evolution. The basic dynamics regarding SAA is that it started its influence in Africa and drifted westward while expanding in area, passing recently over South Brazil (e.g., Jackson et al., 2000; Hartmann and Pacca, 2009). With the new data, and in an unprecedented way, it was demonstrated that the relative increase of non-dipolar components of the field over South America started in $1800 \mathrm{CE}$, therefore suggesting that this is the age of the arrival of SAA in South Brazil.

Based on the high-quality archaeointensity data discussed here, I emphasize the importance of expanding the number of new archaeointensity data for the southern part of the South American continent, particularly for ages prior to $1600 \mathrm{CE}$. This is a promising way to understand the SAA evolution, as well as to bring new insights on the supposedly recurrent nature of this feature (Tarduno et al., 2015, Shaah et al., 2016). New data for different latitudes and longitudes close the southern portion of South America are also crucial for determining the geometry of this anomaly.

\subsection{The Earth's magnetic axial dipole evolution for the last millennia}

In Poletti et al. (2018) a careful analysis of all absolute magnetic intensity estimates derived from archaeological and geological records for the last two thousand years was carried out. To do it, we applied the list of selection criteria above-described (section 3.2.1), in order to retain only high-quality archaeointensity estimates. The main purpose of this analysis was to understand the evolution of the geomagnetic axial dipole for the last millennia.

As aforementioned (section 1.2. in Chapter 1), the main component of the Earth's magnetic field can be approximated by a geocentric and axial dipole. Its stability is balanced by the equilibrium of normal and reverse magnetic flux patches (Olson and Amit, 2006). When normal flux patches move to the poles and reverse patches move to the equator the geomagnetic dipole intensity increase and vice-versa (e.g., Olson and Amit, 2006). In this light, the analysis of geomagnetic field models (Gillet et al., 2013) and geodynamo models (e.g., Aubert et al., 2013) suggests an asymmetry in the advective sources of the field implying in the decrease of the Earth's magnetic dipole intensity in the last 185 years (Finlay et al., 2016). The growth of the SAA is a likely candidate to explain the asymmetry. 
Interestingly, the results presented by Poletti et al. (2018) indicated that the geomagnetic dipole is decaying since about $700 \mathrm{CE}$ and this decay can be described on a millennial scale as a constant trend (i.e., linear). Since the dipole decay trend described by the archaeointensity data is very similar to the mean trend observed from data recorded by observatories and satellites, it was suggested that the process responsible for the current fall in magnetic field intensity started more than 1,300 years ago. In other words, the break in the symmetry of advective sources, which balance the average intensity of the Earth's magnetic field, occurred more than 1000 years before previously thought. Finally, according to Amit et al. (2017) the time-scale for axial dipole secular variation is about 1000 years. Therefore, based on this order of magnitude, we speculate that the dipole will not necessarily continue to drop and therefore the present decay does not represent a sign of an imminent polarity reversal. 


\section{Appendix I}

Here are presented the highlights and supplementary material of each article related to the thesis. Based on recent policies of openness from several scientific journals, I decided to present the full peer-review of each article. I believe that the discussions that lead to the final version of the papers may be of some value to the scientific community. The peer-reviews are marked as follow: in blue the editor's announcements, in red the reviewers' comments (summary, questions, etc.) and in black my (and co-authors) responses.

The references of the four articles are:

i) Poletti, W., Hartmann, G.A., Hill, M.J., Biggin, A.J. and Trindade, R.I.F., 2013. The cooling-rate effect on microwave archeointensity estimates. Geophysical Research Letters, 40(15), 3847-3852.

ii) Poletti, W., Trindade, R.I.F., Hartmann, G.A., Damiani, N. and Rech, R.M., 2016. Archeomagnetism of Jesuit Missions in South Brazil (1657-1706 AD) and assessment of the South American database. Earth and Planetary Science Letters, 445, 36-47.

iii) Hartmann, G. A., Poletti, W., Trindade, R. I. F., Ferreira, L. M. and Sanches, P. New archeointensity data from South Brazil and the influence of the South Atlantic Anomaly in South America. Submitted.

iv) Poletti, W., Biggin, A.J., Trindade, R.I.F., Hartmann, G.A. and Terra-Nova, F., 2018. Continuous millennial decrease of the Earth's magnetic axial dipole. Physics of the Earth and Planetary Interiors, 274, 72-86. 


\section{A1. The cooling-rate effect on microwave archeointensity estimates}

\section{A1.1. Highlights extracted from Poletti et al. (2013)}

- Cooling-rate correction was successful applied on MW archeointensity datasets.

- TT and MW cooling-rate effects have similar physical behavior.

- Difference of cooling times is a significant source of bias on MW estimates.

\section{A1.2. Supplementary material of Poletti et al. (2013)}

Supplementary table A1.2.1: Archeointensity results for all fragments and specimens. Specimen: c represent the specimens used for MW cooling-rate corrections; Lab field direction: directions adopted in MW experiments, where $\mathrm{p}$ and ap represent the parallel and antiparallel applied laboratory fields, respectively; n: number of points used in the Arai diagrams; f, g, q: statistical parameters of acceptance determined by Coe et al. (1978); PI and PI_CR: archeointensity estimates of virgin and pTMRM imparted specimens, respectively; SE: standard error; fMW: MW cooling-rate correction factor; PIC: archeointensity corrected; PIF and SD: archeointensity results and standard deviation for each fragment after MW coolingrate correction, respectively; TT and TR represent the Thellier and Thellier (1959) and Triaxe (Le Goff and Gallet, 2004) methods previously applied for the studied fragments, respectively (extracted from Poletti et al., 2013).

\begin{tabular}{|c|c|c|c|c|c|c|c|c|c|c|c|c|c|c|}
\hline Fragment & Specimen & $\begin{array}{c}\text { Lab } \\
\text { field } \\
\text { direction }\end{array}$ & $\begin{array}{c}\text { Integral } \\
\text { min (W.s) }\end{array}$ & $\begin{array}{c}\text { Integral } \\
\max (\text { W.s) }\end{array}$ & $\mathbf{n}$ & f & g & $\mathbf{q}$ & $\begin{array}{c}\text { PI / } \\
\text { PI_CR } \\
(\mu \mathrm{T})\end{array}$ & $\begin{array}{l}\text { SD } \\
(\mu \mathrm{T})\end{array}$ & fMW & $\begin{array}{l}\text { PIC } \\
(\mu \mathrm{T})\end{array}$ & $\begin{array}{c}\mathbf{P I}_{\mathbf{F}} \\
(\boldsymbol{\mu} \mathbf{T})\end{array}$ & $\begin{array}{c}\text { SD } \\
(\mu \mathbf{T})\end{array}$ \\
\hline \multicolumn{15}{|c|}{ Museu de Arqueologia e Etnologia (MAE2) - (1557-1591 AD) - (1/1 fragments; 6/13 specimens) - (TT) } \\
\hline \multirow[t]{6}{*}{ MAE2-01 } & 1 & $\mathrm{p}$ & 49 & 138 & 10 & 0.55 & 0.88 & 35.8 & 38.4 & 0.5 & 0.81 & 31.2 & & \\
\hline & 2 & $\mathrm{p}$ & 32 & 83 & 7 & 0.4 & 0.82 & 16.2 & 40.0 & 0.8 & 0.81 & 32.5 & & \\
\hline & 3 & $\mathrm{p}$ & 22 & 151 & 7 & 0.76 & 0.77 & 15.2 & 36.9 & 1.4 & 0.81 & 30.0 & & \\
\hline & 4 & ap & 21 & 155 & 8 & 0.61 & 0.84 & 9.3 & 35.1 & 1.9 & 0.91 & 32.0 & & \\
\hline & c1 & $\mathrm{p}$ & 43 & 128 & 7 & 0.6 & 0.83 & 68.5 & 43.1 & 0.3 & & & & \\
\hline & c2 & ap & 52 & 137 & 8 & 0.48 & 0.85 & 14 & 38.4 & 1.1 & & & 31.4 & 1.1 \\
\hline \multicolumn{15}{|c|}{ Igreja Mem de Sá(IMS) - (1561-1591 AD) - (1/1 fragments; 6/19 specimens) - (TT-TR) } \\
\hline \multirow[t]{6}{*}{ IMS-04 } & 1 & $\mathrm{p}$ & 85 & 222 & 12 & 0.4 & 0.9 & 53.5 & 43.7 & 0.3 & 0.86 & 37.7 & & \\
\hline & 2 & $\mathrm{p}$ & 105 & 226 & 6 & 0.51 & 0.79 & 22 & 41.4 & 0.8 & 0.86 & 35.6 & & \\
\hline & 3 & $\mathrm{p}$ & 92 & 181 & 9 & 0.47 & 0.86 & 33.6 & 43.6 & 0.5 & 0.86 & 37.6 & & \\
\hline & 4 & ap & 97 & 252 & 7 & 0.61 & 0.82 & 8.4 & 44.5 & 2.7 & 0.86 & 38.1 & & \\
\hline & c1 & $\mathrm{p}$ & 46 & 180 & 9 & 0.54 & 0.87 & 65.4 & 40.6 & 0.3 & & & & \\
\hline & c2 & ap & 60 & 154 & 7 & 0.48 & 0.82 & 17.5 & 40.9 & 0.9 & & & 37.2 & 1.1 \\
\hline \multicolumn{15}{|c|}{ Praça da Sé 1 (SE1) - (1600-1650 AD) - (1/1 fragments; 3/8 specimens) - (TT-TR) } \\
\hline \multirow[t]{3}{*}{ SE1-193 } & 1 & ap & 70 & 200 & 9 & 0.52 & 0.87 & 15 & 47.4 & 1.4 & 0.88 & 41.5 & & \\
\hline & c1 & $\mathrm{p}$ & 38 & 119 & 10 & 0.55 & 0.88 & 67.8 & 42.0 & 0.3 & & & & \\
\hline & c2 & ap & 34 & 126 & 12 & 0.51 & 0.89 & 22.9 & 40.0 & 0.8 & & & & \\
\hline
\end{tabular}


Praça da Sé 2 (SE2) - (1650-1700 AD) - (1/2 fragments; 5/8 specimens) - (TR)

$\begin{array}{rllllllllllll}\text { SE2-19 } & 1 & \mathrm{p} & 65 & 160 & 8 & 0.4 & 0.83 & 23 & 45.5 & 0.7 & 0.94 & 42.9 \\ & 2 & \mathrm{p} & 59 & 154 & 8 & 0.5 & 0.86 & 55.5 & 43.8 & 0.3 & 0.94 & 41.3 \\ & 3 & \mathrm{ap} & 63 & 200 & 11 & 0.5 & 0.88 & 22.4 & 45.0 & 0.9 & 0.86 & 38.6 \\ & \mathrm{c} 1 & \mathrm{p} & 75 & 139 & 5 & 0.59 & 0.66 & 79.8 & 37.1 & 0.2 & & \\ \mathrm{c} 2 & \mathrm{ap} & 30 & 181 & 11 & 0.64 & 0.88 & 24.5 & 40.8 & 0.9 & & \end{array}$

$40.9 \quad 2.2$

Museu de Arte Sacra (MAS) - (1666-1686 AD) - (2/3 fragments; 10/17 specimens) - (TT-TR)

$\begin{array}{ccccccccccccc}\text { MAS-01 } & 1 & \mathrm{p} & 72 & 167 & 9 & 0.57 & 0.87 & 26.1 & 48.6 & 0.9 & 0.74 & 35.8 \\ & 2 & \mathrm{p} & 31 & 119 & 10 & 0.57 & 0.86 & 43.7 & 50.0 & 0.6 & 0.74 & 36.9 \\ & 3 & \mathrm{ap} & 38 & 132 & 9 & 0.68 & 0.86 & 12.1 & 50.1 & 2.5 & 0.73 & 36.5 \\ & \mathrm{c} 1 & \mathrm{p} & 31 & 87 & 6 & 0.48 & 0.78 & 25.6 & 47.5 & 0.7 & & \\ & \mathrm{c} 2 & \mathrm{ap} & 53 & 130 & 8 & 0.75 & 0.85 & 40.3 & 48.1 & 0.8 & & \\ \text { MAS-03 } & 1 & \mathrm{p} & 41 & 119 & 5 & 0.68 & 0.75 & 12.2 & 47.3 & 2.0 & 0.78 & 36.9 \\ & 2 & \mathrm{p} & 45 & 203 & 10 & 0.81 & 0.88 & 45.8 & 49.9 & 0.8 & 0.78 & 38.9 \\ & 3 & \mathrm{ap} & 44 & 125 & 8 & 0.6 & 0.81 & 27.6 & 47.3 & 0.8 & 0.76 & 36.0 \\ & \mathrm{c} 1 & \mathrm{p} & 40 & 123 & 9 & 0.74 & 0.87 & 72.1 & 44.9 & 0.4 & & \end{array}$

$36.4 \quad 0.5$

$37.2 \quad 1.5$

Casa do Pelourinho 27 (CP27) - (1675-1725 AD) - (2/4 fragments; $11 / 17$ specimens) - (TR)

$\begin{array}{ccccccccccccc}\mathrm{CP} 27-04 & 1 & \mathrm{p} & 31 & 187 & 10 & 0.75 & 0.88 & 50.7 & 39.9 & 0.5 & 0.81 & 32.3 \\ & 2 & \mathrm{p} & 30 & 225 & 12 & 0.68 & 0.91 & 25.2 & 39.6 & 1.0 & 0.81 & 32.1 \\ & 3 & \mathrm{p} & 44 & 214 & 12 & 0.75 & 0.89 & 32.7 & 40.6 & 0.8 & 0.81 & 32.9 \\ & 4 & \mathrm{ap} & 60 & 221 & 10 & 0.66 & 0.88 & 30.6 & 38.9 & 0.7 & 0.81 & 31.5 \\ \mathrm{CP} 27-09 & \mathrm{c} 1 & \mathrm{p} & 30 & 69 & 6 & 0.44 & 0.78 & 28.7 & 43.2 & 0.5 & & \\ & \mathrm{c} 2 & \mathrm{ap} & 29 & 171 & 14 & 0.83 & 0.9 & 28.2 & 43.2 & 1.2 & & \\ & 1 & \mathrm{p} & 34 & 140 & 12 & 0.76 & 0.9 & 54.2 & 49.7 & 0.6 & 0.74 & 36.9 \\ & 2 & \mathrm{p} & 34 & 120 & 9 & 0.53 & 0.86 & 28.6 & 50.2 & 0.8 & 0.74 & 37.3 \\ & 3 & \mathrm{ap} & 34 & 113 & 11 & 0.58 & 0.88 & 17.2 & 47.9 & 1.4 & 0.81 & 38.7 \\ & \mathrm{c} 1 & \mathrm{p} & 32 & 98 & 8 & 0.43 & 0.81 & 46 & 47.1 & 0.4 & & \end{array}$

$32.2 \quad 0.6$

$37.6 \quad 1.0$

Corpo de Bombeiros (CB) - (1767-1777 AD) - (1/2 fragments; 6/6 specimens) - (TR)

$\begin{array}{ccccccccccccc}\text { CB-02 } & 1 & \mathrm{p} & 28 & 116 & 11 & 0.77 & 0.88 & 299.4 & 43.8 & 0.1 & 0.76 & 33.3 \\ & 2 & \mathrm{p} & 15 & 88 & 8 & 0.75 & 0.84 & 29.2 & 41.1 & 0.9 & 0.76 & 31.3 \\ & 3 & \text { ap } & 33 & 142 & 12 & 0.77 & 0.89 & 23.1 & 42.3 & 1.2 & 0.78 & 33.0 \\ & & \text { ap } & 16 & 267 & 11 & 0.75 & 0.88 & 58.6 & 39.5 & 0.5 & 0.78 & 30.8 \\ \text { c1 } & \text { p } & 15 & 81 & 8 & 0.77 & 0.85 & 37 & 46.1 & 0.8 & & \\ \text { c2 } & \text { ap } & 16 & 105 & 11 & 0.59 & 0.89 & 39.1 & 44.8 & 0.6 & \end{array}$

$32.1 \quad 1.2$

Solar Conde dos Arcos (SCA) - (1780-1781 AD) - (2/4 fragments; 9/14 specimens) - (TT)

$\begin{array}{lllllllllllll}\text { SCA-07 } & 1 & \mathrm{p} & 85 & 249 & 9 & 0.5 & 0.86 & 22.9 & 39.2 & 0.7 & & \\ & 2 & \mathrm{p} & 75 & 237 & 10 & 0.51 & 0.87 & 17 & 39.8 & 1.0 & & \\ & 3 & \text { ap } & 71 & 250 & 10 & 0.55 & 0.88 & 14.2 & 38.6 & 1.3 & 0.99 & 38.0 \\ & \text { c2 } & \text { ap } & 78 & 150 & 5 & 0.41 & 0.73 & 6.1 & 35.5 & 1.7 & & \end{array}$




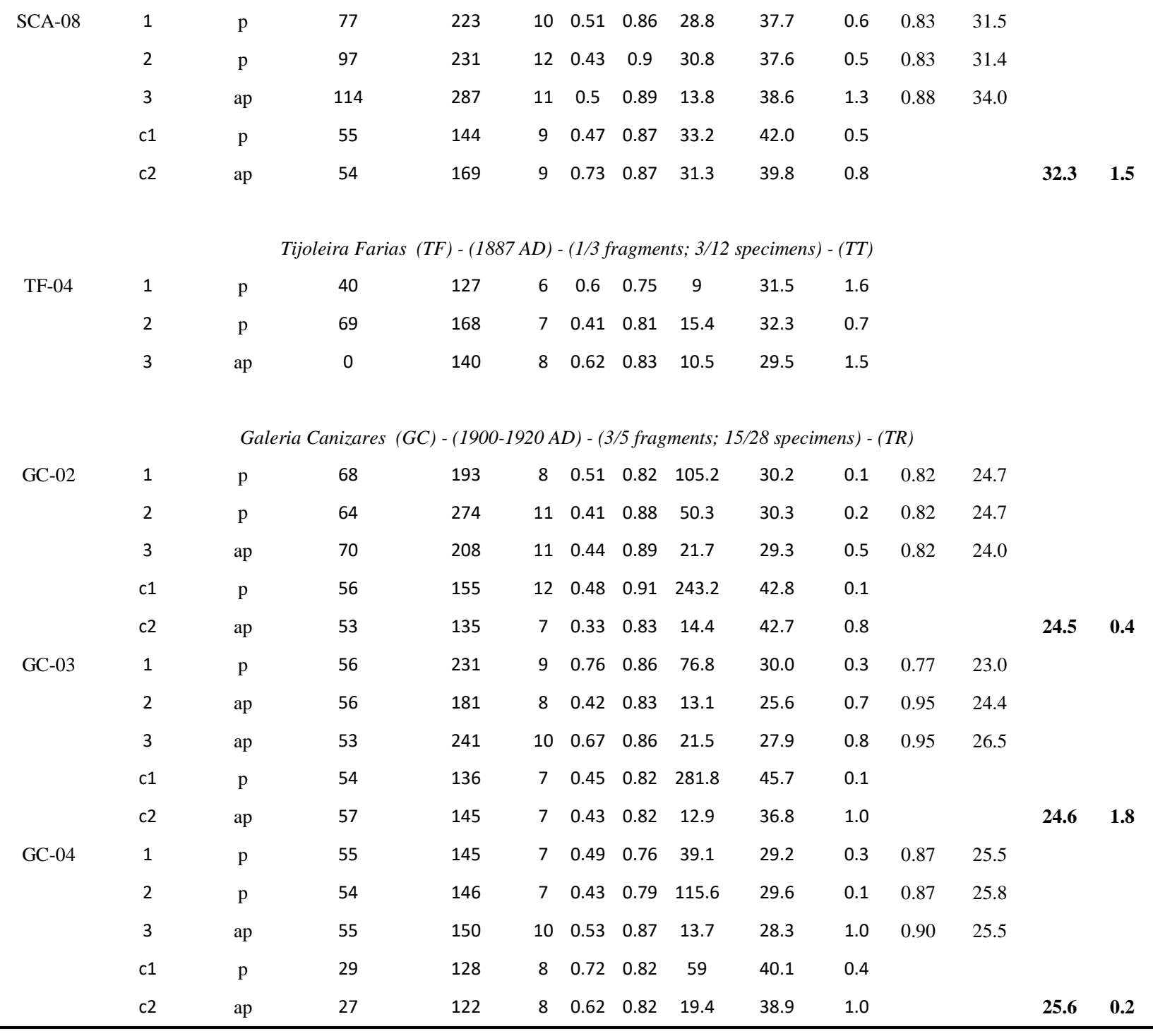

Supplementary table A1.2.2: Selection criteria for MW archeointensity estimates (extracted from Poletti et al., 2013).

1. Vector analysis

2. Arai diagram - ZI protocol

3. Checks

4. Fragment average
An intensity value must have been obtained along the same power-integral interval in which the characteristic magnetic component was isolated (with a $\mathrm{MAD} \leq 10^{\circ}$ ).

Used a minimum of four temperature steps including at least $40 \%$ of the total NRM ( $\mathrm{f} \geq 0.4)$.

Standard errors of the slope below $6 \%$ of the mean $(\beta \leq 0.06)$ (Selkin and Tauxe, 2000).

pTMRM checks and pTMRM tail checks were set at $10 \%$ of original NRM for each temperature step.

A minimum of 2 specimens per fragment was considered to compute an intensity average.

Standard deviation of all estimations were less than $8 \%$ of the mean: this corresponds to a $95 \%$ probability of true deviations of less than $15 \%$ for $n=2$ and above (Paterson et al., 2010). 
Supplementary table A1.2.3: Archeointensity results from SW Pacific Islands pottery and NE Brazilian bricks. MW and TT data from SW Pacific Islands (Stark et al., 2010), TT data from NE Brazilian bricks (Hartmann et al., 2010) and MW data from this study corrected by MW cooling-rate factors obtained from Equation 1. TT - fCR: cooling-rate correction factors for TT data; TT PIcorrected: results after coolingrate correction for TT data; MW PIuncorrected: results before cooling-rate correction for MW data; MW fCR $($ CTlab = $5 \mathrm{~s})$ and MW - fCR $($ CTlab = $90 \mathrm{~s})$ : cooling-rate correction factors for cooling times of $5 \mathrm{~s}$ and 90 s, respectively; (a) MW PIcorrected and (b) MW PIcorrected: results after cooling-rate corrections for MW data, using cooling times of $5 \mathrm{~s}$ and $90 \mathrm{~s}$, respectively (extracted from Poletti et al., 2013).

\begin{tabular}{|c|c|c|c|c|c|c|c|}
\hline Fragment & $\begin{array}{l}\text { TT - } \\
\text { fCR }\end{array}$ & $\begin{array}{l}\text { TT } \\
\text { PIcorrected } \\
(\mu \mathrm{T})\end{array}$ & $\begin{array}{l}\text { MW } \\
\text { Pluncorrected } \\
(\mu \mathrm{T})\end{array}$ & $\begin{array}{l}\text { MW - fCR } \\
(\mathrm{CTlab}= \\
5 \mathrm{~s})\end{array}$ & $\begin{array}{l}\text { (a) MW } \\
\text { PIcorrected } \\
(\mu \mathrm{T})\end{array}$ & $\begin{array}{l}\text { MW - fCR } \\
(\mathrm{CTlab}= \\
90 \mathrm{~s})\end{array}$ & $\begin{array}{l}\text { (b) MW } \\
\text { PIcorrected } \\
(\mu \mathrm{T})\end{array}$ \\
\hline \multicolumn{8}{|c|}{ SW Pacific data (MW and TT data from Stark et al., 2010) } \\
\hline Y294 & 0.98 & 45.5 & 44.8 & 0.95 & 42.6 & 0.97 & 43.6 \\
\hline F225-4 & 0.94 & 46.4 & 51.1 & 0.86 & 44.0 & 0.92 & 47.2 \\
\hline $\mathrm{F} 225-3$ & 0.97 & 25.4 & 25.9 & 0.93 & 24.0 & 0.96 & 24.9 \\
\hline F930-4 & 0.91 & 49.4 & 56.5 & 0.80 & 45.1 & 0.89 & 50.1 \\
\hline F150-3 & 0.98 & 42.1 & 45.9 & 0.95 & 43.6 & 0.97 & 44.7 \\
\hline V044 & 0.92 & 48.2 & 54.4 & 0.82 & 44.5 & 0.90 & 48.9 \\
\hline V060 & 0.91 & 32.0 & 34.1 & 0.80 & 27.2 & 0.89 & 30.2 \\
\hline \multicolumn{8}{|c|}{ NE Brazil data (TT data from Hartmann et al., 2010) } \\
\hline MAS-01 & 0.86 & 38.0 & 49.6 & 0.70 & 34.9 & 0.77 & 38.1 \\
\hline MAS-03 & 0.91 & 37.1 & 48.2 & 0.80 & 38.3 & 0.84 & 40.7 \\
\hline IMS-04 & 0.96 & 36.2 & 43.3 & 0.90 & 39.1 & 0.93 & 40.2 \\
\hline $\begin{array}{l}\text { MAE2- } \\
01\end{array}$ & 0.92 & 33.0 & 37.6 & 0.82 & 30.7 & 0.86 & 32.4 \\
\hline TF-04 & 0.90 & 23.6 & 31.1 & 0.78 & 24.1 & 0.83 & 25.8 \\
\hline SCA-07 & 0.92 & 32.6 & 39.2 & 0.82 & 32.0 & 0.86 & 33.7 \\
\hline SCA-08 & 0.93 & 31.7 & 38.0 & 0.84 & 31.8 & 0.88 & 33.3 \\
\hline
\end{tabular}

\section{A1.3. Peer-review of Poletti et al. (2013)}

First (and only) round of revisions:

Dear Dr. Poletti:

Thank you for the manuscript submission entitled "The cooling-rate effect on microwave archeointensity estimates" [Paper \#2013GL056766] to Geophysical Research Letters. I have now received 2 reviews of the manuscript, which are attached for your reference. Based on the review comments, the manuscript may be suitable for publication after revisions.

Sincerely, 
Michael Wysession

Editor

Geophysical Research Letters

\section{Reviewer \#1}

GRL-2013GL056766-review 2013

The important merit of the MS is that it is based on the palaeointensity data from a region up to now poorly covered with data. Going further in the past epochs and adding the sizable palaeointensity dataset from South America and other regions of Western hemisphere of the Globe is an urgent task for improving the geomagnetic field models. The comparison between MW estimations with the classical double heating and the comparatively new TR method on the sister specimens is a valuable approach for obtaining the reasonable conclusions. The manuscript could be published in GRL elucidating an interesting methodological problem in archaeomagnetism when MW technique is applied. It seems to me that some minor corrections should help:

\section{The Abstract:}

1. The first sentence (lines 12 and 13). The phrase after the semicolon should be excluded or to be as: the same relates to the previously reported values for pottery from Southwestern Pacific islands.

Response: We followed Reviewer's suggestion. The sentence (lines 11-13) now reads: "New microwave (MW) paleointensity data on historical bricks from Northeast Brazil presented a bias towards higher fields when compared to previous corrected doubleheating paleointensity estimates; the same relates to the previously reported values for pottery from Southwestern Pacific islands."

\section{The Text:}

2. Line 60 . Some way should be found to reconcile $\triangle T R M$ with PI estimation. $\triangle T R M$ is defined as a fraction of PI value. It is so implicitly but the reader can be perplexed.

Response: According to the Equation 1, the $\triangle \mathrm{TRM}$ is the TRM fraction under- or overestimated in double-heating paleointensity experiments. The text was changed to make this more clear.

3. Line 163. The end - "and" useless. 
The sentence (lines 164-165) now reads: "Fragment SE2-19 presents very stable thermal Response: demagnetization behavior (Figure 1a)."

4. Lines 178-179. Wouldn't be better instead of "MW-correction" to be specified: "MWCR correction".

Response: Following the suggestion of Reviewer \#1, the sentence (lines 179-181) now reads: "For both collections, this simple theoretical MW cooling-rate correction produces a better agreement between TT and MW data (Supplementary table 3).”

\section{Figure captions:}

5. Line 339. the end - \{plus minus $8 \%$ (b and c) of what?? Perhaps it should be: \{plus minus $35 \%$ (a) and \{plus minus $3 \%$ (b and c) deviations.

Response: We modified the sentence according to suggestion of Reviewer \#1. The sentence (lines 339-341) now reads: "Dashed lines indicate the area within $\pm 12 \%$ (a) and $\pm 25 \%$ (b and c) and light gray area indicates the area within $\pm 5 \%$ (a) and $\pm 8 \%$ (b and c) deviations."

6. Also the associated bars to the experimental results are not defined (SE or SD) presumably they should be SD concerning the fragments but it has to be noticed.

Response: We included the information in figure caption (lines 338-339): "Standard deviations were determined for each fragment (red and blue bars)."

7. Lines 343 and 345 . The above mentioned remark about $\Delta \mathrm{TRM}$ and $\Delta \mathrm{PI}$ ?

Response: Please, see the answer to comment \#2.

\section{Figures}

8. Figure 2. If possible Labels to be: a) MW-TT before CR corr.of MW MW-TT after CR corr.of MW; b) as in a); c) MW-TT before CR corr.of MW; MW-TR before CR corr.of MW; MW-TT after CR corr.of MW; MW-TR after CR corr.of MW

Response: Due to lack of space and the required format of GRL, we decided to change just the Figure 2 caption. 


\section{Reviewer \#2}

Review of 'The cooling rate effect on microwave archeointensity estimates'

By Polettti, Hartmann, Hill, Biggin, and Trindade

Submitted for publication in Geophysical Research Letters

\section{General}

In this interesting contribution bias between classical double heating paleointensity results and results obtained with the microwave technique is attributed to differences in cooling rate. By developing an experiment-based empirical cooling-rate correction the bias is largely resolved and much more coherent and robust paleointensity data are obtained, of crucial value for model-based descriptions of geomagnetic field behavior. The manuscript is well written and I recommend publication after minor revision considering the points raised in my review. It should be emphasized more that the cooling rate correction pertains to bricks and other baked archeological materials and not per se to PSD and MD extrusive rocks for which cooling rate effects are marginal, if present at all, as recent work by one of the co-authors has shown.

Best regards,

Mark J. Dekkers.

\section{Specific}

\section{Abstract}

9. Line 13-15. Apparently, the classical thermal techniques are not biased by cooling rate effects. Is this because cooling rates in the natural situation (here baking the bricks) and the paleointensity experiment are similar? Or was a correction applied to them as well? It is probably wise to be explicit here.

Response: The cooling rate correction was applied in the previous classical doubleheating archeointensity estimates by Hartmann et al. (2010) and Stark et al. (2010). This was clarified in the sentence lines 11-13.

10. Line 17-19. This is probably correct but not discussed that specifically in the material. As such it may not be a direct outcome of the present work. 
Response: We have followed the observation above and rewritten the sentence (lines 1719): "Our results indicate similar experimental behavior between microwave and thermal procedures despite the different ways in which the energy is transferred into the spin system (electromagnetic and lattice vibrations)."

11. Line 19-21. Some of the cooling rates estimated seem extremely short. Can a sample that is $\sim 200$ \{degree sign $\} \mathrm{C}$ after the final microwave step (more than the $15 \mathrm{~W}$ for $3 \mathrm{~s}$ in the diagram of Suttie et al. (2010)) conductively cool to room temperature in less than a second?

Response: Theoretically, only the ferriressonant minerals are directly excited by microwaves, which implies that thermal effects are neglected. Experimentally, microwave absorption rates dictates some thermal effects in the samples around the ferriressonant minerals, which could be associated to different cooling times for the different samples. The very short cooling times observed in our samples, some of less than a second (see fragments IMS-04 and MAS-03, Figure 3) are in the same range as those observed by other authors (e.g. Walton and Boehnel, 2008).

\section{Introduction}

12. Line 30. I know the underlying manuscript is not a review but I would certainly also refer to the IZZI protocol that is often used in classic Thellier-style paleointensity experiments.

Response: We followed the suggestion above and included a reference to the IZZI protocol (lines 31 and 323-324).

13. Line 45. Is the claimed cooling rate independence in the Triaxe protocol for bricks (make clear that the independence claim pertains to bricks) because the bricks happen to have experienced very similar cooling rate during their making as in the paleointensity experiment? Or is this a consequence of the grain assemblage processed? PSD lavas do not show a cooling rate dependence while SD material does.

Response: The Triaxe protocol for archeological baked clay materials (potteries, bricks, ceramics, tiles, etc.) takes into account the cooling-rate correction, independently of the SD or PSD state.

Experimental tests on samples with different cooling-rates have shown that the Triaxe method is immune to the cooling-rate effects (see Le Goff and Gallet, 2004). The 
reason why it is so remains unknown. We have better specified the information about the material in the sentence (lines 46-49): "The Triaxe provides fast paleointensity estimates ( 2.5 hours per sample) and seems to be unaffected by cooling-rate effects on archeological baked clay materials (Le Goff and Gallet, 2004), but the sensitivity of the vibrating sample system limits its application to strongly magnetized samples $\left(>10^{-2}\right.$ $\mathrm{A} / \mathrm{m}) . ”$

14. Line 47. Start a new paragraph before 'In the MW method..'

Response: Done.

15. Line 69. Cooling rate independence because of similar 'natural' and paleointensity experimental coolings? Or because of PSD particles being processed? See also earlier comment. Typo: 'the' cooling-rate $=$ a cooling-rate (there are several options for this correction?)

Response: We followed the suggestion of the reviewer and corrected the sentence (lines 71-74): "In the TR method, paleointensity experiments using different cooling times (25 ${ }^{\circ} \mathrm{C} / \mathrm{min}, 6^{\circ} \mathrm{C} / \mathrm{min}, 2{ }^{\circ} \mathrm{C} / \mathrm{min}$ ) gave similar intensity results suggesting that a cooling-rate correction is unnecessary on archeological baked clay materials (Le Goff and Gallet, 2004; Gallet and Le Goff, 2006)."

\section{Materials and methods}

16. What are typical signal-to-noise ratios in the sample collection processed? Samples are small.

Response: Fragments of collection are very heterogeneous in terms of their natural remanence. We have measured only specimens with magnetization $>15 \mu \mathrm{A} / \mathrm{m}$ (see line 152). The sensitivity of the Tristan SQUID magnetometer is $10^{\wedge}-12$ Am2.

17. Line 115 (also line 151). 'Magnetic alteration' may be unfortunate terminology here. This may be to some degree my own bias. In the sense used as in De Groot et al. (2012 PEPI) it implies subtle magnetic changes (visualized by ARM acquisition curves) in the absence of thermochemical alteration, inferred to be transdomain changes during PTRM acquisition (see also De Groot et al., 2013 GJI). Failure of pTRM checks is often interpreted to indicate thermochemical alteration, pTRM tail checks as indicating MD behavior. OK, in microwave experiments bulk rock is not really heated but the 
titanomagnetite particles themselves? See also the mention of melt spots in the specimens (line 153). Consider rewording.

Response: In fact, for low microwave power bulk specimens are not really heated, but for high microwave power bulk specimens can be heated. Consequently, we can observe mineralogical magnetic alteration in some specimens (visual alteration, as melt spots).

Thanks to reviewer's observations, we have corrected the text:

Lines 119-122: "Magnetic mineralogical alteration was monitored through additional steps of microwave partial remanence ( $\left.\mathrm{pT}_{\mathrm{M}} \mathrm{RM}\right)$ checks $(\mathrm{Coe}, 1978)$ after every two steps. Multidomain bias was determined by applying the $\mathrm{pT}_{\mathrm{M}} \mathrm{RM}$ tail checks (Riisager and Riisager, 2001), also after every two steps."

Line 156: "Magnetic mineralogical alteration was mainly detected after very unstable microwave absorption, which can be attested by the growth of melt spots in the specimens after stepwise measurements."

18. Line 117. What do you infer with 'domain state bias'? The bricks have SD and small PSD magnetic particles?

Response: Domain-state bias is associated with MD-grains influences. We have better referenced the information about it in the sentence (lines 122-125): "In addition, domain state bias was evaluated by applying parallel and antiparallel laboratory fields for at least one specimen per fragment. Following insights from modeling and experiments, if parallel and antiparallel estimates yield the same intensity within error, MD bias is likely to be small (Biggin, 2006; 2010)."

Brazilian bricks have SD and small PSD magnetic particles. Hartmann et al. (2010) determined the magnetic mineralogy in those bricks. The MD state bias (when observed) was minimized by applying the $\mathrm{pT}_{\mathrm{M}} \mathrm{RM}$ tail checks in the brick fragments.

19. Line 126-127. Two questions: 1) is the TRM imparted indeed a full TRM? 480 degree sign $\} \mathrm{C}$ (typo?) is distinctly lower than $580\{$ degree $\operatorname{sign}\} \mathrm{C}$, the ordering temperature of pure magnetite. 2) Did you check for alteration as a consequence of the TRM acquisition? See also line 169.

Response: (1) We have better specified the information about the unblocking temperatures of the bricks in the sentence (lines 101-103): "Unblocking temperatures varied between $200{ }^{\circ} \mathrm{C}$ and $475{ }^{\circ} \mathrm{C}$ for most samples except for fragment MAE2-01 for 
which the maximum unblocking temperature reaches $550{ }^{\circ} \mathrm{C}$." See also Hartmann et al. (2010).

(2) We used the same fragments from Hartmann et al. (2010), which have checked for magnetic alterations. In this work, we check alterations with $\mathrm{pT}_{\mathrm{M}} \mathrm{RM}$ checks during paleointensity experiments.

20. Line 140. "a)" Equation 4 is adding the specimens' intensities and dividing by their number? "b)"No mass weighing is included, useful to do? "c)" How many specimens are considered a minimum for accepting the fragment? "d)"You can calculate the standard deviation per fragment (done in supplementary table 1) and use that as a quality criterion?

Response: a) Equation 4 adds the individual intensities (at specimen level) and divides per number of specimens at fragment level (acronym $m$ in the Equation 4). The sentence (line 146) now reads: "where m represents the number of MW paleointensity results".

b) The results are normalized by the volume (total magnetization). This measurement is a default of microwave system implemented at Geomagnetism Laboratory of University of Liverpool.

c) A minimum of 2 specimens per fragment was considered to compute an intensity average. We added this information in Supplementary table 2.

d) We used the standard deviation as a selection criterion. This information is in Supplementary Table 2: "Standard deviation of all estimations were less than $8 \%$ of the mean: this corresponds to a $95 \%$ probability of true deviations of less than $15 \%$ for $n=2$ and above (Paterson et al., 2010).”

21. Line 141-143. This is rapidly developed. “a)" Was there a difference? "b)"Is this 5\% and $1.5 \%$ mentioned in line 154 and 156 respectively? "c)"I feel that grain size effects may play a role, what is the dominant magnetic grain size?

Response: (a) and (b). The difference mentioned in the lines 141-143 is not the same difference in the lines 154-156. In the lines 141-143, we explain the procedure adopted to correct the paleointensity estimates by applying parallel or antiparallel laboratory fields. An intensity average at fragment level was corrected to their respective coolingrate correction factors determined from parallel or antiparallel applied fields (see Supplementary Table 1). In the lines 154-156, the differences are related to the maximum discrepancies of the $\mathrm{pT}_{\mathrm{M}} \mathrm{RM}$ tail checks when the applied field was parallel (maximum 
discrepancies of $\sim 1,5 \%$ ) or antiparallel (maximum discrepancies of $\sim 5 \%$ ). See explanation of the question 18.

(c) According to the previous archeointensity results (Hartmann et al., 2010) and the new MW results, we do not observe the grain size effects due to MD state bias. Our fragment collection exhibit SD and small PSD grains.

\section{Results and conclusions}

22. Line 156-160. This is a complicated sentence. What do you wish to convey?

Response: We rewrite the sentence to clarify the intensity averages computation at fragment level. The sentence is now: "At fragment level, intensity averages cooling-rate corrected are within $2 \%$ when compared with the global average (product between cooling-rate factors average and PI results average, both determined with parallel and antiparallel laboratory fields).”

\section{Line 163. Typo. Take out 'and' after 'behavior'}

\section{Response: Done.}

24. Line 195. Cooling times of $10^{\wedge}-1$ and $10^{\wedge}-2$ second seem to me unrealistically short. No thermochemical changes as a consequence of TRM acquisition? Also line 196-197.

Response: Please, see explanation of the question 11.

\section{Conclusions, acknowledgements, references, captions}

25. Line 206. There is no mention being made earlier on here of that decay in intensity.

Response: We rewrite the sentence (lines (229-230): “Together they confirm the previous archeointensity results for Northeast Brazil presented by Hartmann et al. (2010) and improve the estimates presented by Stark et al. (2010)."

26. Line 209. It may not be that clear what is implied with possible differences between TT and TR. This aspect is slightly subdued in the main text. That different methods agree to within $8 \%$ (line 213) is a good argument for taking the grand average as robust.

Response: The sentence has been rewritten: "By comparing TT and TR with MW methods we show that the cooling-rate effect could significantly affect MW paleointensity estimates in baked clay materials by up to $25 \%$." 
27. Line 220. Typos: take out 'to' after 'acknowledges' (2x).

\section{Response: Done.}

28. Line 234. Dekkers M.J. rather than Dekkers M.

\section{Response: Done.}

29. Line 237. That paper has meanwhile appeared Geophys. J. Int., 193, 1239-1249. doi: $10.1093 / \mathrm{gji} / \mathrm{ggt078}$

\section{Response: Done.}

30. Line 242. Typo: 18 th is with 'th' in superscript.

Response: In the original title, 18th is not in superscript.

31. Line 313. Typo 'magnetiqué' = 'magnétique'

Response: Done.

32. Line 343. Typos. Insert spaces between CTnatural $=25 \mathrm{~h}$; CTlaboratory $=30 \mathrm{~min} ?$

Response: Done.

33. Figure 1a. Is there a reason for the reversing(?) direction in the Arai plot? No TT or TR thermal plot for the MAS-03 specimens in 1c and 1d?

Response: No. There is no reversing direction in "orthogonal" plot.

The objective of the Figure 1 was to emphasize MW results because TT and TR results were previously presented by Hartmann et al. (2010).

34. Supplementary table 1. Explain terminology and acronyms in a caption.

Response: The terminology and acronyms are presented in the electronic version of the manuscript.

35. Supplementary table 2. Typo in Selkin et al. reference: "eject" = "effect"

Response: Done.

36. Supplementary table 3. Explain acronyms in a caption. 
Response: The terminology and acronyms are presented in the electronic version of the manuscript.

\section{$\underline{\text { Decision }}$}

Dear Dr. Poletti:

I am pleased to accept "The cooling-rate effect on microwave archeointensity estimates" (2013GL056766R) for publication in Geophysical Research Letters. Thank you for your revisions.

Sincerely,

Michael Wysession

Editor

Geophysical Research Letters 
A2. Archeomagnetism of Jesuit Missions in South Brazil (1657-1706 AD) and assessment of the South American database

\section{A2.1. Highlights extracted from Poletti et al. (2016)}

- Three high-quality archeointensity data are presented for South America.

- The South American database is reassessed to retain only high-quality entries.

- The filtered results are coherent and define a well-behaved evolution of the field.

- We prove the 6-specimen average technique does not correct for anisotropy effects.

\section{A2.2. Supplementary material of Poletti et al. (2016)}

Supplementary table A2.2.1: Comparison between archeointensity data acquired at Laboratorio de Paleomagnetismo, Universidade de São Paulo and previous archeointensity estimates by Hartmann et al. (2010, 2011) and Poletti et al. (2013) obtained respectively at IPGP (France) and University of Liverpool (UK) (extracted from Poletti et al., 2016).

Table (a) shows a comparison of archeointensity results before and after anisotropy correction.

\begin{tabular}{ccccc}
\hline & \multicolumn{2}{c}{ This study } & & Hartmann et al. $(2010 ; 2011)$ \\
\cline { 2 - 3 } Fragment & $\begin{array}{c}\text { Paleointensity }(\mu \mathrm{T}) \\
\text { uncorrected }\end{array}$ & $\begin{array}{c}\text { Paleointensity }(\mu \mathrm{T}) \\
\text { anisotropy corrected }\end{array}$ & & $\begin{array}{c}\text { Paleointensity }(\mu \mathrm{T}) \\
\text { anisotropy corrected }\end{array}$ \\
\hline MAS-01 & $37.1 \pm 0.5$ & $43.6 \pm 0.4$ & $44.2 \pm 0.3$ \\
MAS-03 & $42.1 \pm 2.7$ & $42.2 \pm 0.6$ & $40.8 \pm 0.1$ \\
MAS-04 & $41.7 \pm 5.0$ & $42.3 \pm 0.9$ & $42.5 \pm 0.1$ \\
FF2-02 & $30.4 \pm 5.6$ & $30.5 \pm 1.6$ & $31.6 \pm 0.4$ \\
FF3-02 & $43.2 \pm 1.2$ & $37.8 \pm 0.5$ & $37.6 \pm 0.4$ \\
FF3-04 & $36.0 \pm 0.5$ & $37.2 \pm 0.8$ & & $36.1 \pm 1.3$ \\
\hline
\end{tabular}

Table (b) shows a comparison of archeointensity results before and after cooling-rate correction.

\begin{tabular}{|c|c|c|c|c|}
\hline \multirow[b]{3}{*}{ Fragment } & \multicolumn{2}{|c|}{ This study } & \multirow{3}{*}{$\begin{array}{c}\text { Hartmann et al. (2010) } \\
\text { Paleointensity }(\mu \mathrm{T}) \\
\text { cooling rate corrected }\end{array}$} & \multirow{3}{*}{$\begin{array}{c}\text { Poletti et al. (2013) } \\
\text { Paleointensity }(\mu \mathrm{T}) \\
\text { cooling rate corrected }\end{array}$} \\
\hline & Paleointensity $(\mu \mathrm{T})$ & Paleointensity $(\mu \mathrm{T})$ & & \\
\hline & uncorrected & cooling rate corrected & & \\
\hline CP27-04 & $37.9 \pm 3.0$ & $34.4 \pm 0.3$ & $34.2 \pm 0.7$ & $32.2 \pm 0.6$ \\
\hline MAS-04 & $41.7 \pm 5.0$ & $37.3 \pm 0.8$ & $38.2 \pm 0.1$ & - \\
\hline SE2-19 & $44.0 \pm 1.9$ & $38.8 \pm 0.4$ & $37.4 \pm 1.3$ & $40.9 \pm 2.2$ \\
\hline
\end{tabular}



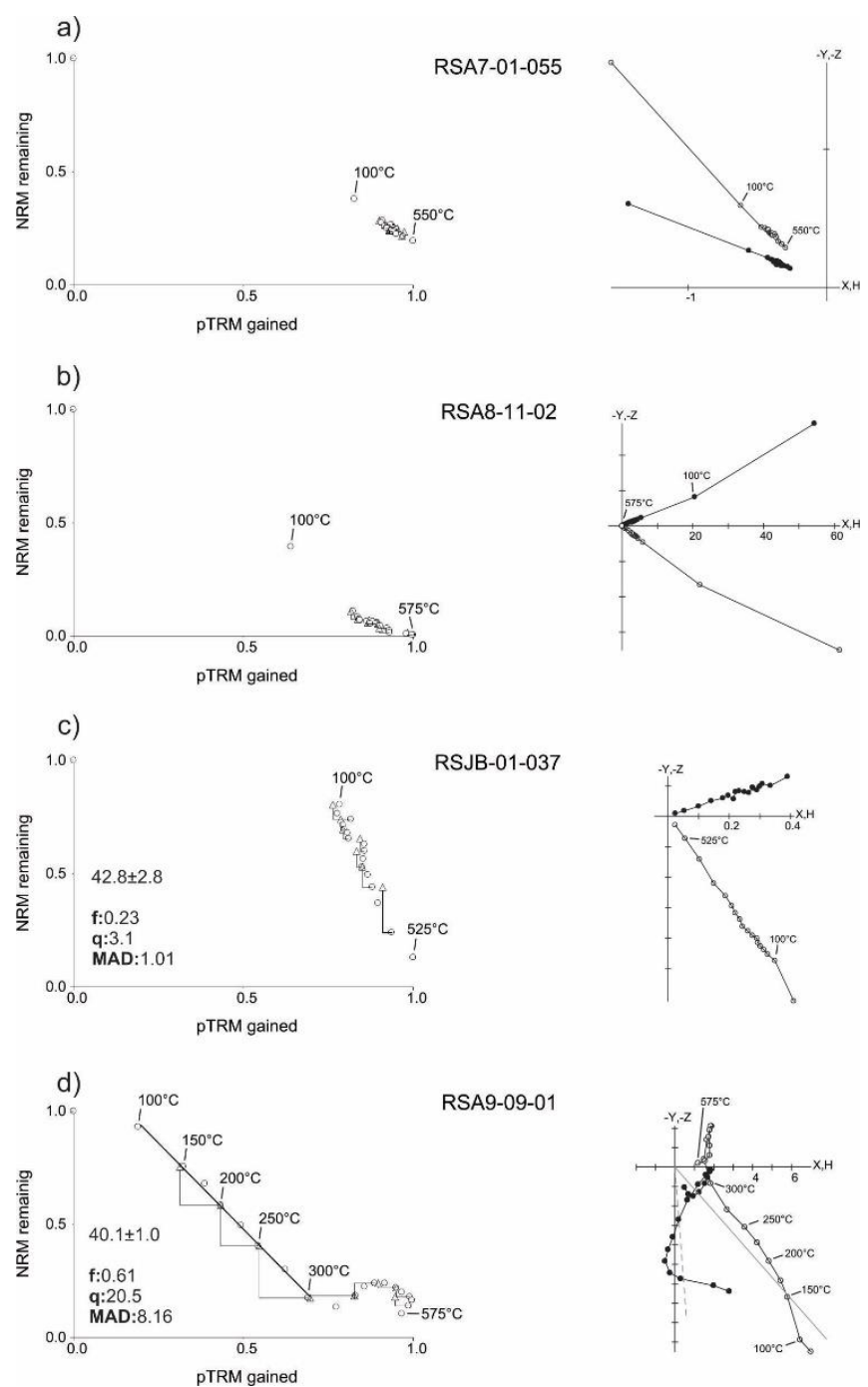

Supplementary figure A2.2.1: Arai diagrams for specimens that were not retained. In Arai diagrams circles represent NRM remaining against pTRM gained and triangles show pTRM checks performed every two temperature steps. In the orthogonal diagrams, black and gray circles indicate vector end points projected onto horizontal and vertical planes, respectively (arbitrary specimen coordinate system). Statistical parameters are provided for (c) and (d) (extracted from Poletti et al., 2016).

Supplementary table A2.2.2 (in Excel format): Complete dataset for all specimens.

Supplementary table A2.2.3: Archeointensities recalculated from Goguitchaichvili et al. (2011, 2015) (extracted from Poletti et al., 2016).

\begin{tabular}{|c|c|c|c|c|c|c|c|c|}
\hline Fragment & $\begin{array}{l}\text { Intensity } \\
(\mu \mathrm{T})\end{array}$ & Error & $\begin{array}{l}\% \\
\text { s.d. }\end{array}$ & $\begin{array}{l}\text { VADM } \\
\left(\mathbf{x 1 0}^{22}\right. \\
\left.\mathbf{A m}^{2}\right) \\
\end{array}$ & Error & $\begin{array}{l}\text { Age } \\
\text { (AD) }\end{array}$ & Error & $\begin{array}{l}\text { Approved } \\
\text { by the } \\
\text { criteria? }\end{array}$ \\
\hline \multicolumn{9}{|c|}{ Goguitchaichvili et al. (2011) } \\
\hline E1-2 & 45,5 & 2,7 & 5,9 & $\mathrm{x}$ & $\mathrm{x}$ & 1460 & 70 & no \\
\hline E1-3 & 49,6 & 3,7 & 7,4 & $\mathrm{x}$ & $\mathrm{x}$ & 1390 & 70 & no \\
\hline E1-4 & 42,3 & 5,1 & 12,2 & $\mathrm{x}$ & $\mathrm{x}$ & 1320 & 40 & no \\
\hline E1-6 & 50,4 & 7,4 & 14,7 & $\mathrm{x}$ & $\mathrm{x}$ & 1380 & 60 & no \\
\hline E1-7 & 64,3 & 9,7 & 15,1 & $\mathrm{x}$ & $\mathrm{x}$ & 1640 & 60 & no \\
\hline
\end{tabular}




\begin{tabular}{|c|c|c|c|c|c|c|c|c|}
\hline E1-11 & 39,3 & 18,4 & 46,8 & $\mathrm{x}$ & $\mathrm{x}$ & 1370 & 80 & no \\
\hline E1-12 & 56,7 & 6,1 & 10,8 & $\mathrm{x}$ & $\mathrm{x}$ & 1710 & 40 & no \\
\hline E1-16 & 54,4 & 11,9 & 21,9 & $\mathrm{x}$ & $\mathrm{x}$ & 1460 & 50 & no \\
\hline E1-18 & 52,0 & 5,0 & 9,6 & $\mathrm{x}$ & $\mathrm{x}$ & 1460 & 50 & no \\
\hline E1-19 & 57,3 & 6,2 & 10,8 & $\mathrm{x}$ & $\mathrm{x}$ & 1390 & 60 & no \\
\hline E1-20 & 55,2 & 5,0 & 9,1 & $\mathrm{x}$ & $\mathrm{x}$ & 1520 & 60 & no \\
\hline E1-21 & 27,7 & 1,2 & 4,3 & $\mathrm{x}$ & $\mathrm{x}$ & $?$ & $?$ & no \\
\hline E1-22 & 48,6 & 6,0 & 12,3 & $\mathrm{x}$ & $\mathrm{x}$ & 1270 & 110 & no \\
\hline E1-23 & 42,2 & 4,9 & 11,7 & $\mathrm{x}$ & $\mathrm{x}$ & 1270 & 110 & no \\
\hline E1-25 & 50,3 & 4,0 & 7,9 & $\mathrm{x}$ & $\mathrm{x}$ & 1130 & 80 & no \\
\hline E1-26 & 45,0 & 1,9 & 4,3 & 9,2 & 0,4 & 1060 & 60 & yes \\
\hline E1-27 & 45,7 & 2,7 & 5,9 & $\mathrm{x}$ & $\mathrm{x}$ & 1360 & 30 & no \\
\hline E1-28 & 49,2 & 4,7 & 9,6 & $\mathrm{x}$ & $\mathrm{x}$ & 1360 & 30 & no \\
\hline E1-29 & 47,5 & 4,4 & 9,4 & $\mathrm{x}$ & $\mathrm{x}$ & 1290 & 70 & no \\
\hline $\begin{array}{l}\text { E1-30 and } \\
30 \mathrm{~b}\end{array}$ & 47,6 & 1,3 & 2,8 & 9,8 & 0,5 & 1380 & 60 & yes \\
\hline E1-31 & 49,6 & 2,1 & 4,3 & 10,2 & 0,4 & 1450 & 60 & yes \\
\hline E1-32 & 41,8 & 4,7 & 11,3 & $\mathrm{x}$ & $\mathrm{x}$ & 1290 & 70 & no \\
\hline E1-33 & 57,7 & 7,6 & 13,2 & $\mathrm{x}$ & $\mathrm{x}$ & $?$ & $?$ & no \\
\hline E1-34 & 43 & 4 & 9 & $\mathrm{x}$ & $\mathrm{x}$ & 1300 & 60 & no \\
\hline E1-35 & 50 & 5 & 9 & $\mathrm{x}$ & $\mathrm{x}$ & 1740 & 60 & no \\
\hline E1-37 & 54 & 0 & 0 & 11 & 0 & 990 & 70 & yes \\
\hline \multicolumn{9}{|c|}{ Goguitchaichvili et al. (2015) } \\
\hline BA2-1 & 40 & 0 & 1 & 7 & 0 & 1590 & 50 & yes \\
\hline BA2-2 & 44 & 2 & 5 & 8 & 0 & 1790 & 30 & yes \\
\hline BA2-4 & 38 & 3 & 7 & $\mathrm{x}$ & $\mathrm{x}$ & 1825 & 5 & no \\
\hline
\end{tabular}

Supplementary table A2.2.4: Evaluation of selection criteria used in archeointensity studies (extracted from Poletti et al., 2016).

\begin{tabular}{llllllllll}
\hline & N & f & $\beta$ & q & MAD & $\alpha$ & $\delta C K$ & $\delta p a l$ & $\delta T R$ \\
Reference & $(\geq 5)$ & $(\geq 0.35)$ & $(\leq 0.15)$ & $(\leq 5)$ & $(\leq 6)$ & $(\leq 15)$ & $(\leq 9)$ & $(\leq 18)$ & $(\leq 20)$
\end{tabular}

\begin{tabular}{llllllllll}
\hline Hartmann et al. (2010) & ok & ok & ok & ok & ok & ok & ok & ok & ok \\
Hartmann et al. (2011) & ok & ok & ok & ok & ok & ok & ok & ok & ok \\
Goguitchaichvili et al. (2011) & ok & ok & ok & ok & - & - & - & - & - \\
Goguitchaichvili et al. (2012) & ok & ok & ok & $\geq 3.8$ & - & - & - & - & - \\
Goguitchaichvili et al. (2015) & ok & ok & ok & $\geq 2.7$ & - & - & - & - & - \\
Roperch et al. (2014) & ok & ok & ok & ok & ok* & - & - & - & - \\
Roperch et al. (2015) & ok & ok & ok & ok & ok & - & - & - & - \\
This Study & ok & ok & ok & ok & ok & ok & ok & ok & ok \\
\hline * Except for three samples & & & & & & & & &
\end{tabular}

Legend: Parameters are referred as in Paterson et al. $(2012,2014)$. 


\section{A2.3. Peer-review of Poletti et al. (2016)}

\section{First round of revision}

Dear Dr Poletti,

Reviewers have now commented on your paper. You will see that they are advising that you make minor revisions your manuscript. If you are prepared to undertake the work required, I would be pleased to reconsider your paper for publication.

Yours sincerely,

Bruce Buffett

Editor

Earth and Planetary Science Letters

\section{Reviewer \#1}

Review of "Archeomagnetism of Jesuit Missions in South Brazil (1657-1706 AD) and Assessment of the Archeointensity database of South America” by Poletti et al.

This work presents new archaeointensity data from southern Brazil from ca. 1700 AD. Paleomagnetic data from South America during the last millennium and older are particularly scarce, which makes this data particularly valuable. The data presented here are also of very high quality, further emphasizing their value.

This presentation of new data is complimented by a reanalysis of all currently available archaeointensity data from South America. After removal of what are regarded as low quality data they conclude that the current generation of field models fit well with the currently available data, but that some degree of scatter is present, mostly likely related to non-dipole effects.

Overall, the manuscript is well written and makes a useful contribution to our understanding of the evolution of the geomagnetic field. My main comment is that I believe that one of the studies may be unfairly excluded from the meta-analysis. Further details are given below. In addition, the discussion of the potential non-dipole effects, which are a highlight of this work, could be expanded.

In all of my reviews I strongly encourage all authors to deposit their data in appropriate repositories. I personally believe that this is extremely important for 
paleointensity data, which are challenging endeavor. I think that this data set in particular, is quite valuable due to its high quality and the fact that it is from a region with sparse data coverage. The authors' own analyses on other data from South America highlight the value of widely available data - many of the concerns over the reliability of other data sets could be addressed if the original measurement data were accessible.

If the authors are interested in making their data available through the MagIC database (earthref.org/MAGIC) then they can contact the MagIC team for assistance with data processing. There are a number of volunteers, who are happy to take on the duties of reformatting data into a MagIC compatible format so that the paleomagnetic community and benefit from this invaluable resource.

Below I have outlined my comments on the manuscripts, split in to main and minor comments. If the authors have any questions or clarifications, please feel free to contact me.

Greig A. Paterson

Institute of Geology and Geophysics, Chinese Academy of Sciences

\section{Main Comments}

Highlight 3: "high-quality data allows one to identify non-dipolar effects on intensity evolution"

This is only briefly mentioned in the manuscript, but not discussed or quantitatively assessed. Is this really a highlight? If so, I would encourage a greater discussion and quantification of the potential effects of non-dipole components.

Response: This point was also raised by Reviewer \#2 (comment 'c'). We decided to withdraw this highlight, but added a complimentary phrase in the Discussion (last paragraph, lines 590-593) stressing that due to the scarcity of good quality data the models are not describing the non-dipole field structure properly, thus "implying that from the beginning of the XVII century the South Atlantic Magnetic Anomaly was already stronger than current models suggest".

Lines 163-170: Was an additional heating in $+\mathrm{X}$ direction performed after the main 6 directions were obtained? This should be used as an alteration check to test the validity of the ATRM correction, which would be invalid if the specimen chemically altered (cf. Paterson, 2013, GJI, doi: 10.1093/gji/ggt033). 
Response: We perform two additional check heatings after ATRM measurements: a pTRM check in $+X$ and a zero field heating (a pTRM tail check). In addition, we continue to constantly monitor thermochemical alteration by doing several pTRM checks throughout the rest of the measurement. We clarified this in the text (lines 197-198).

\section{Line 205 and Table S3}

Is this an anchored or unanchored MAD?

Response: We used unanchored MAD for all specimens. We modified the text to state it clearly (line 237).

Lines 232-234: k-T curves are sensitive to composition and grain size (among other things such as anisotropy etc.). Ms-T curves are dominantly sensitive to composition.

RSLG-01, RSA5-01 and RSLG1-03 all have decreases in k over a relatively narrow temperature range. They also exhibit IRM acquisition over a relatively narrow coercivity range. I would infer that these data are exhibiting dominantly a grain size effect.

The RSJB specimens have broad k-T curves and broad IRM acquisitions. As you correctly note this is mixing of high and low coercivity minerals, but given the broadness of the k-T and IRM curves (at high coercivity), a grain size effect is also likely present.

Response: We modified the text to incorporate the suggestions of the reviewer in lines 265 and 268.

Line 265: It is probably best to avoid using the room temperature step in the paleointensity estimate. Although it is not likely to have a significant impact on the final results, even for well behaved SD grains temperatures on the order 100-150C are still potentially influence by overprinting and should be avoided.

Response: We used the 0-150C steps for only four specimens (RSJB11-42, RSJB12-44, RSJB12-45, RSA4-02-49). Differences observed after elimination of these steps is within experimental error, thus we maintained the original results.

Lines 272-281:

This is not so surprising since the limits of selection thresholds depends strongly on the NRM fraction, f(Paterson et al., 2012, G-Cubed). So most SD-like specimens with 
$\mathrm{f} \geq 0.6(\mathrm{Blab}=\mathrm{Banc})$ should have $\mathrm{q} \geq 14, \beta \leq 0.06$, and $\delta \mathrm{pal} \leq 8 . \delta \mathrm{CK}$ and $\delta \mathrm{TR}$ have little dependency on fraction and both should be $\leq 7$, and $\leq 1$, respectively. Anchored MAD and $\alpha$ should both generally be $\leq 2$ and unanchored MAD $\leq 5$.

Looking at your supplementary table 2, the above is true for the bulk of your samples. I would suggest that the strong similarity between the model predictions and your data would make a compelling argument that these results are dominantly near ideal SD specimens (i.e., near indistinguishable from the best specimens that we could possibly measure).

Response: We added a phrase stating that "the strong similarity between our data and the distribution expected for SD grains as modeled by Paterson et al. (2012) suggest that we are dealing with near ideal magnetic recorders". (lines 320-322).

Lines 314-316: "Therefore, we prove that the average of six orthogonally oriented specimens does not correct for the TRM anisotropy effect."

Excellent!

The averaging of the 6 directions is something that I have been strongly critical of, but my criticisms largely ignored, even after a simple theoretical demonstration based on SD anisotropy theory. I am very glad that you have the data now to show that is it nonsense. I suspect that the "success" of this approach has been due to the fact that most of the specimens used were fairly isotropic (e.g., Goguitchaichvili et al., 2015 measured the anisotropy tensors and found fairly isotropic behavior). It is a shame, however, that it means that some South American data are useless because their reliability is highly questionable. Access to the original measurement data would allow the angel between the applied field and the pTRM gained to be assessed, which would allow some estimate of whether or not anisotropy is significantly affecting the results.

\section{Response: :-}

Table 2: Please double-check some of the studies that corrected anisotropy using the 6 specimen average. As far as I am aware, Goguitchaichvili et al. (2011) used anisotropy tensors for their correction. They may not have applied this to all specimens, however, but which ones were corrected is not clear. 
In Table 2 you say that Goguitchaichvili et al. (2015) is accepted, but there Argentinian data are not presented in Figure $7 \mathrm{~b}$. I assume that this rejection is based solely on their selection criteria (i.e., $q>=2.7$ )? If so, I think that this is an unfair rejection as it does not really fail to meet our current understanding of the selection (Paterson et al., 2012, 2015) nor does it really fail to meet the modified criteria that we have proposed (Paterson et al., 2014, G-Cubed).

We proposed a number of sets of criteria based on modification of 4 existing sets such that they complied with our most up-to-date understanding of SD selection statistics. This meant the criteria that fell outside of the limits defined by Paterson et al. (2012) were adjusted to the limits, but criteria that fell within the limits remained unchanged, even if the threshold values were well within the limits.

Of these modified sets, none made any changes to the selection based on quality and $\mathrm{q}$ thresholds range from $\geq 0$ to $\geq 5$. This is because, based on the 2012 work, we argue that it is not justified to a threshold value of 6.5 or higher for q, because it was likely too strict and would result in the reject of too many ideal SD specimens. So a criterion of $q \geq$ 7 would be too strict, but $\mathrm{q} \geq 6$,would be OK. In this sense all of the studies in Table S3 fit with our understanding of the quality factor from SD-like specimens.

We have some new work now, where we try and factor in the possible influence of multidomain specimens. This has allowed us to define limits on how relaxed selection criteria should be (Paterson et al., 2015, PEPI, doi: 10.1016/j.pepi.2015.06.003). From this, we recommend $\mathrm{q} \geq 4$ as minimum, but this is accompanied with the use of a larger NRM fraction (FRAC $\geq 0.45$ ). Based on this new data, a threshold for q greater than 10 is likely to be too strict, but a threshold value less than 4 is likely to be too relaxed. However, it is important to appreciate that there is a degree of flexibility with this due complex nature of paleointensity data and the difficulty simulating all of the nuanced behavior of natural specimens.

A quick check of the Table 2 in Goguitchaichvili et al. (2015) reveals that only 3 samples fail to meet $q \geq 4$, which is comparable to the 3 results from Roperch et al. (2014), which fail the MAD criterion, but which are still accepted. Therefore, I am not convinced that rejecting a study based solely on its use of a marginally low q threshold is justified. This data set should either be included or more compelling support for its rejection should be provided.

Response: The reviewer is right concerning Goguitchaichvili et al. (2011) and Goguitchaichvili et al. (2015). The former did apply a tensor-based anisotropy correction 
and thus must pass our criteria on the intensity technique. The later must not be discarded based solely on the q parameter. But at the same time, corrections reported in these studies for some specimens are meaningless because they were performed at temperatures where chemical alteration had occurred. In order to answer to this comment we thus recalculated the intensities at fragment level considering only specimens with reliable corrections. We included a Supplementary Table with these new estimates (Table S3-new). Table S3 was corrected and renamed as Table S4. We also changed the discussion in order to add an additional layer of analysis, i.e. in addition to the method and the quality parameters analyzed in the original manuscript, now we also analyze the internal consistency of different datasets (lines 388-397, 445-459, 466-479, 506-536 and 541-551). Figures 7 and 8 were also modified. Note, however, that the essence of our conclusions and highlights does not change.

Figure 4: Were all of these specimens accepted? Part $\mathrm{f}$ shows RSA5-04-02, but this is not in the supplementary table 2 . Is this possibly RSA5-04-30? The intensity values and errors match. For this specimen, the inclination component is not trending to the origin until somewhere between 450-500C. If it is RSA5-04-30, this specimen yields the lowest intensity from the Santo Angelo reduction, which gives sample RSA5-04 the largest uncertainty of all the samples reported here. How confident are you that this is a primary component? Given that the Santo Angelo samples exhibit a diversity of remanence carriers, is it possible that this is a secondary, non-thermal remanence?

Response: The reviewer is right. Lab name RSA5-04-02 is equivalent to specimen - ID RSA5-04-30. We changed the name of this and the other specimens in Figure 4 to avoid confusion. In spite of the slightly bent demagnetization pattern, angular difference across demagnetization is small and within acceptable error. So, we consider that this specimen is indeed recording the ancient field.

\section{Minor Comments}

Lines 122-123: Please state the heating rate used and the mass used. These can have a significant impact on the final curves and Tc values (Jordanova \& Jordanova, 2016, Front. Earth Sci., Thermomagnetic Behavior of Magnetic Susceptibility Heating Rate and Sample Size Effects, doi: 10.3389/feart.2015.00090). 
Section 3.2

The selection criteria don't follow exactly any set outlined by Paterson et al. (2014). Would I be correct to say they are based on the modified TTB, but with stricter q, MAD, but relaxed $\alpha$ ?

Line 250: Please indicate what software was used to process the FORC diagrams. Please also add the smoothing factors either to the figure or the caption.

Supplementary Figure 1: Please add some of the selection statistics to illustrate the reasons for rejection. As a matter of curiosity, SJB-01-037 seems quite unusual - 75\% of the total TRM is gained by $100 \mathrm{C}$, yet only $220 \%$ of the NRM is lost. Do you know why?

Line 28: Change "works" to "work"

Line 54: Change to "... associated with the growth of reversed...."

Line 64: Change "First..." to "The first..."

Line 102: Change "at" to"in"

Line 113: Add a reference for FORCs (e..g, Roberts et al., 2000, JGR, doi: 10.1029/2000JB900326)

Line 143: Delete "atmosphere"

Line 191: Change "Figure" to "Table"

Line 230: Change "at" to "by"

Line 250: Change “...examples commented above..." to "...abovementioned specimens..."

Line 292: Change to "RSA-04-1"

Lines 322,323, and 324: On each line change "...showed..." to "...yields an..."

Line 337: Change "is" to "are"

Line 337: Change "north" to "northern"

Line 401: Change "of" to "in"

Line 418: Change "... is compromised..." to "...are..."

Line 418; Change "...compromising 28..." to "... and is compromised of $28 \ldots$...

Line 432: Change "reduced" to "relocated"

Figure 7: The line widths should be increased to make the figure clearer. 
Caption for Figure 8: Change "...were reduced to the latitude of...” to "... were relocated to a latitude of..."

Table 1: In the header change "uT" to " $\mu \mathrm{T}$ "

Response: We incorporated all suggestions.

\section{Reviewer \#2:}

This paper reports on new archeointensity results from three historical missions in southern Brazil. They come from a location where no previous data existed and have been obtained according to state-of-the-art, elaborate laboratory methods and applying rigorous quality criteria. The reasoning behind the given ages and uncertainties are cleary stated, and I like the laboratory intercomparison that is briefly described and in my opinion is a very useful reassurance. Although a few new data on their own can bring no immediate broad conclusions about the past geomagnetic field evolution, they are highly important as one of many laborious steps to gain a better understanding of past field variations and ultimately the geodynamo process. Moreover, the discussion of the new results is complemented by a valuable assessment of quality indicators in earlier southern American results, and a test of anisotropy corrections. I consider the study suitable for publication in EPSL. It is very well written and methods and results are described clearly. The paper in my opinion could be published as it is, but I have a few minor comments that the authors might want to consider as follows.

a) The results of testing the proposed anisotropy correction of simply averaging results from orthogonally measured specimens (lines $304 \mathrm{ff}$ ) are important and apparently haven't been tested / discussed based on experiment before. I would suggest to mention this finding in the conclusions section and abstract.

Response: We included a corresponding phrase in conclusions (lines 596-599) and in the abstract (lines 40-42).

b) Introduction, 1. 57/58: One or more references on the SAMA would be good here. In fact two abbreviations are commonly used for this feature of the geomagnetic field in the literature: SAMA (South Atlantic Magnetic Anomaly) or SAA (South Atlantic Anomaly). Admittetly a quick and rough literature search to find which one was used first confused rather than enlightened me: it seems that probably SAA was used widely by the magnetospheric / space weather community, whereas SAMA was used more when 
looking at the field, its secular variation and the reverse flux patches responsible for this weak zone of the field. (For example Badhwar (1997, JGR, 102, 2343-2349) used both abbreviations in the introduction). While indeed SAA doesn't contain any reference to the magnetic field I still find it preferable for the following reason: The term "magnetic anomaly" is commonly and widely used for the magnetic field contribution generated by magnetized structures in the Earth's lithosphere. This "magnetic anomaly", however, is a feature of the core field. I guess to avoid any confusion it should have been called "South Atlantic geomagnetic anomaly"(not that I would want to introduce a third abbreviation). So all I really want to say here is that the authors might consider to briefly mention that the two different abbreviations are in use.

Response: We included reference to SAA and SAMA in the text (lines 71-74) and a reference as suggested by the reviewer.

c) Figure 8: Indeed the results from the different regions show quite systematic differences as described, and it is stated that this might be due to complexities in the geometry of the field not appropriately accounted for by the simple axial dipole model used in re-locating the data. This would in particular be the case if the SAA (or similar structure) already was present in the area at that time. Without having checked in more detail now I think this is the time when the SAA is considered to start forming, so probably these differences are stronger than expected from what we know about the SAA so far? That could be tested by looking at model predictions not only from the one location, but actually also comparing the model predictions for Chile and Northeast Brazil, and how different they are to the Southeastern Brazil one. Do they fit the respective data, i.e. does a model describe the non-dipole field properly? Or is the systematic offset between data and model still present in these cases, which would indicate that the model is not describing the non-dipole field structure properly/fully and e.g. could even mean that perhaps the SAA was already stronger than the model suggests and what is taken as present knowledge.

Response: The reviewer is right. Indeed, our data and the final compilation of highquality data from South America imply that from the beginning of the XVII century the South Atlantic Geomagnetic Anomaly (or other important non-dipolar feature of the field) was already stronger than current models suggest (lines 590-593). 
Details

1. 239: the first "and" doesn't belong there (or something additional is missing?)

2. 261: Table 2 here should be Table 1 or S2

3. 269, 271, Fig. S1: the letters a to $d$ are not given in the figure.

4. 418: some form of "comprise" used twice in the sentence, perhaps can be slightly re phrased

Response: We incorporated all suggestions.

\section{Second round of review}

Dear Dr. Poletti,

Please could you attend to the final points listed below on your revised manuscript, and then we should be able to accept it for publication.

Bruce Buffett

Editor

Earth and Planetary Science Letters

\section{Reviewer \#1:}

Only a few minor typographical tweaks are needed.

Line 42: change to "...for the effects of TRM anisotropy..."

Line 468: Change to "... at the fragment..."

Line 469: Change "item" to "section"

Line 472: Change to "the site level..."

Line 472: Change to "...from at least three fragments..."

Greig A. Paterson

Institute of Geology and Geophysics, Chinese Academy of Sciences

Response: We incorporated all suggestions. 


\section{Final decision}

Dear,

I am pleased to confirm that your paper "Archeomagnetism of Jesuit Missions in South Brazil (1657-1706 AD) and assessment of the South American database" has been accepted for publication in Earth and Planetary Science Letters.

Thank you for submitting your work to this journal.

With kind regards,

Bruce Buffett

Editor

Earth and Planetary Science Letters 
A3. New archeointensity data from South Brazil and the influence of the South Atlantic Anomaly in South America

\section{A3.1. Highlights extracted from Hartmann et al. (submitted)}

- Six new high-quality archeointensity results for South Brazil.

- Results mark the continuous decay of geomagnetic field intensity in the region.

- Non-dipolar components in the region are significant at least since 1800 CE.

- New results suggest an earlier arrival of the South Atlantic Anomaly.

\section{A3.2. Supplementary material of the Hartmann et al. (submitted)}

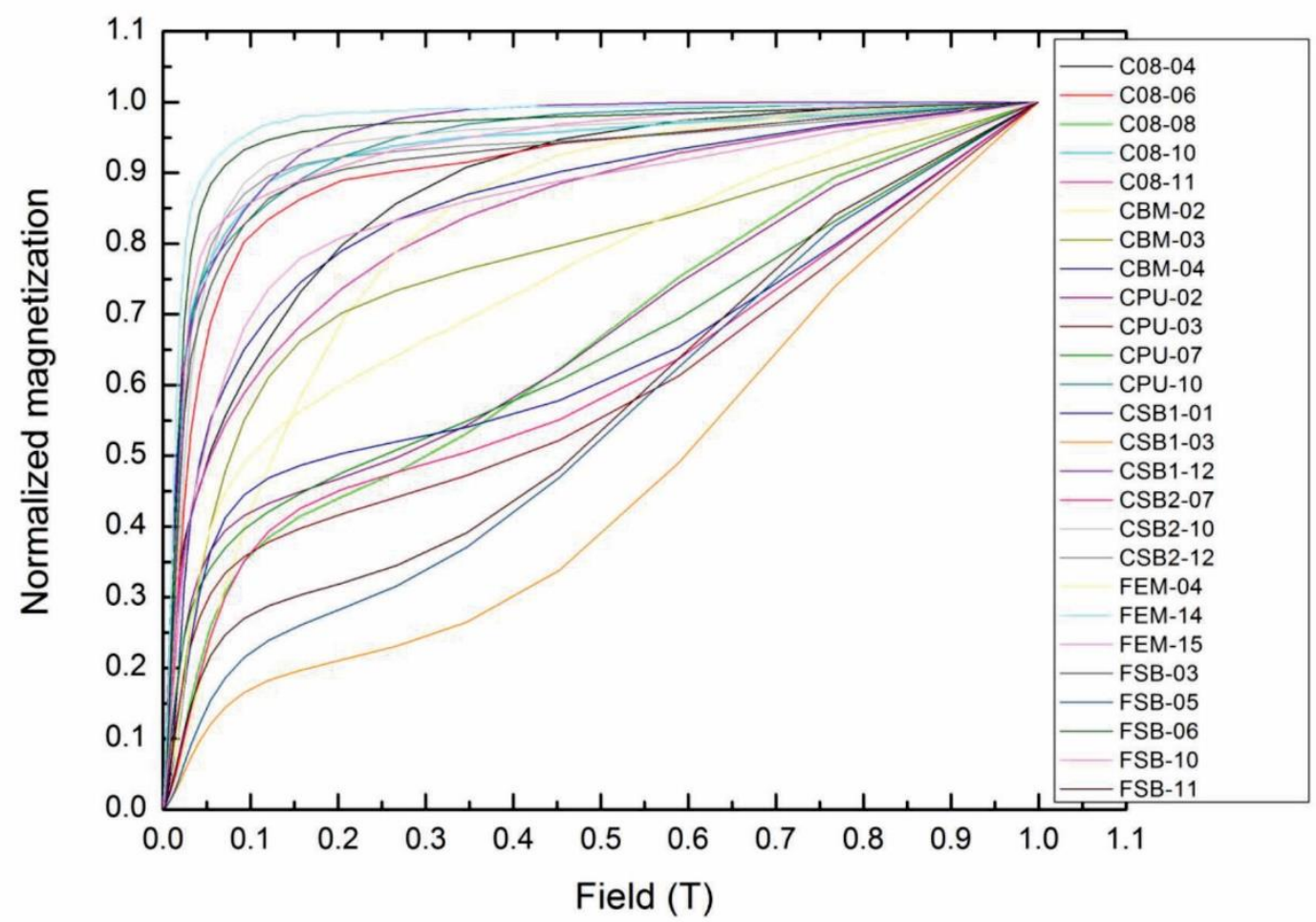

Supplementary figure A3.2.1: IRM acquisition curves for all fragments that presented successful archeointensity estimates (extracted from Hartmann et al., submitted). 
Supplementary table A3.2.1: Archeological and architectural details and archeointensity results of the studied sites from Pelotas, South Brazil $\left(31.8^{\circ} \mathrm{S}, 52.3^{\circ} \mathrm{W}\right.$ ) (extracted from Hartmann et al., submitted).

\section{Site}

\begin{tabular}{|c|c|}
\hline Site & Site description \\
\hline $\begin{array}{l}\text { Charqueada Santa } \\
\text { Bárbara } \\
(\text { CSB1+2) }\end{array}$ & $\begin{array}{l}\text { The first sesmaria letter of this jerky beef farm wa } \\
\text { donated in } 1790 \text { CE to the farmer Theodósio Perir } \\
\text { Jacomé, who sold the property to Antonio Pereira d } \\
\text { Lemos and Rosália Maria Angélica in } 1817 \text { CE. Thi } \\
\text { property was since then called Estância Sant } \\
\text { Bárbara, which consisted of a large jerky bee } \\
\text { complex composed of cattle ranch, jerky beef an } \\
\text { derivatives factory, housing and other improvement } \\
\text { to support the activities in this farm. In its productiv } \\
\text { peak in the } 1850 \text { s, this plantation presented } 61 \text { slave } \\
\text { (60\% were Africans). }\end{array}$ \\
\hline
\end{tabular}

Sampling: 28 brick fragments from the basement of the main house of the farm.

The Chácara da Brigada Militar site was an ancient jerky beef farm of the Passo dos Negros district belonging to João Jacinto de Mendonça and Manoel Soares da Silva. The detailed analysis of the facade and internal structures of the main building (house)

Chácara da Brigada Militar (CBM) shows common building materials and techniques in the XIX century: large and massive bricks, archshaped opening and brick foundations. This building present architectural features, location, and building typology characteristics of the jerky beef farms. In addition, its architecture is similar to the Charqueada Santa Bárbara.

Sampling: 5 brick fragments from the basement of the main house of this jerky beef farm.

This house presents a high basement, a main and a second floor, with two front gardens and an internal patio. Both facades have plaques and pediments, masks and statues of faience, as well as a vast repertoire of ornamental elements. Unique hydraulic tiles in the entrance hall, stucco ceiling and walls remain from the original building. The division between rooms were destined for social and family

Casa Número 08 (C08) (Pedro Osório Square) use, and for domestic service are significantly wellmarked: the service room walls are less thick than the others, the ceiling are lower and the openings smaller than the front rooms of the building. Parietal structures with panels in trompe l'oeil marbled and ceiling plasters with iconography allusive to the use of the room only exist in the social and family use areas of the building. The architectural design of Casa Número 08 is attributed to the Italian José Isella, and was built from 1870-1878 CE.

Sampling: 12 brick fragments from the basement of the house.

Built to be a children's school, and a posthumous tribute to Eliseu Antunes Maciel by his affluent

Casarão da Família Eliseu Maciel (FEM) now Sede dos Conselhos Universitários da UFPel

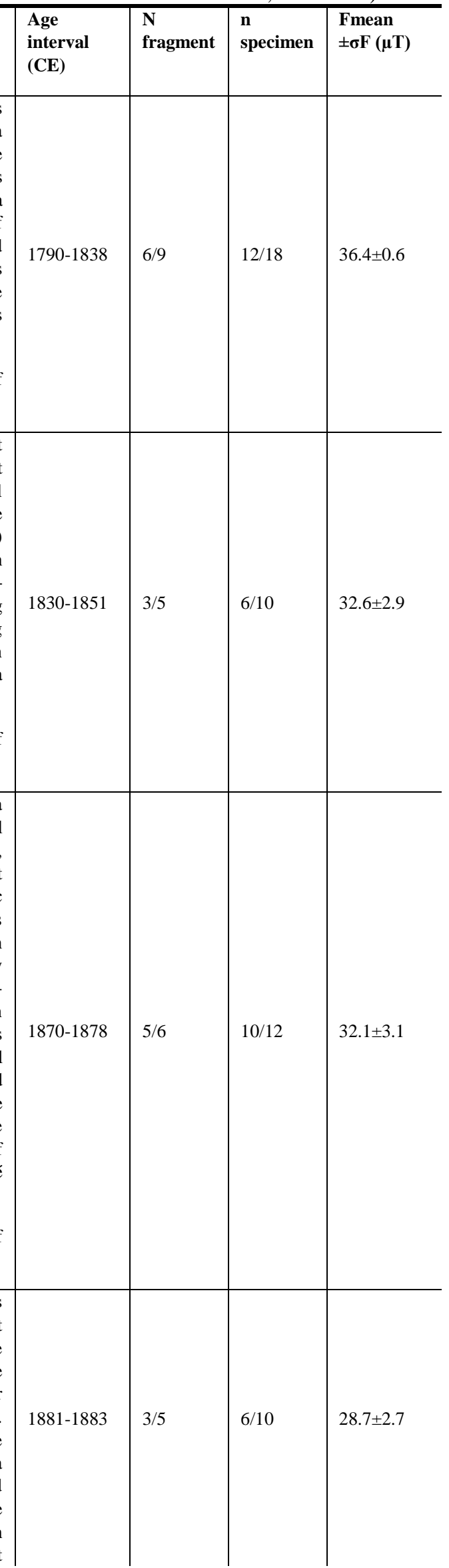




\begin{tabular}{|c|c|c|c|c|c|}
\hline Site & Site description & $\begin{array}{l}\text { Age } \\
\text { interval } \\
\text { (CE) }\end{array}$ & $\begin{array}{l}\mathrm{N} \\
\text { fragment }\end{array}$ & $\begin{array}{l}\text { n } \\
\text { specimen }\end{array}$ & $\begin{array}{l}\text { Fmean } \\
\pm \sigma \mathrm{F}(\mu \mathrm{T})\end{array}$ \\
\hline & $\begin{array}{l}\text { dates of the launching of the cornerstone (July 16, } \\
\text { 1881) and inauguration (April 22, 1883). } \\
\text { Sampling: } 15 \text { brick cores (using a portable drill) } \\
\text { from the basement of the house. }\end{array}$ & & & & \\
\hline $\begin{array}{l}\text { Fundação Simon } \\
\text { Bolívar (Antigo } \\
\text { Casarão da } \\
\text { Faculdade de } \\
\text { Turismo da } \\
\text { UFPEL) (FSB) - } \\
\text { before Casa do } \\
\text { Senador Joaquim } \\
\text { Assumpção }\end{array}$ & $\begin{array}{l}\text { The basement of the house has an independent } \\
\text { entrance and rustic walls, both facades are } \\
\text { ornamented with pilasters with iconic capitals and } \\
\text { shafts, pediments on the openings of the main floor, } \\
\text { frontispieces with plenty and varied iconography } \\
\text { and monogram of the first owner. Balustrades of } \\
\text { faience complete the external ornamentation. The } \\
\text { monumental entrance features windbreaks in wood } \\
\text { and glass and the basement floor is made of bricks, } \\
\text { with obvious marks of continuous use. This house } \\
\text { was built from 1884-1889 CE. } \\
\text { Sampling: } 12 \text { brick cores (using a portable drill) } \\
\text { from the basement of the house. }\end{array}$ & 1884-1889 & $5 / 6$ & $10 / 12$ & $30.1 \pm 2.0$ \\
\hline $\begin{array}{l}\text { Campus Anglo da } \\
\text { UFPEL (CPU) - } \\
\text { before Anglo's } \\
\text { canned meat } \\
\text { factory }\end{array}$ & $\begin{array}{l}\text { The English meat company Vestey Brothers } \\
\text { acquired in } 1921 \text { the six-hectare land that became } \\
\text { the administrative headquarters of the Federal } \\
\text { University of Pelotas (Campus Anglo), but the } \\
\text { construction of a refrigerator industry began only in } \\
\text { 1942, with the aim of supplying canned meat for } \\
\text { allied troops of World War II. The factory was } \\
\text { inaugurated in December 1943. The structure built } \\
\text { had a long-inclined aisle to conduct cattle to the } \\
\text { slaughter area, refrigerated chambers, meat } \\
\text { incubation and processing areas, offices, boxing and } \\
\text { storage sectors, workshops, boiler and chimney. } \\
\text { Concrete and bricks walls were fitted with cork to } \\
\text { preserve low internal temperatures. } \\
\text { Sampling: } 12 \text { brick fragments. }\end{array}$ & $1942-1943$ & $4 / 5$ & $8 / 10$ & $27.8 \pm 2.0$ \\
\hline $\begin{array}{l}\text { Grande Hotel } \\
(\mathrm{GH}) \text { - now } \\
\text { Faculdade de } \\
\text { Hotelaria da } \\
\text { UFPel }\end{array}$ & $\begin{array}{l}\text { The architectural design of the Grande Hotel was } \\
\text { chosen in a contest that was won by the civil } \\
\text { engineer Theóphilo Borges de Barros (who signs the } \\
\text { building in a plaque engraved on the facade). The } \\
\text { construction began in } 1924 \text { or } 1925 \text {, and the } \\
\text { inauguration took place in } 1928 \text {, being the Hotel } \\
\text { immediately affected by the great economic } \\
\text { depression. The hotel presents livable subsoil, a } \\
\text { raised ground floor, noble floor indicated in the } \\
\text { facade and a cylindrical body in the corner, topped } \\
\text { by an imposing dome that marks the main entrance } \\
\text { of the building. Columns and pairs of columns, } \\
\text { pilasters, cornices, alternating arch and rectangular } \\
\text { openings, and shields with the monogram "GH" in } \\
\text { the top complete the external decoration. An } \\
\text { imposing skylight illuminates the interior and the } \\
\text { circulation spaces are widely visible from any point } \\
\text { of the imposing central span. } \\
\text { Sampling: } 14 \text { brick cores (using a portable drill) } \\
\text { from the basement of the hotel. }\end{array}$ & 1924-1928 & $0 / 14$ & - & - \\
\hline $\begin{array}{l}\text { Prédio } 2 \text { do } \\
\text { Instituto de } \\
\text { Ciências Humanas } \\
\text { da UFPel (ICH2) } \\
\text { - now Escola de } \\
\text { Belas Artes }\end{array}$ & $\begin{array}{l}\text { Low basement and two-floor residence with arches } \\
\text { in the upper floor openings, and Roman arches in the } \\
\text { lower openings. An iron gable gate, plaster } \\
\text { frontispiece on the side facade, discreet balconies, } \\
\text { balustrade, statues and vessels of faience complete } \\
\text { the external ornamentation. In the interior, there are } \\
\text { a fireplace, a skylight and art-deco doors in the }\end{array}$ & $1880-1881$ & $0 / 14$ & - & - \\
\hline
\end{tabular}




\begin{tabular}{l|l|l|l|l|l}
\hline Site & Site description & $\begin{array}{l}\text { Age } \\
\text { interval } \\
(\mathbf{C E})\end{array}$ & $\begin{array}{l}\mathbf{N} \\
\text { fragment }\end{array}$ & $\begin{array}{l}\mathbf{n} \\
\text { specimen }\end{array}$ & $\begin{array}{l}\text { Fmean } \\
\pm \boldsymbol{\sigma} \mathbf{F}(\boldsymbol{\mu} \mathbf{T})\end{array}$ \\
\hline $\begin{array}{l}\text { Carmen Trápaga } \\
\text { Simões }\end{array}$ & $\begin{array}{l}\text { second floor, the parietal stucco coatings are limited } \\
\text { to the main hallway of the first floor that underwent } \\
\text { two restorative interventions. The owner family } \\
\text { donated this house to the municipality in the 1960s, } \\
\text { with the condition that "the property is only to be } \\
\text { used for the teaching of Fine Arts". This building } \\
\text { was constructed between 1880 and 1881 CE. } \\
\text { Sampling: 14 brick cores (using a portable drill) } \\
\text { from the basement of the house. }\end{array}$ & & & & \\
\hline
\end{tabular}

Supplementary table A3.2.2 (in Excel format): Complete dataset for all specimens.

Supplementary table A3.2.3: Comparison between estimates of non-dipolar components ( $\left.\mathrm{B}_{\text {archeo }}-\mathrm{B}_{|\mathrm{g} 10|}\right)$ : modified-gufm1 (Poletti et al., 2018) and original gufm1 (Jackson et al., 2000) (extracted from Hartmann et al., submitted).

\begin{tabular}{|c|c|c|c|c|c|c|c|}
\hline \multirow{2}{*}{ Reference } & \multirow[b]{2}{*}{$\begin{array}{l}\text { Age } \\
\text { (CE) }\end{array}$} & \multirow[b]{2}{*}{$\begin{array}{l}\text { Age } \\
\text { Error }\end{array}$} & \multicolumn{2}{|c|}{ gufm1 - modified } & \multicolumn{2}{|c|}{ gufm1 } & \multirow[b]{2}{*}{$\begin{array}{l}\text { Difference between } \\
\text { modified and } \\
\text { original estimates } \\
\text { from gufm1, } \\
\text { respectively }\end{array}$} \\
\hline & & & $\begin{array}{l}\text { Barc-Bg10 } \\
(\mu \mathrm{T})\end{array}$ & $\begin{array}{l}\text { Barc-Bg10 } \\
\text { Error }(\mu \mathrm{T})\end{array}$ & $\begin{array}{l}\text { Barc-Bg10 } \\
(\mu \mathrm{T})\end{array}$ & $\begin{array}{l}\text { Barc-Bg10 } \\
\text { Error }(\mu \mathrm{T})\end{array}$ & \\
\hline Goguitchaichvili et al. (2015) & 1790 & 30 & -1.42 & 2.15 & -2.42 & 2.15 & 1.01 \\
\hline \multirow{14}{*}{ Hartmann et al. (2010) } & 1576 & 15 & -1.29 & 1.60 & - & 1.60 & - \\
\hline & 1605 & 15 & 3.30 & 1.20 & 1.99 & 1.20 & 1.31 \\
\hline & 1625 & 25 & 4.57 & 3.20 & 3.32 & 3.20 & 1.25 \\
\hline & 1675 & 25 & 1.74 & 0.70 & 0.64 & 0.70 & 1.10 \\
\hline & 1676 & 10 & 2.15 & 0.60 & 1.06 & 0.60 & 1.09 \\
\hline & 1692 & 1 & 1.27 & 1.10 & 0.22 & 1.10 & 1.05 \\
\hline & 1699 & 3 & 0.66 & 0.90 & -0.37 & 0.90 & 1.03 \\
\hline & 1700 & 25 & -0.02 & 2.10 & -1.05 & 2.10 & 1.02 \\
\hline & 1705 & 5 & 0.94 & 1.10 & -0.07 & 1.10 & 1.01 \\
\hline & 1772 & 5 & -2.16 & 2.00 & -2.98 & 2.00 & 0.82 \\
\hline & 1780 & 0 & -2.65 & 0.60 & -3.45 & 0.60 & 0.80 \\
\hline & 1887 & 0 & -7.52 & 1.60 & -8.20 & 1.60 & 0.68 \\
\hline & 1901 & 5 & -7.43 & 1.30 & -8.08 & 1.30 & 0.65 \\
\hline & 1910 & 10 & -8.01 & 0.50 & -8.59 & 0.50 & 0.58 \\
\hline \multirow{9}{*}{ Hartmann et al. (2011) } & 1591 & 7 & 0.01 & 2.40 & -1.46 & 2.40 & 1.48 \\
\hline & 1628 & 5 & -0.04 & 0.90 & -1.43 & 0.90 & 1.39 \\
\hline & 1638 & 16 & -2.19 & 1.20 & -3.55 & 1.20 & 1.36 \\
\hline & 1746 & 4 & -4.16 & 1.80 & -5.16 & 1.80 & 1.00 \\
\hline & 1795 & 5 & -7.62 & 2.40 & -8.47 & 2.40 & 0.85 \\
\hline & 1817 & 2 & -9.59 & 1.80 & -10.37 & 1.80 & 0.78 \\
\hline & 1870 & 0 & -9.89 & 1.10 & -10.78 & 1.10 & 0.89 \\
\hline & 1898 & 3 & -11.07 & 1.80 & -11.81 & 1.80 & 0.74 \\
\hline & 1909 & 1 & -11.90 & 0.40 & -12.57 & 0.40 & 0.66 \\
\hline \multirow{3}{*}{ Poletti et al. (2016) } & 1672 & 15 & -3.50 & 2.40 & -4.84 & 2.40 & 1.34 \\
\hline & 1682 & 15 & -4.50 & 1.60 & -5.80 & 1.60 & 1.30 \\
\hline & 1691 & 15 & -2.24 & 1.40 & -3.50 & 1.40 & 1.27 \\
\hline
\end{tabular}


Hartmann et al. (submitted)

\begin{tabular}{llllllll}
\hline & 1540 & 90 & -1.14 & 5.30 & - & 5.30 & - \\
Roperch et al., 2015 & 1735 & 82 & 8.61 & 3.40 & 7.35 & 3.40 & $\mathbf{1 . 2 6}$ \\
& 1751 & 0 & 4.08 & 2.50 & 2.87 & 2.50 & $\mathbf{1 . 2 1}$ \\
& 1770 & 5 & 3.31 & 2.30 & 2.26 & 2.30 & $\mathbf{1 . 0 5}$ \\
This study & 1835 & 0 & -2.83 & 1.80 & -3.73 & 1.80 & $\mathbf{0 . 9 1}$ \\
& 1875 & 4.5 & -10.17 & 3.06 & -11.14 & 3.06 & $\mathbf{0 . 9 7}$ \\
& 1841 & 10.5 & -10.22 & 2.87 & -11.01 & 2.87 & $\mathbf{0 . 7 9}$ \\
& 1943 & 0.5 & -13.29 & 1.99 & -13.67 & 1.99 & $\mathbf{0 . 3 8}$ \\
\hline & 1814 & 24 & -6.86 & 0.56 & -7.74 & 0.56 & $\mathbf{0 . 8 8}$ \\
& 1882 & 1 & -13.45 & 2.71 & -14.35 & 2.71 & $\mathbf{0 . 9 0}$ \\
\hline
\end{tabular}




\section{A4. Continuous millennial decrease of the Earth's magnetic axial dipole}

\section{A4.1. Highlights extracted from Poletti et al. (2018)}

- The global archaeointensity database is reassessed to retain only high-quality data.

- The usefulness of VADM as a proxy for ADM over the last 2000 years is indicated.

- The most recent peak in ADM occurred in the interval 550-750 AD and ADM decayed quasi-linearly since this time.

\section{A4.2. Supplementary material of Poletti et al. (2018)}
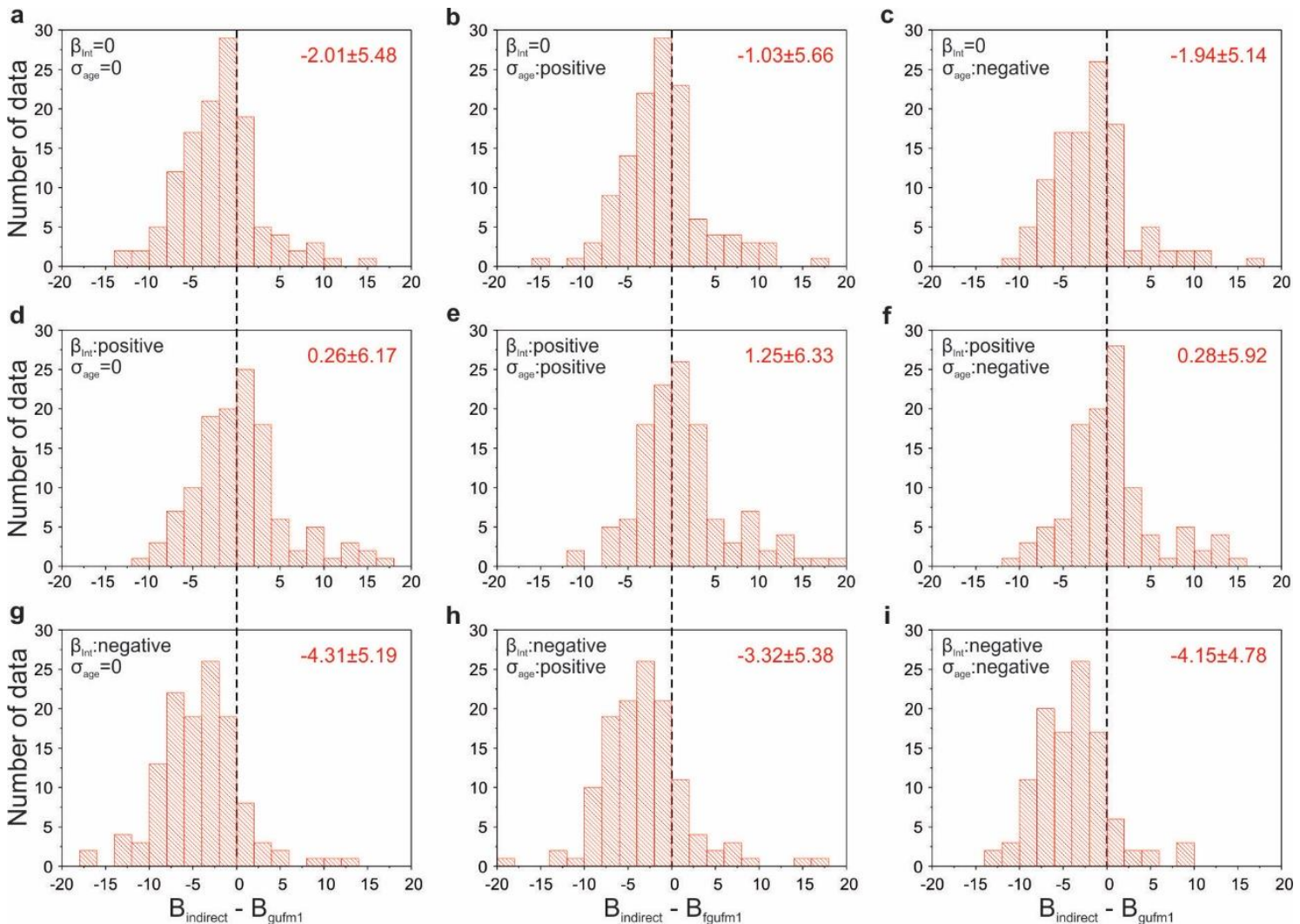

Figure A4.2.1: Normal distributions of the difference between archaeointensity dataset and models. (a-i) shows the normal distribution of the difference between the filtered archaeointensity dataset and gufm1 (Jackson et al., 2000). For this analysis was considered uncertainties of age and intensity ( $\sigma_{\text {age }}$ and $\beta_{\text {int }}$, respectively) of the archaeointensity estimates. For example, considering only one arbitrary archaeointensity of $35 \pm 2 \mu \mathrm{T}$ with age of $1750 \pm 10 \mathrm{yr}$, and for a arbitrary location, we make: 35 - $\mathrm{B}_{\text {gufml }}(1750)$

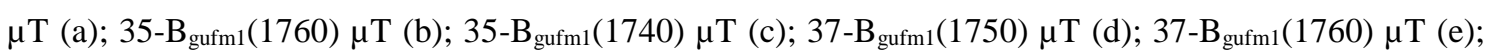

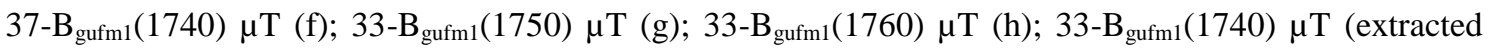
from Poletti et al., 2018). 

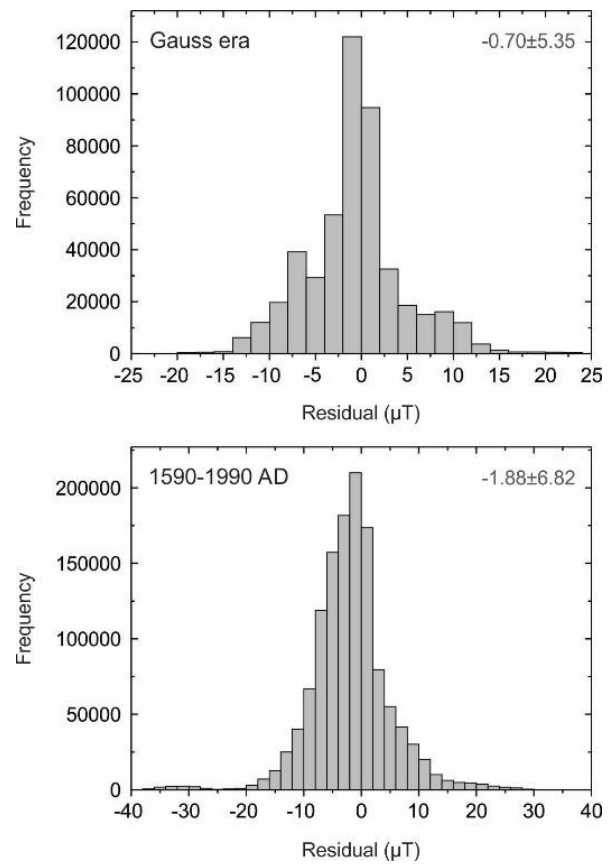

Figure A4.2.2: Residuals simulated by a Monte Carlo approach, using a homogeneous distribution for the intensity and age uncertainties of the archaeointensity data, for (a) Gauss era and (b) 1590-2009 AD interval (extracted from Poletti et al., 2018).
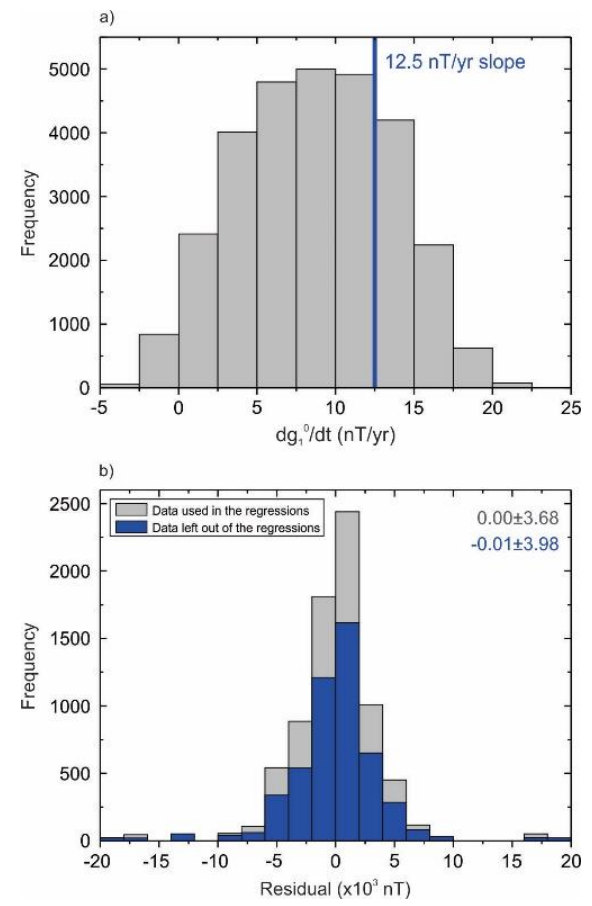

Figure A4.2.3: Statistical test of the slope $12.5 \mathrm{nT} / \mathrm{yr}$ obtained for the period between 1590 and 2009 AD. (a) represents the discretization of the range of all individual solution (every $0.01 \mathrm{nT} / \mathrm{yr}$ ). Each of the 100 solutions was obtained by simulations in which $60 \%$ of 129 archaeointensity data were randomly selected, and then was calculated the $95 \%$ bootstrapping confidence intervals $(\mathrm{N}=1999)$ for each linear regression. Blue line represent the specifically slope of $12.5 \mathrm{nT} / \mathrm{yr}$. (b) Histograms of residuals obtained between the mean linear fit and: grey bars - the data used to compute the linear fit; and blue bars - the data that were not used to compute the linear fit (extracted from Poletti et al., 2018). 

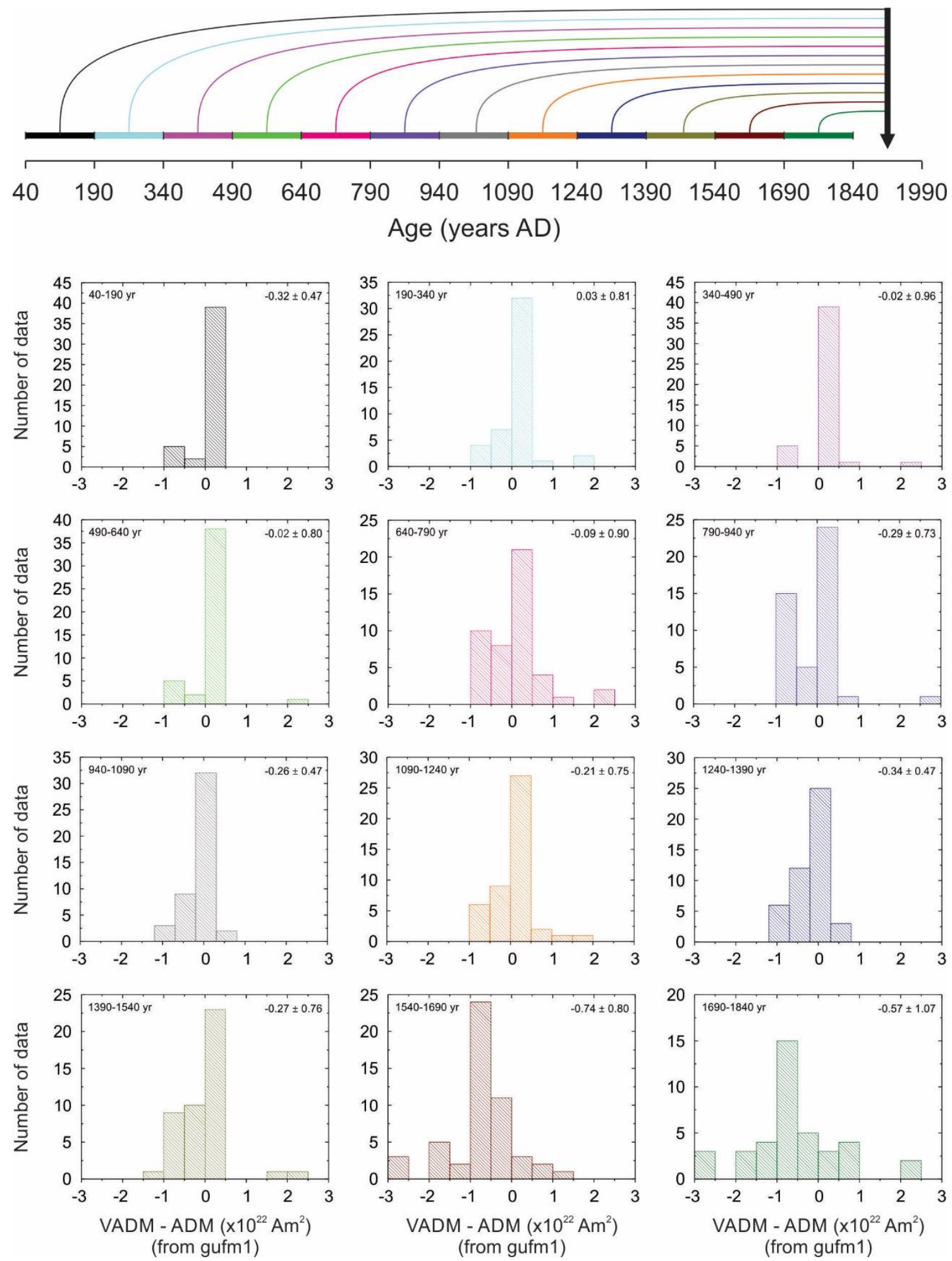

Figure A4.2.4: Test of geographical data distribution. In the top panel there is a schematic representation of the last two millennia segmented in 12 parts of 150 years each. Data distributed for every segment were "transferred" to Gauss era, and then VADMs from gufm1 (1840-1990 AD) were re-sampled taking into account the longitudes and latitudes of each data. Histograms show the normal distribution of the difference between the re-sampled VADMs and the ADMs from gufm1. Colors of histograms are linked with the colors of the scheme (extracted from Poletti et al., 2018). 
Supplementary table A4.2.1: Selected archaeointensity dataset. "a" represents archaeological and "v" represents volcanic (extracted from Poletti et al., 2018).

\begin{tabular}{|c|c|c|c|}
\hline $\begin{array}{l}\text { Number } \\
\text { of data }\end{array}$ & $\begin{array}{l}\text { Age } \\
\text { interval }\end{array}$ & Material & $\begin{array}{l}\text { Reference } \\
\text { ID }\end{array}$ \\
\hline 1 & $0-0$ & $\mathrm{a}$ & 1 \\
\hline 2 & $0-1300$ & $\mathrm{a}$ & 2 \\
\hline 18 & $0-1700$ & $\mathrm{a}$ & 3 \\
\hline 4 & $1030-1546$ & $\mathrm{a}$ & 4 \\
\hline 9 & $1103-1696$ & $\mathrm{a}$ & 5 \\
\hline 6 & $1150-0$ & $\mathrm{a}$ & 6 \\
\hline 2 & $1160-1390$ & $\mathrm{a}$ & 7 \\
\hline 13 & $123-1320$ & $\mathrm{a}$ & 8 \\
\hline 35 & $1237-1832$ & $\mathrm{a}$ & 9 \\
\hline 18 & $1331-1665$ & $\mathrm{a}$ & 10 \\
\hline 5 & $140-1840$ & $\mathrm{v}$ & 11 \\
\hline 6 & $1440-1835$ & $\mathrm{v}$ & 12 \\
\hline 1 & $1450-0$ & $\mathrm{a}$ & 13 \\
\hline 4 & $1550-1750$ & $\mathrm{a}$ & 14 \\
\hline 14 & $1576-1910$ & $\mathrm{a}$ & 15 \\
\hline 9 & 1591-1909 & $\mathrm{a}$ & 16 \\
\hline 7 & $1610-1850$ & $\mathrm{a}$ & 17 \\
\hline 8 & $1610-1950$ & $\mathrm{v}$ & 18 \\
\hline 1 & $1615-0$ & $\mathrm{a}$ & 19 \\
\hline 3 & $1672-1691$ & $\mathrm{a}$ & 20 \\
\hline 1 & $1706-0$ & $\mathrm{v}$ & 21 \\
\hline 1 & $1766-0$ & $\mathrm{~V}$ & 22 \\
\hline 1 & $1766-0$ & $\mathrm{~V}$ & 23 \\
\hline 1 & $1790-0$ & $\mathrm{a}$ & 24 \\
\hline 1 & $1835-0$ & $\mathrm{a}$ & 25 \\
\hline 1 & $1886-0$ & $\mathrm{v}$ & 26 \\
\hline 1 & $1955-0$ & $\mathrm{v}$ & 27 \\
\hline 1 & 1959-0 & $\mathrm{a}$ & 28 \\
\hline 3 & $1960-1982$ & $\mathrm{~V}$ & 29 \\
\hline 2 & $1980-2000$ & $\mathrm{~V}$ & 30 \\
\hline 2 & 1993-1998 & $\mathrm{V}$ & 31 \\
\hline 5 & $220-1138$ & $\mathrm{a}$ & 32 \\
\hline 15 & 235-1959 & $\mathrm{a}$ & 33 \\
\hline 6 & $260-1690$ & $\mathrm{v}$ & 34 \\
\hline 13 & $27-899$ & $\mathrm{a}$ & 35 \\
\hline 2 & $316-601$ & $\mathrm{a}$ & 36 \\
\hline 2 & $330-0$ & $\mathrm{a} / \mathrm{v}$ & 37 \\
\hline 14 & $337-1575$ & $\mathrm{a}$ & 38 \\
\hline 3 & $350-1855$ & $\mathrm{a}$ & 39 \\
\hline 7 & $360-1380$ & $\mathrm{v}$ & 40 \\
\hline 5 & $370-605$ & $\mathrm{a}$ & 41 \\
\hline
\end{tabular}




\begin{tabular}{llll}
3 & $37-100$ & $\mathrm{a}$ & 42 \\
4 & $385-1975$ & $\mathrm{v}$ & 43 \\
10 & $388-424$ & $\mathrm{a}$ & 44 \\
5 & $450-810$ & $\mathrm{a}$ & 45 \\
9 & $480-1660$ & $\mathrm{v}$ & 46 \\
21 & $550-875$ & $\mathrm{a}$ & 47 \\
18 & $588-2009$ & $\mathrm{v}$ & 48 \\
9 & $590-1950$ & $\mathrm{v}$ & 49 \\
8 & $622-1180$ & $\mathrm{a}$ & 50 \\
4 & $691-1320$ & $\mathrm{a}$ & 51 \\
16 & $726-1950$ & $\mathrm{v}$ & 52 \\
4 & $765-1779$ & $\mathrm{v}$ & 53 \\
1 & $775-0$ & $\mathrm{a}$ & 54 \\
5 & $800-1563$ & $\mathrm{v}$ & 55 \\
12 & $815-1797$ & $\mathrm{a}$ & 56 \\
1 & $825-0$ & $\mathrm{a}$ & 57 \\
8 & $850-1088$ & $\mathrm{a}$ & 58 \\
5 & $852-1350$ & $\mathrm{a}$ & 59 \\
11 & $87-1770$ & $\mathrm{v}$ & 60 \\
2 & $934-1783$ & $\mathrm{v}$ & 61 \\
4 & $990-1450$ & $\mathrm{a}$ & 62 \\
\hline
\end{tabular}

Reference ID: 1- Tema et al. (2012); 2- De Marco et al. (2008); 3- Chauvin et al. (2000); 4- Tarduno et al. (2015); 5- Salnaia et al. (2017); 6- Gómez-Paccard et al. (2006a); 7- Stark et al. (2010); 8- Cai et al. (2014); 9- Genevey et al. (2009); 10- Schnepp et al. (2009); 11- Tanka and Kono (1991); 12- Roperch et al. (2015); 13- Shaar et al. (2017); 14- Hartmann et al. (2009); 15- Hartmann et al. (2010); 16- Hartmann et al. (2011); 17- Gallet et al. (2005); 18- Bowles et al. (2005); 19- Osete et al. (2015); 20- Poletti et al. (2016); 21- Kissel et al. (2015); 22- Gratton et al. (2005); 23- Conte-Fasano et al. (2006); 24- Goguitchaichvili et al. (2015); 25- Gómez-Paccard et al. (2006b); 26- Tanaka et al. (2009); 27- Cottrell et al. (1999); 28- Catanzariti et al. (2008); 29- Chauvin et al. (2005); 30- Michalk et al. (2008); 31- Carlut and Kent (2000); 32- Genevey et al. (2003); 33- Gómez-Paccard et al. (2008); 34- Mankinen et al. (1993); 35- Mitra et al. (2013); 36Catanzariti et al. (2012); 37- Böhnel et al. (2003); 38- Genevey and Gallet (2002); 39- Tema et al. (2013); 40- Pressling et al. (2007); 41- Genevey et al. (2017); 42- Gómez-Paccard et al. (2013); 43- Pick and Tauxe (1993); 44- Shaar et al. (2015); 45- Fanjat et al. (2013); 46- Pressling et al. (2006); 47- Genevey et al. (2016); 48- De Groot et al. (2013); 49- Yoshihara et al. (2003); 50- Gómez-Paccard et al. (2012b); 51- Cai et al. (2016); 52- Spassov et al. (2010); 53- Yu (2012); 54- Donadini et al. (2008); 55- Di Chiara et al. (2014); 56- Genevey et al. (2013); 57- Gallet et al. (2009); 58- Gómez-Paccard et al. (2016); 59- GómezPaccard et al. (2012a); 60- Gratton et al. (2005); 61- Stanton et al. (2011); 62- Goguitchaichvili et al. (2011). 


\section{A4.3. Peer-review of Poletti et al. (2018)}

\section{First round of revision}

Dear Wilbor,

Thank you for submitting your manuscript to Physics of the Earth and Planetary Interiors. I have received comments from reviewers on your manuscript. Your paper should become acceptable for publication pending suitable moderate revision and modification of the article in light of the appended reviewer comments.

Kind regards,

Dr Jones

Editor

Physics of the Earth and Planetary Interiors

\section{\#Reviewer_1}

Dear Editor, please, find below my review on the manuscript PEPI_2017_133 entitled Continuous millennial decrease of the Earth's magnetic axial dipole submitted by Wilbor Poletti and collaborators to Physics of the Earth and Planetary Interiors.

The submitted work presents a study about the dipole moment decay of the Earth's magnetic field by means of a set of high-quality paleointensity data covering the last 2 millennia. The authors base their results on different linear fitting performed at different time scales. After discussion of the results, they compare them with previous studies and provide some conclusions about the present state-of-the-art of the past geomagnetic field behavior.

The manuscript is well organized and all the sections and figures are appropriated. The study reflects a laborious work to select the high-quality archeointensity data (including lava flows) for the last 2 millennia. However I have some important considerations in the applied approach as detailed below, including some methodological errors. I recommend to deeply review the manuscript before the publication in the PEPI journal.

I have some major comments summarized by sections: 
2.3. ADMs and VADMs. Some mistakes are found in the equations. I hope this mistakes are only typing mistakes in the manuscript and any error has not been translated to the calculations.

Eq. 1 -> I think the ratio $\mathrm{B}_{\text {field model }} / \mathrm{B}_{\text {indirect }}$ is in the opposite way: $\mathrm{B}_{\text {indirect }} / \mathrm{B}_{\text {field model }}$.

Eq. 2 -> The term " $1+\cos ^{\wedge} 2$ (theta)" should be " $1+\underline{\mathbf{3}^{*}} \cos ^{\wedge} 2$ (theta)". And the ratio (r/a)^2 should be $(\mathrm{a} / \mathrm{r})^{\wedge} 3$. By the way, this value is always 1 , since $\mathrm{r}=\mathrm{a}$.

Eq. 3 -> Again the term " $1+\cos ^{\wedge} 2$ (theta)" should be " $1+\underline{3^{*}} \cos ^{\wedge} 2$ (theta)".

Response: The reviewer is right and we thank him/her for making this correction. The errors in equations 1, 2 and 3 were typos, and did not reflect errors in the calculations. All suggested corrections were made in the manuscript (lines 238, 245 and 251).

\subsection{The geomagnetic ADM for the last four centuries.}

The authors calculate the VADM from both archeointensity databases, i.e. the total set and the high-quality data. As they point out, the first case show a smooth timeaveraged VADM due to the large number of data. However, when the high-quality data are use, the smoothness disappears and the spatial and temporal distribution of the data play an important role in the time-averaged VADM approach. The VADM is hardly biased to the geographical distribution of the data as can be seen in the following Figure. In this example, 1000 synthetic intensity data on a regular grid calculated by using the GUFM1 at 1900 show VADMs values range between $\sim 5$ and $\sim 16\left(10^{22} \mathrm{Am}^{2}\right)$. This spatial difference of around $11 \cdot 10^{22} \mathrm{Am}^{2}$ indicates that the VADM averaging process must be analysed with caution.

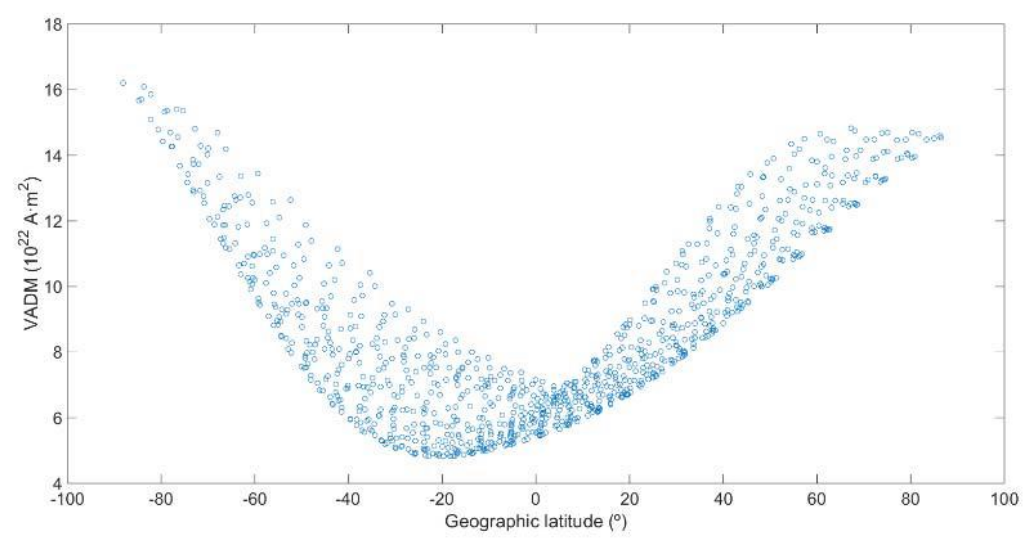

Figure. VADMs from GUFM1 at 1900 (1000 points on a regular grid). 
Response: We thank the reviewer for this important comment. However, before presenting our arguments and modifications, we would like to make a small note about Figure 1 (and consequently Figure 3) presented by reviewer in the review letter.

The intensity of the magnetic field varies for different latitudes, where, on average, the highest intensity values are close to the Earth's poles and the lower intensity values are close to the Earth's equator. As an example, we calculated the distribution of the magnetic intensity at the Earth's surface for the year 1900 AD. For that we used the gufm1 (Jackson et al., 2000) with a geographical coverage spaced every 10 degrees of longitude and 5 degrees of latitude (Fig. R1a).

In relation to VADM, its calculation is performed from the following equation:

$$
V A D M=\frac{4 \pi r^{3}}{\mu_{0}} B\left(\mathbf{1}+3 \cos ^{2} \boldsymbol{\theta}\right)^{-\frac{1}{2}}
$$

where $\mu_{0}$ is the permeability of free space, $r$ is the mean Earth radius, $B$ is the intensity, and $\theta$ is the co-latitude. Note that the VADM calculation has an important geometric function that depends on the co-latitude (highlighted in bold in equation 1).
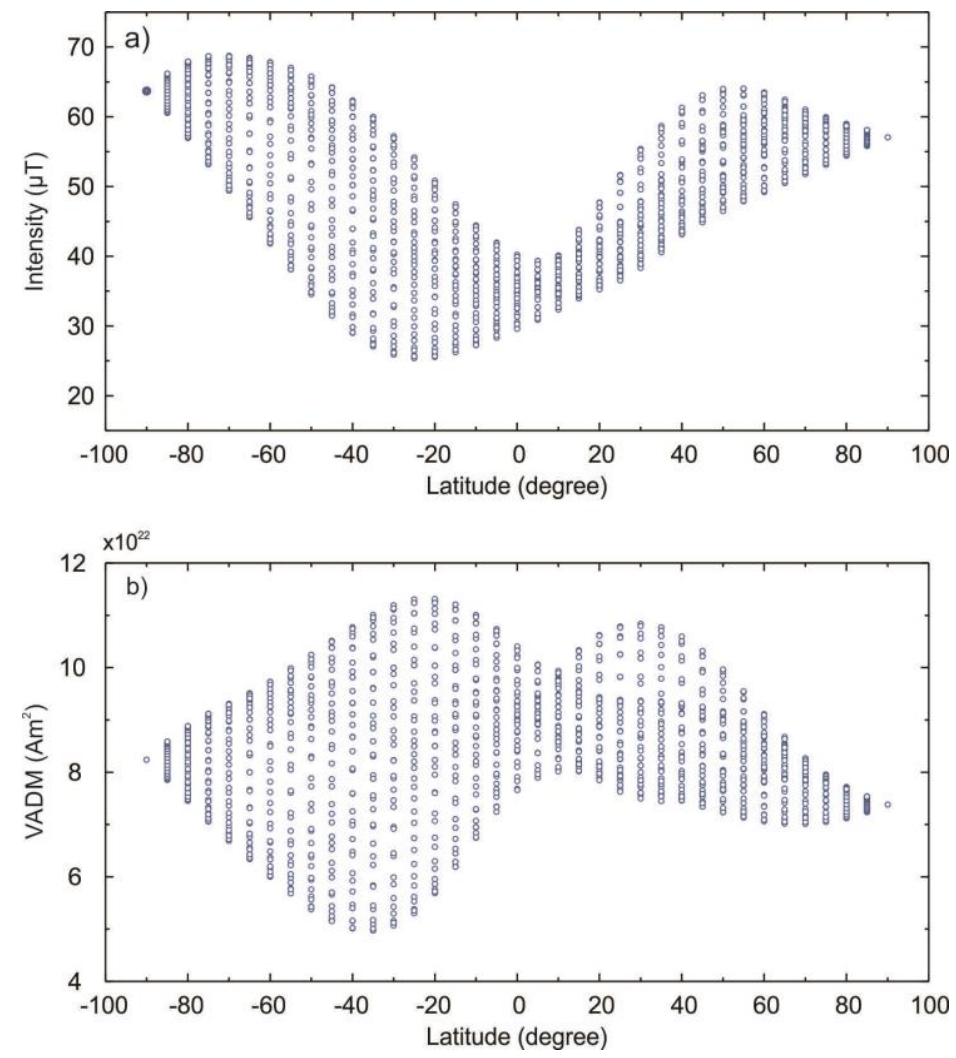

Figure R1: (a) intensity and (b) VADMs from gufm1 at 1900 AD with a geographical coverage spaced every 10 degrees of longitude and 5 degrees of latitude. 
From equation 1 we calculated the VADM values (in $\mathrm{Am}^{2}$ ) using the intensities shown in figure R1a. The distribution of VADM values is presented in Figure R1b. It is important to note that there is an expressive difference between the figure presented by the reviewer and figure R1b. We believe that there was a small error in the calculation performed by the reviewer, where he/she probably multiplied the values of magnetic intensity by a constant (e.g., $4 \pi a^{3} / \mu_{0}$ ). From the distribution shown in Figure R1b, we observe that the VADM values have a range of $7 \times 10^{22} \mathrm{Am}^{2}$ (between $\sim 4 \times 10^{22}$ and $\sim 11$ $\mathrm{x} 10^{22} \mathrm{Am}^{2}$ ), which remains significant. Another important observation is that the greatest differences in VADM values are found in the southern hemisphere. That said, we state that all the comments and suggestions rooted by the reviewer were carefully taken into account in the manuscript.

In the manuscript Figure 1a and $1 \mathrm{~b}$ one can observe increasing values of VADM after 1900 to the present (2009). This does not correspond to the well-known situation, i.e. the decay of the (axial) dipole moment during the last centuries. An important geographic bias is the responsible of this increasing due to the high number of paleomagnetic data coming from Europe and Asia, regions where the regional VADM is increasing during the $20^{\text {th }}$ century. All these considerations make that the use of the VADM and its averaging process must be performed with caution (e.g. Campuzano et al., 2015).

Response: In addition to the fact that there is a poor geographic distribution of data, the increase in magnetic intensity for the last century, described from archaeointensity measurements, is highlighted when the uncertainties of the measures are not considered. The current figure 5 (old-figure 3 ) of the manuscript exemplifies this point very well. It shows a tendency to increase the magnetic intensity from the absolute values; however, taking into account the uncertainties, we have a set with different possibilities to describe the magnetic variation for that period.

In order to clarify the text of the manuscript, and to take into account the comments made above, we divided figure 2 of the first manuscript into two distinct figures (current figures 3 and 4). In the current figure 3 our focus was to present the spatial and temporal distribution of all data used in our work, divided into three periods: 18402009 AD, 1590-2009 AD and 0-2009 AD. In the current figure 4 we present comparisons between the filtered archaeointensity data and the gufm1 estimative in order to discuss the latitudinal variation and the accuracy of the data. 
Please find in the manuscript two new paragraphs (lines 367-394) that argue all these points mentioned.

Other considerations. It is not clear the objectives to be achieved by the comparison between the archeointensity data and those synthetized by GUFM1 in the $1590-2009$ time-window (Figure 2). Residuals show a normal distribution with a clear bias to negative values that is more accentuated when the whole time period is considered. However the authors indicate that these histograms show a "good concordance between measured data and field model". In addition, they perform different test taking into account both age and intensity uncertainties (Fig. S1a-i). They evaluate all the possible scenarios using the mean values and errors. Again, I do not understand the objective of this test. Nevertheless, a more realistic test should be applied. For example, a Monte Carlo approach by using both random Gaussian and homogeneous distribution for the intensity and age uncertainties, respectively.

Response: Our objective was to compare the compatibility between the resulting archaeointensity data filtered by the selection criteria and those calculated for the same coordinates by historical models (which are well established but do not use this type of data).

Although there is a clear bias for negative values of the residual calculated between archaeointensity data and data computed by the historical models mentioned, indicating that these models tend to overestimate the intensity data, on average this bias is within one standard deviation. This indicates that both data types are compatible.

The comparison between the indirect data (taking into account the uncertainties of age and experimental) and the models was performed to make sure that on average all possible scenarios presents compatibility. Nevertheless, we did the test suggested by the reviewer, resulting in a similar behavior to what had already been presented (current supplementary figure 2).

Please find the modifications in the text of the manuscript (lines 395-409).

\subsection{The geomagnetic ADM four the last four centuries.}

The ADM for each selected data is calculated following the theorem of Hulot et al. (1997). Firstly for the Gauss period (1840 - 2009) and then for the rest of the GUFM1 timewindow, i.e. 1590 - 1840 . The indirect ADM values are then fitted by a linear regression performed in different time windows (Figures 3 and 4). It is surprising that after this 
laborious procedure, finally the authors decide to use a unique linear regression from 1590 to 2009 (blue line in Figure 4). I have no problem with that, but then, I would expect a discussion about the found differences between the seven $\alpha$-slopes shown in Figure $4 \mathrm{a}$ and the final $\alpha$-slope of $10.5 \mathrm{nT} / \mathrm{yr}$.

Response: In relation to this point we have restructured the last paragraph of this session (lines 445-477). In addition, the reviewer can find more detail in two new paragraphs in the section Methods, which were inserted in order to answering the point \#6 of the reviewer \#2 (lines 278-324).

Then they calculate some residuals comparing the effect of the new $\mathrm{g}_{1}{ }^{0}$ coefficient. Residual histograms (Figure 4b) calculated by using the new Gauss coefficient, based on the previous slope of $10.5 \mathrm{nT} / \mathrm{yr}$., seem more symmetric. I think this results is not relevant, since they use a modified GUFM1 model according to the selected paleomagnetic data and then, they again use the same data to validate their results (Figure S1j-r). I mean, it is redundant the use of a set of data to fit a parameter and then one calculates the residuals using this parameter and the same set of data. In this context, an alternative approach could be more suitable: a) to apply a Monte Carlo bootstrap in the linear fitting by using the $50 \%$ or $60 \%$ of data (randomly selected) from 1590 to 2009 and then calculate the residuals using the data that are not included in the fitting. This kind of test could provide more information since all the difference random scenarios are involved in the fitting approach.

Response: Our objective with Figure S1j-r was to show that the intensity estimates calculated from the modified gufm1 (by our g10 linear trend) are compatible with archaeointensity data and its uncertainties. We agree that this is not strong information, so we put it as supplementary material.

However, we appreciate the suggestion given by the reviewer and performed the mentioned test. Please find the modifications in the text of the manuscript (lines 478-489) and in the new supplementary figure 3 .

\subsection{The geomagnetic ADM for the last two millennia: VADM application as a proxy.} The authors perform different tests to investigate if the indirect VADM are representative of the axial dipole moment (ADM). Firstly they focus the analysis during the GUFM1 period (when both VADM and ADM are available) and then they extrapolate the results to the last 2 millennia (when ADM is not available). My main comment is that the authors 
perform this test using only a low and fix number of data, i.e. the selected data. In my view, a more realistic test should be carried out by using synthetic data covering all the Earth's surface (for example, by means of perturbed intensity synthetic data from GUFM1 model).

Response: Our tests were based on a limited number of data, since we chose to apply strict selection criteria in the archaeointensity results. From this restricted number of data and their respective intensity/age uncertainties, our objective was to describe the geomagnetic axial dipole variation in a robust and parsimonious form. According to our analyses for the period 1590-2009 AD, the linear solutions were statistically satisfactory and sufficiently robust to provide a good and clear new point-of-view regarding the dipole evolution (please see the tests performed in the first version of the manuscript and those performed based on the suggestion of the reviewers).

Another important point is that there are several possible approaches to describe the variations of the intensity (VADM and ADM) as a function of age from the dataset used in our work. However we chose the linear one since it tends to minimize the effects of rapid, local and non-linear influences in the geomagnetic field (please see the new paragraph in the Methods section; lines 278-324). In this way, we can stride toward quantitative assessments of physical processes that describe the mechanism of Earth's magnetic field generation.

I'd like to illustrate this issue with this example.

Next panel shows the differences between VADM and ADM by means of the GUFM1. The VADM is calculated in the 1000-point regular grid over the Earth's surface and the ADM is proportional to the first GUFM1 Gauss coefficient. The calculations were performed every 200 years from 1590 to 1900 . 

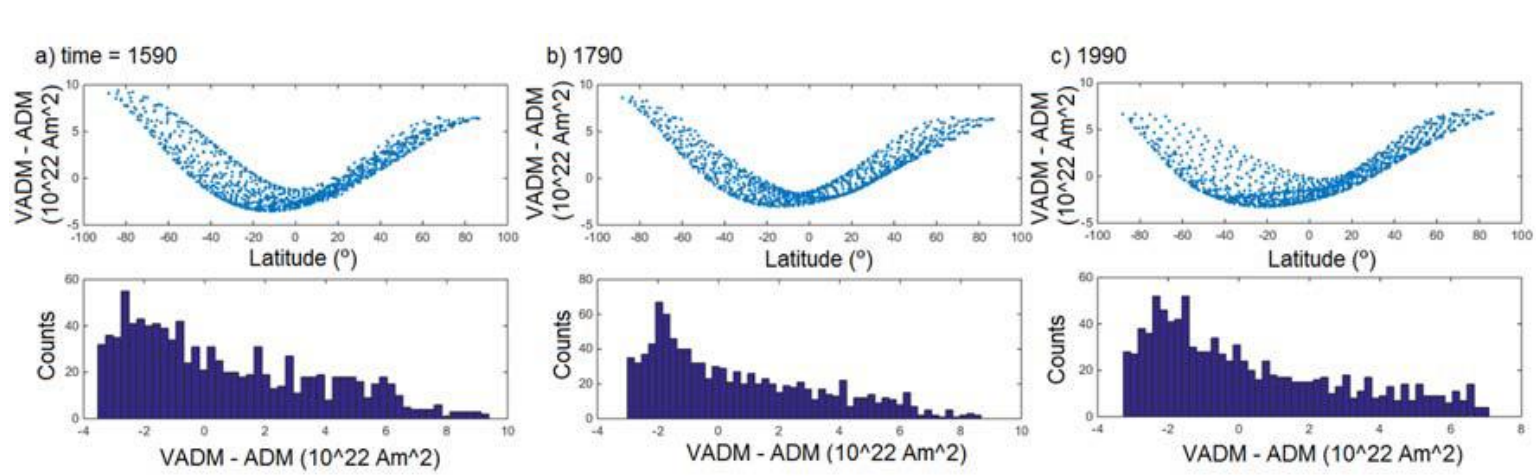

Figure. VADM - ADM using GUFM1 and a regular grid of 1000 points over the Earth' surface from 1590 to 1990 (every 200 years). Up shows residuals versus latitude. Down are the histogram of the residuals.

The above figure shows a clear important dispersion between VADM and ADM calculated from the GUFM1 model. All the mean residuals are positive indicating that the spatial-averaged VADM is higher than the ADM at each time. This result points out the relevance of the rest of harmonic contributions (i.e. g11, h11, g20, g21, etc.) that play an important role in the VADM estimations (mostly due to the g11 and h11 contributions). ADM only depends on the $\mathrm{g}_{1}{ }^{0}$ Gauss coefficients and thus lower values are expected. This result does not agree with the histogram of Figure 5c where the VADM - ADM values (using the locations and time of the selected data) from GUFM1 are plotted. More details should be provided about this issue. According to the above indications, I am not sure that the test carried out by the authors in the historical window is so robust to apply it for the rest of the time period $(0-1590)$. Their assumptions also should indicate that a similar harmonic content is expected during the prehistorical period, but they do not mention that in the manuscript.

Response: We address the question about latitudinal variation vs archaeointensity data in the manuscript (lines 377-394). According to the results presented in the current Fig. 4a and $4 \mathrm{~b}$, most of the data is in the northern hemisphere, which the residual between VADM and ADM tend to be lower (see circles from gufm1). When we look at the selected dataset plotted in the same figure, it is possible to verify a good agreement between VADMs calculated from indirect estimations and ADM from gufm1, and also they lower residual. In relation to Fig. 5c of the first manuscript (current Fig. 7), in fact it is observed that the mean of the residual indicates that the values of $\mathrm{ADM}_{\text {models }}$ is an overestimate of $\mathrm{VADM}_{\text {indirect. }}$ However, on average, they are equivalent, since they tend to zero within one standard deviation. This point can also be observed in the new Fig. $4 \mathrm{a}$ and $4 \mathrm{~b}$, where 
data from the northern hemisphere (i.e., the majority of the dataset) present mean values of $\mathrm{VADM}_{\text {indirect }}$ smaller than $\mathrm{ADM}_{\text {gufm1 }}$ but compatible with each other and with gufm1.

We believe that, after taking into account all the suggestions provided by the reviewers, the premise of using VADM as a "proxy" of ADM for the pre-historical period has become more satisfactory. Finally, we would like to illustrate that the VADM values calculated by gufm 1 and from our linear g10 fit inserted into (Fig. R2). In Figure R2 it is possible to see that the residual of the mean values for the Gauss era is $\sim 0.4 \mu \mathrm{T}$, which represents only $\sim 8.5 \%$ of the lowest VADM value for this period. Between 1590 and1990 $\mathrm{AD}$ the residual is almost zero. Furthermore, it is important to note that the shape of the VADMs distribution does not change. This shows that our linear model of the geomagnetic axial dipole is a good approximation for the historical period. Thus, the way in which we calculated this result is, again, robust enough to be applied in the period investigated in this work.
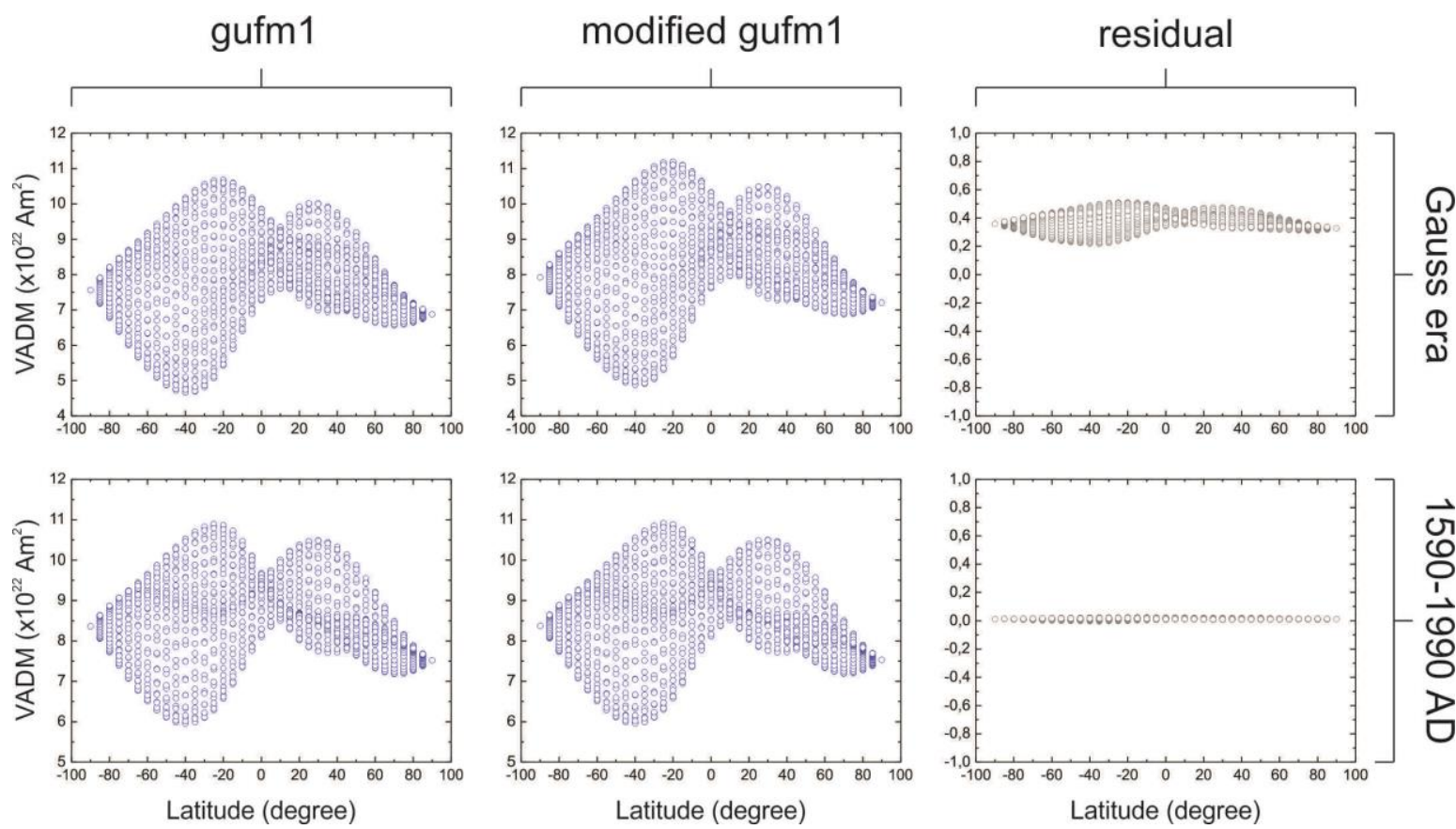

Figure R2: Latitude vs VADM plots.

At the end of this section, the authors study the differences between the original GUFM1 model and that modified by the new $\mathrm{g}_{1}{ }^{0}$ Gauss coefficient with rate of $10.5 \mathrm{nT} / \mathrm{yr}$. (Figure 6b-g). A first view of the residual maps show how these residuals are given by horizontal bands in the Aitoff or Hammer map-projection. This surprises me!!!! Can a little change in the $\mathrm{g}_{1}{ }^{0}$ Gauss coefficient generate this rare residual distribution of $\mathrm{Br}$ at the $\mathrm{CMB}$ ? 
To analyse this issue, I perform a similar map (next figure) using the averaged $\mathrm{Br}$ at the CMB from 1590 to 1990 every 10 years. The obtained residual map does not show the result of the manuscript. I think the error could be related to the modified GUFM1 model. In fact, when I simply exchange the g10 GUFM1 coefficient by the new g10 proposed by the authors, I obtain the map of residuals given by the authors (framed as red in the next figure). This indicate me that the GUFM1 modification was not performed correctly! The authors have directly replace the original g10 coefficient for the new one and this procedure is not correct. The modification must be done also following the Theorem of Hulot et al. (1997). All the Gauss coefficients must be firstly normalized by the original g10 coefficient and then they are rescaled by the new one: $\mathrm{g}_{\mathrm{n}}{ }^{\mathrm{m}}{ }_{\text {new }}=\mathrm{g}_{\mathrm{n}}{ }^{\mathrm{m}}{ }_{\text {GUFM1 }} \times \mathrm{g}_{1}{ }^{0}{ }_{\text {new }} /$ $\mathrm{g}_{1}{ }^{0}$ GUFM1. Then, I suggest to completely review the calculations of the modified GUFM1 model in the whole manuscript.

Average $\mathrm{Br}$ - GUFM1

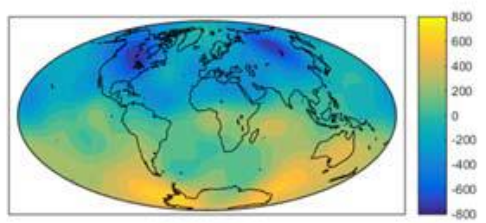

Average $\mathrm{Br}$ - GUFM1

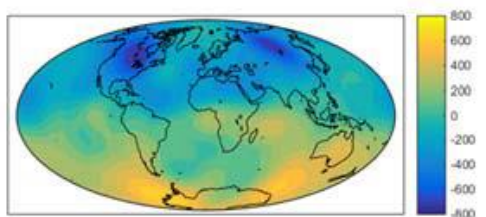

Average $\mathrm{Br}$ - Author modification rescaling all Gauss coefficients

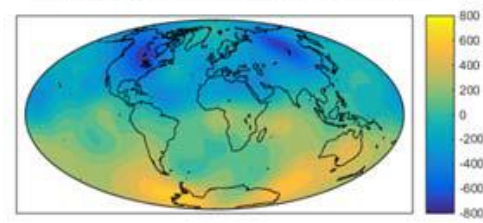

Average $\mathrm{Br}$ - Author modification just changing g10

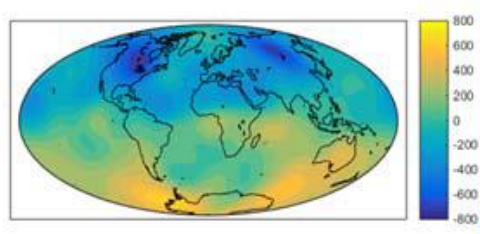

Residuals

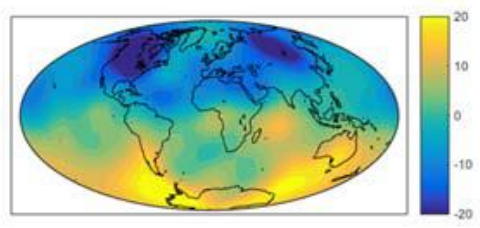

Residuals

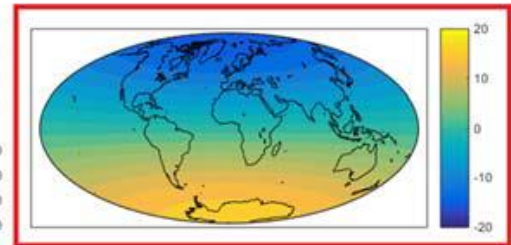

Figure. Maps (a,b) of averaged Br at CMB (1590 - 1990) and the residual map (c).

Response: We thank the reviewer for the observation. We exhaustively demonstrated that there is a statistical equivalence between the description of the geomagnetic axial dipole presented by us and by the gufm1. Therefore, we have chosen to only replace the dipole term (g10) and verify its influence in the gufm1. However, we understand that the form suggested by the reviewer is more appropriate. We state the method of substituting coefficients in the text of the new manuscript (line 467-477) and change the Fig. 6 of the first manuscript (current Fig. 8). It is important to mention that the extreme values of the residuals did not change our interpretations (line 530). In addition, we would like to point 
out that the reviewer's concern that there was a serious mistake spread throughout the manuscript is unfounded, since the conclusions drawn by this work have remained intact.

Reference: Campuzano, S. A., Pavón-Carrasco, F. J., \& Osete, M. L. (2015). Non-Dipole and Regional Effects on the Geomagnetic Dipole Moment Estimation. Pure and Applied Geophysics, 172(1), 91-107.

End of review.

\section{\#Reviewer 2}

This paper is interesting, well written and well presented. My main concern is that I am not fully convinced by the technique used by the authors that leads to a very parsimonious description of the dipole evolution. I don't see a real progress relative to previous dipole determinations. However I consider that the authors made a serious work and I recommend the publication of their paper. I list below a series of comments and questions.

1. Section 2.1, line 118: Instead of indicating 'and references therein', better to cite at least several references in the main text.

Response: We replace "and references therein" by a list with the main references that compare the TT, TR and MW palaeointensity methods (lines 118-124). References were separated by the type of comparison made (TT-TR, TT-MW and TT-TR-MW).

2. Section 2.2, line 145: Do you mean that only the data having pTRM tail checks (except TR data) were retained? How many data satisfying all the other criteria are eliminated due to this single criterion? Is it critical for your estimates?

Response: Strictly speaking we emphasize the need to have additional steps as pTRM tail check or other way to investigate the MD grain influence (see below the paragraph extracted from the first manuscript).

“....as well as additional steps, referred to as pTRM tail checks (Riisager and Riisager, 2001), to verify possible MD grains influence or other tests that check for this source of bias." 
However, we have revised the text for this criterion to "We required at least one test-type to verify possible MD grains influence (e.g., Riisager and Riisager, 2001; Krása et al., 2003; Yu et al., 2004), in order to avoid the violation of the principles of additivity and reciprocity, which are part of the backbone of the Thellier-Thellier method (Yu and Dunlop, 2003; Dunlop, 2011)". This makes it independent of the others, and emphasizes the importance of a good control over possible MD grain influences (lines 163-167). Although we revised this criterion, the number of samples rejected by it remained the same (665 entries) (lines 349-357; new Figure 1).

3. Section 2.2, line 154: According to the text, it seems that only the data with estimates of their TRM anisotropy tensors were retained. The authors thus rejected all the data for which measurements were carried out on their susceptibility or ARM anisotropy tensors. Can you comment this point?

Response: In order to answer this important comment we added the explanation in the manuscript (lines 174-182).

4. Why not considering a cooling rate effect of $5 \%$ for the data without that correction (this order of magnitude is very reasonable). Same remark as in \#2: How many data satisfying all the other criteria are rejected due to the cooling rate effect. What is the implication of this rejection? What's happen if you consider a cooling rate effet of $5 \%$ for those data?

Response: We totally agree that considering a cooling rate effect of $5 \%$ on results that have not been corrected is very reasonable. However, our main objective in this part of the work (section 2.2) is to select the maximum number of results that satisfy the most restricted criteria. For example, Genevey et al. (2009), Hartmann et al. (2010) and Poletti et al. (2013) showed that the cooling rate effect can affect the final results up to 10, 15 and $25 \%$, respectively. Since we are working with a restricted catalog of results, considering the effect of 5\% could imply an accumulation of errors which, in turn, could imply greater uncertainties in our sets of linear regressions. In total, only 80 data were discarded because they did not present the cooling rate correction (3.2\% of all dataset) (lines 355-356). Of these 80 data, the application of other selection criterion (current vii) would still be necessary, which would imply in the reduction of this number. Incorporating the data corrected by a factor of 5\% would hardly change our end result, 
but again, it would increase the sets of linear solutions, and this could bring different possibilities of interpretation based on data that we know to be noisy.

To balance the text of the topic in question with the main text, we have added the expressions that can be read on lines 187-190.

5. Important to indicate somewhere in the text that the definition of the archeomagnetic sites may be very different from one study to another (several samples/specimens from a single fragment, several fragments with a single sample each, several fragments with several samples each, etc.). Do you consider that all sites are equivalent, even though their definition is very different?

Response: We thank the reviewer for making this important observation. Attached to the topic (current vii) we have written a new paragraph dealing with the different definitions about archaeomagnetic site. In our work there was no distinction about the different forms of definition of archaeomagnetic site. This issue was also addressed in a new paragraph (lines 198-222).

6. Section 2.4, lines 221-226: OK but not clear to me what is the advantage and benefit of the linear regression method relative to the others (inversion, time/spatial averaging, etc.). In particular, justification of this approach by simply referring to Gubbins et al.'s work (lines 217-218) is not sufficient.

Response: In order to make clear the reason why we approach the description of the geomagnetic axial dipole evolution by linear regressions, we insert two new paragraphs in section 2.4 that give all details of our strategy (lines 278-324).

7. Section 2.4, lines 234-238: It is hard to realize how the linear regression technique allows one to avoid a bias due to the poor spatial distribution of the data. Figure 3 is appealing but the range of solutions is quite large.

Response: We agree that the range of solutions presented in the figure 3 of the first manuscript is quite large (current figure 5). However, for long periods (e.g., last millennia) the strategy of multiple linear regressions emerged as a robust approach enough to capture a single linear solution that was able to describe the main trend of the geomagnetic axial dipole for the last millennium (current Fig. 9). Please see also the response for the point \#6. 
In additional, and answering the comment made by reviewer \#1 in the point: "3.1 The geomagnetic ADM for the last four centuries", we checked the latitudinal influence on the selected data and presented more statistical tests regarding the comparisons made between filtered data and those derived by gufm1 (Jackson et al., 2000) and CHAOS-5 (Finlay et al., 2015) for the periods 1840-2009 AD and 1590-2009 AD (lines 378-410; and new figures 3 and 4 ).

8. Section 2.4, lines 240-242: OK but 50 years is obviously too short to eliminate all nondipole field components.

Response: When using to rapid time-variations we not refer to all non-dipolar components but to the higher degree components of the field $(1>\sim 9$, where 1 is the spherical harmonic degree). Note that the SV time scale decays as $\tau_{\mathrm{sv}} / 1$ where $\tau_{\mathrm{sv}}$ is equal to $415+55 /-45$ (Lhuillier et al., 2011). For example, for the quadrupole the SV timescales is between 190-235 yr. In order to clarify we modified our statement (lines 339-341).

\section{Section 3.1, lines 246-252: see point \#5 above.}

Response: Please see the answer given to point \#5. In addition, the mentioned paragraph (lines 246-252 of the first manuscript) has been rewritten in order to provide more details (lines 345-357).

10. Section 3.1, lines 246-252 and supplementary material: It seems to me that there is a number of missing references/data, for instance Gallet et al. C R Physics 2009, Donadini et al. JAS 2012, di Chiara et al. PEPI 2014, Kissel et al. EPSL 2015, Shaar et al. GGG 2015, Hammond et al. Archaeometry 2016, Salnaia et al. PEPI 2017, Kapper et al. Nature Sci. Rep. 2017, etc.

Response: We appreciate the references provided by the reviewer. All mentioned works and other additional were evaluated. Please find below the list of references and the number of data that were uploaded in our analysis.

Sequence of information: first author; journal; year of publication; if the data were considered; if yes - the number of uploaded data, if not - justification.

\section{References provided by the reviewer:}

Gallet et al. C R Physics 2009 - ok - 1 data;

Donadini et al. JAS 2012 - no - AARM*; 
di Chiara et al. PEPI 2014 - ok - 5 data;

Kissel et al. EPSL 2015 - ok - 1 data;

Shaar et al. GGG 2015 - ok - 10 data;

Hammond et al. Archaeometry 2016 - no - the samples are not dated (archaeomagnetic dating study);

Salnaia et al. PEPI 2017 - ok - 9 data;

Kapper et al. Nature Sci. Rep. 2017 - no - AARM*.

\section{Further references sourced by the authors:}

Cai et al. EPSL 2014 - ok - 4 data;

Cai et al. PNAS 2016 - ok - 13 data;

Genevey et al. JAS 2017 - ok - 5 data;

Goguitchaichvili et al. PEPI 2011 - ok - 4 data;

Goguitchaichvili et al. PEPI 2015 - ok - 1 data;

Pick and Tauxe JGR 1993 - ok - 4 data;

Roperch et al. PEPI 2015 - ok - 6 data;

Shaar et al. GRL 2017 - ok - 1 data.

*AARM means that the data were corrected from ARM tensors (see point \#3).

At this point of the revision it is important to mention that after uploading the above mentioned data, all the calculations were repeated and all the figures that represented results from the analysis were adjusted.

Please find the change in the text of the manuscript (lines 345-357) and in the current figures $1,2,3,6,7,8,9$ and 10 .

11. Section 3.1, lines 314-315: But several studies emphasized the relatively poor accuracy of the early segment of gufm1 (see for instance the recent paper of Le Goff and Gallet, EPS 2017). In your discussion, please discuss and take into account this source of uncertainties.

Response: The modifications regarding this point were inserted in the text of the manuscript (lines 445-457). 
12. Section 3.3 (Fig. 7). The authors should also show (and discuss) a comparison of their curve with previous VADM curves computed using temporal and spatial averaging (Knudsen et al. EPSL 2008, Genevey et al. GGG 2008, Usoskin et al. A\&A 2016).

Response: Please find the modifications in the text of the manuscript (lines 607-639) and in the current Fig. 10.

13. As the dipole estimates proposed by Genevey et al. (2008) and Hartmann et al. (2011) rely on the accuracy of the geomagnetic field geometry given by gufm1 (together with Hulot et al.'s theorem), the authors suggest by their sentence that something went wrong for these two datasets satisfying all the selection criteria. Please explain better and present arguments.

Response: The part of the text that discusses this point is composed by two phrases:

1) "Some studies reported that regional high-quality archaeointensity data have sufficient resolution to describe oscillatory behavior of the geomagnetic axial dipole (Genevey et al., 2009; Hartmann et al., 2011).”

2) "However, given the inherent experimental errors and limited geographical coverage, we suggest that the current global archaeointensity dataset cannot reproduce small fluctuations in the geomagnetic axial dipole."

In phrase 1 we emphasize that the data proposed by Genevey et al. (2009) and Hartmann et al. (2011) do have high enough resolution to describe an oscillatory behavior of the geomagnetic axial dipole. As opposed to reviewer's comment, there is no mention of anything wrong with the data from these two papers. However, we think it is more accurate to change the word "describe" by "suggest" (line 572).

In phrase 2 we have changed the point highlighted in bold: "... archaeointensity dataset, on average, cannot reproduce..."; (line 575) in order to present a clear distinction between local results and global mean.

14. Section 4.2: see comment \#11. Please make a comparison with previous estimates.

Response: Please see the response for the comment \#11. 
15. Section 4.3: The decrease of the axial dipole field moment over the past 150 years has been related to the emergence of the South Atlantic Magnetic Anomaly. Does it mean that, for the authors, this anomaly would have started about 1000 years ago?

Response: We thank the reviewer for this interesting question. Although SAA and dipole decay may be linked, some care is needed with this type of analysis, once one is field morphology and the other is an SV process, respectively. If the dipole decay is ancient it may mean that SAA started evolving long time ago, not that SAA was around long time ago. There is a subtle difference here. Regardless, it is interesting to use our $\mathrm{g} 10(\mathrm{t})$ to track SAA for 1590-1840 AD. Our tracking results were similar to those in Hartmann and Pacca (2009), which is expected since the SAA position is highly sensitive to the positions of non-dipolar features on the CMB (Terra-Nova et al., 2017). Nevertheless, a more comprehensive assessment of the age of the SAA is out of the scope of this work.

16. Section 4.3, lines 482-489, in particular the last sentence: Please explain much better your speculation, with more explanation on the constraints provided by Amit et al.'s work.

Response: We better explain our speculation. Please find the modifications in the text of the manuscript (lines 670-674).

17. In order to make more visible the effort made by the investigators, it would be better to present the supplementary table 1 and the related reference list in an appendix at the end of the main text.

Response: We accept the suggestion made by the reviewer and transfer the Table S1 of the first manuscript to the new Appendix section.

\section{References used by the authors in the reviewers' letter}

Cai, S., Jin, G., Tauxe, L., Deng, C., Qin, H., Pan, Y. and Zhu, R., 2016. Archaeointensity results spanning the past 6 kiloyears from eastern China and implications for extreme behaviors of the geomagnetic field. Proc. Natl. Acad. Sci. 114, 39-44.

Cai, S., Tauxe, L., Deng, C., Pan, Y., Jin, G., Zheng, J., Xie, F., Qin, H. and Zhu, R., 2014. Geomagnetic intensity variations for the past $8 \mathrm{kyr}$ : New archaeointensity results from Eastern China. Earth Planet. Sci. Lett. 392, 217-229.

Dunlop, D. J., 2011. Physical basis of the Thellier-Thellier and related paleointensity methods. Phys. Earth planet. Inter. 187, 118-138. 
Finlay, C.C., Olsen, N. and Toeffner-Clausen, L., 2015. DTU candidate field models for IGRF-12 and the CHAOS-5 geomagnetic field model. Earth Planets and Space, 67.

Genevey, A., Gallet, Y., Rosen, J. and Le Goff, M., 2009. Evidence for rapid geomagnetic field intensity variations in Western Europe over the past 800 years from new French archaeomagnetic data. Earth Planet. Sci. Lett. 284, 132-143.

Genevey, A., Kondopoulou, D., Pétridis, P., Aidona, E., Muller, A., Blondé, F. and Gros, J. S., 2017. New constraints on geomagnetic field intensity variations in the Balkans during the Early Byzantine period from ceramics unearthed at Thasos and Delphi, Greece. J. Archaeol. Sci. In Press.

Goguitchaichvili, A., Greco, C. and Morales, J., 2011. Geomagnetic field intensity behavior in South America between 400 AD and 1800 AD: first archeointensity results from Argentina. Phys. Earth Planet. Int. 186, 191-197.

Goguitchaichvili, A., Morales, J., Schavelzon, D., Vásquez, C., Gogorza, C. S., Loponte, D. and Rapalini, A., 2015. Variation of the Earth's magnetic field strength in South America during the last two millennia: New results from historical buildings of Buenos Aires and re-evaluation of regional data. Phys. Earth Planet. Int. 245, 15-25.

Hartmann, G. A. and Pacca, I. G., 2009. Time evolution of the South Atlantic magnetic anomaly. An. Acad. Bras. Cien. 81, 243-255.

Hartmann, G. A., Genevey, A., Gallet, Y., Trindade, R. I., Etchevarne, C., Le Goff, M. and Afonso, M. C., 2010. Archaeointensity in Northeast Brazil over the past five centuries. Earth Planet. Sci. Lett. 296, 340-352.

Hartmann, G. A., Genevey, A., Gallet, Y., Trindade, R. I., Le Goff, M., Najjar, R., Etchevarne, C and Afonso, M. C., 2011. New historical archaeointensity data from Brazil: Evidence for a large regional non-dipole field contribution over the past few centuries. Earth Planet. Sci. Lett. 306, 66-76.

Jackson, A., Jonkers, A. R. and Walker, M. R., 2000. Four centuries of geomagnetic secular variation from historical records. Phil. Trans. R. Soc. Lond. A 358, 957-990.

Krása, D., Heunemann, C., Leonhardt, R. and Petersen, N., 2003. Experimental procedure to detect multidomain remanence during Thellier-Thellier experiments. Phys. Chem. Earth. 28, 681-687.

Lhuillier, F., Fournier, A., Hulot, G. and Aubert, J., 2011. The geomagentic secular vatiation timescale in observations and numerical dynamo models. Geophys. Res. Lett. 38, L055306. 
Pick, T. and Tauxe, L., 1993. Holocene paleointensities: Thellier experiments on submarine basaltic glass from the East Pacific Rise. J. Geophys. Res. 98(B10), 1794917964.

Poletti, W., Hartmann, G. A., Hill, M. J., Biggin, A. J. and Trindade, R. I. F., 2013. The cooling-rate effect on microwave archaeointensity estimates. Geophys. Res. Lett. 40, 3847-3852.

Riisager, P. and Riisager, J., 2001. Detecting multidomain magnetic grains in Thellier palaeointensity experiments. Phys. Earth planet. Inter. 125, 111-117.

Roperch, P., Chauvin, A., Lara, L. E. and Moreno, H., 2015. Secular variation of the Earth's magnetic field and application to paleomagnetic dating of historical lava flows in Chile. Phys. Earth planet. Inter. 242, 65-78.

Shaar, R., Tauxe, L., Goguitchaichvili, A., Devidze, M. and Licheli, V., 2017. Further evidence of the Levantine Iron Age geomagnetic anomaly from Georgian pottery. Geophys. Res. Lett. 44, 2229-2236.

Terra-Nova, F., Amit, H., Hartmann, G. A., Trindade, R. I. and Pinheiro, K. J., 2017. Relating the South Atlantic Anomaly and geomagnetic flux patches. Phys. Earth planet. Inter. 266, 39-53.

Yu, Y. and Dunlop, D. J., 2003. On partial thermoremanent magnetization tail checks in Thellier paleointensity determination. J. Geophys. Res. 108(B11).

Yu, Y., Tauxe, L. and Genevey, A., 2004. Toward an optimal geomagnetic field intensity determination technique. Geochem. Geophys. Geosyst. 5, Q02H07.

\section{$\underline{\text { Final Decision }}$}

Dear Wilbor,

I am pleased to inform you that your paper has been accepted for publication. There are a few reviewer comments below, but these are only for information and future work.

Kind regards,

Chris Jones

Editor

Physics of the Earth and Planetary Interiors 


\section{Comments from the editors and reviewers:}

\section{\# Reviewer 1}

Dear Poletti and co-authors.

First, I would like to apologise for my wrong calculations of the VADM in my review. I changed by mistake in my software the geographical colatitude by the latitude. The correct figure of my review should be that given by the authors in the review letter. However, the correct figure (as shown by the authors in the new Fig. 4 of the new manuscript) also confirms that the VADM must be taken into account with caution and now the authors have included new material in the manuscript describing this issue. I think the VADM biases generated by the poor spatial and temporal distribution of the present archeomagnetic/volcanic data must be remarked. In the new manuscript, the authors have pointed out these aspects with new paragraphs and figures.

The authors have also corrected the mistakes in their equations and they have performed new statistical tests providing robustness to their results. In addition, a correct use of the modified GUFM1 model was performed using the re-normalized Gauss coefficients as indicated in the new manuscript.

After the authors' review, I would like to suggest the publication of the new manuscript in Physics of the Earth and Planetary Interiors.

Best.

End of review.

\section{- Reviewer 2}

I was surprised by the different points raised by Reviewer 1 who made an impressive work (a big chance for the authors!). In particular, I could not imagine that the authors were only replacing the dipole term when modifying the gufm1 models on the basis of Hulot et al's theorem (same for the equations). This was indeed a real mistake, even if the results are not very different.

I did not check the VADM values from gufm1 at 1900, but I think that the authors show the correct distribution (Figure R1).

Here my main concern: I do not want to be an ardent advocate of the VADM technique for recovering the dipole term, but it seems to me that a spatial and temporal averaging (for instance over sliding windows of several hundred years) of the VADMs should exhibit a dipole evolution not that far from the reality (or as good/bad as the results 
provided by more sophisticated techniques, including the 'linear' method). As underlined by the authors, this is indeed the case for the time interval spanning the past 800 years (whatever the data selection and treatment; Fig. 10). Yet the results are very different for the older periods, with a pronounced peak around 700-800 AD when using the linear method whereas all the other methods lead to a limited maximum (and variations lying in the error bars). This is the most important result of this study, but the reason for this discrepancy is unclear and relatively poorly discussed. So my concern is the following: could the authors estimate (and discuss) a mean-VADM curve using their data set (and show it in Fig. 10b). This would allow one to better constrain whether the pronounced peak is data-related or essentially method-related.

The authors made a significant revision of their manuscript. I consider that they satisfactorily answered to the different issues I raised in my previous review. In particular, I am satisfied to see that they realized the importance of the definition of the archeomagnetic sites.

Only one point of criticism (but I do not ask for any change): it is still unclear to me how the authors reconcile the dipole evolution discussed in Genevey et al. (2009) and Hartmann et al. (2011), with the linear decrease they propose over the past millennium. Their text explanation is rather elusive: this cannot be a problem of limited geographical coverage, as relying on Hulot's theorem, or of resolution); it thus remains the issue of experimental errors (and, in this case, there is something wrong with the data!).

To summarize, I consider that this paper could be published in its present form, even though I would like to see the VADM evolution derived from their data set. 


\section{References}

Aitken, M. J., Alcock, P. A., Bussel, G. D. and Shaw, C. J., 1981. Archaeomagnetic determination of the past geomagnetic intensity using ancient ceramics: allowance for anisotropy. Archaeometry 23, 53-64.

Aitken, M. J., Allsop, A. L., Bussel, G. D. and Winter, M. B., 1988. Determiation of the intensity of the Earth's magnetic field during archaeological times: Reliability of the Thellier technique. Rev. Geophys. 26, 3-12.

Amit, H. and Pais, M. A., 2013 Differences between tangential geostrophy and columnar flow. Geophys. J. Int. 194, 145-157.

Amit, H., Coutelier, M. and Christensen, U.R., 2017 On equatorially symmetric and antisymmetric geomagnetic secular variation timescales. Phys. Earth planet. Inter, 276, 190-201.

Amit, H., Korte, M., Aubert, J., Constable, C. and Hulot, G., 2011 The time-dependence of intense archaeomagnetic flux patches. J. Geophys. Res. 116, B12.

Arneitz, P., Egli, R. and Leonhardt, R., 2017a. Unbiased analysis of geomagnetic data sets and comparison of historical data with paleomagnetic and archaeomagnetic records. Rev. Geophys., 55, 5-39.

Arneitz, P., Leonhardt, R., Schnepp, E., Heilig, B., Mayrhofer, F., Kovacs, P., Hejda, P., Valach, F., Vadasz, G., Hammerl, C., Egli, R., Fabian, K. and Kompein, N., 2017b. The HISTMAG database: combining historical, archaeomagnetic and volcanic data. Geophys. J. Int. 210, 1347-1359.

Aubert, J., 2014. Earth's core internal dynamics 1840-2010 imaged by inverse geodynamo modelling. Geophys. J. Int. 197, 119-134. 
Aubert, J., Finlay, C. C., and Fournier, A., 2013. Bottom-up control of geomagnetic secular variation by the Earth's inner core. Nature 502, 219-223.

Baptista, J., 2010. O Temporal: sociedade e espaços missionais. Dossiê Missões, 1. $2^{\mathrm{a}}$ edição (2015). Rio Grande do Sul.

Bevington, P. R. and Robinson, D. K., 2003. Data reduction and error analysis for the physical sciences (McGraw-Hill).

Biggin, A. J., Piispa, E. J., Pesonen, L. J., Holme, R., Paterson, G. A., Veikkolainen, T. and Tauxe, L., 2015. Palaeomagnetic field intensity variations suggest Mesoproterozoic inner-core nucleation. Nature, 526(7572), 245.

Biggin, A. J., Steinberger, B., Aubert, J., Suttie, N., Holme, R., Torsvik, T. H., Van der Meer, D. G. and Van Hinsbergen, D. J. J., 2012. Possible links between long-term geomagnetic variations and whole-mantle convection processes. Nature Geo., 5(8), 526.

Biggin, A.J., 2006. First-order symmetry of weak-field partial thermoremanence in multi-domain (MD) ferromagnetic grains: 2. Implications for Thellier-type palaeointensity determination. Earth Planet. Sci. Lett., 245, 454-470.

Biggin, A.J., 2010. Are systematic differences between thermal and microwave Thellier-type palaeointensity estimates a consequence of multidomain bias in the thermal results? Phys. Earth Planet. Int. 180, 16-40.

Biggin, A.J., Badejo, S., Hodgson, E., Muxworthy, A., Shaw, J. and Dekkers, M.J., 2013. The effect of cooling-rate on the intensity of thermoremanent magnetization (TRM) acquired by assemblages of pseudo-single domain, multi domain, and interacting single domain grains. Geophys. J. Int. 193, 1239-1249. 
Biggin, A.J., Thomas, D.N., 2003. The application of acceptance criteria to results of Thellier palaeointensity experiments performed on samples with pseudo singledomain-like characteristics. Phys. Earth Planet. Int., 138, 279-287.

Bloxham, J., Gubbins, D., 1985. The secular variation of the Earth's magnetic field. Nature, 317, 777-781.

Bloxham, J., Zatman, S. and Dumberry, M., 2002. The origin of geomagnetic jerks. Nature, 420(6911), 65.

Böhnel, H., Biggin, A. J., Walton, D., Shaw, J. and Share, J. A., 2003. Microwave palaeointensities from a recent Mexican lava flow, baked sediments and reheated pottery. Earth Planet. Sci. Lett. 214, 221-236.

Bowles, J., Gee, J. S., Kent, D. V., Bergmanis, E. and Sinton, J., 2005. Cooling rate effects on paleointensity estimates in submarine basaltic glass and implications for dating young flows. Geochem. Geophys. Geosyst. 6, Q07002.

Brown, M. C., Donadini, F., Korte, M., Nilsson, A., Korhonen, K., Lodge, A., Lengyel, S.N. and Constable, C.G., 2015. GEOMAGIA50. v3: 1. general structure and modifications to the archaeological and volcanic database. Earth Planets Space 67:83.

Burke, K., Steinberger, B., Torsvik, T.H. and Smethurst, M.A., 2008. Plume generation zones at the margins of large low shear velocity provinces on the core-mantle boundary. Earth Planet. Sci. Lett., 265(1-2), 49-60.

Cai, S., Jin, G., Tauxe, L., Deng, C., Qin, H., Pan, Y. and Zhu, R., 2016. Archaeointensity results spanning the past 6 kiloyears from eastern China and implications for extreme behaviors of the geomagnetic field. Proc. Natl. Acad. Sci. $114,39-44$. 
Cai, S., Tauxe, L., Deng, C., Pan, Y., Jin, G., Zheng, J., Xie, F., Qin, H. and Zhu, R., 2014. Geomagnetic intensity variations for the past 8 kyr: New archaeointensity results from Eastern China. Earth Planet. Sci. Lett. 392, 217-229.

Campuzano, S. A., Pavón-Carrasco, F. J. and Osete, M. L., 2015. Non-Dipole and Regional Effects on the Geomagnetic Dipole Moment Estimation. Pure Appl. Geophys. 172, 91-107.

Cardoso, F.H., 2003. Capitalismo e escravidão no Brasil meridional: o negro na sociedade escravocrata do Rio Grande do Sul. Rio de Janeiro, 5a Edição, Editora Civilização Brasileira, 375 pp.

Carlut, J. and Kent, D. V., 2000. Paleointensity record in zero-age submarine basalt glasses: Testing a new dating technique for recent MORBs. Earth Planet. Sci. Lett. 183, 389-401.

Casas, L., Shaw, J., Gich, M. and Share, J. A., 2005. High-quality microwave archaeointensity determinations from an early 18th century AD English brick kiln. Geophys. J. Int. 161, 653-661.

Catanzariti, G., Gómez-Paccard, M., McIntosh, G., Pavón-Carrasco, F. J., Chauvin, A. and Osete, M. L., 2012. New archaeomagnetic data recovered from the study of Roman and Visigothic remains from central Spain (3rd-7th centuries). Geophys. J. Int. 188, 979-993.

Catanzariti, G., McIntosh, G., Gómez-Paccard, M., Ruiz-Martínez, V. C., Osete, M. L., Chauvin, A. and AARCH Scientific Team, 2008. Quality control of archaeomagnetic determination using a modern kiln with a complex NRM. Phys. Chem. Earth. 33, 427-437. 
Chauvin, A., Garcia, Y., Lanos, Ph. and Laubenheimer, F., 2000. Palaeointensity geomagnetic field recovered on archaeomagnetic sites from France. Phys. Earth Planet. Int. 120, 111-136.

Chauvin, A., Roperch, P. and Levi, S., 2005. Reliability of geomagnetic paleointensity data: the effects of the NRM fraction and concave-up behavior on paleointensity determinations by the Thellier method. Phys. Earth Planet. Int. 150, 265-286.

Coe, R. S., 1967. The determination of paleointensities of the Earth's magnetic field with emphasis on mechanisms which could cause non-ideal behavior in Thelier's method. J. Geomag. Geoelectr. 19, 157-179.

Coe, R. S., Grommé, C. S. and Mankinen, E. A., 1978. Geomagnetic paleointensities from radiocarbon dated lava flows on Hawaii and the question of the Pacific nondipole low. J. Geophys. Res. 83, 1740-1756.

Constable, C., Korte, M. and Panovska, S., 2016. Persistent high paleosecular variation activity in southern hemisphere for at least 10000 years. Earth Planet. Sci. Lett. 453, $78-86$.

Conte-Fasano, G., Urrutia-Fucugauchi, J., Goguitchaichvili, A. and Morales-Contreras, J. 2006. Low-latitude paleosecular variation and the time-averaged field during the late Pliocene and Quaternary-Paleomagnetic study of the Michoacan-Guanajuato volcanic field, Central Mexico. Earth Planets Space, 58, 1359-1371.

Costa, C.A.S., 2005. Materiais construtivos do sítio da primeira catedral do Brasil: modelos de estudos para telhas, tijolos, cravos e azulejos aplicados aos materiais do sítio da antiga igreja da Sé, Salvador, Bahia. Clio Arqueológica, 19, 43-78.

Cottrell, R. D. and Tarduno, J. A., 1999. Geomagnetic paleointensity derived from single plagioclase crystals. Earth Planet. Sci. Lett. 169, 1-5. 
Davies, C. and Constable, C., 2017. Geomagnetic spikes on the core-mantle boundary. Nat. Commun. 8, 15593.

de Boor, C., 1978. A practical guide to splines. New York (Springer).

de Groot, L. V., Biggin, A. J., Dekkers, M. J., Langereis, C. G. and Herrero-Bervera, E., 2013. Rapid regional pertubations to the recent global geomagnetic decay reveled by a new Hawaiian record. Nat. Commun. 4, 2727.

De Marco, E., Spatharas, V., Gómez-Paccard, M., Chauvin, A. and Kondopoulou, D., 2008. New archaeointensity results from archaeological sites and variation of the geomagnetic field intensity for the last 7 millennia in Greece. Phys. Chem. Earth. 33, $578-595$.

Demetrescu, C. and Dobrica, V., 2014. Multi-decadal ingredients of the secular variation of the geomagnetic field. Insights from long time series of observatory data. Phys. Earth planet. Inter., 231, 39-55.

Di Chiara, A., Tauxe, L. and Speranza, F., 2014. Paleointensity determination from São Miguel (Azores Archipelago) over the last 3ka. Phys. Earth Planet. Int. 234, 1-13.

Dodson, M. H. and McClelland-Brown, E., 1980. Magnetic blocking temperatures of single-domain grains during slow cooling. J. Geophys. Res. 85(B5), 2625-2637.

Donadini, F., Korte, M. and Constable, C. G., 2009. Geomagnetic field for 0 - 3ka: 1. New data sets for global modeling. Geochem. Geophys. Geosyst. 10, Q06007.

Donadini, F., Kovacheva, M., Kostadinova, M., Hedley, I. G. and Pesonen, L. J., 2008. Palaeointensity determination on an early medieval kiln from Switzerland and the effect of cooling rate. Phys. Chem. Earth. 33, 449-457.

Dumberry, M. and Finlay, C.C., 2007. Eastward and westward drift of the Earth's magnetic field for the last three millennia. Earth Planet. Sci. Lett. 254, 146-157. 
Dunlop, D. J., 2011. Physical basis of the Thellier-Thellier and related paleointensity methods. Phys. Earth planet. Inter. 187, 118-138.

Dunlop, D.J., 1981. The rock magnetism of fine particles. Phys. Earth Planet. Int., 26(12), 1-26.

Egli, R., Chen, A.P., Winklhofer, M., Kodama, K.P., Horng, C.S., 2010. Detection of noninteracting single domain particles using first-order reversal curve diagrams. Geochem. Geophys. Geosyst., 11, Q01Z11.

Ertepinar, P., Langereis, C. G., Biggin, A. J., de Groot, L. V., Kulakoğlu, F., Omura, S. and Süel, A., 2016. Full vector archaeomagnetic records from Anatolia between 2400 and 1350 BCE: Implications for geomagnetic field models and the dating of fires in antiquity. Earth Planet. Sci. Lett. 434, 171-186.

Ertepinar, P., Langereis, C.G., Biggin, A.J., Frangipane, M., Matney, T., Ökse, T., Engin, A., 2012. Archaeomagnetic study of five mounds from Upper Mesopotamia between 2500 and 700 BCE: Further evidence for an extremely strong geomagnetic field ca. 3000 years ago. Earth Planet. Sci. Lett., 357-358, 84-98.

Fabian, K. and Leonhardt, R., 2010. Multiple-specimen absolute paleointensity determination: an optimal protocol including pTRM normalization, domain-state correction, and alteration test. Earth Planet. Sci. Lett., 297(1-2), 84-94.

Fanjat, G., Camps, P., Valdivia, L. A., Sougrati, M. T., Cuevas-Garcia, M. and Perrin, M. (2013). First archeointensity determinations on Maya incense burners from Palenque temples, Mexico: New data to constrain the Mesoamerica secular variation curve. Earth Planet. Sci. Lett. 363, 168-180.

Feng, Y., Holme, R., Cox, G.A. and Jiang, Y., 2018. The geomagnetic jerk of 2003.5characterisation with regional observatory secular variation data. Phys. Earth planet. Inter., 278, 47-58. 
Finlay, C. C., Aubert, J. and Gillet, N., 2016. Gyre-driven decay of the Earth's magnetic dipole. Nat. Commun. 7, 10422.

Finlay, C.C., 2008. Historical variation of the geomagnetic axial dipole. Phys. Earth Planet. Int. 170, 1-14.

Finlay, C.C., Olsen, N. and Toeffner-Clausen, L., 2015. DTU candidate field models for IGRF-12 and the CHAOS-5 geomagnetic field model. Earth Planets Space, 67.

Folgheraiter, M., 1899. Sur les variations sècularies de I'inclinasion magnètique dans I'antiquitè. J. Phys. 5, 600-667.

Fox, J.M.W. and Aitken, M.J., 1980. Cooling-rate dependence of thermoremanent magnetization, Nature. 283, 462-463.

Gallet, Y. and Le Goff, M., 2006. High-temperature archeointensity measurements from Mesopotamia. Earth Planet. Sci. Lett. 241, 159-173.

Gallet, Y., Genevey, A. and Fluteau, F., 2005. Does Earth's magnetic field secular variation control centennial climate change? Earth Planet. Sci. Lett. 236, 339-347.

Gallet, Y., Genevey, A., Courtillot, V., 2003. On the possible occurrence of archeomagnetic jerks in the geomagnetic field over the past three millennia. Earth Planet. Sci. Lett., 214, 237-252.

Gallet, Y., Genevey, A., Le Goff, M., Warmé, N., Gran-Aymerich, J. and Lefèvre, A., 2009. On the use of archeology in geomagnetism, and vice-versa: recent developments in archeomagnetism. Comptes Rendus Physique 10, 630-648.

Gallet, Y., Hulot, G., Chulliat, A., Genevey, A., 2009. Geomagnetic field hemisphere asymmetry and archeomagnetic jerks. Earth Planet. Sci. Lett., 284, 179-186.

Gallet, Y., Le Goff, M., Genevey, A., Margueron, J.C., Matthiae, P., 2008. Geomagnetic field intensity behavior in the Middle East between 3000 BC and 1500 BC. Geophys. Res. Lett., 35, L02307. 
Games, K.P., 1977. The magnitude of the palaeomagnetic field: a new non-thermal, non-detrital method using Sun-dried bricks. . Geophys. J. of the Royal Astro. Soc., $48,315-329$.

Genevey, A. and Gallet, Y., 2002. Intensity of the geomagnetic field in western Europe over the past 2000 years: New data from ancient French pottery. J. Geophys. Res. 107, B11, 2285.

Genevey, A., Gallet, Y. and Margueron, J. C., 2003. Eight thousand years of geomagnetic field intensity variations in the eastern Mediterranean. J. Geophys. Res. 108(B5).

Genevey, A., Gallet, Y., Constable, C. G., Korte, M. and Hulot, G., 2008. ArcheoInt: An upgraded compilation of geomagnetic field intensity data for the past ten millennia and its application to the recovery of the past dipole moment. Geochem. Geophys. Geosyst. 9, Q04038.

Genevey, A., Gallet, Y., Jesset, S., Thébault, E., Bouillon, J., Lefèvre, A. and Le Goff, M., 2016. New Archaeointensity Data from French Early Medieval Pottery Production (6th-10th century AD). Tracing 1500 years of Geomagnetic Field Intensity Variations in Western Europe. Phys. Earth Planet. Int. 257, 205-219.

Genevey, A., Gallet, Y., Rosen, J. and Le Goff, M., 2009. Evidence for rapid geomagnetic field intensity variations in Western Europe over the past 800 years from new French archaeomagnetic data. Earth Planet. Sci. Lett. 284, 132-143.

Genevey, A., Gallet, Y., Thébault, E., Jesset, S. and Le Goff, M., 2013. Geomagnetic field intensity variations in Western Europe over the past 1100 years. Geochem. Geophys. Geosyst. 14(8), 2858-2872.

Genevey, A., Kondopoulou, D., Pétridis, P., Aidona, E., Muller, A., Blondé, F. and Gros, J. S., 2017. New constraints on geomagnetic field intensity variations in the 
Balkans during the Early Byzantine period from ceramics unearthed at Thasos and Delphi, Greece. J. Archaeol. Sci. In Press.

Gillet, N., Jault, D. and Finlay, C. C., 2015. Planetary gyre and time-dependent midlatitude eddies at the Earth's core surface. J. Geophys. Res. 120, 39914013.

Gillet, N., Jault, D., Finlay, C. C. and Olsen, N., 2013. Stochastic modeling of the Earth's magnetic field: inversion for covariances over the observatory era. Geochem. Geophys. Geosyst. 14, 766-786.

Goguitchaichvili, A., Greco, C. and Morales, J., 2011. Geomagnetic field intensity behavior in South America between 400 AD and 1800 AD: first archeointensity results from Argentina. Phys. Earth Planet. Int. 186, 191-197.

Goguitchaichvili, A., Loponte, D., Morales, J., Acosta, A., 2012. The archaeointensity of the Earth's magnetic field retrieved from Pampean ceramics (South America). Archaeometry, 54, 2, 388-400.

Goguitchaichvili, A., Morales, J., Schavelzon, D., Vásquez, C., Gogorza, C. S., Loponte, D. and Rapalini, A., 2015. Variation of the Earth's magnetic field strength in South America during the last two millennia: New results from historical buildings of Buenos Aires and re-evaluation of regional data. Phys. Earth Planet. Int. 245, 1525.

Gómez-Paccard, M., Beamud, E., Mc Intosh, G. and Larrasoana, J. C., 2013. New archaeomagnetic data recovered from the study of three Roman kilns from north-east Spain: A contribution to the Iberian palaeosecular variation curve. Archaeometry 55, $159-177$.

Gómez-Paccard, M., Catanzariti, G., Ruiz-Martínez, V. C., McIntosh, G., Núñez, J. I., Osete, M. L., Chauvin, A., Lanos, Ph., Tarling, D.H., Bernal-Casasola, D. and 
Thiriot, J., 2006b. A catalogue of Spanish archaeomagnetic data. Geophys. J. Int. $166,1125-1143$.

Gómez-Paccard, M., Chauvin, A., Lanos, P. and Thiriot, J., 2008. New archeointensity data from Spain and the geomagnetic dipole moment in western Europe over the past 2000 years. . J. Geophys. Res. 113(B9).

Gómez-Paccard, M., Chauvin, A., Lanos, P., Dufresne, P., Kovacheva, M., Hill, M. J., Beamud, E., Blain, S., Bouvier, A., Guibert, P. and Archaeological Working Team, 2012b. Improving our knowledge of rapid geomagnetic field intensity changes observed in Europe between 200 and 1400 AD. Earth Planet. Sci. Lett. 355, 131-143.

Gómez-Paccard, M., Chauvin, A., Lanos, P., Thiriot, J. and Jiménez-Castillo, P., 2006a. Archeomagnetic study of seven contemporaneous kilns from Murcia (Spain). Phys. Earth Planet. Int. 157, 16-32.

Gómez-Paccard, M., McIntosh, G., Chauvin, A., Beamud, E., Pavón-Carrasco, F. J. and Thiriot, J., 2012a. Archaeomagnetic and rock magnetic study of six kilns from North Africa (Tunisia and Morocco). Geophys. J. Int. 189, 169-186.

Gómez-Paccard, M., Osete, M.L., Chauvin, A., Pavón-Carrasco, F.J., Pérez-Asensio, M., Jiménez, P. and Lanos, P., 2016. New constraints on the most significant palaeointensity change in Western Europe over the last two millennia. A non-dipolar origin? Earth Planet. Sci. Lett. 454, 55-64.

Gratton, M. N., Goguitchaichvili, A., Conte, G., Shaw, J. and Urrutia-Fucugauchi, J., 2005. Microwave palaeointensity study of the Jorullo volcano (Central Mexico). Geophys. J. Int. 161, 627-634.

Gratton, M. N., Shaw, J. and Herrero-Bervera, E., 2005. An absolute palaeointensity record from SOH1 lava core, Hawaii using the microwave technique. Phys. Earth Planet. Int. 148, 193-214. 
Gubbins, D., 1999. The distinction between geomagnetic excursions and reversals. Geophys. J. Int., 137(1), F1-F3.

Gubbins, D., Jones, A. L. and Finlay, C. C., 2006. Fall in Earth's magnetic field is erratic. Science 312, 900-902.

Gunn, N.M., Murray, A.S., 1980. Geomagnetic field magnitude variations in Peru derived from archaeological ceramics dated by thermoluminescence. Geophys. J. of the Royal Astro. Soc., 62, 345-366.

Halgedahl, S. L., Day, R. and Fuller, M., 1980. The effect of cooling rate on the intensity of weak-field TRM in single-domain magnetite. J. Geophys. Res. 85(B7), $3690-3698$

Hammer, Ř., Harper, D. A. T. and Ryan, P. D., 2001. PAST: Paleontological Statistics Software Package for Education and Data Analysis. Palaeontol. Electron. 4: 9pp.

Hare, V.J., Tarduno, J.A., Huffman, T., Watkeys, M., Thebe, P.C., Manyanga, M., Bono, R.K. and Cottrell, R.D., 2018. New Archeomagnetic Directional Records From Iron Age Southern Africa (ca. 425-1550 CE) and Implications for the South Atlantic Anomaly. Geophys. Res. Lett., 45(3), 1361-1369.

Harrison, R.J., and Feinberg, J.M., 2008, FORCinel: An improved algorithm for calculating first-order reversal curve distributions using locally weighted regression smoothing, Geochem. Geophys. Geosyst., 9, Q05016.

Hartmann, G. A., Genevey, A., Gallet, Y., Trindade, R. I., Etchevarne, C., Le Goff, M. and Afonso, M. C., 2010. Archaeointensity in Northeast Brazil over the past five centuries. Earth Planet. Sci. Lett. 296, 340-352.

Hartmann, G. A., Genevey, A., Gallet, Y., Trindade, R. I., Le Goff, M., Najjar, R., Etchevarne, C and Afonso, M. C., 2011. New historical archaeointensity data from 
Brazil: Evidence for a large regional non-dipole field contribution over the past few centuries. Earth Planet. Sci. Lett. 306, 66-76.

Hartmann, G. A., Poletti, W., Trindade, R. I. F., Ferreira, L. M. and Sanches, P. New archeointensity data from South Brazil and the influence of the South Atlantic Anomaly in South America. Submitted.

Hartmann, G. A., Trindade, R. I., Goguitchaichvili, A., Etchevarne, C., Morales, J. and Afonso, M. C., 2009. First archeointensity results from Portuguese potteries (15501750 AD). Earth Planets Space, 61, 93-100.

Hartmann, G.A., Pacca, I.G., 2009. Time evolution of the South Atlantic Magnetic Anomaly. An. Acad. Bras. Ciênc., 81, 243-255.

Hellio, G. and Gillet, N., 2018; Time-correlation based regression of the geomagnetic field from archeological and sediment records. . Geophys. J. Int.

Hill, M. J., Gratton, M. N. and Shaw, J., 2002a. A comparison of thermal and microwave palaeomagnetic techniques using lava containing laboratory induced remanence. Geophys. J. Int. 151, 157-163.

Hill, M. J., Gratton, M. N. and Shaw, J., 2002b. Palaeomagnetic investigation of Tertiary lava from Barrington Tops, NSW, Australia, using thermal and microwave techniques. Earth Planet. Sci. Lett. 198, 245-256.

Hill, M.J. and Shaw, J., 1999. Palaeointensity results for historic lavas from Mt Etna using microwave demagnetization/remagnetization in a modified Thellier-type experiment. Geophys. J. Int. 139, 583-590.

Hill, M.J., Shaw, J., 2000. Magnetic field intensity study of the 1960 Kilauea lava flow. Hawaii, using the microwave palaeointensity technique. Geophys. J. Int., 142, 487504. 
Holme, R., 2015. Large-scale flow in the core. In: Olson, P. (Ed.), Treatise on Geophysics, Elsevier, Second ed., vol. 8, 107-130.

Hongre, L., Hulot, G., Khokhlov, A., 1998. An analysis of the geomagnetic field over the past 2000 years. Phys. Earth Planet. Int., 106, 311-335.

Hulot, G. and Le Mouël, J.L., 1994. A statistical approach to the Earth's main magnetic field. Phys. Earth planet. Inter. 82, 162-183.

Hulot, G., Khokhlov, A. and Le Mouël, J. L., 1997. Uniqueness of mainly dipolar magnetic fields recovered from directional data. Geophys. J. Int. 129, 347-354.

Jackson, A., 2003. Intense equatorial flux spots on the surface of Earth's core. Nature $424,760-763$.

Jackson, A., Jonkers, A. R. and Walker, M. R., 2000. Four centuries of geomagnetic secular variation from historical records. Phil. Trans. R. Soc. Lond. A 358, 957-990.

Kelly, P., Gubbins, D., 1997. The geomagnetic field over the past 5 million years. Geophys. J. Int., 128, 315-330.

Kissel, C., Laj, C., Rodriguez-Gonzalez, A., Perez-Torrado, F., Carracedo, J. C. and Wandres, C., 2015. Holocene geomagnetic field intensity variations: Contribution from the low latitude Canary Islands site. Earth Planet. Sci. Lett. 430, 178-190.

Kitazawa, K., Kobayashi, K., 1968. Intensity variation of the geomagnetic field during the past 4000 years in South America. J. Geomag. Geoelectric., 20, 7-19.

Knudsen, M. F., Riisager, P., Donadini, F., Snowball, I., Muscheler, R., Korhonen, K. and Pesonen, L. J., 2008. Variations in the geomagnetic dipole moment during the Holocene and the past 50 kyr. Earth Planet. Sci. Lett. 272, 319-329.

Kono, M., (Ed.), 2010. Geomagnetism: Treatise on Geophysics., Second ed., vol. 5, pp. 589, Elsevier. 
Kono, M., 2007. Geomagnetism in Perspective In: Kono, M. (Ed.), Treatise on Geophysics, Elsevier, vol. 5, 1-31.

Kono, M., Ueno, N., Onuki, Y., 1986. Paleointensities of the geomagnetic field obtained from Pre-Inca potsherds near Cajamarca, Northern Peru. J. Geomagn. Geoelectr., 38, 1339-1348.

Korte, M. and Constable, C. G., 2011. Improving geomagnetic field reconstructions for 0-3 ka. Phys. Earth Planet. Inter. 188, 247-259.

Korte, M., Constable, C., Donadini, F., Holme, R., 2011. Reconstructing the Holocene geomagnetic field. Earth Planet. Sci. Lett., 312, 497-505.

Korte, M., Constable, C.G., 2005. Continuous geomagnetic field for the past 7 millennia: 2.CALS7K. Geochem. Geophys. Geosyst., 6, 1, Q02H16.

Korte, M., Donadini, F. and Constable, C. G., 2009. Geomagnetic field for 0-3 ka: 2. A new series of time-varying global models. Geochem. Geophys. Geosyst. 10, Q06008.

Korte, M., Donadini, F., Constable, C.G., 2009. Geomagnetic field for 0 - 3ka: 2. A new series of time-varying global models. Geochem. Geophys. Geosyst., 10, 6, Q06008.

Kovacheva, M., Chauvin, A., Jordanova, N., Lanos, Ph., Karloukovski, V., 2009. Remanence anisotropy effect on the paleointensity results obtained from various archaeological materials, excluding pottery. Earth Planet. Space, 61, 711-732.

Krása, D., Heunemann, C., Leonhardt, R. and Petersen, N., 2003. Experimental procedure to detect multidomain remanence during Thellier-Thellier experiments. Phys. Chem. Earth. 28, 681-687.

Laj, C. and Channell J.E.T., 2007. Geomagnetic Excursions. In: Kono, M. (Ed.), Treatise on Geophysics, Elsevier, vol. 5, 373-416. 
Le Goff, M. and Gallet, Y., 2004. A new three-axis vibrating sample magnetometer for continuous high-temperature magnetization measurements: applications to paleo- and archeo-intensity determinations. Earth Planet. Sci. Lett. 229, 31-43.

Le Goff, M. and Gallet, Y., 2017. A reappraisal of instrumental magnetic measurements made in Western Europe before AD 1750: confronting historical geomagnetism and archeomagnetism. Earth Planets Space 69, 32.

Lee, S-S., 1975. Secular variation of the intensity of the geomagnetic field during the past 3,000 years in North, Central, and South America. PhD Thesis. University of Oklahoma, Oklahoma, USA.

Leonhardt, R., C. Heunemann, C., Krasa, D., 2004. Analyzing absolute paleointensity determinations: Acceptance criteria and the software ThellierTool4.0. Geochem. Geophys. Geosyst., 5, Q12016.

Leonhardt, R., Matzka, J., Menor, E.A., 2003. Abolute paleointensities and paleodirections of Miocene and Pliocene lavas from Fernando de Noronha, Brazil. Phys. Earth planet. Inter., 139, 285-303.

Lhuillier, F., Fournier, A., Hulot, G. and Aubert, J., 2011. The geomagentic secular vatiation timescale in observations and numerical dynamo models. Geophys. Res. Lett. 38, L055306.

Licht, A., Hulot, G., Gallet, Y. and Thebault, E., 2013. Ensembles of low degree archaeomagnetic field models for the past three millennia. Phys. Earth planet. Inter. $224,38-67$.

Livermore, P.W., Fournier, A. and Gallet, Y., 2014. Core-flow constraints on extreme archaeomagnetic intensity changes. Earth Planet. Sci. Lett. 387, 145-156.

Lowrie, W., 1990. Identification of ferromagnetic minerals in a rock by coercivity and unblocking temperatures properties. Geophys. Res. Lett., 17, 159-162. 
Mandea, M., Holme, R., Pais, A., Pinheiro, K., Jackson, A. and Verbanac, G., 2010. Geomagnetic jerks: rapid core field variations and core dynamics. Space Sci. Rev., 155(1-4), 147-175.

Mankinen, E. A. and Champion, D. E., 1993. Broad trends in geomagnetic paleointensity on Hawaii during Holocene time. J. Geophys. Res. 98(B5), 79597976.

McClelland, E., Muxworthy, A.R., Thomas, R.M., 1996. Magnetic properties of the stable fraction of remanence in large multidomain (MD) magnetite grains: Singledomain or MD? Geophys. Res. Lett., 23, 2831-2834.

McIntosh, G., Kovacheva, M., Catanzariti, G., Donadini, F., Osete, M.L., 2011. High coercivity remanence in baked clay materials used in archeomagnetism. Geochem. Geophys. Geosyst., Q02003.

McIntosh, G., Kovacheva, M., Catanzariti, G., Osete, M.L., Casas, L., 2007. Widespread occurence of a novel high coercivity, thermally stable, low unblocking temperature magnetic phase in heated archeological material. Geophys. Res. Lett., 34, L21302.

Michalk, D. M., Muxworthy, A. R., Böhnel, H. N., Maclennan, J. and Nowaczyk, N., 2008. Evaluation of the multispecimen parallel differential pTRM method: a test on historical lavas from Iceland and Mexico. Geophys. J. Int. 173, 409-420.

Mitra, R., Tauxe, L. and McIntosh, S. K., 2013. Two thousand years of archeointensity from West Africa. Earth Planet. Sci. Lett. 364, 123-133.

Morales, J., Goguitchaichvili, A., Acosta, G., González-Moran, T., Alva-Valdivia, L., Robles-Camacho, J. and del Sol Hernández-Bernal, M., 2009. Magnetic properties and archeointensity determination on Pre-Columbian pottery from Chiapas, Mesoamerica. Earth Planets Space, 61(1), 83-91. 
Muscheler, R., Joos, F., Beer, J., Müller, S.A., Vonmoos, M., Snowball, I., 2007. Solar activity during the last 1000 yr inferred from radionuclide records. Quat. Sci. Rev., 26, 82-97.

Muxworthy, A.R. and Heslop, D., 2011. A Preisach method for estimating absolute paleofield intensity under the constraint of using only isothermal measurements: 1 . Theoretical framework. J. Geophys. Res., 116, 1-13.

Nagata, T., Arai, Y., Momose, K., 1963. Secular variation of the geomagnetic total force during the last 5000 years. J. Geophys. Res., 68, 5277-5281.

Nagata, T., Kobayashi, K., Schwarz, E.J., 1965. Archeomagnetic intensity studies of South and Central America. J. Geomag. Geoelectric., 17, 399-405.

Néel, L., 1955. Some theoretical aspects of rock-magnetism. Adv. Phys., 4, 191-243.

Nilsson, A., Holme, R., Korte, M., Suttie, N. and Hill, M., 2014. Reconstructing Holocene geomagnetic field variation: new methods, models and implications. Geophys. J. Int. 198, 229-248.

Olsen, N., Hulot, G. and Sabaka, T. J., 2007. The Present Field. In: Kono, M. (Ed.), Treatise on Geophysics, Elsevier, vol. 5, 33-75.

Olson, P. and Amit, H., 2006. Changes in Earth's dipole. Naturwissenschaften 93, 519542.

Osete, M. L., Catanzariti, G., Chauvin, A., Pavón-Carrasco, F. J., Roperch, P. and Fernández, V. M., 2015. First archaeomagnetic field intensity data from Ethiopia, Africa (1615 \pm 12 AD). Phys. Earth Planet. Inter. 242, 24-35.

Pais, A. and Jault, D., 2008. Quasi-geostrophic flows responsible for the secular variation of the Earth's magnetic field. Geophys. J. Int. 173, 421-443. 
Paterson, G.A., Biggin, A.J., Yamamoto, Y., Pan, Y., 2012. Towards the robust selection of Thellier-type paleointensity data: The influence of experimental noise. Geochem. Geophys. Geosyst., 13, 5, Q05Z43.

Paterson, G.A., Tauxe, L., Biggin, Shaar, R. and Jonestrask, L.C., 2014. On improving the selection of Thellier-type palaeointensity data. Geochem. Geophys. Geosyst. 15, 1180-1192.

Pavón-Carrasco, F. J., Osete, M. L., Torta, J. M. and De Santis, A., 2014. A geomagnetic field model for the Holocene based on archaeomagnetic and lava flow data. Earth Planet. Sci. Lett. 388, 98-109.

Pavón-Carrasco, F.J., Gómez-Paccard, M., Hervé, G., Osete, M.L., Chauvin, A., 2014. Intensity of the geomagnetic field in Europe for the last 3ka: influence of data quality on geomagnetic field modeling. Geochem. Geophys. Geosyst., 15, doi: 10.1002/2014GC005311.

Pavón-Carrasco, F.J., J. Rodríguez-González, M.L. Osete, and J.M. Torta, 2011. A matlab tool for archaeomagnetic dating. Journal of Archaeological Science, 38 (2), 408-419.

Pesonen, L.J., Elming, S.Å., Mertanen, S., Pisarevsky, S., D'Agrella-Filho, M.S., Meert, J.G., Schmidt, P.W., Abrahamsen, N. and Bylund, G., 2003. Palaeomagnetic configuration of continents during the Proterozoic. Tectonophysics, 375(1-4), 289324.

Pick, T. and Tauxe, L., 1993. Holocene paleointensities: Thellier experiments on submarine basaltic glass from the East Pacific Rise. J. Geophys. Res. 98(B10), 17949-17964. 
Poletti, W., Biggin, A. J., Trindade, R. I., Hartmann, G. A. and Terra-Nova, F., 2018. Continuous millennial decrease of the Earth's magnetic axial dipole. Phys. Earth Planet. Inter., 274, 72-86.

Poletti, W., Hartmann, G. A., Hill, M. J., Biggin, A. J. and Trindade, R. I. F., 2013. The cooling-rate effect on microwave archaeointensity estimates. Geophys. Res. Lett., 40, 3847-3852.

Poletti, W., Trindade, R. I. F., Hartmann, G. A., Damiani, N. and Rech, R. M., 2016. Archaeomagnetism of Jesuit Missions in South Brazil (1657-1706 AD) and assessment of the South American database. Earth Planet. Sci. Lett. 445, 36-47.

Pressling, N., Brown, M. C., Gratton, M. N., Shaw, J. and Gubbins, D., 2007. Microwave palaeointensities from Holocene age Hawaiian lavas: investigation of magnetic properties and comparison with thermal palaeointensities. Phys. Earth Planet. Inter. 162, 99-118.

Pressling, N., Laj, C., Kissel, C., Champion, D. and Gubbins, D., 2006. Palaeomagnetic intensities from 14 C-dated lava flows on the Big Island, Hawaii: 0-21 kyr. Earth Planet. Sci. Lett. 247, 26-40.

Rech, R.M., 2008. Relatório de Vistoria Arqueológica no Lote Urbano S01 Q14 L13 Área do Sítio da Antiga Redução de Santo Ângelo Custódio. Santo Ângelo.

Riisager, P. and Riisager, J., 2001. Detecting multidomain magnetic grains in Thellier palaeointensity experiments. Phys. Earth planet. Inter. 125, 111-117.

Roberts, A.P., Cui, Y., Verosub, K. L., 1995. Waspwaisted hysteresis loops: Mineral magnetic characteristics and discrimination of components in mixed magnetic systems. J. Geophys. Res., 100, 17,909-17,924. 
Roberts, A.P., Heslop, D., Zhao, X., Pike, C.R., 2014. Understanding fine magnetic particle systems through use of first-order reversal curve diagrams. Rev. Geophys., $52,557-602$.

Rogers, J., Fox, J. and Aitken, M. J., 1979. Magnetic anisotropy in ancient pottery, Nature 277, 644-646.

Roperch, P., Chauvin, A., Lara, L. E. and Moreno, H., 2015. Secular variation of the Earth's magnetic field and application to paleomagnetic dating of historical lava flows in Chile. Phys. Earth planet. Inter. 242, 65-78.

Roperch, P., Chauvin, A., Le Pennec, JL., Lara, L.E., 2014. Paleomagnetic study of juvenile basaltic-andesite clasts from Andean pyroclastic density current deposits. Earth planet. Inter., 227, 20-29.

Salnaia, N., Gallet, Y., Genevey, A. and Antipov, I., 2017. New archeointensity data from Novgorod (North-Western Russia) between c. 1100 and 1700 AD. Implications for the European intensity secular variation. Phys. Earth planet. Inter. 269, 18-28.

Sanchez, S., Fournier, A., Aubert, J., Cosme, E. and Gallet, Y., 2016. Modelling the archaeomagnetic field under spatial constraints from dynamo simulations: a resolution analysis. Geophys. J. Int. 207, 983-1002.

Schnepp, E., 2003. On correction of loss of mass during Thellier experiments. Phys. Earth Planet. Int., 135, 225-229.

Schnepp, E., Lanos, P. and Chauvin, A., 2009. Geomagnetic palaeointensity between 1300 and $1750 \mathrm{AD}$ derived from a bread oven floor sequence in Lübeck, Germany. Geochem. Geophys. Geosyst. 10(8).

Selkin, P. A., Tauxe, L., 2000. Long-term variations in palaeointensity. Phil. Trans. R. Soc. London, 358, 1065-1088. 
Shaar, R., Ben-Yosef, E., Ron, H., Tauxe, L., Agnon, A. and Kessel, R., 2011. Geomagnetic field intensity: How high can it get? How fast can it change? Constraints from Iron Age copper slag. Earth Planet. Sci. Lett. 301, 297-306.

Shaar, R., Tauxe, L., Ben-Yosef, E., Kassianidou, V., Lorentzen, B., Feinberg, J. M. and Levy, T. E., 2015. Decadal-scale variations in geomagnetic field intensity from ancient Cypriot slag mounds. Geochem. Geophys. Geosyst. 16, 195-214.

Shaar, R., Tauxe, L., Goguitchaichvili, A., Devidze, M. and Licheli, V., 2017. Further evidence of the Levantine Iron Age geomagnetic anomaly from Georgian pottery. Geophys. Res. Lett. 44, 2229-2236.

Shaar, R., Tauxe, L., Ron, H., Ebert, Y., Finkelstein, I., Agnon, A., 2016. Large geomagnetic field anomalies revealed in Bronze to Iron Age archaeomagnetic data from Tel Megiddo and Tel Hazor, Israel. Earth Planet. Sci. Lett. 442, 173-185.

Shah, J., Koppers, A.A., Leitner, M., Leonhardt, R., Muxworthy, A.R., Heunemann, C., Bachtadse, V., Ashley, A.D. and Matzka, J., 2016. Palaeomagnetic evidence for the persistence or recurrence of geomagnetic main field anomalies in the South Atlantic. Earth Planet. Sci. Lett., 441, 113-124.

Shaw, J., 1974. A new method of determining the magnitude of the paleomagnetic field application to 5 historic lavas and five archeological samples. Geophys. J. of the Royal Astro. Soc. 39, 133-141.

Shaw, J., Share, J.A., 2007. A new automated microwave demagnetiser/remagnetiser system for palaeointensity studies, Eos Trans. AGU, Fall Meet. Suppl., 88(52), Abstract, GP53C-1371.

Shaw, J., Walton, D., Yang, S., Rolph, T. C. and Share, J. A., 1996. Microwave archaeointensities from Peruvian ceramics. Geophys. J. Int. 124, 241-244. 
Shaw, J., Yang, S., Rolph, T. A. and Sun, F. Y., 1999. A comparison of archaeointensity results from Chinese ceramics using microwave and conventional Thellier's and Shaw's methods. Geophys. J. Int. 136, 714-718.

Spassov, S., Valet, J. P., Kondopoulou, D., Zananiri, I., Casas, L. and Le Goff, M., 2010. Rock magnetic property and paleointensity determination on historical Santorini lava flows. Geochem. Geophys. Geosyst. 11(7).

Stanton, T., Riisager, P., Knudsen, M. F. and Thordarson, T., 2011. New palaeointensity data from Holocene Icelandic lavas. Phys. Earth planet. Inter. 186, 1-10.

Stark, F., Cassidy, J., Hill, M. J., Shaw, J. and Sheppard, P., 2010. Establishing a first archaeointensity record for the SW Pacific. Earth Planet. Sci. Lett. 298, 113-124.

Stephenson, A., Sadikun, S. T. and Potter, D. K., 1986. A theoretical and experimental comparison of the anisotropies of magnetic susceptibility and remanence in rocks and minerals. Geophys. J. Int. 84, 185-200.

St-Onge, G., Stoner, J., Hillaire-Marcel, C., 2003. Holocene paleomagnetic records from the St. Lawrence Estuary, eastern Canada: centennial- to millennial- scale geomagnetic modulation of cosmogenic isotopes. Earth Planet. Sci. Lett., 209, 113130.

Suttie, N., Holme, R., Hill, M. J. and Shaw, J., 2011. Consistent treatment of errors in archaeointensity implies rapid decay of the dipole prior to 1840. Earth Planet. Sci. Lett. 304, 13-21.

Suttie, N., Shaw, J., Hill, M. J., 2010. Direct demonstration of microwave demagnetization of a whole rock sample with minimal heating, Earth Planet. Sci. Lett., 292, 357-362. 
Tanaka, H. and Kono, M., 1991. Preliminary Results and Reliability of Palaeointensity Studies on Historical and 14C Dated Hawaiian Lvas. J. Geomag. Geoelectr. 43, 375388.

Tanaka, H., Komuro, N. and Turner, G. M., 2009. Palaeosecular variation for 0.1-21 Ka from the Okataina Volcanic Centre, New Zealand. Earth Planets Space 61, 213-225.

Tarduno, J. A., Watkeys, M. K., Huffman, T. N., Cottrell, R. D., Blackman, E. G., Wendt, A., Scribner, C. A. and Wagner, C. L., 2015. Antiquity of the South Atlantic Anomaly and evidence for top-down control on the geodynamo. Nat. Commun. 6, 7865

Tauxe, L., 2008. Essentials of Rock and Paleomagnetism. Scripps Institution of Oceanography, pp. 496.

Tauxe, L., Yamazaki, T., 2007. Paleointensities. In: Kono, M. (Ed.), Treatise on Geophysics, Elsevier, vol. 5, 509-563.

Tema, E., Gómez-Paccard, M., Kondopoulou, D. and Almar, Y., 2012. Intensity of the Earth's magnetic field in Greece during the last five millennia: New data from Greek pottery. Phys. Earth planet. Inter. 202, 14-26.

Tema, E., Morales, J., Goguitchaichvili, A. and Camps, P., 2013. New archaeointensity data from Italy and geomagnetic field intensity variation in the Italian Peninsula. Geophys. J. Int. 193, 603-614.

Terra-Nova, F., Amit, H., Hartmann, G. A. and Trindade, R. I. F., 2016. Using archaeomagnetic field models to constrain the physics of the core: robustness and preferred locations of reversed flux patches. Geophys. J. Int. 206, 1890-1913.

Terra-Nova, F., Amit, H., Hartmann, G. A., Trindade, R. I. and Pinheiro, K. J., 2017. Relating the South Atlantic Anomaly and geomagnetic flux patches. Phys. Earth Planet. Int., 266, 39-53. 
Terra-Nova, F., Amit, H., Hartmann, G.A. and Trindade, R.I.F., 2015. The timedependence of reversed archaeomagnetic flux patches. J. Geophys. Res. 120, 2,691704.

Thellier, E. and Thellier, O., 1959. Sur l'intensité du champ magnétique terrestre dans le passé historique et géologique. Ann. Geophys. 15, 285-376.

Trindade, R.I., D'Agrella-Filho, M.S., Epof, I. and Neves, B.B.B., 2006. Paleomagnetism of Early Cambrian Itabaiana mafic dikes (NE Brazil) and the final assembly of Gondwana. Earth Planet. Sci. Lett., 244(1-2), 361-377.

Tsunakawa, H., Shaw, J., 1994. The Shaw method of paleointensity determinations and its application to recent volcanic rocks. Geophys. J. Int., 118, 781-787.

Usoskin, I. G., Gallet, Y., Lopes, F., Kovaltsov, G. A. and Hulot, G., 2016. Solar activity during the Holocene: the Hallstatt cycle and its consequence for grand minima and maxima. Astron. Astrophys. 587, A150.

Valet, J. P. and Fournier, A., 2016. Deciphering records of geomagnetic reversals. Rev. Geophys., 54(2), 410-446.

Valet, J.P., Herrero-Bervera, E., LeMouel, J.L. and Plenier, G., 2008. Secular variation of the geomagnetic dipole during the past 2000 years. Geochem. Geophys. Geosyst. 9, Q01008.

Valet, J-P., Herrero-Bervera, E., 2000. Paleointensity experiments using alternating field demagnetization. Earth Planet. Sci. Lett.,177, 43-58.

Valet, J-P., Quidelleur, X., Tric, E., Gillot, P.Y., Brassart, J., Le Meur, I., Soler, V., 1996. Absolute paleointensity and magnetomineralogical changes. J. Geophys. Res., $101,25,029-25,044$. 
Veitch, R., Hedley, I. and Wagner, J. J., 1984. An investigation of the intensity of the geomagnetic field during Roman times sing magnetically anisotropic bricks and tiles. Arch. Sci. 37, 359-373.

Walton, D., Boehnel, H.N., 2008. The microwave frequency method. Phys. Earth Planet. Int., 167, 145-148.

Walton, D., Share, J., Rolph, T.C., Shaw, J., 1993. Microwave magnetization. Geophys. Res. Letters., 20, 109-111.

Walton, D., Shaw, J., Share, J., Hakes, J., 1992. Microwave demagnetization. J. Applied Phys., 71, 1549-1551.

Whaler, K. A. and Holme, R., 2011. The axial dipole strength and flow in the outer core. Phys. Earth planet. Inter., 188, 235-246.

Yang, S., Shaw, J., Rolph, T., 1993. Archaeointensity studies of Peruvian pottery - from 1200 B.C. to 1800 A.D. J. Geomag. Geoelectric., 45, 1193-1207.

Yoshihara, A., Kondo, A., Ohno, M. and Hamano, Y., 2003. Secular variation of the geomagnetic field intensity during the past 2000 years in Japan. Earth Planet. Sci. Lett. 210, 219-231.

Yu, Y. and Dunlop, D. J., 2003. On partial thermoremanent magnetization tail checks in Thellier paleointensity determination. J. Geophys. Res. 108(B11).

Yu, Y., 2011. Importance of cooling-rate dependence of thermoremanence in paleointensity determination. J. Geophys. Res., 116, B09101.

Yu, Y., 2012. High-fidelity paleointensity determination from historic volcanoes in Japan. J. Geophys. Res. 117(B8).

Yu, Y., Dunlop, D. J. and Özdemir, Ö., 2003. Are ARM and TRM analogs? Thellier analysis of ARM and pseudo-Thellier analysis of TRM. Earth Planet. Sci. Lett. 205, 325-336. 
Yu, Y., Dunlop, D.J., Özdemir, O., 2003. On the resolution of multivectorial remanences. Earth Planet. Sci. Lett., 208, 13-26.

Yu, Y., Tauxe, L. and Genevey, A., 2004. Toward an optimal geomagnetic field intensity determination technique. Geochem. Geophys. Geosyst. 5, Q02H07. 